Portland State University

PDXScholar

$12-2-1993$

\title{
Evaluation of Information Resource Management: Measuring Change in a Federal Bureaucracy
}

Randolph D. Perrin

Portland State University

Follow this and additional works at: https://pdxscholar.library.pdx.edu/open_access_etds

Part of the Urban Studies and Planning Commons

Let us know how access to this document benefits you.

\section{Recommended Citation}

Perrin, Randolph D., "Evaluation of Information Resource Management: Measuring Change in a Federal Bureaucracy" (1993). Dissertations and Theses. Paper 4678.

https://doi.org/10.15760/etd.6561

This Thesis is brought to you for free and open access. It has been accepted for inclusion in Dissertations and Theses by an authorized administrator of PDXScholar. Please contact us if we can make this document more accessible: pdxscholar@pdx.edu. 
AN ABSTRACT OF THE DISSERTATION OF Randolph D. Perrin for the Doctor of Philosophy in Urban Studies presented December 2, 1993.

Title: Evaluation of Information Resource Management: Measuring Change in a Federal Bureaucracy

APPROVED BY THE MEMBERS OF THE DISSERTATION COMMITTEE:

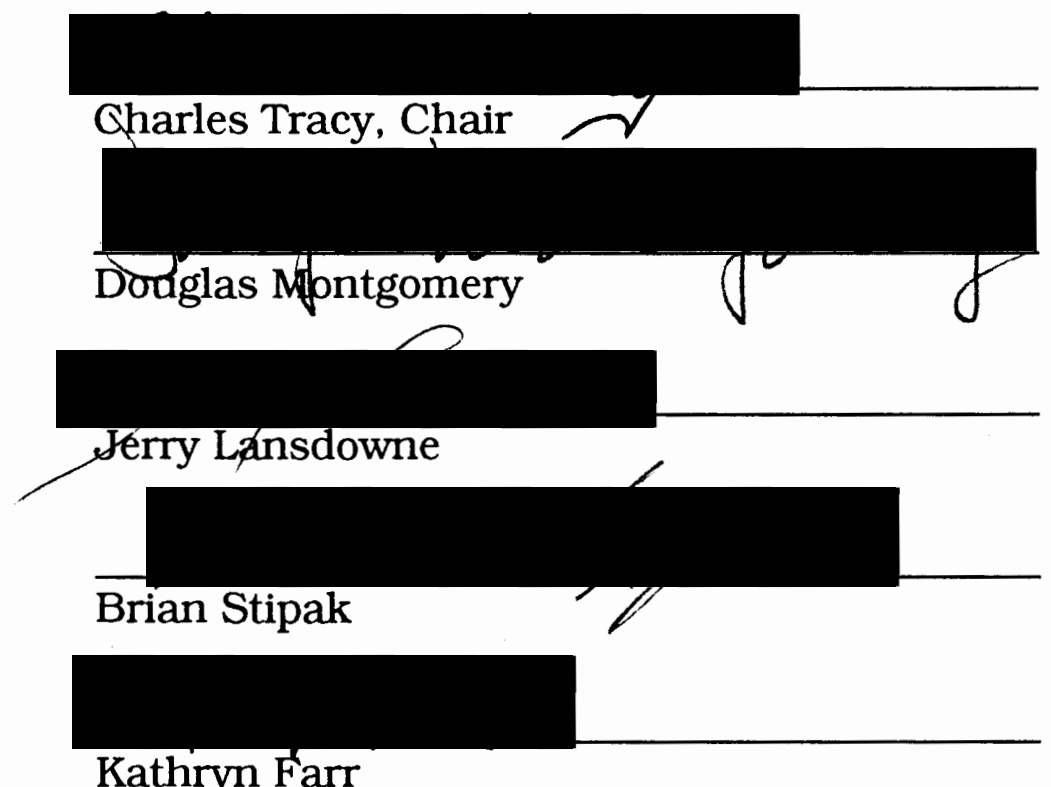

This is a case study of a federal bureaucracy and its Information Resource Management (IRM) organization. The Bonneville Power Administration (BPA), a federal power marketing agency and part of the Department of Energy, significantly impacts the western United States. $\mathrm{BPA}$ is responsible for developing electric power resources, 
transmission of electric resources, power conservation programs, and fish and wildlife programs.

The focus of the study is the perception of the quality of information supplied to management, assuming that better information makes better decisions. The study uses a pre-experimental research design to evaluate the satisfaction executive and middle management with information they use to make decisions. The study uses both questionnaire and interview methodologies to examine management opinions before the establishment of IRM and two years after the establishment of IRM.

Literature on bureaucracy indicates that decision making has limits and processes. Channels of communication, both formal and subformal are used by decision makers to gather information to fill information gaps. The gaps exist because formal channels of information do not supply sufficient information. Consequently, decision makers constantly search for information.

There is a great deal of literature addressing IRM and other similar organizations. The technical and operational sides of information management are occasionally conflicting but, adequately addressed. Information assessment and evaluation are approached inadequately. 
Questionnaires and interviews provide congruent methodologies to provide complete data for analysis. Questionnaire data was statistically analyzed and content analysis was used to analyze interviews.

Analysis revealed that information in BPA is better since the installation of the IRM organization, but probably not because of the IRM. Information is difficult to see in use, but can be found in formal and subformal communication networks which often mirror formal and informal organizational structures in bureaucracy. If formal channels that supply information fail then subformal channels must supply information. Subformal channels are used in times of crisis. However, subformal information channels are the least reliable. Therefore, an organization in crisis may use the least reliable information to make decisions. Automation of the least reliable sources of information has both positive and negative consequences. 


\author{
EVALUATION OF INFORMATION \\ RESOURCE MANAGEMENT: \\ MEASURING CHANGE IN A FEDERAL BUREAUCRACY
}

by

RANDOLPH D. PERRIN

A dissertation submitted in partial fulfillment of the requirements for the degree of

DOCTOR OF PHILOSOPHY

in

URBAN STUDIES

Portland State University

1993 
TO THE OFFICE OF GRADUATE STUDIES:

The members of the Committee approve the dissertation of Randolph D. Perrin presented December 2, 1993.
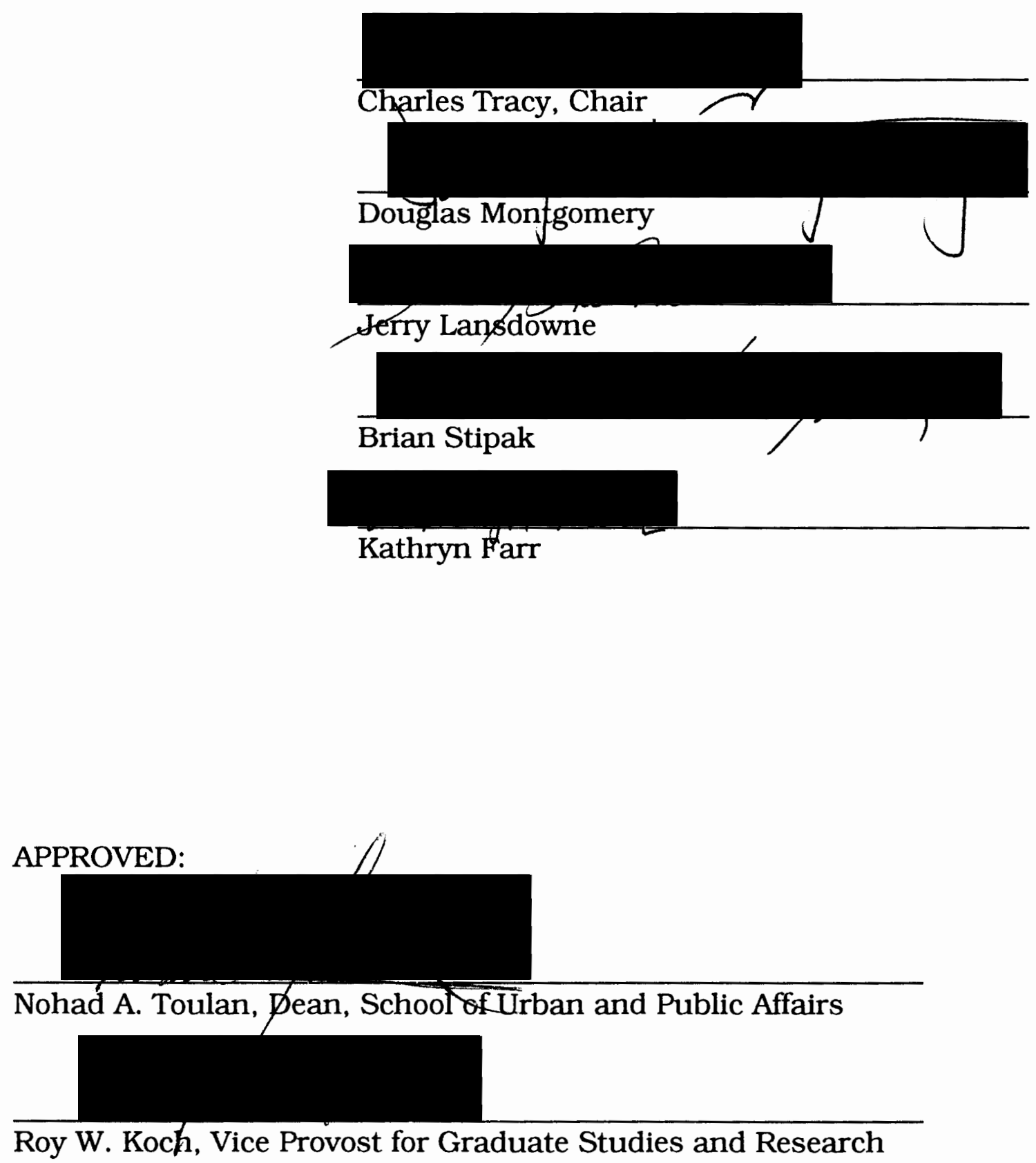


\section{ACKNOWLEDGMENTS}

I want to acknowledge the following people for their help in completing this study: my wife, Annette, and my daughter Krystal for their constant support and understanding; The Bonneville Power Administration and its staff for cooperating in this study; Doug Montgomery for his enthusiastic support; Kathy Farr for her diligent editing; and Chuck Tracy for his coordination and listening. 
TABLE OF CONTENTS

PAGE

ACKNOWLEDGMENTS............................................................. ii

TABLE OF CONTENTS ................................................................. ii

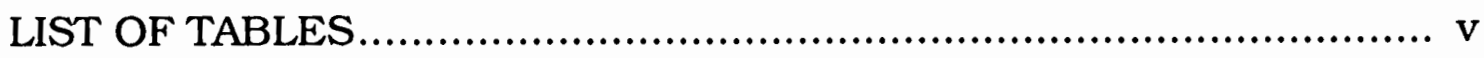

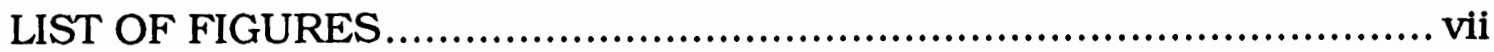

\section{CHAPTER}

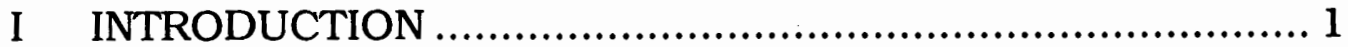

Background ...................................................... 1

Information ........................................................ 4

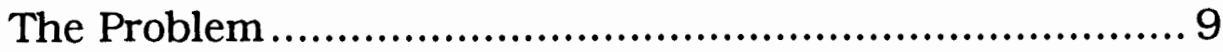

Conceptualization ................................................. 11

The Case Study Organization .................................. 13

Study Design........................................................ 13

Methods .............................................................. 16

Operationalization .............................................. 18

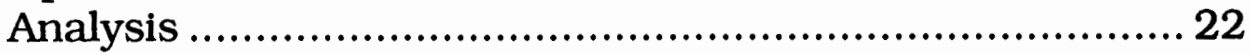

II LITERATURE REVIEW ........................................... 24

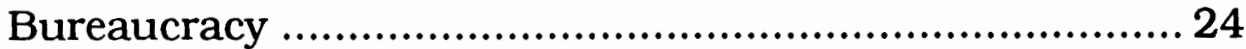

Information Resource Management ............................ 40

Evaluation Research ............................................. 49

III METHODOLOGY ................................................. 53

The Case Study Organization .................................... 53

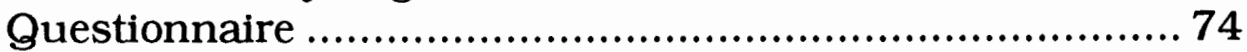

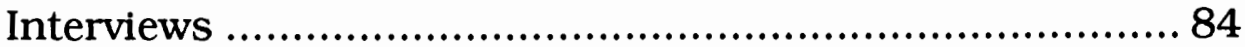

Conceptualization .............................................. 84

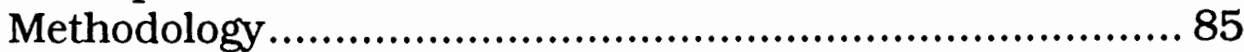

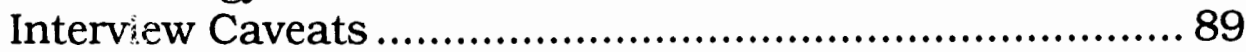




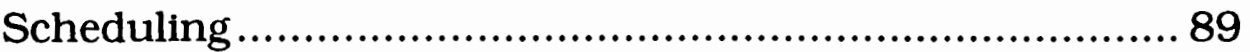

Recording and Transcription ................................... 90

Population........................................................... 90

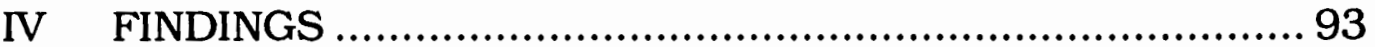

Questionnaire Analysis ........................................... 93

Interview Analysis ............................................. 117

Pretest Interviews ............................................. 118

Posttest Interviews ........................................... 121

VI CONCLUSIONS ................................................. 133

BIBLIOGRAPHIC REFERENCES .................................. 150

LIST OF ATTACHMENTS................................................ 156 


\section{TABLES}

Definitions

and Posttest

and Posttest Sorted by Question

Responses

4.7 Significance Levels of Categories Sorted by Question and Budget Classification 
4.8 Question A Changes in Mean of

Variables

4.9 Question B Changes in Mean of

Variables

Variables

4.11 Question D Changes in Mean of

Variables

4.12

Budget Category "C" Mean Change

112

4.13

Budget Category "G" Mean Change

113

4.14

Budget Category "GB" Mean Change

113

4.15

Budget Category "GM" Mean Change

114

4.16

Budget Category "GP" Mean Change

115

4.17

Budget Category " $M$ " Mean Change

116

4.18

Budget Category "S" Mean Change

116 
FIGURES

Table Number

2.1

2.2

2.3

2.4
Title

Subformal Communication Diagram

Formal Communication Diagram

Mainframe Model Diagram

LAN Model
Page

32

38

41

42 


\section{CHAPTER I \\ INTRODUCTION}

Bureaucracies are often viewed as slow unyielding institutions that are unchanging icons of modern life. Outward appearances of bureaus tend to bolster that concept. Not so apparent are efforts to change and vitalize bureaus from within. This research proposes to measure internal change through examining a bureau, its goals, and outcomes as a result of information resource management. The problem is to comparatively identify and measure information to determine if changes have occurred as a result of the installation of an information resource management organization.

\section{Background}

Bureaucracy is a social institution of modern life. Max Weber characterizes it as, "the most efficient method of solving large-scale organizational tasks." 1 The organizational tasks are carried out through, "(1) the continuity of official business; (2) the delimitation of authority through stipulated rules; (3) the supervision of its exercise; and (5) the separation of office and incumbent; and (6) the documentary basis of official business." 2 Bureaucracy is a purposefully impersonal

\footnotetext{
1 Bendix, R., Max Weber: An Intellectual Portrait, University of California Press, Berkley CA., 1977, pg. 451.

2 Bendix, pg. 424.
} 
organization that concentrates on the of administration of law or rules evenly while developing relationships that make the organization indestructible. ${ }^{3}$

Further, "Bureaucracy is the means of carrying 'community action' over into rationally ordered 'societal action'." It is, "an instrument for 'societalizing' relations of power, bureaucracy has been and is a power instrument of the first order." 4 Bureaucracy, as a social institution, " is administration in the hands of officials who possess the requisite technical knowledge."5

Implementation of law and rules by bureaucracy must have "the requisite technical knowledge," in order to convert community action into societal action. Therefore, it is important that policy makers, decision makers, and managers in bureaucracy have knowledge based upon accurate, valid, useful, and timely information.

Information is the basic input to decision-making. ${ }^{6}$ "Obviously, a \{Sic\} man's judgment cannot be better than the information on which he has based it."7 The quality of information supplied to policy and

\footnotetext{
$3 \quad$ Bendix, pg. 427-430.

4 Gerth, H. and Mills, C. Wright editors, From Max Weber: Essays in Sociology, Oxford University Press, New York, N.Y.. 1946, pg. 228.

$5 \quad$ Bendix, R., pg. 452.

6 Mintzberg, H., Mintzberg on Management, The Free Press, New York, N.Y., 1989, pg. 19.

$7 \quad$ Arthur Hays Sulzberger, Address to the New York State Publisher's Assoctation, August 30, 1948, Bartlett's Famtliar Quotations, John Bartlett, ed. Emily Morison Beck, 15th ed., Little, Brown, and Co., Boston MA., pg. 820-11, 1980.
} 
decision makers directly affects their decisions. ${ }^{8}$ Decisions and the supporting quality of information affect implementation of law or rules, institutional structures and social behavior. ${ }^{9}$

Information is provided in a variety of ways, including printed material, personal contact, and technological interfaces. Technology plays an ever increasing role in the presentation of information. Introduction of technology changes the social and organizational structure of institutions, often with unpredictable results. ${ }^{10}$

Transfer of information using technology has special problems:

-inappropriate levels of summarization of data,

- inappropriate technological application,

- duplicate information, 11 -poor quality, control, and validation of data/information, 12 -learning to use new technology to do work, ${ }^{13}$ and -fluctuating credibility due to lack of sufficient precedents. ${ }^{14}$

A variety of organizational structures have been developed to overcome the problems. Common organizational structures are: information systems (I/S), management information systems (MIS), information management (IM), and information resource management

8 Jones, J, and Mcleod, R., The Structure of Executive Information Systems: An Exploratory Analysis, Decision Science, Vol 17, Pgs. 220-249, 1986

$9 \quad$ Bendix, R., pg. 429.

10 van Gigch, J., Applied Systems Theory, 2nd ed., Harper and Row, New York, N.Y., pg. 408, 1978.

11 Crescenzi, A., The Dark Side of Strategic IS Implementation, Information Strategy: The Executive Journal, Fall, 1988, pgs. 14-20

12 Martin, J and Leben, J., pgs. 123-125

13 Barley, S., The Alignment of Technology and Structure through Roles and Networks, Administrative Science Quarterly, vol 35, no. 1, March, 1990, pgs. 64-65

14 van Gigch, pg. 412. 
(IRM). Recently, trends have been toward the use of IRM. IRM is defined as a process of planning, organizing, staffing, directing and controlling of resources necessary to produce and distribute information. ${ }^{15}$ IRM is an attempt to integrate all forms of information (books, publications, geographic systems, etc.) but is primarily an electronic or computer oriented enterprise. In an organizational context IRM proposes to find, record and present information while providing accessibility, accountability, privacy, and security.

The use of IRM is increasing because IRM is global in scope and often includes information organizations such as: libraries, records management, graphics, printing, and telecommunications. In theory, IRM is not strictly dedicated to automated data processing (ADP) to provide information solutions. IRM is by definition, therefore, more comprehensive in addressing information needs than other kinds of information management. The concept of IRM is considered so important that its existence is required by law for federal agencies. ${ }^{16}$

\section{Information}

The term information is variably defined as:

"1. : the communication or reception of knowledge or intelligence 2 a (1) : knowledge obtained from investigation, study, or instruction (2) : INTELLIGENCE, news (3) :

FACTS, DATA b: the attribute inherent in and

\footnotetext{
15 Burk, C. and Horton, F., InfoMap: A Complete Guide to Discovering Corporate Information Resources, pg. 10-12, Prentice-Hall, Englewood Cliffs N.J, 1988 
communicated by one of two or more alternatives sequences or arrangements of something (as nucleotides in DNA or binary digits in a computer program) that produce specific effects c (1) : a signal or character (as in a communication or computer) representing data (2) : something (as a message, experimental data, or a picture) which justifies change in a construct $d:$ a quantitative measure of the content of information; specif: a numerical quantity that measures the uncertainty in the outcome of an experiment to be performed 3 : the act of informing against a person 4 : a formal accusation of a crime made by a prosecuting officer as distinguished from an indictment presented by a grand jury -"17

Such wide and varied definitions make the term problematic and confusing. Information comes in all shapes and sizes. ${ }^{18}$ It is not limited to the capacity of a computer to supply it. As previously mentioned, IRM theoretically includes all forms of information. It is not limited to printed material or electronic media. ${ }^{19}$ Perhaps a useful definition for the purpose at hand is: information consists of facts assembled and communicated in a meaningful way and is constructed from data (unrelated facts). ${ }^{20}$

17 Ninth New Collegiate Dictionary, Merriam-Webster Inc., 1985.

Tufte, E., Envisioning Information, Graphics Press, Cheshtre Ct., pgs. 9-10, 1990.

Stephenson, B., Management by Information, Information Strategy: The Executive Journal, pg. 29, summer 1985.

20 Garvin, A. and Bermont, H, How to Win with Information or Lose without it, Bermont Books, Washington D.C., pg. 58-59, 1980. 
The second definition of information gives grounds for a constant struggle to identify needed information, determine what data compose the information, and find the best alternatives to acquire, record, process and deliver data as the information. Often the struggle is complicated by the scientists and engineers who design and program ADP equipment. They do not understand how management makes decisions. ${ }^{21}$ Scientists and engineers are unaccustomed to, "the murky 'corridors of power'."22 They have difficulty evaluating the information products of their technological labors.

IRM organizations are often composed of technologists who assume technology users know what information they desire, how to access and formulate data into information, and that the information is correct. ${ }^{23}$ It is important to find out the need and quality of information. ${ }^{24}$

Observations of available literature on the methods used to establish and plan the IRM function demonstrate that present strategies tend to be oriented toward hardware (the computer itself), or software (the programs or applications that run the computer). ${ }^{25}$ Solutions are usually based on technological capacity and performance, the right

\footnotetext{
$21 \quad$ van Gigch, pg. 402.

22 Heany, D.F., "Is TIMS Talking to Itself?", Management Science, vol 12, No. 4, pg. B-152, 1965.

23 Heany, pg. B-152.

24 Mann,R. and Emberton, J., "Methodology for effective information systems planning", Information and Software Technology, Vol. 30, No. 4, May, 1988, pgs. 244-249.

25 Dictionary of Electronics, 4th ed., Tandy Corporation, Fort Worth Texas, 1974.
} 
computer and right applications. Essentially, ADP professionals argue that if the form is correct, the function will follow. Information needs of the end user (the person who uses the application and needs the information) often become secondary. ${ }^{26}$

In an article presented at an American Management Association course on long-range information planning, problems with current information resource management methods were explained as follows:

"Unfortunately, today's I/S \{Sic\} planning methods are simply streamlined and automated versions of the methods available in 1980. The developers of I/S planning methods have failed to see The Catch \{sic\}. The emphasis in I/S planning methodology is still data architecture, variously named everything from Information architecture and Information Resource management to enterprise modeling. The goal is still technological flexibility to cope with MIS's primary problem, unpredictable user demands -unpredictable due to low managerial involvement. Ironically, in pursuit of a comprehensive and rigorous data architecture, the requirements for management participation are still increasing." 27

This quote refers to information systems [I/S] planning methods and identifies problems with the way management information systems

\footnotetext{
26 Crescenzi, A., The Dark Side of Strategic IS Implementation, Information Strategy: The Executive Journal, Fall, 1988, pgs. 14-20

27 The I/S Strategic Planning Catch, vers. 2, pg. 3, American Management Association course manual, Oct 1988, San Fransico, CA, Instructor Stan Ostaszewsk.
} 
[MIS] resources are addressed. The statement certainly underscores the gap between supplied information and needed information. Many existing planning methods are based on the concept that technology substantially changes fundamental information needs. Perhaps technology does not change information needs but information delivery. However, the lack of management involvement in IRM activities may be the result of inaccurate or unreliable information, management angst of technology, or a lack of understanding of needed management information. A strategy which reflects the value of management and its information is needed.

In a recent survey of thirty Fortune 500 companies, only seventeen percent (5) companies met the goals they intended to achieve with an information system. The survey notes that failure of the remaining eighty-three percent was due to inability to focus on intended goals. ${ }^{28}$ The goal of information resource management is to supply the appropriate information to the right person when the information is needed. ${ }^{29}$

Therefore, apparent or not, information is the driving force behind IRM. Quality information is important for IRM to support quality decision making. Ergo, the quality of bureaucratic institutions and their behavior is affected by information. The question remains, can needed information be ideritified and its quality determined? Can management

28 Crescenzi, A., pg 15. 
information be identified, captured, measured, and compared for guidance in the use of resources to supply information? What effect does IRM have in this pursuit?

\section{The Problem}

Evaluation of IRM's organizational performance is difficult. Production and distribution of information is not like measuring widgets produced on an assembly line. Information is more elusive and less quantifiable. Production of information is more like a service than a tangible product.

Common IRM strategies in use focus on computer capacity, software, and system performance. These three perspectives, systems, hardware, and software are most often used in IRM evaluation because they easily track budget expenditures for information. ${ }^{30}$ These three perspectives have value but, they do not focus on information needs or services provided. They produce data for the input side of the evaluation equation but not the other, output. ${ }^{31}$ The crux is that these perspectives do not address all information because they focus on systems, hardware and software instead of daily business activities. ${ }^{32}$

As service customers, managers and policy makers are uncomfortable with IRM's irability to focus on management information

$30 \quad$ Martin, J and Leben, J., Strategic Information Planning Methodologies,2nd ed., Prentice-Hall, Englewood Cliffs N.J., pgs. 124-130, 1989.

31 Joanne Kelleher, "Tackling Information Management", Business Computer Systems, October 1985, pgs. 64-68.

32 Sass, J., and Keefe, T., "MIS For Strategic Planning and a Compettive Edge", Joumal of Systems Management, June, 1988, pgs. 14-16. 
needs. Service customers are uncomfortable because they know that those who control information have considerable power. Often decisionmakers feel that evaluation and planning perspectives control the corporate environment rather than create needed management information. ${ }^{33}$ Such control may be distrusted in the atmosphere of corporate politics. ${ }^{34}$

If the Fortune 500 study mentioned previously is correct, then vast resources are spent annually to develop solutions which meet their goals seventeen percent of the time. If the purpose of IRM is to provide information in support of management and organizational goals, then better solutions are needed. IRM needs to know when it hits its information target and when it does not.

A way is needed that identifies, defines, and measures information use and quality to see if organizational solutions help in providing information. Previous strategies have met with little success. Therefore, the problem is to evaluate IRM by: (1) identifying and measuring information. (2) determining if changes have occurred as a result of the implementation of IRM. (3) examining the effects IRM has had on the organization. These objectives can be attained through evaluation of information use and perceived quality using the traditional research methods. This can be done by looking at the differences in information, comparing information supplied to managers before and after the

33 Crescenzi, A., "The Dark Side of Strategic IS Implementation", Information Strategy: The Executive Journal, Fall, 1988, pgs. 14-20.

34 Pfeffer, J., Organizations and Organizational Theory, Pitman, Marshfleld MA., 1982, pg. 74. 
development of an IRM organization. The next section develops this treatise further.

\section{Conceptualization}

Information existed before computers. Work was accomplished and decisions were made without electronic technological assistance. Usually, management or staff assimilated data in a meaningful way to make information. This task more and more falls to IRM. Strategies designed to implement information management seldom identify and measure the quality of information. Without knowing the full extent of information or its quality, IRM has difficulty meeting its goals because it does not know when it is going in the right direction. Usually this is done through development of integrated and controlled information through policy. ${ }^{35}$

To keep IRM organizations on track, information must be evaluated. Some of the questions that need to be asked are: what information is used, where do they get the information, and how useful is the information? Similar questions are asked when evaluating whether programs, agencies and organizations should: continue or discontinue programs, improve practices and procedures, add or drop specific programs or institute similar programs elsewhere, allocate resources

35 Martin, J and Leben, J., Strategic Information Planning Methodologles, 2nd ed., Prentice-Hall, Englewood Cliffs N.J., pgs. 24-28, 1989. 
among competitive programs, and accept or reject a program approach or theory. These kinds of questions are common in research evaluation. ${ }^{36}$

Clients for this kind of research are most often policy makers, program directors, and practitioners. Research evaluation is used primarily to examine social programs. Evaluation consists of the use of traditional social science methodology which will provide measurable data upon which to base findings and recommendations. Evaluation research consists of four basic steps: (1) "Find out the program's goals," (2) "Translate the goals into measurable indicators of goals achievement," (3) "Collect data on the indicators for those who participated in the program," (4) "Compare the data on participants \{and controls\} with the goal criteria." 37

Because IRM and the management it supports is ongoing and occurs at specific sites, this research is best undertaken as a field or case study. The study organization must: (1) have an active and recently installed IRM organization, (2) be accessible to investigation and be willing to be studied, (3) depend on data both from the IRM function and other sources, (4) be large enough to provide a large sample size, and (5) be stable over time. The Bonneville Power Administration is an organization with the above qualities and affords opportunity for study. A further description of the agency is given in the methodology chapter. The next section discusses study design.

36 Weiss, C, Evaluation Research; Methods of Assessing Program Effectiveness, Prentice-Hall, Englewood Cliffs NJ., 1972, pg. 16.

37 Weiss, pg. 13-14. 
The Case Study Organization

The Bonneville Power Administration (BPA) is the organization selected for this case study. BPA is the select organization because: (1) BPA has an active and recently created IRM organization, (2) BPA is presently accessible, (3) BPA uses both ADP and other sources of information for decision making, (4) BPA is a large enough organization to provide a large sample size, and (5) BPA is a federal bureaucratic organization over fifty years old and is therefore stable over time. BPA fits the criteria and is similar to other organizations used in case studies of the effects of technology and information. ${ }^{38}$

\section{Study Design}

This study uses a pre-experimental, one-group pretest/posttest design to investigate whether implementation of an IRM organizational format makes a difference in the information supplied to management and, therefore, the organization it serves. As shown in Table 1.1 below, the study design examines the information in the pre-existing organization; the new IRM organization is installed and then information is tested again. Because of limited time and resources the use of a control group is not a reasonable option for the study design. The study design can be diagrammed as:

\footnotetext{
38 Burkhard, M., and Brass, D., Changing Patterns or Patterns of Change: The Effects of Change in Technology on Social Network Structure and Power, Administrative Science Quarterly, vol 35, no. 1. March 1990, pgs. 104-127.
} 
Study Design

\begin{tabular}{|c|c|c|}
\hline $\begin{array}{c}\text { O } \\
\text { Measurement } \\
\text { Before IRM }\end{array}$ & $\begin{array}{c}\mathrm{X} \\
\text { Implementation } \\
\text { of IRM }\end{array}$ & Measurement After IRM \\
\hline
\end{tabular}

Table 1.1

The study design selected is pre-experimental using an observation (O), treatment (X, establishment of IRM), and a second observation (O). ${ }^{39}$ The design is called a one group pretest-posttest design. The design works for field research, but there are some problems with the internal and external validity of the design. ${ }^{40}$

\section{Internal Validity Problems}

First, history may make it difficult to attribute change strictly to IRM. Other events dependent upon external stimuli that occurred between pretest and posttest might be the cause of different outcomes. For example, scheduled institutional events or changes in organizational leadership can make a difference. History becomes more of a problem the longer the time between pretest and posttest.

Second, maturation, or the passage of time may change the results independent of external events. In this case, the passage of time all

$39 \quad$ Barley, S., The Alignment of Technology and Structure Through Roles and Networks, Administrattve Science Quarterly, vol 35, no. 1, pg. 61-103.

40 Campbell, D., and Stanley, J., Experimental and Quasi-Experimental Designs for Research, Rand $\mathrm{M}^{\mathrm{C}}$ Nally College Publishing Company, Chicago IL., 1963. pg. 7. 
kinds of events may have occurred in the IRM corporate environment which might contribute to misinterpretation of the study results.

Third, testing itself may sensitize the study population and produce study results that are different or improved in the posttest. This is due to the educational effects of using the same testing instrument twice, as is the case in this study. The problem arises most often when the test itself acts as a stimulus. The best example is the "Hawthorne Effect." Test subjects begin to realize that certain answers are expected of them.

Fourth, the survey instrument may not be as accurate on the second test as on the first test. This is generally true if mechanical devices are used to measure subjects. The devices may fatigue causing inaccurate measurements in the posttest. The same problem applies to situations which use observers.

Fifth, statistical regression may occur as a result of having been tested before. Regression is most common when comparisons are made between extreme groups. For example, testing the highest IQ students and the lowest IQ students may produce results which indicate that, in posttest, the high IQ students have lower IQ than in pretest and low IQ students have a higher IQ than in pretest. This is attributable to a natural tendency of scores to move toward the mean score over time. ${ }^{41}$

41 Campbell, D., and Stanley, pgs. 7-24. 
Finally, there is the possibility that the interactive effects of any of the previously mentioned problems may compound to more significantly effect the outcome. ${ }^{42}$

\section{External Validity Problems}

External validity problems refer to the generalizability of the results of the study to groups outside the environment and constructs of this study. "Induction or generalization is never fully justified logically", because studies are designed to fit a specific population. The liklihood that there is an exact same population elsewhere is slim. Additionally, the process of selection of subjects and the institution of study also can pose problems. In this case, however, all executives were interviewed in pretest and a random selection interviewed in posttest. All middle managers were invited to participate through questionnaires in both pretest and posttest. ${ }^{43}$

As noted in the previous section, this is field research using a case study of the Bonneville Power Administration's IRM organization. Data for the case study were collected using interviews and questionnaires.

\section{Methods}

Traditionally, two kinds of interview techniques, qualitative and quantitative, have been used for this kind of study. Quantitative interviews rely primarily on structured questionnaires administered and 
recorded in a structured format. The method requires a strict set of questions and immediate note taking. On the other hand, a qualitative approach, particularly a phenomenological orientation, is less structured and allows the interview to flow where it will. ${ }^{44}$ Quantitative interviews are usually easily coded and can be analyzed statistically. Qualitative interviews are less easily quantified, but may provide a richer understanding of the study subjects and environment. Qualitative research methods are well suited for field research. 45 Since a contextual understanding of the organization is important for this study, a qualitative interview technique has been selected.

Another tool for research is the survey questionnaire. Survey questionnaires have several advantages. First, they allow wide geographical distribution. Second, they can be self-administered which saves time. Third, they can be given to a large population which would be normally unobservable. And fourth, they can be structured to allow the results to be quantified. ${ }^{46}$

Both questionnaires and interviews have merit. In this case, a combination of both will be helpful. The combination of the two techniques has been used with great success and advantage. ${ }^{47}$ First, the interviews allow observation of the subjects and aid in getting a flavor for

\footnotetext{
44 Bogan, R. and Taylor, S., Introduction to Qualitative Research Methods: A Phenomenological Approach to the Social Sciences, Wiley and Sons, New York, N.Y., 1975

45 Golden, P., The Research Experience, F. E. Peacock Publishers Inc., Ithica Illinois, 1976, pg. 22.

$46 \quad$ Golden. pgs. 315

47 Beer, M., Eisenstat, R., Spector, B., The Critical Path to Corporate Renewal, Harvard Business School Press, Boston MA., 1990.
} 
the environment. Interviews also facilitate familiarization with ideas and language that are unique to the study environment. Second, using the information from interviews, a more relevant questionnaire can be constructed that can be used on a wider population. In the next section is a discussion of how these methods were put to use in this study.

\section{Operationalization}

\section{Interviews}

For this study I selected a qualitative interview technique for two reasons. First, qualitative techniques provide a better feel for the research environment. Second, the interview technique used here, modified grounded theory, allows little room for assumptions. $\underline{48}$ This technique assumes that in the initial part of the study the interviewer knows very little about the topic. Each successive interview uses knowledge gained from previous interviews both to construct new questions and to develop verification of key facts and events collected in the subsequent interviews. Grounded theory also helps the interviewer develop an understanding of the milieu and unique cultural traits. Additionally, quality information from the interviews provides an excellent basis for questionnaire development.

Multi-faceted elements in an interview environment include: eye contact, body language, and facial expressions. Sometimes an interview goes beyond the rigid constraints of preconceived questions which may

$48 \quad$ Glaser, B. and Strauss, A., The Discovery of Grounded Theory: Strategies for Qualitative Research, Adline Publishing, Chicago Ill., 1965 
be revealing to the interviewee or may indicate new directions of questioning to the interviewer. Finally, one can probe in some areas in order to develop a broader understanding of a particular event, decision or occurrence.

\section{Interview Caveats}

Limitations exist with this interview technique. Interview findings can be difficult to quantify which allows only limited statistical analysis. Verification of interview results can be difficult. Notes taken during the interview may not have captured all important elements during the process.

\section{The Questionnaire}

Designed to gather generic information, the questionnaire is based on interview information and was extremely difficult to construct. Because the case study agency is diversified in its activities (over 150 occupations), specific questions on organizational processes could not be asked; there were simply too many. Instead, generic questions with general topics were explored. The questionnaire focuses on four specific areas; (1) Information/data needed from others to make decisions, (2) Information generated to support others' decisions, (3) Information not available that would be helpful in making decisions, and (4) Information available but not needed in decision making. ${ }^{49}$ The answers to these questions were then rated by the respondent according to eleven predetermined categories. The results were then easily recorded and collated.

\section{Questionnaire Caveats}

Questionnaires have several limitations. First, they are rigid measurement instruments. They are rigid because, once questionnaires are disseminated, the researcher cannot go back and change them or

49 See attachment two - the questionnaire. 
probe for more in-depth information. Second, not everyone returns a questionnaire. Therefore, a certain bias is added because the data are limited to those who are motivated to return the questionnaire. Those who do not respond may also have important information, but perceive no reward in response. Thus, there is a risk that important data may be missed. Finally, it is possible that an important piece of information or data may be overlooked at the conceptualization of questions for the survey. Once the questionnaires are disseminated, there is no turning back. And in the real world, there is often no second chance.

Limitations of the questionnaire are in contrast with those of the interview. The questionnaire instrument is rigid, but can be completed faster than an interview. One cannot probe for in-depth information with a questionnaire, but can reach a wider audience. Interviews are slower to administer, while questionnaires are faster. Questionnaires are more easily quantified than interviews.

\section{Research Population}

The study population is limited to management employees of BPA. In this case, the group consisted of eighteen executive interviewees (twenty pretest, five in posttest) and one hundred-ten mid-level manager questionnaire respondents (fifty-four pretest, fifty-six posttest). Participation was limited to those who, upon receiving an invitation, decided to be interviewed or fill-out a questionnaire. Each mid-level manager who participated with a questionnaire developed an 
information-use log by filling out the questionnaire. Then they rated each logged entry. Together the logs create a composite information map at a single point in time for the organization. Below is the study population participation(Table 1.2).

Survey and Interview Table

\begin{tabular}{|c|c|c|c|}
\hline Measurement & Date & Interviews & $\begin{array}{c}\text { Questionnaires } \\
\text { Sent }\end{array}$ \\
\hline Pretest & May 1989 & 20 & $54(22$ returned) \\
\hline Posttest & Sept. 1991 & 5 & $56(28$ returned) \\
\hline
\end{tabular}

Table 1.2

\section{Ethical Considerations}

Initial interviews were part of an internal review for BPA. ${ }^{50}$ All interviewees gave their consent to participate in that study. The initial study is cited and the interviewees names and exact positions in the agency are not revealed.

Follow-up interviews were handled differently. When the interviews were conducted there was some confusion as to the appropriate ethical consideration necessary to protect the participants. As a result interviewees were re-interviewed. All interviewees were informed of the interviews and consented in writing to participate. At no time is information used in this study associated with a specific individual. Interviewees' names were not associated with the interview 
notes. Interviews were conducted using two people (interviewer and note taker) and were held in the interviewees' office. Comments the interviewees wished not to be attributed to themselves were left out of the interview notes. Interview notes and consent forms were locked for the participants' protection.

Questionnaires were mailed to respondents. Their names appeared no where on the questionnaire. Instead, a code list was used to track participation. Therefore, none of the questionnaire data for this study can be associated with an individual or specific organization within BPA.

\section{Analysis}

Analysis of this study occurred on multiple levels. First, questionnaire data were divided into general budget classifications of information (e.g. budget, finance, personnel, requirements, and so on). Next, each classification was segregated into information types (information supplied to others, used to make decisions, needed information, and undesirable information). Each type and classification was then analyzed via the eleven categories used to measure the quality of information. In this way, a composite picture of information needs and problems was compiled. Specific statistical techniques were defined as the data were coded and posted.

Finally, interviews provided contextual data about the business environment, topics, and the cultural environment of the agency. 
Contents of the interviews were summarized into statements of observation and findings. Each interview was carefully analyzed for information sources and ratings of these sources. The interview's findings and analysis were combined for an overall perspective of executive management views of information. 


\section{CHAPTER II \\ LITERATURE REVIEW}

Bureaucracy

The environment in which a study is conducted is important. This study is of a middle sized federal bureaucracy. Therefore, it is important to understand bureaucracy in its historical, political, economic, and sociological forms. Though this study's intent is not to deduce the subtleties of bureaucracy, a review of pertinent literature can provide insight.

Early insight comes from the "positivistic organicism", 51 writings of sociologists Emile Durkheim and Ferdinand Tonnies. Tonnies conveyed the idea of collective will. The idea of collective will, he believed, came out of exchange or barter and the "interrelationship" that results. $\mathrm{He}$ classified relationships into those of rational will (Kurwille) and natural will (Wesenwille). He believed that the kind of will predominant in a social group was related to the composition of society. He concluded that the result was two ideal types, communities (Gemeinschaft) and societies (Gesellschaft).52 According to Tonnies, communities and societies differ in social types. Communities are controlled mainly by mores and

51 Though positivism and organicism are often viewed as part of a single movement in sociology, there is a subtle distinction between the two. Positivism emphasizes scientific method as a means to understand society. Organicism views society as a kind of organism with all its functional parts.

52 Tonnies, F., Community and Society, Loomis, C. (translator), Michigan State University Press, 1957. pgs. 9-10. 
folkways, concord, and religion resulting in family law and extended kin groups as central institutions. Societies, on the other hand, are controlled by convention, legislation, and public opinion that result in the state and capitalistic economy. ${ }^{53}$

Durkheim added to the philosophical understanding of society when he studied the division of labor in society. ${ }^{54}$ Durkheim examined the cohesion or solidarity of society and broke it down into two basic types, mechanical and organic. Mechanical solidarity exists in small communities. In small communities little specialization is necessary. Individual choice, therefore individuation, is unnecessary. Mechanical solidarity is characterized by repressive laws. ${ }^{55}$

Organic solidarity is the cohesion of more complex societies, according to Durkheim. Organic solidarity is characterized by complex relationships of individual to state, work, family, and economy. In complex societies, specialization and individuation are necessary for society to survive. Restitutive law is a fundamental characteristic of organic solidarity. ${ }^{56}$

An often overlooked part of organic solidarity is contractual solidarity. Contractual solidarity is the contract, both social and legal,

53 Martindale, D., The Nature and Types of Sociological Theory, Houghton Mifflin, Boston MA., 1960, pgs. 81-85.

54 The term, "division of labor", was actually coined by Adam Smith.

55 Durkheim, E., The Division of Labor in Society, translated by George Simpson, The Free Press, New York, N.Y., 1933, pgs. 70-110. 
devised to bind citizens of society to their individual or collective tasks. Contractual solidarity consists of bonds not only to keep society from disharmony, but to bring together in agreement of tasks, the divisions of labor. Contractual solidarity is characterized by penal, domestic, and administrative laws. ${ }^{57}$

Both Tonnies and Durkheim viewed law as a point of study. They both viewed societies as changing from simple to complex and the rules that control the societies, likewise changing. Tonnies' and Durkheim's philosophies of complex societies' laws, taken together, envision social bonds through convention, legislation, and public opinion resulting in restitutive (as well as repressive) laws and contracts authoritatively translated into penal, domestic, and administrative laws.

The power or authority to administer such laws was addressed in detail by Max Weber. Weber wrote:

"Law exists when there is a probability that an order will be upheld by a specific staff of men who will use physical or psychical compulsion with the intention of obtaining conformity with the order, or of inflicting sanctions for infringement of it. The structure of every legal order directly influences the distribution of power, economic or otherwise, within its respective community. This is true of all legal orders and not only that of the state. In general, we understand by

57 Durkheim, pgs. 200-229. 
'power' the chance of a man or of a number of men to realize their own will in a communal action even against the resistance of others who are participating in the action." 58

Weber's comparative studies of legitimation of power produced three primary ways power is attained; rationally, charismatically, and traditionally. Rational power is simply the belief that power is where it belongs, that is, the rules are resonable and logical as they should be. Charismatic power comes from magic or the personal power of an individual. Traditional power comes out of customs. Power can be bestowed, earned, or taken. ${ }^{59}$ Organizational structures which are the conduit of power are of utmost concern to this study.

Weber studied bureaucracy as one of the rational structures of power. He defined bureaucracy as a large scale organization that has:

"(1) the continuity of official business; (2) the delimitation of authority through stipulated rules; (3) the supervision of its exercise; and (5) the separation of office and incumbent; and (6) the documentary basis of official business." 60

Bureaucracy is a purposefully impersonal organization that concentrates the means of administration of law or rules evenly while developing

\begin{tabular}{ll}
\hline 58 & Gerth H., and Mills, C., pg. 180. \\
59 & Martindale, pgs. $389-390$. \\
60 & Martindale, pg. 424.
\end{tabular}


relationships that make the organization indestructible. Bureaucracies exist in the public (government) and private (corporate) sectors. Weber considered bureaucracy to be the most efficient way to carry-out large tasks. ${ }^{61}$

Not everyone agrees. Some believe that bureaucracies are too large and control too much power. For example, Milton and Rose Friedman contend that bureaucratic productivity (public and private) decreases as funding for bureaucracies increases. They believe that the laws that created public organizations are far too complex to be understood and therefore to be of any value. ${ }^{62}$ Still others contend that bureaucracies cannot be true servants of the people. No amount of presidential power or administrative authority can control or produce consistent and coherent policies, given sources of intervention and the size of the administrative "apparatus" of bureaus. In this country, the public is unwilling to grant enough power to any individual necessary to significantly effect bureaucratic structure. ${ }^{63}$

William $\mathrm{H}$. Whyte would, ultimately, agree. As a student of bureaucracy he wrote in his book, The Organization Man, of the condition of individuals who work in bureaus. Whyte contends that the United States of America once valued individual freedom above all else. He observes that bureaucratic organizadionis now serve as substitutes for

\footnotetext{
$61 \quad$ Martindale, pg. 427-430.

62 Friedman, M. and R., Free to Choose, Avon, New York, N.Y., 1980, pgs. 283-286.

63 Ermann, D., and Lundman, R., Corporate and Governmental Deviance: Problems of Organizational Behavior in Contemporary Soctety, Oxford University Press, New York, N.Y., 1978, pgs. 321 -322.
} 
community and overshadow individual freedom. He proposes that the concept of individual freedom once upheld in this country is substituted in bureaucracy by:

1. the belief that the group is a source of creativity,

2. the belief in belongingness as the ultimate need of the individual, and

3. a faith in the application of science to achieve this belongingness. ${ }^{64}$

Whyte's observations imply allegiance to bureaucracy, a bond. Within the bond are the threads which create social networks coming from those who believe enough to substitute belonging for individual freedom. Though bureaucracies are created to perform functions in society, they also serve as community. There are many facets to bureaucracies.

One of the facets of bureaucracies is the way they are internally organized. Anthony Downs examines the internal functions of bureaucracy. He writes that bureaus have:

1. A hierarchical structure of formal authority.

2. Hierarchical formal communication networks.

3. Extensive systems of formal rules.

4. An informal structure of authority.

5. Informal and personal communications networks.

64 Whyte W., The Organization Man, Simon and Schuster, New York, N.Y., 1956. 
6. Formal impersonality of operations.

7. Intensive personal loyalty and personal involvement among officials, particularly in the highest ranks of hierarchy.

These seven functions of bureaucracy demonstrate the formal and informal structures Whyte observed in respect to social networks and the bonds that serve as the basis for community. Many bureaucracies are vertically organized with several layers of management, one layer stacked upon another. In this country public bureaucracies are typically vertical in nature. 65

Downs' list also presents some observations about communication in bureaucracies. He states that communication exists in two forms, formal and subformal. Formal communication networks transmit messages recognized as official communication (organization charts, directives, and so on). Subformal communication arises from informal authority structures and relationships that exist in every organization. There are two kinds: subformal communication on formal communication networks, and subformal communication on informal networks. Subformal communication on formal networks usually serves to fill in the gaps left in formal communication. Informal networks spring up where ever needed and are not restricted to vertical organization lines of communication. ${ }^{66}$

\footnotetext{
65 Downs, A., Inside Bureaucracy, Little, Brown and Company, Boston MA., 1967, pg. 49. 66 Downs, pgs. 113-115.
} 
Subformal channels of communication have some important characteristics:

1. A high degree of correlation exists between subformal communication and interdependent activities.

2. High degrees of uncertainty proliferate subformal channels.

3. In times of crisis subformal channels are more often used because they are faster. Top managers searching for information during a crisis tend to rely on subformal channels.

4. Organizational conflict curtails subformal communication.

5. New or changing organizations have fewer subformal channels than old organizations. ${ }^{67}$

A subformal network might look something like Figure 2.1. Notice how all nodes in the network are connected to all other nodes, not strictly following the official lines of authority speeds communication.

67 Downs, pgs 114-115. 


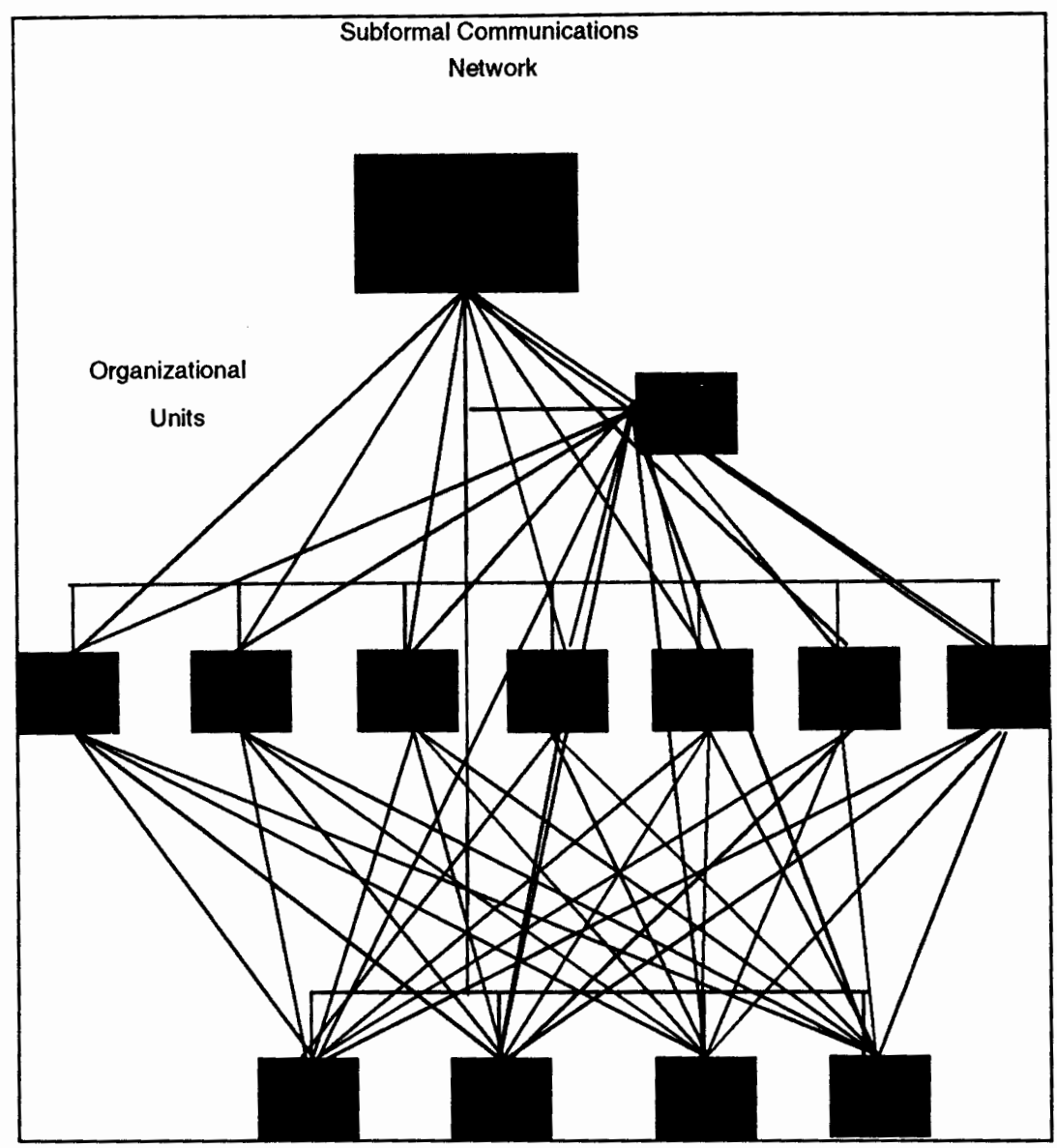

Figure 2.1

Downs also addresses personal communication. Personal communications are most often used to stabilize personal relationships. However, information attained from personal communication is always verified through subformal or formal channels of communication. ${ }^{68}$

Communication channels arise to gather and transmit information. Individuals, usually management, continuously scan their environment for dependable information. Information is necessary to create a knowledge base. Individuals depend upon an accurate knowledge base 
to choose between alternatives, to make decisions. ${ }^{69}$ Decision making is usually an individual activity which has limits and processes which will be discussed later.

Decision making has inherent limits because there are limits in the real world. No one makes perfect decisions because nothing that contributes to the decision process is perfect. Again, Downs posits the following limitations.

"1. Each decision-maker can devote only limited time to decision making.

2. Each decision maker can mentally weigh and consider only a limited amount of information at one time.

3. The functions of most officials require them to become involved in more activities than they can consider simultaneously; hence they must normally focus their attention on only part of their major concerns, while the rest remain latent.

4. The amount of information initially available to every decision maker about each problem is only a small fraction of all the information potentially available on the subject.

5. Additional information bearing on any particular problem can usually be procured, but the costs of 
procurement and utilization may rise rapidly as the amount of data increases.

6. Important aspects of many problems involve information that cannot be procured at all, especially concerning future events; hence many decisions must be made in the face of some eradicable uncertainty."70

All things being equal, the process of decision making involves:

"1. Perception. He $\{$ Sic $\}$ obtains new information as a result of his automatic search.

2. Assimilation. The information he has received alters his image of the world.

3. Performance Assessment. When he compares this altered image of the world with his goals, he discovers a performance gap large enough to exceed his inertia threshold. In short, he believes he ought to do something.

4. Formixlation of Alternatives. He designs a number of possible actions directed at reducing the performance gap.

5. Analysis of Alternatives. He then analyzes each possible action by testing it against his image of the world in order to discover its likely consequences. 6. Evaluation of Alternatives. He evaluates these consequences by measuring them against his goals. 
7. Strategy Formulation. If one or more of the actions appears likely to eliminate the performance gap, he incorporates it (or them) into a strategy of action under various conditions.

8. Action Selection. He then re-examines his image of the world to discover what conditions exist, and carries out the appropriate action in accordance with his strategy.

9. Continuous Data Acquisition. His information inputs during steps 3 through 8 as follows:

a. He receives a stream of information from his automatic search which constantly alters his image of the world.

b. He may engage in special-project search aimed at discovering additional facts relevant to any of these.

10. Action Impact. His action affects the world in some way, giving rise to a new condition therein. 11. Action Feedback. He receives information about these new conditions.

12. Assimilation of Feedback. This feedback information alters his image of the world once more. 13. Performance Reassessment. He compares this revised image of the world with his goals to determine whether any performance gap still exists. 
a. If the gap has been eliminated, he is once more in a position of equilibrium and returns to his automatic level of search intensity.

b. If a performance gap still exists but is below his inertia threshold, he will probably continue some special-project search. However, he will not go through the action cycle again.

c. If a performance gap still exists and it exceeds his inertia threshold, he repeats the action cycle until either condition $a$ or $b$ above prevails. 71 This process shows that a continuous cycle of information must flow to the decision maker.

Information can also become distorted. Festinger's socialpsychological theory of cognitive dissonance accounts for part of the distortion. Beginning with a decision, some information supports the decision and some does not. A constant state of tension exists both from the negative aspects of the path chosen and the positive aspects of the path not chosen. Hence, the decision maker is constantly looking for ways to reduce dissonance through supportive information and discounting non-supportive information. ${ }^{72}$

Dissonance exists in all decision making. In most bureaucracies, decision makers are organizational or program managers. These

\footnotetext{
71 Downs., pgs. 175-176.

72 Festinger, L., A Theory of Cognitive Dissonance, Stanford University Press, Irvine CA., 1957, pgs 7071.
} 
individuals tend to be like nerve centers of the organization. Part of their function is to gather and relay information. ${ }^{73}$ Of course, managers are not the only conveyers of information. All members of organizations obtain and relay information as seen in Figure 2.1. More will be discussed on this point later. Downs identifies ways in which dissonance is decreased and why common biases occur:

1. Each official tends to distort information passed upward to maximize his own position and minimize his shortcomings.

2. Officials exhibit bias toward policies and alternatives which serve their interests and programs over others.

3. Officials vary the degree of compliance with directives depending upon whether or not their interests are served.

4. Officials will seek out additional responsibilities and risks depending upon their own goals. ${ }^{74}$

Most informal information seldom finds its way into a formal organizational structure. On the other hand, formal organization

73 Mintzberg, H., Mintzberg On Management: Inside Our Strange World of Organizations, The Free Press, New York, N.Y., 1989, pg. 17.

74 Downs,A., pgs 77-78. 


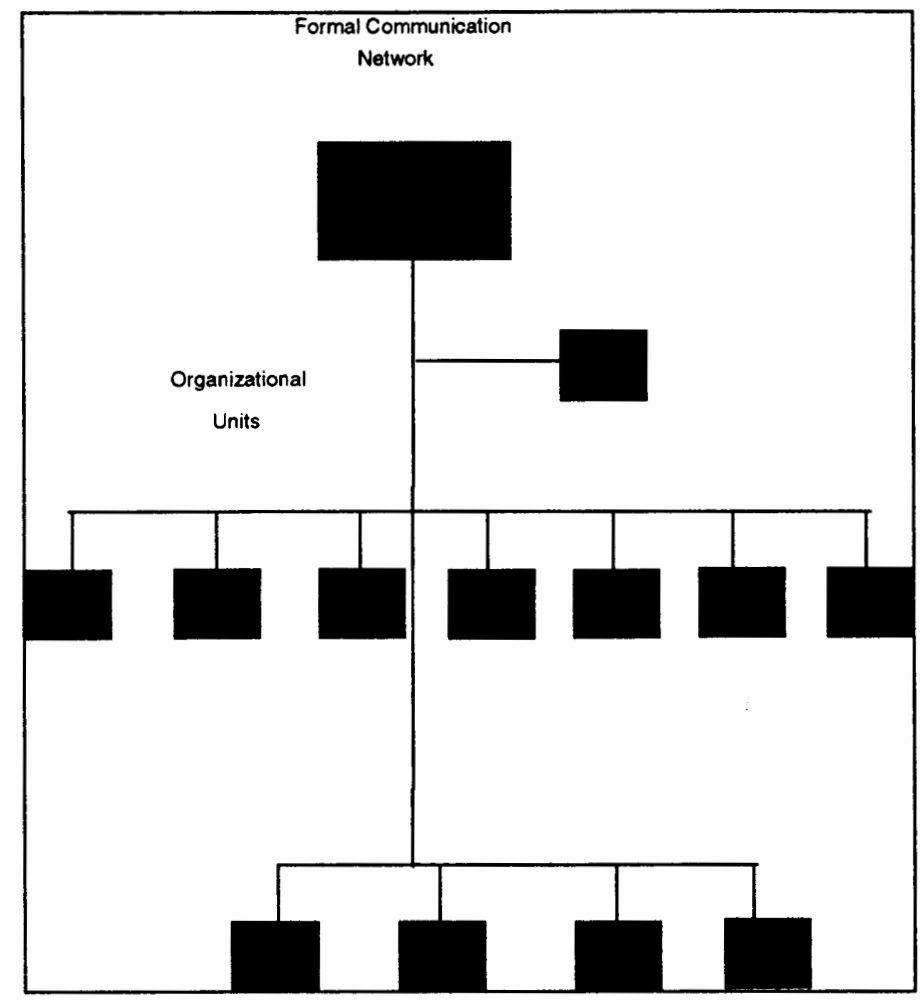

Figure 2.2

structures are the public face of organizations seldom seen. Most of the dissonance is not present, formally. Figure 2.2 is an example of a formal communication and authority structure. Typically, the lines of authority touch each organization one time.

Henry Mintzberg states that much of the information in an organization that decision makers use is communicated orally....the information exists in the heads of the decision maker and reporter. Mintzberg claims that formal information, specifically information processing, is not useful for the following reasons.

1. Formal information is too limited. The information tends to be limited in what is not (sales missed and so on) and in external information. 
2. Formal information, by aggregated data, is often too general for managers. Specific reasons for an event may be more important than cumulative data.

3. Much formal information is too late. It takes time to gather, record, and process data.

4. Some formal information is unreliable. Formal data depend upon agreed upon measures which may or may not be useful. ${ }^{75}$

Mintzberg also cites some problems in vertical organizations when problems get bumped up the hierarchy. The problems tend to land on the same desk and at that point become a bottle-neck. Large organizations like bureaucracies tend to try to solve the problem with the functions contained within management information systems (MIS). However, these solutions often do not work because of reasons stated by Downs earlier; good performance data get enhanced and bad performance data get played down. ${ }^{76}$

Administrators have noticed these tendencies and have instituted an action which Downs calls the "by-pass". The by-pass is simply the process of going outside the management chain into the organization to find the source of information. By going directly to the information source, the manager or administrator eliminates much of the distortion. The result is two-fold, better information is attained, and middlemanagement is rendered ineffective. ${ }^{77}$

\begin{tabular}{ll}
\hline 75 & Mintzberg, pgs 73-74. \\
76 & Mintzberg, pg. 148-149. \\
77 & Downs, pgs. 123-126.
\end{tabular}


It is also important to recognize that managers and administrators are not the only players in the information exchange game. Others, not included in this study, supply and receive information. Decision making is not a closed information system.

A flatter organization structure reduces steps of communication and information distortion. Performing by-pass activities enact the same results. Providing the same information electronically may also have the same effect. ${ }^{78}$

This is the environment in which IRM exists. What is unique about IRM in relation to other information organization types and to the literature just presented is IRM is an attempt to encompass all forms of information. The task may prove to be impossible. The next section examines the literature specifically focused on information management.

\section{Information Resource Management}

The following are the critical areas affecting IRM. Each area adds to the body of knowledge about IRM and the strategies it uses to identify and distribute information. These topics are the foundation upon which this IRM review was developed. They include strategies which examine hardware, software, and systems design. 
Hardware

Most literature advocating the use of hardware as a strategy for information management identifies three mechanisms: (1) computer connectivity, (2) personal computers, and (3) information centers.

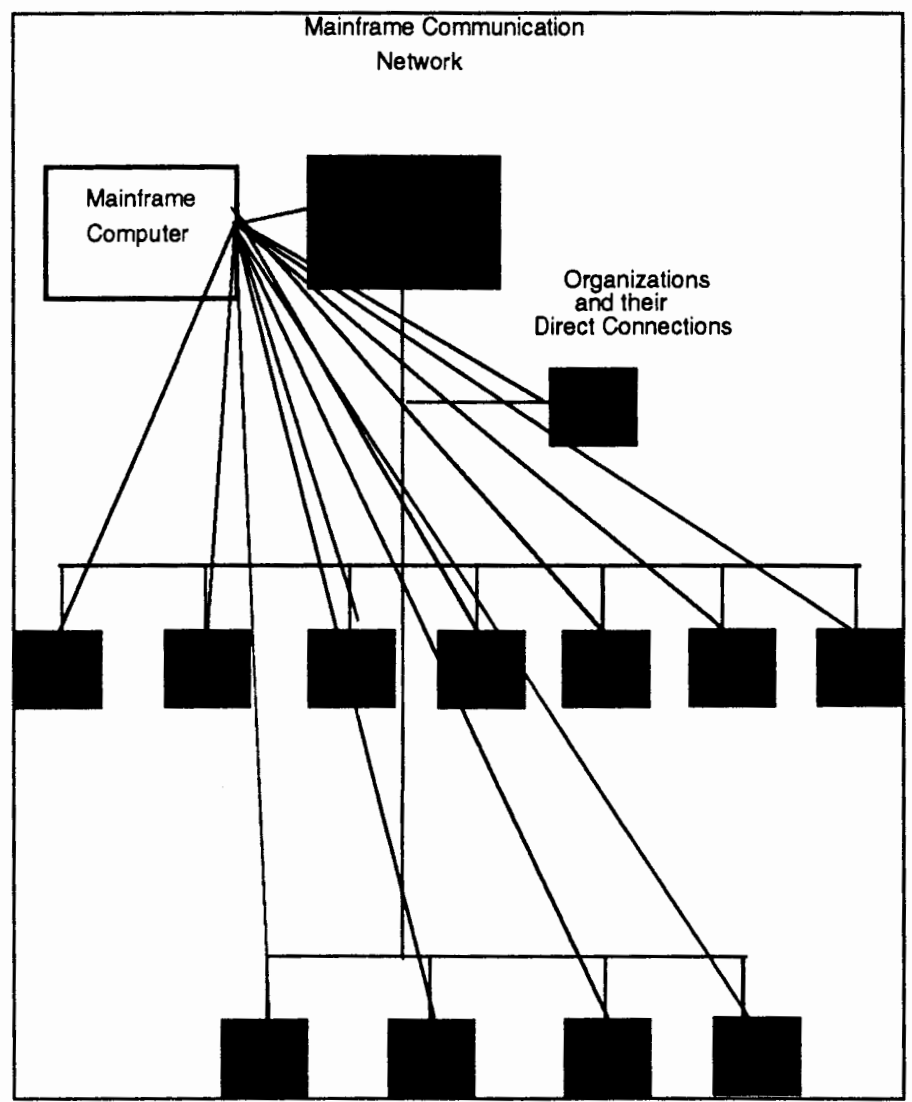

Figure 2.3

Connectivity, the ability to put one computer in contact with another in a compatible way, is an activity which provides opportunity but little control or standardization. Most large organizations use large mainframe computers. Mainframe computers demand that computing direct connectivity. Other strategies use configurations which do not require direct connection. Figure 2.3 demonstrates the connectivity of mainframe computing while Figure 2.4 show local area network (LAN) 
connections. Synnott and Gruber, in their book, Information Resource

Management. Opportunities and Strategies for the 1980's, agree that connectivity is extremely important ${ }^{79}$. They go further by strongly emphasizing that technology will drive information management. Engineering organizations are particularly fond of this philosophy. ${ }^{80}$ In a course presented by the Manus Consulting Group it is stated that, "islands of technology" will exist without connectivity. ${ }^{81}$ As long as information is power, this will probably be the case. Some information resource managers believe that information development goes where

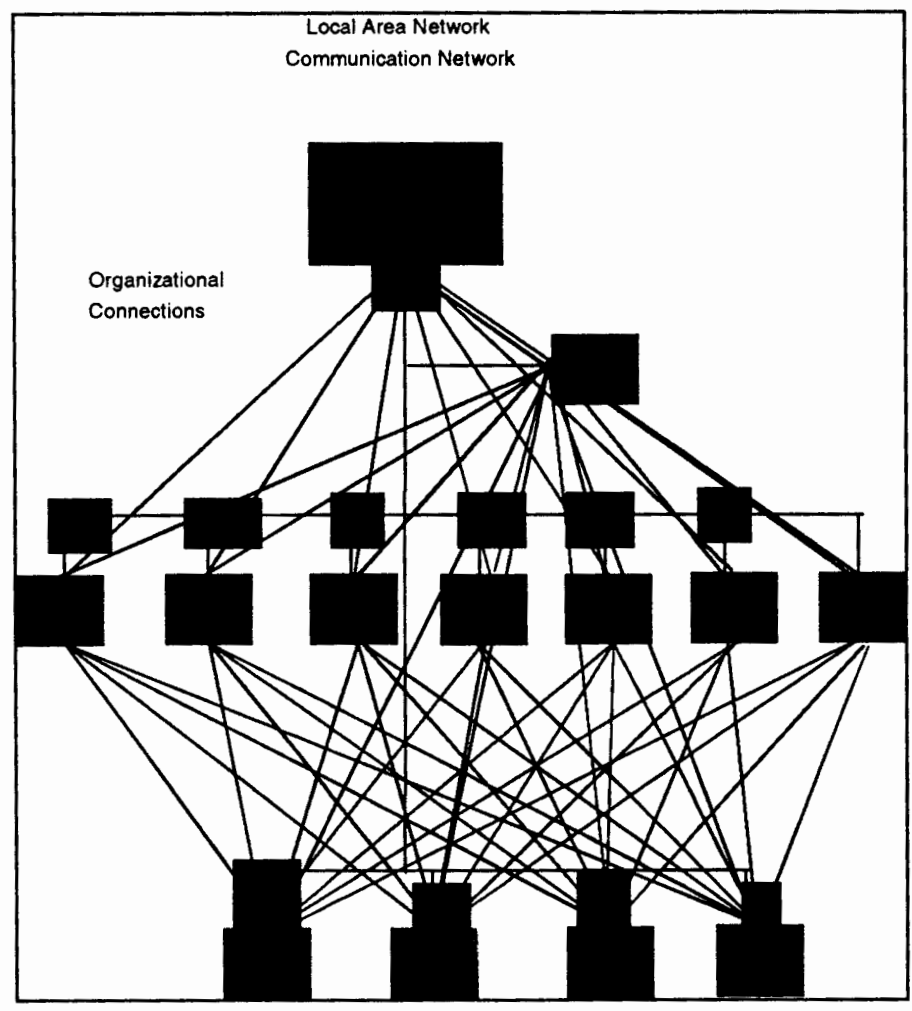

Figure 2.4

\footnotetext{
79 Synnott, W. and Gruber, W., Information Resource Management: Opportunities and Strategies for the 1980's, Wiley, New York, N.Y., pg. 200-212, 1981

80 Beyer, D., Information Management, Inform, December, Pg. 16-18,1987

81 Information Resource Management, Course book by Manus Professional Services, Olympia Washington, W. Smith Instructor, pg. C.1.7, 1986
} 
connectivity goes.

Personal computers (PC's) have certainly had a significant impact on computing. ${ }^{82}$ The Director of Computing for Pacific Gas and Electric (PGE) sees personal computers as part of the corporate computing block....a large monolith. These small desk top computers are becoming more and more a part of the corporate perspective of distributive computing power, a way of spreading computing across the organization. ${ }^{83}$ The corporate monolith view prevails in low cost computer operations because personal computers are less expensive than mini or mainframe computers. Additionally, they do not require full-time programmers to maintain them.

Personal computers are the most common mechanism for computing among bureaucracies. ${ }^{84}$ Personal computers create little islands of data, managed, controlled, developed and maintained by the individuals who operate them. The individuals who work in this kind of isolation are likely to ignore data other than their own, and duplicate data which may exist elsewhere. In this way, personal computers promote some disjointed incrementalism; that is, progress is not the result of a corporate coordinated effort, but of individuals pulling in

\footnotetext{
82 Earl, M., Management Strategies for Information Technology, Prentice-Hall, Englewood Cliffs N.J., 1989.

83 Madnick, S. editor, The Strategic Use of Information Technology, Oxford University Press, New York, N.Y., articles from Sloan Management Review, Sullivan, C., System Planning in the Information Age, pgs. 121 $124,1987$.

84 U.S. Army Materlals Command, Information Resource Management: Information Strategy for the 90's, DCS Command for Information Management, 1987.
} 
individual is playing different pieces of music. Eventually they all progress toward the end of the music but in a disjointed and noisy way there is no orchestrated effort. Supporters of hardware approaches to information management argue that modems (a telecommunication device) and local area networks (LANs) can overcome data isolation ${ }^{85}$. However, no matter how sophisticated the system and its connections, a computing device controlled by an individual is still subject to the decision made by its user; therefore, so is the information provided.

Information centers are organizations developed by IBM in the late 70 's and promoted during the early 80's. Their purpose was to provide the computer end-users with support for applications they do not understand. Information centers were developed in response to other computer companies development of fourth generation languages (4GL, a computer language composed of simple terms which allow mainframe users to easily manipulate databases without programmer assistance). ${ }^{86}$ Many large corporations have installed information centers. ${ }^{87}$ Their installation is a common response to complaints that software is too difficult or hardware is too technical. ${ }^{88}$ The reason why information centers are included in the discussion of hardware is because these organizations were developed by hardware companies. Their solutions,

\footnotetext{
85 Burk, C. and Horton, F., InfoMap:A Complete Guide to Discovering Corporate Information Resources, Prentice-Hall, Englewood Cliffs N.J., 1988

86 The development of Information Centers as described in an American Management Assoctation Course titled "4GL: fourth Generation Languages", Portland OR., 1985.

87 Atre, S., Information Center: Strategies and Case Studies, Atre International Consultants, 1986

88 Federal IRM Planning Support Center, The IRM Organization: Concepts and Considerations, Government Printing Office (GPO), 1989.
} 
however, tend to be hardware solutions. By the late 1980's most information centers had changed and become problem solution centers. No longer are they used for training or teaching. 89 One could characterize these centers as quick-fix operations. These observations apply to all organizations that employ the use of information centers, with minor exceptions.

Information management in the federal government is not much different from that in other organizations. The primary difference is that much of the activity in information management in a federal agency is mandated by federal law. Several articles and small publications are written about computing and the federal government. For example, publications written by the federal government address a variety of topics from contingency planning for computer security. ${ }^{90}$

Occasionally, federal computing is the subject of articles in various ADP publications. Information Week published an article in 1986 on what the federal government was doing to "clean up its data processing act". 91 Federal computing is expensive and does not always do what it is supposed to do. For example, an article written by Jake Kirchner discusses the "good and the bad," but provides no solutions. ${ }^{92}$

\footnotetext{
$89 \quad$ Atre, S., Information Center: Strategies and Case Studies, Atre International Consultants, 1986 90 Computers: Crimes, Clues and Controls, A Management Guide, Presidents Council on Integrity and Efficiency, March, 1986. 


\section{Software}

Recent developments have convinced many ADP professionals that information can be successfully managed by focusing on software. ${ }^{93}$ Software are the instructions or programs that operate computer hardware. Within the last five years significant improvements in software have made the interface between the computer and the user much friendlier and easier to use. Some IRM authors believe that this friendlier interface encourages information development. 94 Indeed, great strides have been made in software. One trend has been to develop software that helps develop software, like "CASE" management tools. "CASE" tools are a series of programmers' tools developed primarily for mainframe software development. 95 Another friendly user interface is "Windows", a software management tool for PC's.

Some software methods are identified as data or information architecture. Data architecture methods address how data elements interface and integrate with each other and with programs. These relationships are important because they prevent duplication of effort

\footnotetext{
93 Madnick, S. editor, The Strategic Use of Information Technology, Oxford University Press, New York, N.Y., articles from Sloan Management Review, Aker. J., A Responsible Future: An Address to the Computer Industry, pgs. 140-156, 1987.

94 Marchand, D., Infotrends: Profiting from Your Information Resources, Wiley, New York, N.Y., pgs. $25-30,1986$

95 Martin, J and Leben, J., Strategic Information Planning Methodologes, 2nd ed., Prentice-Hall, Englewood Cliffs N.J., pgs. 124-130, 1989.
} 
and allow better management of technological resources by reducing both the amount of time and resources required to store and to retrieve data.

Architecture of data and information can take another form defined as a data dictionary. This allows computer users to lookup databases and to see what information is available. While a data dictionary appears to be a major breakthrough, access and control of data are seldom used by people who need information. The data dictionary is as difficult to operate as other software. ${ }^{96}$ They are also difficult to maintain since new databases are constantly being created and old databases modified.

\section{Systems}

Though most systems literature deals with software, its intent is usually to link software and hardware as one unit. This concept seeks to free the information manager and supporting staff from repetitious tasks and allow them to think creatively. Given the resources of hardware, software and the user's work, a feedback system is created which enables the information customer to acquire information. ${ }^{97}$ One systems approach is systems engineering.

96 Lytle, R., Information Resource Management: A Flve Year Plan, Information Management Review, Vol 3, No. 3, 1988

97 Palmer, R. and Varnet, H., How to Manage Information: A Systems Approach, pgs. 16-19, ORYX Press, Phoenix AR., 1990. 
Systems engineering is a highly structured way to perform system development. Systems engineering uses different tools-- modeling techniques, planning tools, action diagrams, and impact analysis -- to create an information management system. Current management jargon - "critical success factors" and top management "buy-in", along with extremely technical analytical diagrams are elements used to describe the concept. ${ }^{98}$ Based upon engineering principles, this method is far too complex for a single manager or systems analyst to understand or to apply. The focus of systems engineering is the system. ${ }^{99}$

Another system approach is called "Enterprise engineering." Enterprise engineering is sometimes considered a subset of systems engineering because enterprise modeling uses the steps of the systems engineering method. Enterprise engineering is a distinct method because it attempts to bring business into the ADP modeling area by placing company objectives in the system loop. ${ }^{100}$ Some of the successes of a systems approach have been achieved with the "enterprise model" because of its focus on business activity.

Project management, sometimes mistaken for a perspective, is often called an information resource management methodology .101 However, project management is considerably less than a methodology.

\footnotetext{
98 Martin, J and Leben, J, Strategic Information Planning Methodologies, 2nd ed.,pgs. 5-15, PrenticeHall, Englewood Cliffs N.J., 1989.

99 IE/IMPACT, Information Engineering Management Guide, Pacific Information Management, Inc., Santa Monica CA., 1989.

100 Bryce,M. and Bryce, T., The IRM Revolution: Blueprint for the 21 st Century, pgs. 99-124, MBA Publications, Palm Harbor Florida, 1988 
It is more a mode of operation than methodology. Project management tracks and schedules both events and resources necessary to complete a task. While project management is not normally part of a discussion of information resource management methods, it is a technique often used by managers to make decisions and control IRM resources.

\section{Evaluation Research}

Many sources exist upon which to draw when performing research evaluation. Some address public enterprise while others are more generic and look at enterprise(s) in general. Some sources address costs and benefits, and budgeting and organizational performance in general. All of the sources seem to wrestle with the same questions: is the program efficient, is it effective, what are the outcomes, what needs to be monitored.

All of the evaluation literature examines measurement of program goals and objectives for efficiency (the best use of resources) and effectiveness (the impact of the resources used). For example, it is efficient to shop for the least cost materials to build widgets, but it is not effective because no one buys widgets. On the other hand, it is effective to cure cancer, but not at a cost equal to the national defense budget on a per case basis. Joseph Wholey uses zero-base budgeting as the focus 
of his work. ${ }^{102} \mathrm{He}$ is careful to note that the impact of services should not suffer. Still one wonders when budgetary constraints are the focus of evaluation, if the focus is too narrow. Cost based analysis is not always desirable. Effectiveness may be more important than cost. ${ }^{103}$ A more balanced approach may be Hatry, Voytek and Holmes' examination of alternatives based on costs. ${ }^{104}$ Beginning with the desired impact and searching for ways to provide an alternative seems more sensible.

Several of the sources address program evaluation by location. For example, the Practical Program Evaluation of State and Local

Government suggests several ways evaluation research may differ in government. 105 One of the ways it may differ is in continuous monitoring of services rather than looking at specific outcomes. For example, a private business exists to make a profit. When profits diminish, it is prudent to examine the reason why. The focus is on outcomes. The business wants to know why the outcome has changed. On the other hand, continuous monitoring is probably the best approach in measuring municipal services. 106 Many government services are hard to quantify, and therefore, hard to measure.

\footnotetext{
102 Wholey,J., Zero-Base Budgeting and Program Evaluation, Lexington Books, D. C. Heath and Company, Lexington MA., 1978.

103 Caudle, S., "Vision Statement, Principles and Strategic Goals: Initial Steps for Managing Information Resources", Joumal of Management Science Policy Analysis, Vol. 8, No. 2, Winter, 1990-91, pgs. $172-184$.

104 Hatry, H., Voytek, K., and Holmes, A., Building Innovation into program Reviews, The Council of State Governments, The Urban Institute Press, Washington D. C., 1989.

105 Hatry, H., Winnie, R., Fisk, D., Practical Program Evaluation for State and Local Governments, 2nd ed., The Urban Institute Press, Washington D.C., 1981.
}

106 Measuring the Effectiveness of Basic Municipal Services, initial report from The Urban Institute and the International City Management Association, 1974. 
In addition, there are many other monographs describing evaluation research. They all seem to describe the same process, determine program goals, find appropriate measures, collect data, attach costs (optional), and determine the degree of success. ${ }^{107}$

Traditionally evaluation research has been used to measure programs in a social setting. Evaluation research is viewed as a way to increase rationality in decision and policy making. In general, evaluation research does not come up with unequivocal findings about the worth of a program. More often, it shows small or ambiguous changes. 108 Without a doubt, the purpose of evaluation is to see if things are betteroff than they were.

Evaluation research often requires study over a period of time. It is, therefore, well suited to a one group pretest-posttest design, such as applied in this study. One of the uses is in an action setting where an on-going program is serving people. ${ }^{109}$

Evaluation research uses a variety of methods to do research and identify the efficiency and effectiveness of programs. In this study the program is IRM. The intended recipients of the services provided by the IRM are the

\footnotetext{
107 Murphy, J., Getting the Facts: A Field Guide For Evaluators and Policy Analysts, Goodyear Publishing Co., Santa Monica CA., 1980.

108 Weiss, C., Evaluation Research: Methods of Assessing Program Effectiveness, Prentice- Hall Inc., Englewood Cliffs New Jersey, 1972, pg 4-5. 
policy and decision makers of BPA. It is the purpose of this study then, to determine if the recipients of services are better-off with IRM than without it. 


\section{CHAPTER III}

\section{METHODOLOGY}

This chapter discusses the selection criteria for this case study and the methods used to study it. The first section addresses the selection of the organization and introduces the organization. The second section presents one of the methods used to study the organization, the questionnaire. Finally, the third section presents the second method used to study the organization, interviews. The results are presented in the chapter which follows.

\section{The Case Study Organization}

This is a discussion of the case study organization, considerations for selection of the organization as well as selection criteria. Additionally, other facts about the organization selected are introduced to assist the reader in understanding the corporate environment of this organization.

\section{$\underline{\text { Selection Considerations }}$}

A primary consideration with any case study is availability of an organization for study. All too often organizations are too busy to allow study, do not wish to be held up to public light, or simply are not willing to tolerate the disruption which comes with any study. So, the first 
consideration for a subject of study is the willingness and availability of the organization to participate.

The second consideration is that the organization exist throughout the life of the study. Occasionally, corporations dissolve or change so radically that the results of the study cannot be duplicated or do not hold any predictive value. While no guarantee can be made on the future of an organization, well entrenched bureaucratic organizations with an established history can reduce uncertainty.

A third consideration for selection of a case study organization is that the organization possess the necessary components for study.

In this case, the opportunity to study an organization first hand presents itself. The organization, the Bonneville Power Administration (BPA), is available for study by virtue of the employment of the author in BPA and the willingness of BPA to be studied. The organization will benefit from the process. Additional opportunities to study information resource management and its relationship to its parent organization have presented themselves through various assignments which have in turn provided changes in perspective within the organization. This organization is a target of opportunity for study.

Several other factors are important to the selection of BPA. First, BPA is a quasi-governmental organization with fifty years of history. The BPA was established by an act of Congress, so it is not likely to 
disappear during the study. Second, BPA is a firmly entrenched bureaucracy organizationally connected to the Department of Energy, the United States Congress, and several state and regional governmental bodies. Therefore, BPA is likely to act like a government bureaucracy and like a private utility, in that it is funded by several sources, including ratepayers.

Finally, BPA has a large information resource management program. BPA originally was an engineering oriented organization. Much of the organization still is. Therefore, some of the uses of information are unique and technically foremost in the world. Unfortunately, many of those areas are in the area of electrical transmission grid control and sensing which is strictly off limits for this study. ${ }^{110}$ Only business applications necessary to operate the remainder of the agency's information needs are covered in this study. This in no way limits the validity or reliability of this study, only its scope. The business portion of BPA is more likely to resemble other bureaucratic organizations.

The same literature applies to BPA as a bureaucracy. The purpose of BPA is to "societialize" the relations of power through the use of laws, rules, and directives. Overall, BPA is a fairly normal large bureaucratic institution subject to observations made of other bureaucracies.

110 The electrical transmission grid is off-limits for two reasons. First, The western United States are dependent upon BPA's transmission grid controls. Thus, grid control is a national security issue. Second, the work is considered inherently governmental and therefore, not contractible. BPA sees no reason to open doors where entry is not allowed. 


\section{A Brief History}

Early in the 1900's, industrial development in the United States was broad and sweeping in scope. Every opportunity to develop and take advantage of natural resources in this country was taken. Rivers, in particular, provided a bounty of natural resources tapped since industrial development of the United States began. Not only did rivers provide clean water and fish, they also provided avenues of transportation, irrigation and power for industries like textiles and milling of lumber and grain. Rivers provided all of these benefits without much control. They often represented power out of control. Floods and drought were often the result of the uncontrolled power. ${ }^{111}$

In the early 1800's the eastern United States developed small rivers and streams through the use of water wheels, locks, dams, and levees. While development was extensive, projects tended to be small because building materials and construction techniques were limited. In the mid and late 1800's, the development of steel production and the resulting use of steel and concrete in construction opened the possibilities for building on a large scale.

The invention of the incandescent light bulb by Thomas Edison along with major technological advances in the electric motor began to provide more incentive to develop cheap electrical energy. Coal and oil

\footnotetext{
111 Springer, V., Power and the Pacific Northwest. A History of the Bonneville Power Administration, U.S. Department of the Interior, 1977, pgs. 1-12.
} 
provided energy to fire boilers to create steam for early dynamos.

However, the cost of the electricity generated by this method was dependent upon the price for coal and oil. Additionally, coal and oil were both labor dependent sources of energy. The energy had to be discovered, mined, processed, and delivered. In some cases delivery was expensive because railways did not go everywhere. Finally, both coal and oil were dirty fuels and they left smell and smoke wherever they were used.

The federal government began the development of water power after World War I. The best known early project undertaken by the government was the development of the Tennessee River under control of Tennessee Valley Authority (TVA). The TVA was a river project developed and built in the 1920's and 1930's. The project provided flood control and electrical power through the construction of dams. The project also established an authority for the development, use, distribution, and sale of power from the dam. Authority for the government to provide these services was established through several acts of Congress.

Establishment of this authority was instrumental in the creation of other projects. ${ }^{112}$

In the late 1800's the northwestern United States, particularly Washington, Oregon, Idaho, Montana, and Nevada, began to understand what this kind of project meant. Surveys of the land and waterways of the region touched off much debate on the subject of river development.

112 Tollefson, G., BPA and The Struggle for Power at Cost, BPA, 1987. 
Large areas of these five states are arid and far enough inland that they require both large scale transportation and a way to irrigate rich soil. Additionally, land areas east of the cascade mountain range were difficult to reach. Only the major rivers penetrate the mountain range. Therefore, many newspaper articles and commentaries were dedicated to the subject of river development as a waterway and a source of irrigation. Much of the media debate argued points of who would control such development, who would benefit, who would pay, and where development would take place. Little of the editorial comment was seriously devoted to development of the rivers as a source of electrical power. Even as late as the 1930's many Northwesterners felt that an electrical power project could not pay for itself. ${ }^{113}$

Hence, a great deal of regional debate preceded development of the rivers and the involvement of the federal government. In 1932 presidential candidate Franklin D. Roosevelt opined that development of hydro-electric resources in America was needed and the greatest potential in the United States was in the Pacific Northwest. Surveys, river navigation, and flood control legislation beginning at the turn of the century brought greater federal government involvement in natural resources, particularly water. Thus, in 1932 soon-to-be President Roosevelt's comments fostered a long political process of harnessing congressional wills, states rights, and natural resources. ${ }^{114}$ The debate was not merely moved to a larger political arena, but grew to include new

113 U.S. Department of Energy, Columbia River Power for the People; A History of Policies of the Bonneville Power Administration, DOE-BP-7. pgs. 29-41.

114 Springer, pgs. 11-18. 
arenas. The Bonneville Power Administration has thus always been the subject of great political debate within regional and national politics.

\section{The Organization and its Structure}

Bonneville Power Administration (BPA), created by the Bonneville Project Act of 1937, is an electrical power marketing agency situated in the Northwestern United States whose mission states:

"BPA will work in a regional partnership to define and achieve the electric power, conservation, and fish and wildlife objectives of the Pacific Northwest. We will provide our customers a low-cost, reliable, and environmentally sound power supply and transmission system. We will do so in an open and businesslike way, responsive to citizen's concerns and to our obligations as a Federal agency. We will provide creative leadership and fulfill our responsibilities with professional excellence."115

BPA is funded by electric rate payers, though operations depend on congressional loan authority, and is part of the U.S. Department of Energy. The result is an agency that depends on private and publicly own utilities for operating expenses and debt repayment, while being funded by Congress, and being organizationally accountable to the

\footnotetext{
115 Bonneville Power Administration Manual, Chapter 0, page 1, Organization, Functions, Redelegation, Mission Statement.
} 
Department of Energy. BPA is, therefore, a high profile political actor in the Pacific Northwest.

BPA is a quasi-public organization with advantages and disadvantages of both public and private sector organizations. BPA sells electric power to public, private, and direct service industries of the northwest and to customers outside this region. The agency is also responsible for conservation program activities and fish and wildlife programs identified in 1980 legislation entitled the Pacific Northwest Regional Power and Conservation Act. The BPA sets rates for power and is a strong economic and political force in the five states it serves. BPA's total operating revenues in 1989 were $\$ 2,063,866,000$. The agency controls 14,700 miles of power transmission lines and 387 substations. ${ }^{116}$

The BPA headquarters is located in a large federal building complex in Portland Oregon. BPA employs approximately 3700 staff in more than 150 occupational positions, ranging from research scientists in electrical engineering to political liaison staff. The BPA also employs about 1,000 contractor employees. The BPA is organizationally structured into seven Offices, ${ }^{117}$ four Area Offices, and two special Offices. ${ }^{118}$ Each Office has a distinct mission. Offices are sub-divided into divisions, which are divided into branches, which are sub-divided

116 Bonneville Power Administration, 1989 Financial Summary, pg 1.

117 An office is an organizational unit consisting of from 200 to 500 personnel.

118 See Attachment three for organizational chart. 
into sections. A few sections are divided into the smallest increment of organizational measure called a unit. Area Offices may also have as many as three district offices. ${ }^{119}$ The seven Offices are listed in Table 3.1 .

\begin{tabular}{|l|c|}
\hline \multicolumn{1}{|c|}{ Office } & Office Code \\
\hline Office of the Administrator & A \\
\hline Office of Financial Management & D \\
\hline Office of Engineering & E \\
\hline $\begin{array}{l}\text { Office of Construction and } \\
\text { Maintenance }\end{array}$ & M \\
\hline Office of Power Sales & $\mathrm{P}$ \\
\hline Office of Energy Resources & $\mathrm{R}$ \\
\hline Office of Management Services & $\mathrm{S}$ \\
\hline Lower Columbia Area Office & $\mathrm{L}$ \\
\hline Puget Sound Area Office & $\mathrm{T}$ \\
\hline Upper Columbia Area Office & $\mathrm{U}$ \\
\hline Snake River Area Office & $\mathrm{W}$ \\
\hline
\end{tabular}

Table 3.1

An examination of BPA's organizational chart shows its formal structure is vertical because several layers of the organization are stacked one on top of another. This means that information travels slowly from bottom to top. ${ }^{120}$ For example, if an individual who works in a "unit" wishes to transmit information to the Administrator there are six levels through which the information must pass to get to the top (from the individual to the unit supervisor $\{1\}$, to the section chief $\{2\}$, to the branch chief $\{3\}$, to the division director $\{4\}$, to the assistant administrator for the Office $\{5\}$, to the Administrator $\{6\})$.

119 The smallest measure of organizational structure shown in the organization chart is a division. A division usually consists of 100 to 200 personnel.

120 Downs, A., Inside Bureaucracy, Little, Brown and Company, Boston MA., 1967, pgs 114-115. 
While BPA's organizational structure is vertical, it is a matrix managed organization. Matrix management is a type of management used initially by large corporations (initially in the aircraft industry and NASA) where staff are assigned to decentralized locations. Many staff have dual responsibilities: to a local manager for day-to-day operations, and functionally to their head Office specialist. ${ }^{121}$ For example, if BPA wished to build a electrical power transmission line, a project team might be formed with personnel from the Office of Engineering to design the necessary towers, lines and substations; the Office of Construction and Maintenance to build the facilities; the Office of Management Services to procure the necessary equipment; the Office of Energy Resources to acquire resources for additional customers; the Office of Financial Management for financing; the Office of Power Sales for transmission contracts with utility customers, and so on.

BPA has identified 26 functional programs to manage and implement the activities of fish and wildlife, residential conservation, commercial conservation and so on. Of further complexity, BPA uses 14 financial programs to account for the activity of the seven Offices. Table 3.2 demonstrates how BPA matrix management works. The matrix is of functional/financial programs by Office. In the table each $\mathrm{X}=$ lead or responsible Office, and each $\mathrm{O}=$ participating Office..$^{122}$

\footnotetext{
121 Dinsmore, P., Human Factors in Project Management, Amacom, American Management Association, 1984, pgs. 85-97.

122 This table was provided by Marsha Ard, Program and Financial analyst BPA.
} 
The table shows the unique budgetary responsibility for each budget program for each Office. While an Office may have budget responsibility, it by no means has singular participation in the program. Therefore, BPA's organizational structure and accompanying management methods have a definite effect on BPA's corporate culture. BPA Program Management Table

Office Code

\begin{tabular}{|c|c|c|c|c|c|c|c|c|c|c|c|}
\hline $\begin{array}{l}\text { Financial Program } \\
\text { (Program code) }\end{array}$ & A & $\mathrm{D}$ & $\mathrm{E}$ & $\mathrm{L}$ & $\mathrm{M}$ & $\mathrm{P}$ & $\mathrm{R}$ & $\mathbf{S}$ & $\mathrm{T}$ & $\mathrm{U}$ & W \\
\hline Transmission System Developmen & & & $\mathrm{X}$ & O & ol & 0 & & & $\mathrm{O}$ & 0 & 0 \\
\hline Residential Exchange(E) & $\mathrm{O}$ & $\mathrm{X}$ & & & & & & & & & \\
\hline Fish and Wildlife(F) & $\mathrm{O}$ & & O & & O & $\mathrm{X}$ & & & & & \\
\hline $\begin{array}{l}\text { G \& A Corporate Overhead } \\
\text { (G)+(Management)(Budget) } \\
\text { (Personnel)(Finance) }\end{array}$ & $\mathrm{O}$ & o) & $\mathrm{O}$ & O & 이 & 0 & o & $\mathrm{X}$ & O & 0 & 0 \\
\hline System Operations(H) & & O) & O & O & $\mathrm{X}$ & & & & O & $\mathrm{O}$ & 0 \\
\hline Interest \& Associate Projects(J) & & $\mathrm{X}$ & & & & $\mathrm{O}$ & O & & & & \\
\hline Information Resources(L) & $\mathrm{X}$ & O & O & O) & $\mathrm{O}$ & $\mathrm{O}$ & o & O) & O) & $\mathrm{O}$ & $\mathrm{O}$ \\
\hline System Maintenance(M) & $\mathrm{O}$ & & O) & O) & $\mathrm{X}$ & & & & $\mathrm{O}$ & $\mathrm{O}$ & 0 \\
\hline Planning Council(N) & $\mathrm{X}$ & & & & & & & & & & \\
\hline Power Marketing(P) & $\mathrm{O}$ & & O & O & & $\mathrm{X}$ & & & o & $\mathrm{O}$ & 0 \\
\hline Reimbursable(R) & $\mathrm{O}$ & $\mathrm{X}$ & O & O & O & O & O & 0 & O & 0 & 0 \\
\hline Power Scheduling(S) & 0 & & & & & $\mathrm{X}$ & & & & & \\
\hline Energy Resources(T) & 0 & O & O & O & O & & $\mathrm{x}$ & & O & $\mathrm{O}$ & 0 \\
\hline Support Services(U) & 0 & O & 이 & & O] & & & $\mathrm{X}$ & & & \\
\hline
\end{tabular}

$\mathrm{X}=$ Lead or Responsible Office, $\mathrm{O}=$ Participating Office Table 3.2 


\section{The Corporate Culture}

Disagreement persists over the definition of culture which is most often the work of social anthropologists. Defining a corporate culture is also problematic. However, simply because it is difficult to specifically define does not mean it does not exist. By summarizing many definitions, a culture can be defined as the shared experience of norms, values, beliefs and artifacts that result from living in a particular social structure. ${ }^{123}$ One publication characterizes corporate culture as an "extremely multifaceted concept characterized by many different approaches, many different view points, and many researchers working on the idea that there is a notion that corporate culture is implicit, invisible, intrinsic, and informal." 124 Another definition is that a corporate "culture is the commonly held and relatively stable beliefs, attitudes and values that exist within the organization."125 Perhaps a more useful definition can be constructed from the definition of culture..... a corporate culture might be considered the experience of shared norms, values, beliefs and artifacts which are the result of working in a corporate structure. This definition of corporate culture is specific enough and has utility for the purposes of this research.

\footnotetext{
123 This definition is summarized from various publications but, primarily from Martindale, D. pages 457-459.

124 Scholz, C., Corporate Culture and Strategy - The Problem of Strategic Fit, Long Range Planning, Vol. 20. No. 4, 1987, page 80 .

125 Williams, A., Dobson, P., and Walters, M., Changing Culture, Institute of Personnel Management, London, 1989.
} 


\section{External Environment}

The history of BPA began embroiled in regional politics and escalated to the arena of national politics. The current organization chart of BPA's structure still reflects the importance of political involvement. The Administrator's staff has a Washington D.C. office and a liaison to the Northwest Power Planning Council. There is also a staff dedicated to "External Affairs", public relations, and in addition, each Area Office provides state and local government liaisons.

The Administrator's staff also includes a sizable legal staff under the direction of the General Counsel. Recent years have required raising rates and BPA has found itself in litigation over rate cases. ${ }^{126}$ Also, a great deal of litigation occurred as a result of the Washington Public Power Supply System (WPPSS) default on bonds. The WPPSS bond default has also effected BPA's external credibility.

There are other areas of legal activity. All the power sold to all other entities is done through sales contracts. The contracts portion of BPA's work is a large share of its activity. Finally, BPA has been involved with the WPPSS Hanford Nuclear facility for some time. This involvement, combined with one of the super fund environmental sites at BPA's Ross Complex may prove the need for additional legal work in the expanding area of environmental issues.

126 BPA must prove that rate (the price charged to customers for electricity) increases are justified. This is done through a public and judicial process. BPA must also prove it has provided ample involvement of the public when justifying rate increases. 
The last two presidential administrations have tried to expedite BPA's debt repayments. This action would have the effect of a significant rate increase to BPA's customers. BPA has, so far, been successful in derailing the attempts. There have also been attempts to privatize BPA, selling the agency and its assets to the highest bidder. These attempts have also been unsuccessful. BPA's political ties to a strong Pacific Northwest Congressional delegation have proven fruitful in protecting the agency.

What is unique about BPA is that it is funded by the public through rates. BPA was created by and still has developmental projects funded directly by Congress, yet it is part of the Department of Energy. However, BPA exists in an organizationally complex climate, influenced by the legislative branch of the government, the executive branch, and its northwest customers - the ratepayers.

\section{Internal Environment}

The external environmental factors mentioned above have affected the internal environment of BPA. One effect of externalities influences the Administrator's Office. The effect has been to shape the organization's structure so that the tools of survival are grouped in the Administrator's Office (General Counsel, Washington D.C. Office, Environment, etc.). The structure and location of various organizational components can indicate their value to the organization. In this case, these political and legal tools are what the Administrator uses to lead BPA. 
Other dimensions of BPA's internal culture can be derived from its structure. BPA is vertically structured. In the terms of Anthony Downs, formal communication in a vertical organization is difficult and slow. Sub-formal communication serves as a faster way to transact daily business. ${ }^{127}$ This fact directly affects the management of information in the organization.

However, characteristics common to matrix management described below improved lateral and vertical communication:

"Efficient use of Resources-Individual specialists as well as equipment can be shared.

Improved Information Flow-Communications are enhanced both laterally and vertically.

Project integration-There is a clear and workable mechanism for coordinating work across functional lines.

Flexibility-Frequent contact between members from different departments expedites decision making and adaptive responses.

Discipline Retention-Functional experts and specialists are kept together even though projects come and go.

Improved Motivation and commitment-Involvement of members in decision making enhances commitment and motivation.

Power Struggles-Conflict occurs since boundaries of authority and responsibility deliberately overlap.

Heighten conflict-Competition over scarce resources occurs especially when personnel is being shared across projects. 
Slow Reaction Time-Heavy emphasis on consultation and shared decision making retards timely decision making.

Difficulty Monitoring and Controlling-Multi-discipline involvement heightens information demands and makes it difficult to evaluate responsibility.

Excessive Overhead-Double management by creating project managers.

Experienced Stress-Dual reporting relations contributes to ambiguity and role conflict." 128

While these traits appear to characterize BPA management, they are mitigated by the fact BPA is not a pure functional matrix managed organization. Some parts of BPA depend on matrix managed projects while others depend on the vertical Office structure. So, the effects are somewhat unpredictable.

Other corporate culture factors involve employee issues. BPA employees are federal employees under the general schedule (GS) system. Hence, salaries are no secret. If your "GS" level is known, so is your salary. Consequently, "GS" levels are common knowledge. A "GS" level is rather like a badge. This is one kind of internal stratification system.

Another component of "GS" employment is that it is difficult to hire and fire employees. There are rules which govern both. It takes a long time to hire or fire. Marginally functioning employees are often not fired but assigned marginal tasks, sometimes for the duration of their careers.

128 Larson,E. and Gobeli, D., Matrix Management: Contradictions and Insights, California Management Review, Vol 29, No. 4., Summer 1987, pgs 130-131. 
BPA has a flex-time schedule for reporting to work. Personnel may arrive as early as 6:30 AM or as late as 8:45 AM. They must work their complete shift and may depart when it is completed. Vacation time may usually be scheduled anytime the employee has sufficient leave accrued to cover the time off. BPA is very flexible about employee involvement in professional and community organizations such as engineering societies or charities. However, as federal employees, BPA personnel are prohibited from participation in partisan politics by federal law.

For the most part, BPA employees dress casually. Managers and career track employees consistently wear suits. However, there is no dress code at BPA. Many employees are as likely to wear jeans. It is an unspoken rule that the management team always wear business clothes.

Expectations for employees reflect the culture. Though not often written into performance standards, "connectedness" and political savvy are highly valued qualities. The more politically astute, the more valued the employee. It is no surprise that career track employees (employees who are groomed and given opportunities in management) are the most "connected" and politically savvy. Non career track employees are much less likely to be given opportunities for special projects and high profile work. ${ }^{129}$

129 The information on the internal culture of BPA is a combination of experlence as an employee of the BPA and a matter of record from the personnel department. 


\section{BPA's IRM Organization}

The IRM organization in BPA is part of the Administrator's Office, much like a large staff. It is located there as a rejuvenated group with a major mission for changing the way BPA handles information. The IRM organization consists of about one hundred employees, who are directly employed in IRM work. Another one hundred-fifty contractors provide services for the IRM. The BPA spends between $\$ 20$ and $\$ 40$ million annually on ADP, depending upon major purchases and application development.

The IRM portion of BPA consists of computing and telecommunications (see attachment four). The function of telecommunications was recently relocated to the IRM.130 In addition to the IRM organization structure, each BPA Office has an ADP Coordinator. It is the ADP Coordinators' job to see that his/her Office's activities are reflected in IRM activity.

The computing portion of the organization is responsible for the operation of a $3084 \mathrm{Q}$ mainframe computer, several VAX mini computers, several WANG mini computers, and about 1500 personal computers. The computing organization also sets computing standards, purchases and installs software and hardware, installs and maintains all support cabling, networking, and microwave communications, and handles all 
computer training. The IRM organization does not run or maintain the computing equipment which controls the electrical transmission grid. These operations are controlled among the Offices of Power Sales, Engineering, Operations and Maintenance, and Construction.

As BPA's information arm, IRM has developed an information center as a strategy to improve operations. Like other federal agencies, BPA seeks primarily hardware solutions: buy a bigger computer. ${ }^{131}$ The $\mathrm{BPA}$ is also an engineering organization. Consequently, very complex software solutions have also been developed as the means to solve problems and provide information for a host of organizational decisions.

IRM, previous known at BPA as the Division of Information Services (DIS), began in the Office of Financial Management and later moved to the Office of Management Services. Until 1989, BPA's ADP was the responsibility of the DIS which was responsible for the planning, acquisition, operation, and implementation of computing resources. Though DIS administered computing resources agency-wide, most other Offices in BPA were developing their own computing resources. Acquisition of resources was slow and implementation of several major programs failed to be on time, costing considerably more than expected.

In 1983 and 1984, studies conducted by the General Accounting Office (GAO), concluded that the BPA needed to improve BPA's data

131 U.S. Army Materials Command, Information Resource Management: Information Strategy for the 90's, DCS Command for Information Management, 1987 
processing resource management controls. ${ }^{132}$ The study recommended that, (1) BPA should adopt IRM concepts and delegate the responsibility to a manager who reports directly to the administrator, (2) define a timephased action plan for implementing IRM, and (3) periodically report to the Department of Energy on progress of IRM toward cost effective control practices. ${ }^{133}$ In 1988, the Department of Energy (DOE) concluded in an audit that many of the financial systems at BPA were not in compliance with the intent or specifics of federal requirements.

Earlier, in 1980, the Paperwork Reduction Act mandated the establishment of IRM in federal agencies. BPA complied by conferring the title of Information Resource Manager on the Executive Assistant Administrator for Management Services. In 1988, in order to comply with cost/benefit guidelines for contracting (A-76), a study team was formed to examine data processing in BPA. Several findings of that study team concluded that ADP resources were so disbursed throughout so many parts of BPA that it was impossible to conduct a comprehensive cost/benefit analysis. The team's recommendation was to form an IRM organization that could begin to encompass agency-wide ADP activity. The result was the establishment of the present IRM organization in 1989.134

132 Law, M.H., Guide to Information Resources Dictionary System Applications: General Concepts and Strategic Systems Planning, GPO/Institute for Computer Science and Technology, 1988.

133 Federal Evaluations: A Directory issued by the Comptroller General, 1984 Congressional Sourcebook Series, U.S. General Accounting Office, Information Handling and Support Facility, Gaithersburg MD, 1984. 134 See Attachment 11 for details. 
Within six months DIS became IRM and was relocated in the Administrator's Office. The new IRM manager began to talk to customers within the agency to determine their needs, re-define the mission of IRM, get budgetary control of ADP and centralize control of ADP in BPA while decentralizing its power. One of IRM's first acts was to loosen the acquisition controls on personal computers. This act had interesting consequences for BPA. Clearly, an effort was being made to regain the trust of the remainder of the agency. ${ }^{135}$

The study began in 1988 before IRM became an organizational component of BPA and concluded in 1991 after IRM was established. In the next two parts of this chapter the methods used to study IRM are defined and discussed. 


\section{Questionnaire}

This is a discussion of the questionnaire portion of this study.

- How the questionnaires were conceptualized, developed, disseminated, collected, collated, and analyzed are discussed. The population for the distribution of the questionnaires is also described along with the precautions taken to protect individual responses. Analysis and findings are presented in the next chapter.

\section{Conceptualization}

The questionnaire was conceived and designed with the idea that information is best judged by the receiver of the communication. Information is only data until it becomes information in the mind of the receiver. Therefore, the best judge of the information is the information user, in this case, management at BPA.

\section{Questionnaire Concept}

The questionnaire was designed to gather generic data on information and its uses, and was based on available literature and interviews conducted as part of a cost/benefit analysis of BPA data processing. Because BPA is diversified and complex in its activities, specific questions on organizational processes could not be asked; there are far too many. Instead, general topics were explored through four basic questions: 
(A) List the information/data you need from others to make decisions,

(B) List the information you generate to support others decisions,

(C) List the information which would be helpful but you cannot get for making decisions, and

(D) List the information you get but do not need for decision making. ${ }^{136}$

In response to the four questions each respondent made a list of information corresponding to each of the four questions. After the list was made, each topic was rated on specific categories defined in Table 3.3.137

The operational definitions of each of these categories presents a significant challenge because of differences in perspective within BPA. For example, my definition of what is "useful" may be different than your definition of what is useful because we have different jobs. Categories used here are common in other types of ADP accessing and planning. ${ }^{138}$ After creating a large list of categories gleaned from the literature, individuals in the ADP organization, interviews, and organizations were contacted for comment on the list of categories compiled. Then other

\footnotetext{
136 See attachment two, the questionnaire.

137 Jones, J. and McLeod, R., The Structure of Executive Information Systems: An Exploratory Analysis, Decision Science, Vol 17, Pgs. 220-249, 1986.

138 Burk, C. and Horton, F., InfoMap:A Complete Guide to Discovering Corporate Information Resources, Prentice-Hall, Englewood Cliffs N.J., 1988
} 
categories were added or deleted from the list. The categories shown in

Table 3.3 are the outcome from the process.

\section{Questionnaire Categories}

\begin{tabular}{|c|c|c|}
\hline Category & Definition & Scale \\
\hline Useful & $\begin{array}{l}\text { The extent to which the information is appropriate and fits } \\
\text { with other information to support your work and decision } \\
\text { making. }\end{array}$ & $0-9$ \\
\hline Complete & $\begin{array}{l}\text { The extent to which the information satisfies all needs for } \\
\text { decision making from a single source rather than multiple } \\
\text { sources. }\end{array}$ & $0-9$ \\
\hline Timely & $\begin{array}{l}\text { The extent to which the information is supplied when } \\
\text { needed. }\end{array}$ & $0-9$ \\
\hline Accurate & The extent to which the information is correct and reliable. & $0-9$ \\
\hline Relevant & $\begin{array}{l}\text { The extent to which the information can contribute to } \\
\text { meeting the organization's goals and objectives. }\end{array}$ & $0-9$ \\
\hline Outside Requirement & $\begin{array}{l}\text { The extent to which the information is used to satisfy } \\
\text { requirements outside BPA. }\end{array}$ & $0-9$ \\
\hline Format & $\begin{array}{l}\text { The extent to which the information is presented in a usable } \\
\text { configuration. }\end{array}$ & $0-9$ \\
\hline Frequency & $\begin{array}{l}\text { The extent to which you either receive or provide } \\
\text { information with constancy. }\end{array}$ & $0-9$ \\
\hline Present Origin & $\begin{array}{l}\text { What is the present source of origin of information you } \\
\text { provide or receive? }\end{array}$ & $1-9$ \\
\hline Preferred Origin & $\begin{array}{l}\text { Is there another origin for the information that is better } \\
\text { than the way you provide or receive it now? }\end{array}$ & $1-9$ \\
\hline Check & $\begin{array}{l}\text { Is the information different (altered or summarized by staff) } \\
\text { than originally supplied. }\end{array}$ & $\begin{array}{l}\text { yes }(1) \text { or no } \\
\text { (0) }\end{array}$ \\
\hline
\end{tabular}

Table 3.3

A unique data set was constructed by rating each item of information.

Each item, along with its rating became the data set categories.

Three additional categories were added to the data set, "info", "class", and "times". The category "info" was the name or title of the information reported by the respondent (e.g., budget report). 
The category "class" was used to identify budget program classifications. It is represented by a one or two letter code. The budget code classifications were added by a BPA financial analyst using the BPA program management table (Table 3.2). For example, a respondent might report using personnel information. Personnel information is generated in the General and Accounting Overhead budget category, personnel. So, a code of "G" + "P" or "GP" (general, personnel) would be assigned to the information reflecting its origin. Only the General and Accounting classification codes have more than one letter because they are so large and contain so much important information. All other budget programs use single letter codes. Each of the budget codes is defined in Table 3.4 on the following page. 
Budget Program Classifications and Definitions

\begin{tabular}{|c|c|}
\hline $\begin{array}{l}\text { Financial Program } \\
\text { (Program code) }\end{array}$ & Definition \\
\hline $\begin{array}{l}\text { Transmission System } \\
\text { Development(C) }\end{array}$ & $\begin{array}{l}\text { Information generated by and used primartly for decision making in } \\
\text { work which controls, directs, staffs, plans or organizes the electrical } \\
\text { transmission system development. }\end{array}$ \\
\hline Residential Exchange(E) & This budget category is not valid for information generation - excluded. \\
\hline Fish and Wildlife(F) & $\begin{array}{l}\text { Information generated by and used primarily for decision making in } \\
\text { work which controls, directs. staffs, plans or organizes fish and wildlife } \\
\text { programs. }\end{array}$ \\
\hline $\begin{array}{l}\text { G \& A Corporate Overhead } \\
\text { (G)+(Management)(Budget) } \\
\text { (Personnel)(Finance) }\end{array}$ & $\begin{array}{l}\text { Information generated by and used primartly for decision making in } \\
\text { work which controls, directs, staffs, plans or organizes corporate } \\
\text { programs considered overhead. General overhead, Management, budget. } \\
\text { personnel, and finance is the information Included in this category.. }\end{array}$ \\
\hline System Operations(H) & $\begin{array}{l}\text { Information generated by and used primarlly for decision making in } \\
\text { work which controls, directs. staffs, plans or organizes the operation of } \\
\text { the electrical transmission. system. }\end{array}$ \\
\hline Interest \& Associate Projects $(\mathrm{J})$ & This budget category is not valid for information generation - excluded. \\
\hline Information Resources(L) & $\begin{array}{l}\text { Information generated by and used primartly for decision making in } \\
\text { work which controls, directs, staffs, plans or organizes information } \\
\text { resources. }\end{array}$ \\
\hline System Maintenance(M) & $\begin{array}{l}\text { Information generated by and used primarily for decision making in } \\
\text { work which controls, directs, staffs, plans or organizes the maintenance } \\
\text { of the electrical transmission. system. }\end{array}$ \\
\hline Planning Council(N) & This budget category is not valid for information generation - excluded. \\
\hline Power Marketing(P) & $\begin{array}{l}\text { Information generated by and used primarily for decision making in } \\
\text { work which controls, directs, staffs, plans or organizes the marketing } \\
\text { and sale of the electrical power. }\end{array}$ \\
\hline Reimbursable(R) & This budget category is not valid for information generation - excluded. \\
\hline Power Scheduling(S) & $\begin{array}{l}\text { Information generated by and used primartly for decision making in } \\
\text { work which controls, directs, staffs, plans or organizes the scheduling } \\
\text { of the electrical transmisslon. system. use and loads. }\end{array}$ \\
\hline Energy Resources(T) & $\begin{array}{l}\text { Information generated by and used primartly for decision making in } \\
\text { work which controls, directs, staffs, plans or organizes the kinds and } \\
\text { mix of re-sources for electrical transmission.. }\end{array}$ \\
\hline Support Services(U) & $\begin{array}{l}\text { Information generated by and used primarly for decision making in } \\
\text { work which controls, directs, staffs, plans or organizes the support } \\
\text { services for all other Offices activity. }\end{array}$ \\
\hline
\end{tabular}

Table 3.4

"Times" refers to whether the data was from the pretest (1) or posttest (2) and if the data was in answer to question A, B, C, or D. An example of the category "times" is 1A. In this example, the data would 
be from the pretest (1) in response to question A (information supplied to you for decision making).

The questionnaire was designed to collect generic information based upon the work activities of each respondent. The data gathering process consisted of each participant developing a list of information which they use in decision making, then rating the information list according to eleven categories using scales and definitions provided on the questionnaire. The questionnaire was administered to four individuals about a month before the questionnaire was used. Most of their questions about the instrument had to do with clarification of the instructions. Suggestions for change were incorporated into the final questionnaire before it was used.

\section{Measurement Scales}

Two scales were taken from the categories in Table 3.3 and used in the questionnaire so the respondent could determine the relative value of the information $s /$ he supplied. The first scale was used on eight of the fourteen categories ("useful" through "format"). The respondent was requested to apply a rating score from 0-9 (zero to nine, Table 3.5). So, for example, when determining a value for information used in decision making for the category "useful", the respondent must determine what percentage of the time the information is "useful". Then a value was assigned to the category. Where no value was reported by respondents, the data was treated as missing. If zero, "Don't know" was selected, the case was considered as missing data except where frequency 
distributions are shown. Tables 3.5 and 3.6 show the values used to rate categories:

Ordinal Category Scales
(Categories Useful through Format)
\begin{tabular}{|l|l|}
\hline $\begin{array}{l}\text { Ordinal } \\
\text { Values }\end{array}$ & Meaning \\
\hline $0=$ & Don't know \\
\hline $1=$ & $0 \%$ \\
\hline $2=$ & \\
\hline $3=$ & $25 \%$ \\
\hline $4=$ & \\
\hline $5=$ & $50 \%$ \\
\hline $6=$ & \\
\hline $7=$ & $75 \%$ \\
\hline $8=$ & \\
\hline $9=$ & $100 \%$ \\
\hline $5=$ &
\end{tabular}

Table 3.5

The remaining three categories on the questionnaire (regarding present origin, preferred origin, and check) provided nominal data. The category "check" is bipolar (the column labeled check here on the questionnaire). "Present" and "Preferred" origin are categorized from a list of choices shown below (Table 3.6):

Nominal Categories Scale

(Present and Preferred Origin)

\begin{tabular}{|l|l|}
\hline Nominal Value & \multicolumn{1}{c|}{ Equivalent } \\
\hline 1 & Hard copy report \\
\hline 2 & Electronic data \\
\hline 3 & Floppy diskette \\
\hline 4 & Perlodicals/ library \\
\hline 5 & Personal Contact \\
\hline 6 & Observation \\
\hline
\end{tabular}




\begin{tabular}{|l|l|}
\hline 7 & Historical/ Performance Rec \\
\hline 8 & Staff work \\
\hline 9 & Experience \\
\hline
\end{tabular}

Table 3.6

\section{Questionnaire Dissemination}

A short cover letter was drafted and attached to each questionnaire for distribution through the internal BPA mail system. The letter simply stated the purpose of the questionnaire, when the questionnaire was expected back, and what phone number to call for additional information.

Instructions on the front of the questionnaire explained exactly how to fill out the questionnaire and how to return it. The back of each questionnaire was designed as a mailer with a self-address and an area for comments.

Upon completion of the questionnaire the respondent was expected to fold the questionnaire in half, staple it, and return it via the internal mail system. There were no markings on the outside of the questionnaire to indicate who the respondents were or to what organization they belonged. After a period of ten working days, another letter and questionnaire was sent to all the respondents to remind them of the study and encourage their participation. No further follow-up was done.

Population 
The population for questionnaires was mid-level managers. In BPA it is not difficult to assess this status. Based upon routing or internal mail codes, anyone who manages an organization with a two letter mail code can be considered a mid-level manager (division director). The first time the questionnaires were sent out in May 1989, there were fifty-four mid-level managers or people holding similar positions in BPA. The second time, September 1991, the questionnaires were sent to fifty-six mid-level managers. There is no way of knowing how many of the respondents who participated in the second questionnaire were part of the study the first time the questionnaire was administered because of anonymity constraints. Only the organizational positions they occupied were relevant to the study.

Caution was taken not to identify who provided what data. There is no way to trace questionnaires back to individuals or organizations. The only time a list of names was used was in mailing. That list, along with all returned questionnaires, was secured in accordance with the Federal Privacy Act. ${ }^{139}$

\section{Data Collation}

Upon return of the questionnaires the data were entered into a matrix for analysis (a spreadsheet). The data were then double checked for accuracy. Next, each line of data was classified according to the budget program (see Table 3.2), whether it was a pre or posttest response, and which question the respondent was answering.

139 June 1, 1977, P.L. 95-38, 5 USCS, 2000aa note. 
Finally the data were uploaded from a personal computer to the mainframe for analysis. This enabled rapid sorts and high performance of the statistics software. The data set for this study can be viewed in Attachment five. 
Interview conceptualization and methodology are discussed in this section. The target population for the interviews is also examined and precautions to protect individual responses are addressed. Findings are presented in the next chapter.

\section{Conceptualization}

Personal, open-end interviews are often preferable to other methods of gathering data because they allow observation, interaction, and probing that questionnaires cannot provide. In this case, interviews were selected because they are better suited to the study population and more personal than questionnaires. Executives in this organization will give finite portions of their time to individuals for interviews, but will seldom take time to answer a questionnaire. Interviews are more personal because the interviewer and interviewee both have the luxury of checking periodically to be sure a common understanding is being achieved. This periodic checking is valuable because it gives both parties more of a sense of control and improves communication. It also reduces the amount of unfounded information. Problems can occur with interviews when the interviewer identifies with the interviewee, thus biasing the information gathered in the interview. The only protection against this problem is to be aware of it and guard against it.

In planning this study, early conversations with management at $\mathrm{BPA}$ revealed that all management preferred interviews over 
questionnaires. However, for reasons stated earlier, interviews were not possible for the entire study population. Instead, the natural division between executive and middle management provided a convenient line of demarcation. Upper management is a smaller, but politically more powerful population. Their desire to be interviewed rather than complete a questionnaire could not be ignored. It was also felt that it would be more difficult to quantify executive management's perspective because they are a small population. It was important to gain a qualitative feel for what it was like to manage large parts of the organization and to thoroughly understand their uses of information. So, it was decided that interviews of executive managers best suited the purpose of this study.

\section{Methodology}

Interviews can take many forms. They can be quantitative and/or qualitative in structure. Qualitative interview methods attempt to learn the characteristics, attributes, or the nature of a subject. Quantitative interview methods usually consist of preconceived questions, categorized responses, and numerical manifestation of the responses. Interviews can be loosely structured with questions, tightly structured, with questionnaires containing scales and numbered response questions, or unstructured as in a grounded theory approach. ${ }^{140}$ Each of the interview structures has advantages and disadvantages.

140 Grounded theorists would argue that there is a structure but it is defined by the data, not the researcher. 
In general, interviews have a high response rate. ${ }^{141}$ Respondents are often more open to a person than to a survey questionnaire. The data collected through interviews are more likely to be complete and include personal mannerisms (e.g. gestures, expressions) of the interviewee than questionnaires. ${ }^{142}$ On the other hand, interviews are subject to several problems. First, there is always the possibility that prejudices, biases, or simply the presence of the interviewer may influence the outcome of an interview. Second, interviewing takes a longer period of time. Third, interviews are labor intensive. And finally, interviews are typically considered to have less validity and greater reliability than questionnaires. ${ }^{143}$

Unstructured interviews are based on the assumption that the interviewee knows more about the topic than the researcher....if you want to know about something, the best way to find out is ask. Unstructured interviews are a useful tool for the development of grounded theory. The grounded theory persepective assumes that the researcher knows little about the topic. The interviewee becomes the teacher. Usually, grounded theory interviews are tape recorded and later transcribed word for word. From each interview the researcher gains more and more information about the topic and thereby re-formulates questions with each successive interview. As transcripts are made of each interview the researcher begins to look for similarities and patterns

\footnotetext{
$141 \quad$ Babbie pg. 345

142 Babbie, pgs 162-164.

143 Babbie, pgs 344-349.
} 
which describe the milieu or social phenomena. Each transcript is reviewed by the researcher who then writes "memos" from the transcripts which distill the essence of the research topic. Interviews continue until the researcher is sure $s /$ he understands the topic. Grounded theory interviewers must do two things, continuously get the chronology and probe. Grounded theory interviews provide a data rich result, with insight into the nature of a subject. ${ }^{144}$

However, such interviews have problems. First, they are timeconsuming. Interviews can last for hours. Verbatim transcripts can be tedious to transcribe and their length is often overwhelming. Second, grounded theory interviews can meander from the topic of investigation and sometimes miss the target. Finally, interviewers using this method can become so closely connected to the subject that objectivity may be difficult.

In this study a modified grounded theory was selected for interviews. Grounded theory was selected because of the need to understand both the subjects and their use of information. Their use of information is so closely connected to the performance of their work that understanding the relationship between the two is very important. ${ }^{145}$

There are three concerns, however, that made it necessary to modify grounded theory methodology. The population interviewed would

\footnotetext{
144 Glaser and Strauss, pg 18-20.

145 Glaser and Strauss, pg 22-41.
} 
not allow tape recording during the interviews, which is not unusual in BPA. This kind of interviewing has been done before without tape recorders by taking copious notes. Second, much of the study population refused to be interviewed without knowing the questions in advance. Therefore, a set of questions was constructed and given to them in advance of the interview.146 In most cases, the questions were not mentioned during the interview. However, the questions were generic enough to allow a great deal of latitude in questioning which allowed a dialogue to develop. No one inquired as to why certain questions were asked or not asked. Using this technique, three purposes were achieved . First, the questions sensitized the interviewees to the topic and its importance. Second, the interviewees became more supportive to the interview because of its finite character. Third, the questions served as a common base for initiating the interview process.

The only assumption going into interviews was that the interviewee was the expert in the acquisition and use of information for decision making and the interviewer was there to learn everything about information used to make decisions. Because of the interview schedules, interviews had to be limited to a reasonable amount of time, usually one to one and one-half hours per interview. The interview data were then analyzed, with an eye toward content relevant to the use of information at BPA. 


\section{Interview Caveats}

Interviews have several limitations. First, not everyone is comfortable being interviewed. Sometimes people prefer the solitude afforded by a questionnaire. Interviews may make some subjects feel pressured to provide answers even when they do not know the answer to a question.

A certain bias may be added because only those who are willing are interviewed. Those who refuse to be interviewed may have important information, but perceive no reward in being interviewed. Thus, there is a risk that important data may be missed. In this case, only one executive scheduled, was not interviewed.

\section{Scheduling}

Scheduling the interviews was a problem. Interviews had to be scheduled during business hours. Additionally, requested time for each interview was an hour and a half. Most of the executives are not used to scheduling so much time for a single activity, particularly one which makes no promise of a tangible result. The interviews were also seen as less important than other business. Consequently, the interviews were scheduled and rescheduled many times each. Interviews were scheduled so no more than two interviews were conducted each day. This allowed time to record and to transcribe each interview. 


\section{Recording and Transcription}

A note taker as well as an interviewer went to each interview. This freed the interviewer to pay strict attention to the interviewee. It also gave the interviewer the opportunity to establish a rapport with the interviewee while noting expression, body language, and gestures for clarity of meaning. After each interview, notes were immediately dictated into a dictaphone in a dialogue format. Dictation tapes were then transcribed into text for content analysis. Dictation tapes were immediately erased and transcribed interview notes were securely locked.

Transcription was done by a clerk typist. The date and time of interview, persons present, and what the location and environment were noted for each interview. Transcribed interviews ranged from three to five, single spaced, type written pages.

\section{Population}

Based upon routing or internal mail codes, anyone who managed an organization with a single letter mail code was considered executive management (Office Assistant Administrators and their Deputies). ${ }^{147}$ All of the interviewees were rated as "SES" employees (executive service) of the federal government. "SES" employees are appointees and serve in

$147 \quad$ Assistant Administrators and their deputy assistant administrators are equivalent to the office of vice president and deputy vice president in the private sector. 
their positions at the will of the Administrator of BPA. All but one of the population contacted for interviews were interviewed. All the interviewees were notified of the purpose of the interviews and consented to be interviewed.

The first interviews were conducted in April 1989. Each interview was conducted in the interviewee's office when possible. Both the Assistant Administrator and Deputy Assistant Administrator for each Office was present for most interviews. In total, twenty individuals were interviewed in fourteen interviews for the pretest: seven BPA Offices, four Area Offices, and two senior assistant administrators.

Posttest interviews were done in October and November 1991. Only five follow-up interviews were performed. Only the Office Assistant Administrator or Area Office Manager was interviewed the second time. Posttest interviews were scheduled using random selection from the positions originally interviewed. Interestingly, an excellent cross-section of the original interviewees was selected because two of the interviewees had previously been in other executive positions and were interviewed during the pretest.

The selection of five names for posttest interviews represents a twenty-five percent sample. The names were selected without replacement from a hat by a disinterested party. The random selection yielded two Assistant Administrators, two Area Office Managers, and a Deputy Assistant Manager. 
Caution was taken not to identify respondents in this study. There is no way to identify individuals or organizations. Names appeared only for scheduling and on the original transcription. The scheduling list along with all transcribed interviews are secured in accordance with the Federal Privacy Act. ${ }^{148}$ 


\section{CHAPTER IV}

\section{FINDINGS}

This chapter contains the findings and analysis of the data. The first part addresses the questionnaire data and uses statistical analysis as the tools to present the questionnaire findings. Next, the interviews are analyzed using content analysis techniques which produce the findings. Finally, a combination of the findings from both analyses is presented.

\section{The Questionnaire Analysis}

The questionnaire data were examined by observing the data, then by using analysis of frequency distributions, and measures of central tendency computations contained in the Statistical Analysis System (SAS) software. The statistical routines from SAS are called "Proc Freq" and "NPARIWAY". "NPARIWAY" provides the following statistics:

\begin{tabular}{|c|c|c|}
\hline NPARIWAY scores & $\begin{array}{l}\text { correspond to these } \\
\text { tests if data are } \\
\text { classified into two } \\
\text { levels... }\end{array}$ & $\begin{array}{l}\text { correspond to these } \\
\text { tests for a one-way } \\
\text { layout or k-sample } \\
\text { location test... }\end{array}$ \\
\hline $\begin{array}{l}\text { Wilcoxon } \\
\text { Van der Waerden } \\
\text { Median } \\
\text { Savage }\end{array}$ & $\begin{array}{l}\text { Wilconxon rank sum } \\
\text { test/Mann-Whitney U } \\
\text { test } \\
\text { Van der Waerden test } \\
\text { median test for two } \\
\text { samples } \\
\text { Savage test }\end{array}$ & $\begin{array}{l}\text { Kruskal-Wallis test } \\
\text { K-sample van der } \\
\text { Waerden test } \\
\text { k-sample median } \\
\text { test(Brown-Mood) } \\
\text { k-sample Savage test }\end{array}$ \\
\hline
\end{tabular}


1. Analysis of variance

2. effect mean square

3. error mean square

4. level

5. $\mathbf{N}$

6. sum of scores

7. expected sum of scores under Ho:

8. Standard Deviation

9. mean score $(\bar{X})$

10. chi-square (CHISg)

11. degrees of freedom (DF)

12. $\mathrm{PROB}>\mathrm{CHISQ}$ or significance probability

13. smallest mean score as "S"

14. the ratio (S-expected)/std as $Z$, which is approximately normally distributed under the null hypothesis

15. $P R O B>[Z]$, the probability of a greater observed $Z$ value

16. T-Test Approx., the significance level for the t-test. 149

The products listed in boldface type were used for the analysis (5, $7,9,10,16)$. The "NPARIWAY" routine was used on the data using, pretest(1) and posttest(2).

\section{Observations}

Fifty-four questionnaires were distributed in the pretest and twenty-two of them were returned. Fifty-six questionnaires were distributed in posttest, twenty-eight were returned. So, the pretest has about forty-one percent participation and the posttest has nearly fifty percent participation. If the questionnaires were used as the only information source, then the response rates would be low and barely acceptable. However, in this case, the questionnaire data was used with interview data and source documentation. So, both of the response rates

149 SAS User's guide: Statistics, 1982 ed., SAS Institute Inc., Cary North Carolina, pgs. 206-208. 
(pretest and posttest) for the return of the questionnaires were acceptable for the sample size. ${ }^{150}$

Some respondents did not use all eleven categories to rate each information element on all eleven categories. In some cases, they rated only part of the information. This leaves some holes in the data set. There are also holes in the data set for other reasons. For example, some of the information needed to make decisions two years ago is no longer needed, and, conversly, information required at the end of the study for decision making was not necessary two years ago

When data are sorted by question, most of the responses are to question " $\mathrm{A}$ " (information supplied to the decision maker), then to question "B" (information supplied by the decision maker), still fewer to " $\mathrm{C}$ " (information desired by the decision maker) and finally to question "D" (information not wanted by the decision maker). Reason for this distribution might be: managers require more information to make decisions than to support others decisions, managers may have few ideas of what more information they need, or they may have already weeded out the information they receive but do not need. Another possibility is that the managers got tired of answering successive questions.

\section{Frequencies}

Both relative and general frequency distributions are presented here. ${ }^{151}$ Frequency analysis of the data is divided into two parts; general 
frequency tables and specific findings. The general frequency tables are: pretest/posttest by category, summarized in bar charts (attachment six) and in Table 4.1, pretest/posttest, by category, by question (A, B, C, D) shown in Table 4.2 , and sorted by category, by question, by budget classification shown in attachment eight.

Frequency of Responses from Pretest and Posttest

\begin{tabular}{|c|c|c|c|c|c|c|c|c|c|c|c|}
\hline PRETEST & & & & & & & Categories & & & & \\
\hline Values & USEFUL & COMPLETE & TIMELY & ACCURATE & RELEVANT & o/s REQ. & FORMAT & FREQ. & PRESOR & PREFOR & CHECK \\
\hline NO RESP. & 27 & 22 & 26 & 26 & 22 & 25 & 34 & 34 & 24 & 74 & 43 \\
\hline 0 & 4 & 11 & 8 & 15 & 4 & 54 & 5 & 6 & 3 & 8 & 214 \\
\hline 1 & 12 & 4 & 9 & 7 & 10 & 13 & 18 & 9 & 217 & 144 & 75 \\
\hline 2 & 12 & 16 & 13 & 7 & 4 & 0 & 16 & 12 & 9 & 55 & \\
\hline 3 & 13 & 22 & 31 & 8 & 15 & 22 & 15 & 10 & 1 & 5 & \\
\hline 4 & 8 & 17 & 17 & 12 & 6 & 10 & 19 & 13 & 20 & 12 & \\
\hline 5 & 30 & 49 & 39 & 37 & 30 & 23 & 41 & 33 & 10 & 4 & \\
\hline 6 & 18 & 27 & 27 & 33 & 28 & 13 & 39 & 39 & & & \\
\hline 7 & 67 & 53 & 59 & 51 & 52 & 30 & 44 & 61 & 2 & 3 & \\
\hline 8 & 66 & 60 & 49 & 88 & 66 & 21 & 54 & 62 & 45 & 27 & \\
\hline 9 & 75 & 51 & 54 & 48 & 95 & 35 & 47 & 53 & 1 & & \\
\hline TOTAL & 332 & 332 & 332 & 332 & 332 & 332 & 332 & 332 & 332 & 332 & 332 \\
\hline POSTTEST & & & & & & & Categories & & & & \\
\hline & USEFUL & COMPLETE & TIMELY & ACCURATE & RELEVANT & O/S RE $\theta$. & FORMAT & FREQ. & PRESOR & PREFOR & CHECK \\
\hline NO RESP. & 40 & 39 & 39 & 39 & 41 & 42 & 46 & 44 & 50 & 54 & 111 \\
\hline 0 & 8 & 12 & 11 & 12 & 12 & 50 & 16 & 22 & 7 & 7 & 166 \\
\hline 1 & 6 & 4 & 3 & 3 & 4 & 41 & 5 & 8 & 163 & 124 & 28 \\
\hline 2 & 4 & 3 & 7 & 5 & 1 & 9 & 6 & 2 & 14 & 92 & \\
\hline 3 & 8 & 14 & 13 & 14 & 10 & 16 & 16 & 3 & 1 & 2 & \\
\hline 4 & 9 & 11 & 14 & 7 & 4 & 13 & 4 & 3 & 2 & 2 & \\
\hline 5 & 15 & 32 & 26 & 25 & 15 & 40 & 23 & 22 & 14 & 5 & \\
\hline 6 & 18 & 13 & 12 & 20 & 9 & 4 & 19 & 16 & 2 & & \\
\hline 7 & 26 & 44 & 48 & 48 & 31 & 21 & 49 & 39 & 10 & 11 & \\
\hline 8 & 35 & 35 & 54 & 55 & 39 & 20 & 57 & 62 & 41 & 7 & \\
\hline 9 & 136 & 98 & 78 & 77 & 139 & 49 & 64 & 84 & 1 & 1 & \\
\hline total & 305 & 305 & 305 & 305 & 305 & 305 & 305 & 305 & 305 & 305 & 305 \\
\hline
\end{tabular}

Table 4.1 


\section{Discussion of Frequencies}

Table 4.1 shows that there are twenty-seven more responses in the pretest than in the posttest (327-305), less than a ten percent difference. Pretest and posttest data sets are about equal.

Examination of the frequency distribution of the data shows a shift in the distribution from mid-range to the high range of scores. Pretest data have more scores ranging in the middle range. Pretest distributions have a tendency to appear more bimodal than normal. Bimodality represents a split in responses given by respondents, some express moderate satisfaction and some strong satisfaction. Pretest distributions do better resemble a normal bell curve, though the data are negatively skewed.

Posttest data are also negatively skewed and the curve which represents the distribution of data is flat, playkurtic. Posttest data appear to have a strong tendency toward higher overall scores. The posttest distribution analysis with pretest data reveals that respondents did not rate some categories in posttest. 
Frequency of Responses From

Pretest and Posttest Sorted by Question and Category

\begin{tabular}{|c|c|c|c|c|c|c|c|c|c|c|c|}
\hline Question & & & & & & Categorles & & & & & \\
\hline PRETEST & USEFUL & COMP & TMMELY & ACCUR. & RELVNT & O/S REg & FORMAT & FREQ & PRESOR & PREFOR & CHECK \\
\hline A & 168 & 168 & 168 & 168 & 168 & 167 & 162 & 163 & 166 & 138 & 149 \\
\hline B & 94 & 98 & 98 & 98 & 98 & 98 & 98 & 98 & 101 & 82 & 97 \\
\hline C & 17 & 18 & 14 & 14 & 18 & 18 & 14 & 14 & 16 & 20 & 20 \\
\hline D & 23 & 26 & 26 & 26 & 23 & 24 & 24 & 23 & 25 & 18 & 25 \\
\hline TOTAL & 302 & 310 & 306 & 306 & 307 & 307 & 298 & 298 & 308 & 258 & 291 \\
\hline & & & & & & & & & & & \\
\hline POSTTEST & & & & & & & & & & & \\
\hline & USEFUL & COMP & TMMELY & ACCUR. & RELVNT & O/S REQ & FORMAT & FREQ & PRESOR & PREFOR & CHECK \\
\hline A & 148 & 148 & 148 & 148 & 148 & 144 & 147 & 147 & 142 & 127 & 148 \\
\hline B & 81 & 86 & 86 & 86 & 81 & 86 & 81 & 84 & 89 & 88 & 89 \\
\hline C & 23 & 19 & 19 & 19 & 22 & 20 & 18 & 17 & 11 & 25 & 25 \\
\hline D & 13 & 13 & 13 & 13 & 13 & 13 & 13 & 13 & 13 & 11 & 13 \\
\hline TOTAL & 265 & 266 & 266 & 266 & 264 & 263 & 259 & 261 & 255 & 251 & 275 \\
\hline
\end{tabular}

Table 4.2

In the second analysis (Table 4.2 ), both pretest and posttest are sorted by question (see Attachment seven for graphs). Responses to question "A" were the most frequent $(N>150)$ followed by question "B" ( $N$ $>75$ ). However, though the differences are small, responses to questions "C" $(\mathrm{N}<=25)$ and "D" $(\mathrm{N}<=25)$ change. In the pretest "D" was responded to more often than "C". But in posttest, "C" was more frequent than "D".

The third analysis of pretest/posttest was by question by "class" (attachment eight). The table of analysis is too large to include in the text. Examination of the frequencies resulted in the following observations. First, there were no requests for fish and wildlife (F) data until the posttest. Second, several budget classifications have data in the pretest but not in the posttest, and vice versa. Third, moderate 
declines have occurred in frequency for management information (G) and personnel information (GP).

\section{Specifc Frequency Findings}

The frequency analysis also shows how respondents receive their information. Though these data have not been subjected to the rigors of a "t-test", they are presented to report changes in frequency. Here is how they receive (PRESOR, present origin of information) their information according to pre/posttest results. 
Origin of Information

\begin{tabular}{|l|c|c|c|}
\hline \multicolumn{1}{|c|}{ Source } & $\begin{array}{c}\text { Frequency(\%) } \\
\text { Pretest }\end{array}$ & $\begin{array}{c}\text { Frequency(\%) } \\
\text { Posttest }\end{array}$ & $\begin{array}{c}\text { Change } \\
\text { in Percent }\end{array}$ \\
\hline No response & $24(7.2 \%)$ & $50(16.4 \%)$ & -9.2 \\
\hline Don't know & $3(0.9 \%)$ & $7(2.3 \%)$ & -1.4 \\
\hline $\begin{array}{l}\text { Hard copy } \\
\text { report }\end{array}$ & $217(65.4 \%)$ & $163(53.4 \%)$ & 12 \\
\hline Electronic data & $9(2.7 \%)$ & $14(4.6 \%)$ & -2.1 \\
\hline Floppy diskette & $1(0.3 \%)$ & $1(0.3 \%)$ & 0 \\
\hline $\begin{array}{l}\text { Periodicals/ } \\
\text { library }\end{array}$ & $20(6 \%)$ & $2(0.6 \%)$ & 5.4 \\
\hline $\begin{array}{l}\text { Personal } \\
\text { Contact }\end{array}$ & $10(3 \%)$ & $14(4.6 \%)$ & -1.6 \\
\hline Observation & $(0 \%)$ & $2(0.6 \%)$ & -.6 \\
\hline $\begin{array}{l}\text { Historical/ } \\
\text { Performance } \\
\text { Rec }\end{array}$ & $2(0.6 \%)$ & $10(3.3 \%)$ & -2.7 \\
\hline Staff work & $45(13.6 \%)$ & $41(13.4 \%)$ & .2 \\
\hline Experience & $1(0.3 \%)$ & $1(0.3 \%)$ & 0 \\
\hline
\end{tabular}

Table 4.3

There has been a reduction from sixty-five percent to fifty-three percent of those who report getting hard copy reports. There is also a change from seven percent to sixteen percent who did not respond to the question. Staff work remained the same throughout the test period, while the use of periodicals and library dropped about five percent.

Here are the frequencies for the question, "How would you like to receive the information you get?" The presentation is the same as shown above. 
Preferred Origin of Information

\begin{tabular}{|c|c|c|c|}
\hline Source & $\begin{array}{c}\text { Frequency(\%) } \\
\text { Pretest }\end{array}$ & $\begin{array}{c}\text { Frequency(\%) } \\
\text { Posttest }\end{array}$ & $\begin{array}{c}\text { Change } \\
\text { in Percent }\end{array}$ \\
\hline No response & $74(22.3 \%)$ & $54(17.7 \%)$ & 4.6 \\
\hline Don't know & $8(2.4 \%)$ & $7(2.3 \%)$ & .1 \\
\hline Hard copy report & $144(43.4 \%)$ & $124(40.7 \%)$ & 2.7 \\
\hline Electronic data & $55(16.6 \%)$ & $92(30.2 \%)$ & -13.2 \\
\hline Floppy diskette & $5(1.5 \%)$ & $2(0.7 \%)$ & .8 \\
\hline Periodicals/ library & $12(3.6 \%)$ & $2(0.7 \%)$ & 2.9 \\
\hline Personal Contact & $4(1.2 \%)$ & $5(1.6 \%)$ & -.4 \\
\hline Observation & $(0 \%)$ & $(0 \%)$ & 0 \\
\hline Historical/ Performance & $3(0.9 \%)$ & $11(3.6 \%)$ & -2.7 \\
\hline Rec & & & 5.8 \\
\hline Staff work & $27(8.1 \%)$ & $7(2.3 \%)$ & -.3 \\
\hline Experience & $(0 \%)$ & $1(0.3 \%)$ & \\
\hline
\end{tabular}

Table 4.4

There are some changes in the data from pretest to posttest. In the tests which examined gross categories like pretest/posttest by rating category by question, enough data was present in each test to provide some results.

Frequency counts show that in the pretest, $65 \%$ of mid-level managers reported that they receive information as a hard copy report. Only $53 \%$, in the posttest report that to be the case. Oddly, $16 \%$ in posttest give "no response" to the question of "how do you presently get your information." Less than $8 \%$ had no response in the pretest. Certainly, this may indicate confusion on the part of some mid-level managers as to where they get information. 
When asked how they prefer to get information $22 \%$ had no response in the pretest, while $17 \%$ had no response in the posttest. In the pretest and posttest about the same percentage reported a preference for hard copy reports (40\%). However, 16\% reported a preference for electronic data in the pretest and 30\% reported the same in the posttest.

Below in Table 4.5 responses to the category "check" is shown. The question: "Does staff alter or summarize the information from the original report?"

The Category "Check"

"Does Staff Handle the Information?"

\begin{tabular}{|c|c|c|c|}
\hline Question & $\begin{array}{c}\text { Frequency (\%) } \\
\text { Pretest }\end{array}$ & $\begin{array}{c}\text { Frequency } \\
\text { Posttest (\%) }\end{array}$ & $\begin{array}{c}\text { Change } \\
\text { in Percent }\end{array}$ \\
\hline A & $149(51.2 \%)$ & $148(53.8 \%)$ & -2.6 \\
\hline B & $97(33.3 \%)$ & $89(32.4 \%)$ & .9 \\
\hline C & $20(6.9 \%)$ & $15(5.8 \%)$ & 1.1 \\
\hline D & $25(8.6 \%)$ & $13(4.7 \%)$ & 3.9 \\
\hline
\end{tabular}

Table 4.5

Staff handle information for decision making about half the time. Information supplied to others for decision making is checked only about a third of the time. Seven percent of the time staff is sent to look for information that would be helpful in decision making. Finally, "staff alter or summarize information that is not needed or wanted for decision making" was reported by about $8.5 \%$. The highest number of responses to any question in the pretest is 310 . That means if 310 is considered $100 \%$ of the responses, then staff alter or summarize information $93.8 \%$ of the time. 
In posttest, the responses to the category "check" for question A, information supplied to the respondent for decision making, is yes; is still about half the time. Also, information supplied to others for decision making is checked is still only about a third of the time. Six percent of the time staff is sent to look for information that would be helpful in decision making. Finally, staff alter or summarize information that is not needed or wanted for decision making is checked about $5 \%$ of the time. The highest number of responses to a category in the posttest is 265 . That means if 265 is considered $100 \%$ of the responses, then staff alter or summarize information $100 \%$ of the time.

\section{Measures of Change}

Measures of central tendency examine the position and distribution of data points on a scale responding to a typical, representative, or central score. ${ }^{152}$ Measures of central tendency are the mean, median and mode. For this study, the primary interest is the mean.

Consequently, a mean $(\bar{X})$ was calculated for each question and budget classification for both pretest and posttest. Differences in the mean $(\bar{X})$ will show changes from pretest to posttest. This shows change, indicating the state of BPA's information.

Generally, the purpose of statistical testing is to "make an educated guess". Since whatever comes out of these probabilistic tests is 
only an educated guess, it might be wrong. So, selecting a significance level has very real consequences. ${ }^{153}$ An appropriate significance level is important because the level can increase or decrease the chance of rejecting a case when it is true (type I error) or accepting a case when it is false (type II error). The significance level for this study is 0.1. We are increasing the possibility of accepting a case when it is false to include more cases in the study.

Here is why. First, the results of the statistical analysis will be used in conjunction with interviews, so additional information will help support or reject the statistical results. Second, the results of these analyses are only looking for trends in the data, not precise scientific findings. And, third, some of this data has a small "N" or number of participants. A small "N" may limit the application of some of the data discovered in this study because parametric statistics lose accuracy with a small " $N "$. A small " $N$ " may cause rejection of data that may prove of value.

Another common statistical tool used here for analysis is the " $t$ test". The "t-test" provides a score which easily computes a significance level and is common enough to be understood by a wide audience. So, the statistical procedure to be use on the data is a two tailed "t-test". 154

\footnotetext{
153 McCall, pgs 191-193.

154 McCall, pg. 213.
} 
The "t-test" will provide the answer to questions of significance levels and to determine if the data are within the normal parameters of the population distribution and what significances can be attributed to each result. Only the first eight categories will be tested (see Table 3.1). 
Statistics on Pretest and Posttest Responses

Sorted by Questions

\begin{tabular}{|c|c|c|c|c|c|}
\hline $\begin{array}{l}\text { Category Name } \\
\text { pretest } N / \text { post } N\end{array}$ & $\begin{array}{c}\operatorname{Mean}(\bar{X}) \\
\text { pre/post }\end{array}$ & $\begin{array}{l}\text { Std Dev. } \\
\text { under Ho: }\end{array}$ & $\begin{array}{c}\text { CHISQ/ } \\
\text { PROB>CHIS } 9\end{array}$ & $\begin{array}{c}\text { T-test } \\
\text { signif. } \\
\text { level } \\
.1 \text { or better } \\
\end{array}$ & Diff. in mean ( $\overline{\bar{X}}$ ) \\
\hline \multicolumn{6}{|l|}{ Useful } \\
\hline A- $168 / 148$ & $6.93 / 7.38$ & 4.22 & $12.47 / .0004$ & .0005 & .45 \\
\hline B-94/81 & $7.24 / 7.85$ & 3.30 & $12.30 / .0005$ & .0033 & .61 \\
\hline C- $17 / 23$ & $7.71 / 7.70$ & 1.58 & $1.72 / .1894$ & .2832 & -.01 \\
\hline$D-23 / 13$ & $2.31 / 2.92$ & 1.47 & $0.05 / .8203$ & .6792 & .61 \\
\hline \multicolumn{6}{|l|}{ Complete } \\
\hline A- $168 / 148$ & $6.26 / 6.80$ & 4.37 & $7.04 / .008$ & .0015 & .54 \\
\hline B-98/86 & $6.99 / 7.21$ & 3.27 & $3.03 / .0817$ & .3035 & .22 \\
\hline C- $18 / 19$ & $3.39 / 5.53$ & 1.53 & $6.14 / .0132$ & .0349 & 2.14 \\
\hline D. $26 / 13$ & $3.46 / 5.54$ & 1.49 & $6.05 / .0139$ & .0722 & 2.08 \\
\hline \multicolumn{6}{|l|}{ Timely } \\
\hline A- $168 / 148$ & $6.02 / 6.46$ & 4.25 & $3.15 / .0759$ & .0416 & .44 \\
\hline B-98/86 & $7.00 / 7.52$ & 3.11 & $2.90 / .0884$ & .0081 & .52 \\
\hline C- $14 / 19$ & $3.07 / 5.95$ & 1.44 & $9.24 / .0024$ & .0452 & 2.88 \\
\hline D-26/13 & $4.00 / 5.23$ & 1.47 & $1.29 / .2559$ & .2984 & 1.23 \\
\hline \multicolumn{6}{|l|}{ Accurate } \\
\hline A- $168 / 148$ & $6.53 / 6.76$ & 4.39 & $.74 / .3907$ & .1088 & .23 \\
\hline B-98/86 & $7.62 / 7.33$ & 3.09 & $1.48 / .2236$ & .8971 & -.29 \\
\hline C- $14 / 19$ & $3.43 / 5.26$ & 1.42 & $1.85 / .1735$ & .1350 & 1.83 \\
\hline $\mathrm{D}-26 / 13$ & $2.96 / 5.08$ & 1.48 & $0.81 / .3673$ & .0491 & 2.12 \\
\hline \multicolumn{6}{|l|}{ Relevant } \\
\hline A- $168 / 148$ & $7.04 / 7.66$ & 4.31 & $23.26 / .0001$ & .0001 & .62 \\
\hline B- $98 / 81$ & $7.76 / 7.77$ & 0.00 & $0.00 / 1.000$ & .2001 & .01 \\
\hline C- $18 / 22$ & $6.94 / 7.09$ & 1.59 & $1.58 / .2094$ & .4026 & .15 \\
\hline $\mathrm{D}-23 / 13$ & $3.23 / 3.23$ & 1.45 & $0.48 / .4907$ & .9279 & 0 \\
\hline \multicolumn{6}{|l|}{ Outstde Req. } \\
\hline A- $167 / 144$ & $3.50 / 4.01$ & 4.40 & $1.00 / .3170$ & .1059 & .51 \\
\hline B-98/86 & $3.64 / 4.71$ & 3.39 & $4.18 / .0409$ & .0521 & 1.07 \\
\hline C- $18 / 20$ & $3.50 / 4.75$ & 1.56 & $1.64 / .1997$ & .4198 & 1.25 \\
\hline$D-24 / 13$ & $3.08 / 4.15$ & 1.46 & $0.89 / .3446$ & .8074 & 1.07 \\
\hline \multicolumn{6}{|l|}{ Format } \\
\hline A- $162 / 147$ & $5.98 / 6.76$ & 4.25 & $5.86 / .0155$ & .0004 & .78 \\
\hline B-98/81 & $7.08 / 7.10$ & 2.98 & $0.53 / .4655$ & .5975 & .02 \\
\hline C- $14 / 18$ & $2.79 / 3.72$ & 1.43 & $0.49 / .4830$ & .7603 & .93 \\
\hline $\mathrm{D}-24 / 13$ & $3.00 / 3.85$ & 1.47 & $0.49 / .4839$ & .4851 & .85 \\
\hline \multicolumn{6}{|l|}{ Frequency } \\
\hline A- $163 / 147$ & $6.49 / 6.95$ & 4.38 & $11.87 / .0006$ & .0018 & .46 \\
\hline B- $98 / 84$ & $7.28 / 7.42$ & 3.14 & $3.93 / .0474$ & .0379 & .14 \\
\hline$C-14 / 17$ & $2.57 / 3.35$ & 1.32 & $2.57 / 3.35$ & .9199 & .78 \\
\hline$D-23 / 13$ & $4.65 / 4.85$ & 1.46 & $1.63 / .2021$ & 1.000 & .20 \\
\hline
\end{tabular}

Table 4.6 
Descriptive statistics computed from the study data and sorted by budget classification are given in Table 4.7. The computational results which meet the significance level are in boldface. For additional statistical information see attachment nine. Attachment nine also shows the data along with the "class", "times", $N$, mean $(\bar{X})$, standard deviation, and change in mean $(\bar{X}$ ) score. 
Significance Levels of Categories Sorted by Question and Budget Classification

\begin{tabular}{|c|c|c|c|c|c|c|c|c|c|c|c|c|c|}
\hline & & & & & & & & Category & & & & & \\
\hline Question & $\mathrm{C}$ & $F$ & $G$ & GA & $\overline{\mathrm{GB}}$ & GM & GP & $\mathrm{H}$ & $\mathrm{L}$ & $\bar{M}$ & P & 5 & $T$ \\
\hline $\begin{array}{c}\text { Useful } \\
\text { A } \\
\text { B } \\
\text { C } \\
\text { D }\end{array}$ & $\begin{array}{c}.0012 \\
.4401 \\
.2904 \\
.\end{array}$ & $:$ & $\begin{array}{c}.4767 \\
.7128 \\
1.00 \\
\end{array}$ & $\begin{array}{c}.4220 \\
.7421 \\
\\
.\end{array}$ & $\begin{array}{l}.0267 \\
.1396 \\
.2942 \\
.6298 \\
\end{array}$ & $\begin{array}{l}.0887 \\
.0001 \\
.8806 \\
.2954 \\
\end{array}$ & $\begin{array}{l}.1507 \\
.9555 \\
.4740 \\
.8230 \\
\end{array}$ & $\begin{array}{c}.6623 \\
.4370 \\
. \\
\end{array}$ & $\begin{array}{c}.4186 \\
\vdots \\
\end{array}$ & $\begin{array}{c}.4026 \\
.3456 \\
* \\
\end{array}$ & $\begin{array}{c}.5528 \\
1.00 \\
\vdots \\
\end{array}$ & $\begin{array}{c}.5104 \\
.1403 \\
\bullet \\
.3013 \\
\end{array}$ & $\begin{array}{c}.5403 \\
1.00 \\
\bullet \\
\bullet\end{array}$ \\
\hline $\begin{array}{c}\text { Complete } \\
\text { A } \\
\text { B } \\
\text { C } \\
\text { D } \\
\end{array}$ & $\begin{array}{c}.0500 \\
.8390 \\
.3293 \\
*\end{array}$ & $:$ & $\begin{array}{c}.0678 \\
.5083 \\
\bullet \\
.6027 \\
\end{array}$ & $\begin{array}{c}1.000 \\
.7431 \\
\\
\end{array}$ & $\begin{array}{c}.1622 \\
.2165 \\
1.00 \\
.3980 \\
\end{array}$ & $\begin{array}{l}.0171 \\
.0031 \\
.4022 \\
.2360 \\
\end{array}$ & $\begin{array}{l}.0192 \\
.5707 \\
.3293 \\
1.00 \\
\end{array}$ & $\begin{array}{c}.8230 \\
.4370 \\
\bullet \\
\end{array}$ & $\begin{array}{c}.7442 \\
\vdots \\
\end{array}$ & $\begin{array}{c}.4858 \\
.2897 \\
\vdots \\
\end{array}$ & $\begin{array}{c}.6026 \\
1.00 \\
\vdots \\
\end{array}$ & $\begin{array}{c}.8537 \\
.6045 \\
\bullet \\
.3486 \\
\end{array}$ & $\begin{array}{c}.6026 \\
1.00 \\
\bullet \\
\end{array}$ \\
\hline $\begin{array}{c}\text { Timely } \\
\text { A } \\
\text { B } \\
\text { C } \\
\text { D } \\
\end{array}$ & $\begin{array}{c}.2471 \\
.9798 \\
.6514 \\
\bullet \\
\end{array}$ & 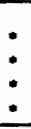 & $\begin{array}{c}.0144 \\
.4601 \\
. \\
.6027 \\
\end{array}$ & $\begin{array}{c}.3059 \\
.7646 \\
\bullet \\
\end{array}$ & $\begin{array}{l}.7299 \\
.0349 \\
.6288 \\
.6739 \\
\end{array}$ & $\begin{array}{l}.0465 \\
.0003 \\
.1135 \\
.2113 \\
\end{array}$ & $\begin{array}{l}.0987 \\
.8029 \\
.5528 \\
.6623 \\
\end{array}$ & $\begin{array}{c}.6623 \\
.4153 \\
\vdots \\
\end{array}$ & $\begin{array}{c}1.00 \\
:\end{array}$ & $\begin{array}{c}.2181 \\
.2920 \\
\vdots \\
\end{array}$ & $\begin{array}{c}.6026 \\
1.00 \\
\vdots \\
\end{array}$ & $\begin{array}{c}.7342 \\
.1548 \\
\bullet \\
1.00 \\
\end{array}$ & $\begin{array}{c}.6026 \\
1.00 \\
* \\
.\end{array}$ \\
\hline $\begin{array}{c}\text { Accurate } \\
\text { A } \\
\text { B } \\
\text { C } \\
\text { D } \\
\end{array}$ & $\begin{array}{c}.6092 \\
.5827 \\
.2848 \\
. \\
\end{array}$ & $:$ & $\begin{array}{c}.0079 \\
1.00 \\
.6026 \\
\end{array}$ & $\begin{array}{c}.9535 \\
.7381 \\
. \\
\end{array}$ & $\begin{array}{c}.2585 \\
.2222 \\
1.00 \\
.6682 \\
\end{array}$ & $\begin{array}{l}.4545 \\
.9892 \\
.2426 \\
.1861 \\
\end{array}$ & $\begin{array}{l}.0140 \\
.5583 \\
1.00 \\
1.00 \\
\end{array}$ & $\begin{array}{c}1.00 \\
.4153 \\
* \\
.\end{array}$ & $\begin{array}{c}.7411 \\
\vdots \\
\end{array}$ & $\begin{array}{c}1.00 \\
.1869 \\
* \\
\end{array}$ & $\begin{array}{c}.6026 \\
1.00 \\
\vdots \\
\end{array}$ & $\begin{array}{c}.9507 \\
.0799 \\
\bullet \\
.7415 \\
\end{array}$ & $\begin{array}{c}.6026 \\
.6026 \\
\bullet \\
\end{array}$ \\
\hline $\begin{array}{c}\text { Relevant } \\
\text { A } \\
\text { B } \\
\text { C } \\
\text { D } \\
\end{array}$ & $\begin{array}{r}.0009 \\
.3359 \\
.1819 \\
\end{array}$ & : & $\begin{array}{c}1478 \\
1.00 \\
1.00 \\
\end{array}$ & $\begin{array}{c}.2567 \\
.7381 \\
\bullet \\
\end{array}$ & $\begin{array}{l}.1353 \\
.3305 \\
.2061 \\
1.00 \\
\end{array}$ & $\begin{array}{l}.0631 \\
.0995 \\
.7182 \\
.4769 \\
\end{array}$ & $\begin{array}{l}.0051 \\
.2942 \\
1.00 \\
.5240 \\
\end{array}$ & $\begin{array}{c}1.00 \\
.4153 \\
\bullet \\
\end{array}$ & $\begin{array}{c}1.00 \\
: \\
\end{array}$ & $\begin{array}{c}.1932 \\
.4458 \\
\vdots \\
\end{array}$ & $\begin{array}{c}.6026 \\
.4153 \\
\vdots \\
\end{array}$ & $\begin{array}{c}.2334 \\
.3381 \\
* \\
.7415 \\
\end{array}$ & $\begin{array}{c}.6026 \\
1.00 \\
\bullet \\
.\end{array}$ \\
\hline $\begin{array}{c}\text { O/side Req. } \\
\text { A } \\
\text { B } \\
\text { C } \\
\text { D } \\
\end{array}$ & $\begin{array}{c}.2837 \\
.1530 \\
.4245 \\
. \\
\end{array}$ & $:$ & $\begin{array}{c}.2332 \\
.4975 \\
\bullet \\
.6026 \\
\end{array}$ & $\begin{array}{c}.4927 \\
.5611 \\
. \\
\end{array}$ & $\begin{array}{l}.7685 \\
.9138 \\
.3997 \\
.3351 \\
\end{array}$ & $\begin{array}{l}.1434 \\
.2886 \\
.4438 \\
.4717 \\
\end{array}$ & $\begin{array}{l}.5533 \\
.0658 \\
.6026 \\
.5757 \\
\end{array}$ & $\begin{array}{c}1.00 \\
.6514 \\
\vdots \\
\end{array}$ & $\begin{array}{c}.2789 \\
\cdots \\
. \\
\end{array}$ & $\begin{array}{c}.0713 \\
.4779 \\
\bullet \\
\end{array}$ & $\begin{array}{c}1.00 \\
1.00 \\
. \\
\end{array}$ & $\begin{array}{c}.4821 \\
.7853 \\
\bullet \\
.3262 \\
\end{array}$ & $\begin{array}{c}1.00 \\
1.00 \\
\bullet \\
\end{array}$ \\
\hline $\begin{array}{c}\text { Format } \\
\text { A } \\
\text { B } \\
\text { C } \\
\text { D } \\
\end{array}$ & $\begin{array}{c}1.000 \\
.9205 \\
.3081 \\
* \\
\end{array}$ & 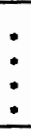 & $\begin{array}{c}.0174 \\
1.00 \\
1.00 \\
\end{array}$ & $\begin{array}{c}.3865 \\
1.00 \\
\bullet \\
\end{array}$ & $\begin{array}{c}.0783 \\
.4422 \\
1.00 \\
1.00 \\
\end{array}$ & $\begin{array}{l}.0187 \\
.0183 \\
.3776 \\
.3047 \\
\end{array}$ & $\begin{array}{l}.0337 \\
.5682 \\
.6514 \\
1.00 \\
\end{array}$ & $\begin{array}{c}.7761 \\
.4153 \\
\vdots \\
\end{array}$ & $\begin{array}{c}.3368 \\
\vdots \\
\bullet\end{array}$ & $\begin{array}{c}.0663 \\
.6417 \\
* \\
\end{array}$ & $\begin{array}{c}.6026 \\
1.00 \\
\vdots \\
\end{array}$ & $\begin{array}{c}.5607 \\
.3878 \\
\bullet \\
.7415 \\
\end{array}$ & $\begin{array}{c}.6026 \\
1.00 \\
\bullet \\
\bullet\end{array}$ \\
\hline $\begin{array}{c}\text { Freqency } \\
\text { A } \\
\text { B } \\
\text { C } \\
\text { D } \\
\end{array}$ & $\begin{array}{c}.8636 \\
1.00 \\
.3081 \\
. \\
\end{array}$ & : & $\begin{array}{c}.1457 \\
.7040 \\
1.00 \\
\end{array}$ & $\begin{array}{c}.1107 \\
1.00 \\
\vdots \\
\end{array}$ & $\begin{array}{l}.2257 \\
.3594 \\
1.00 \\
1.00 \\
\end{array}$ & $\begin{array}{l}.0033 \\
.0037 \\
.8971 \\
.3326 \\
\end{array}$ & $\begin{array}{l}.1593 \\
.3812 \\
1.00 \\
1.00 \\
\end{array}$ & $\begin{array}{c}1.00 \\
.4153 \\
* \\
\end{array}$ & $\begin{array}{c}1.00 \\
: \\
\end{array}$ & $\begin{array}{c}1.00 \\
.2024 \\
\vdots \\
\end{array}$ & $\begin{array}{c}6026 \\
1.00 \\
\vdots \\
\end{array}$ & $\begin{array}{c}.1632 \\
.0534 \\
\bullet \\
1.00\end{array}$ & $\begin{array}{c}.5528 \\
1.00 \\
\bullet \\
\bullet\end{array}$ \\
\hline
\end{tabular}

- Indicates no scores due to insufficient data. Category (U) is not present on the chart because no data was classified as support services data. Table 4.7 
Significant Changes as measured by $t$-test

"T-test" significance levels $(<=.1)$ are met for fourteen of thirty-two classifications as shown in Table 4.7. In the tables below the categories are listed by question. Adjacent to each category is the difference in means $(\bar{X})$ and the percent change where $\mathrm{pl}$ is pretest and $\mathrm{p} 2$ is posttest. The differences between means $(\bar{X})$ is also shown along with the differences which have been converted to a percent.

Question "A" Changes in Mean of Categories "Information Received from Others to Support Decision Making?"

\begin{tabular}{|l|l|}
\hline \multicolumn{1}{|c|}{ Categories } & \multicolumn{1}{|c|}{$\begin{array}{c}(\overline{\mathrm{X}}) \mathrm{p} 2-(\overline{\mathrm{X}}) \mathrm{p} 1=\mathrm{dif} \\
(+/-) \% \text { change }\end{array}$} \\
\hline Useful & $7.39-6.93=.45(+5 \%)$ \\
\hline Complete & $6.80-6.26=.54(+6 \%)$ \\
\hline Timely & $6.46-6.02=.44(+4.9 \%)$ \\
\hline Relevant & $7.66-7.04=.62(+6.9 \%)$ \\
\hline Format & $6.76-5.98=.78(+8.7 \%)$ \\
\hline Frequent & $6.95-6.49=.46(+5.1 \%)$ \\
\hline
\end{tabular}

Table 4.8

Based upon the results shown in Table 4.8 it can be stated that information supplied to mid-level managers has improved from pretest to posttest, for the categories useful, complete, timely, relevant, frequent, and the format.. Information supplied to managers for decision making (question A) has improved for seventy-five percent of the reported responses. 
Question "B" Changes in Mean of Categories

"Information Supplied to Others to Support

Decision Making?"

\begin{tabular}{|l|l|}
\hline \multicolumn{1}{|c|}{ Categories } & \multicolumn{1}{c|}{$\begin{array}{c}(\overline{\mathrm{X}}) \mathrm{p} 2-(\overline{\mathrm{X}}) \mathrm{p} 1=\text { dif } \\
(+/-) \% \text { change }\end{array}$} \\
\hline Useful & $7.85-7.24=.61(+6.8 \%)$ \\
\hline Timely & $7.52-7.00=.52(+5.8 \%)$ \\
\hline Outside Requirement & $4.71-3.64=1.07(+11.9 \%)$ \\
\hline Frequent & $7.42-7.28=.14(+1.6 \%)$ \\
\hline
\end{tabular}

Table 4.9

It can be concluded that there is change in information that midlevel managers supply to others for decision making. The ratings on useful, timely, outside requirements, and frequency all have improved from those of May 1989. Information supplied by managers for decision making (question $\mathrm{B}$ ), has improved in fifty percent of the reported responses.

Question "C" Change in Mean of Categories "Information Respondent Would Like to Support Decision Making?"

\begin{tabular}{|l|c|}
\hline \multicolumn{1}{|c|}{ Categories } & $\begin{array}{c}(\overline{\mathrm{X}}) \mathrm{p} 2-(\overline{\mathrm{X}}) \mathrm{p} 1=\text { dif } \\
(+/-) \% \text { change }\end{array}$ \\
\hline Complete & $5.53-3.39=2.14(+23.8 \%)$ \\
\hline Timely & $5.95-3.07=2.88(+32 \%)$ \\
\hline
\end{tabular}

Table 4.10

There has been a change in ratings for information respondents desire for decision making. The information mid-level managers desire will have to be complete and timely to meet their expectations. Information managers would like for decision making (question D), needs to be timely and complete to be desirable in twenty-five percent of the reported responses. 
Question "D" Changes in Mean of Categories

"Information Respondent Does Not Need to Support

Decision Making?"

\begin{tabular}{|l|c|}
\hline \multicolumn{1}{|c|}{ Categories } & $\begin{array}{c}(\overline{\mathrm{X}}) \mathrm{p} 2-(\overline{\mathrm{X}}) \mathrm{p} 1=\text { dif } \\
(+/-) \% \text { change }\end{array}$ \\
\hline Complete & $5.54-3.46=2.08(+23.1 \%)$ \\
\hline Accurate & $5.08-2.96=2.12(+23.6 \%)$ \\
\hline
\end{tabular}

Table 4.11

There is a change in information not needed by respondents for decision making. Respondents find that the information they get for decision making, even that which is not needed, is complete and accurate, as noted in Table 4.11. So, information managers get, but do not need has also improved twelve and a half percent.

So, it can be said that categories displayed in Table 4.7 (ratings by question) have changed in forty-four percent of the reported responses.

\section{Changes in Budget Classifications}

Next, the budget classifications results contained in Table 4.7 show "t-test" significance levels by category, by question, by budget classificaton. The following Tables show results of ratings which meet the significance level of .01 or better and the differences (+\-) in mean $(\bar{X})$ for each category. For a complete list of means $(\bar{X})$ and changes see attachment nine.

(C) Transmission System Design 
There was an improvement in the transmission system design information as perceived by mid-level managers. Respondents consider the information they get more useful, complete, and relevant than they did two and a half years ago. The changes for the non-significant comparisons are shown in attachment nine.

Budget Category "C" Mean Change

\begin{tabular}{|c|c|}
\hline Question A Categories & Mean $(\overline{\mathrm{X}})$ Rating Change \\
\hline Useful & +1 \\
\hline Complete & +1 \\
\hline Relevant & +1.17 \\
\hline
\end{tabular}

Table 4.12

Fish and Wildlife

No fish and wildlife data appear in the pretest (therefore there is no Table to show changes). Demand for fish and wildlife information is new. It appears only in the posttest. Only two respondents said they use these data to make decisions. They found the data useful, complete, accurate, and relevant. But, they rated the category timely low.

\section{(G) Overhead}

In the budget category of General Overhead for question A, data show that the categories complete, timely, accurate, and format, meet the significance test. The largest change is in format, almost four points. There is not enough data in question $\mathrm{C}$ in the category of Overhead to perform analysis. Worth mention is a substantial decrease in the use of overhead data for outside requirements. 
Budget Category "G" Mean Change

\begin{tabular}{|c|c|}
\hline Question A Categories & Mean $(\overline{\mathrm{X}})$ Rating Change \\
\hline Complete & +2.42 \\
\hline Timely & +2.83 \\
\hline Accurate & +2.83 \\
\hline Format & +3.89 \\
\hline
\end{tabular}

Table 4.13

(GA) Overhead - Accounting

None of the responses met the significance level of 0.1 . (GB) Overhead - Budget

Budget information supplied to managers for decision making is considered useful and the format has improved, or they are more used to the format now. Information that managers supply for decision making is timely. Of note is the fact that almost twice as many responded with budget items in the posttest ( 36 for question A) as did in the pretest ( 20 for question A). Budget appears to have become more important.

Budget Category "GB" Mean Change

\begin{tabular}{|c|c|}
\hline Question A Categories & Mean $(\overline{\mathrm{X}})$ Rating Change \\
\hline Useful & +1 \\
\hline Format & +1.03 \\
\hline Question B Categories & +2.03 \\
\hline Timely & \\
\hline
\end{tabular}

Table 4.14

(GM) Overhead - Management

This category has the most categories which meet the significance level of 0.1 , twelve of thirty-two. Information supplied to managers for decision making has improved on: useful, timely, complete, relevant, 
format, and frequent. Information managers supply to others for decision making has improved in exactly the same categories.

\section{Budget Category "GM" Mean Change}

\begin{tabular}{|c|c|}
\hline Question A Categories & Mean $(\overline{\mathrm{X}})$ Rating Change \\
\hline Useful & +.89 \\
\hline Complete & +1.56 \\
\hline Timely & +1.28 \\
\hline Relevant & +1.06 \\
\hline Format & +1.69 \\
\hline Frequent & +1.61 \\
\hline Question B Categories & +2.2 \\
\hline Useful & +2.02 \\
\hline Complete & +2.06 \\
\hline Timely & +1.07 \\
\hline Relevant & +1.30 \\
\hline Format & +1.31 \\
\hline Frequency & \\
\hline
\end{tabular}

Table 4.15

(GP) Overhead - Personnel

The perception of managers was that information for decision making on personnel has improved. It was more timely, accurate, relevant, and the format was better. Managers also felt that information they supply to others for decision making was better for outside requirements. 
Budget Category "GP" Mean Change

\begin{tabular}{|c|c|}
\hline Question A Categories & Mean ( $\overline{\mathrm{X}})$ Rating Change \\
\hline Complete & +.78 \\
\hline Timely & +.95 \\
\hline Accurate & +.91 \\
\hline Relevant & +1.08 \\
\hline Format & +1.07 \\
\hline Question B & \\
\hline Outside Requirement & +2.32 \\
\hline
\end{tabular}

Table 4.16

(H) System Operations

Though system operations information was not included in the study, some managers outside of system operations use the information and budget category. Therefore, this category of information has little activity. No rating categories meet the significance level in this category.

\section{(L) Information Resources}

None of the variables in this category reached the 0.1 significance level. Only question " $A$ " had enough responses to allow a test of significance. In all, only eight responses were recorded for this category, two in the pretest and six in the posttest.

(M) System Maintenance

Information used in system maintenance is unusual. Nine reports of information were given in the pretest and two in the posttest. The average mean $(\bar{X})$ in ratings in the pretest is only 4.11 and 9.0 in the posttest. While information supplied to managers for making decisions on "outside requirements" is at an acceptable significant level, it must be 
taken viewed skeptically considering the drop in the number of respondents from pretest to posttest. The best we can say is that fewer respondents use the information, but they liked it.

Budget Category "M" Mean Change

\begin{tabular}{|c|c|}
\hline Question A Categories & Mean $(\overline{\mathrm{X}})$ Rating Change \\
\hline Outside Requirement & +4.89 \\
\hline
\end{tabular}

Table 4.17

(N) Planning Council

No reports of planning council information were given in pretest or posttest by mid-level managers.

(P) Power Marketing

No reports of power marketing information was given by respondents which qualified under the significance level of 0.1 .

\section{(S) Power Scheduling}

Power scheduling information is supplied to others for decision making. Managers who supply the information consider its accuracy and frequency improved.

Budget Category "S" Mean Change

\begin{tabular}{|c|c|}
\hline Question B Categories & Mean $(\overline{\mathrm{X}})$ Rating Change \\
\hline Accurate & +.69 \\
\hline Frequency & +1.1 \\
\hline
\end{tabular}

Table 4.18 


\section{(T) Energy Resources}

No reports of energy resource information of significance were reported in pretest or posttest by mid-level managers.

\section{(U) Support Services}

No support services data were reported by respondents.

\section{Summary}

It is clear that for some categories there was quantifiable evidence of change among those who responded. The greatest change occurred in Overhead-management information. About forty percent of the categories in the budget category show improvement from pretest to posttest. Specifically, information supplied to managers for decision making has changed. However, several categories had no change.

The findings from the questionnaire are be combined with the interview findings later in this chapter.

\section{INTERVIEW ANALYSIS}

The interviews were subjected to a content analysis. ${ }^{155}$ Just as a researcher might go through a diary or magazine to identify relevant information, each interview was carefully scrutinized for pertinent information. Each element or fact was highlighted and transferred to a list of interview notations. Interview notations were then summarized in 
a memo list. The memo lists were then summarized into a unified list of statements. The statements do not identify organizations, locations or interviewees. The unified list of pretest results follow.

\section{Pretest Interviews}

- Without exception, all managers read Clearing Up (a regional utilities publication) and clips (newspaper and magazine clippings collected from regional and national publications).

- Most manage by exception; that is they devote most of their time to events or situations which are out of the ordinary (the $80 / 20$ rule, $80 \%$ of the business gets $20 \%$ of the attention, and $20 \%$ of the business gets $80 \%$ of the attention).

- Most of management's time is spent acquiring information.

- Information reduces uncertainty.

- Politically sensitive issues raise uncertainty levels.

- Most executives trust information more after their staff has examined, verified and generally massaged it.

- Executives have staff massage information because it may contain hidden agendas or they simply distrust data acquired where there is no accountability for the condition of the data.

- There is not enough information on the day-to-day operational activity of BPA.... a current activity bulletin board is needed. 
- BPA is drowning in data .... BPA needs less data that is better focused....quality not quantity.

- Managers need access to all data.

- When FTE (full time equivalence, personnel) are cut, those who are the communicators are the first to go.

- The more information is altered to suit an executive's needs, the more time it takes and the less useful the information.

- Distrust brings additional reporting requirements.

- Hand written notes add a personal touch which helps build trust.

- There are too many requirements and duplicate requirements for data input into systems.

- Written communications need to be limited to one page where possible.

- Secretaries are important information gatherers and filterers... they need to be recognized for that.

- Networks and personal computers need to be attached into the communication system.

- BPA needs to trust qualified staff more.

- A catalog of dependable databases needs to be created.

- Routine contract writing needs to be automated.

- BPA needs a way to create and access corporate memory.

- Standardize data in databases so there is only one source.

- Prioritize 
- Do not confuse information precision with information accuracy.

- Most managers prefer personal contact for information even if the information is already in written form.

- Information that is provided by systems that are shared or public is sterile because it is filtered for political reasons before it is input.

- Have systems share data.

- Establish electronic (E) mail with customers.

- Improve the legibility of PACS (payroll, accounting and costs system).

- Reporting requirements need to pass a test to see if they are already available.

- Information analysis is more important than more information, we have enough information.

- Many managers want to see an "event" report because it is what the customer sees (an event is a power outage or disruption of service).

- Management is there to articulate the process of doing business; the information needed is the status of the process.

- Most data used in BPA are administrative, yet there is not an administrative database.

- There seems to be a converse relationship of information and management....the higher up in the organization the manager, the softer (information not written down, usually 
word of mouth) the information....the lower the manager the harder (written information) the information.

-Short term decisions are limited in scope and are exceptions ..... long term decisions are wider in scope.

- It takes as much effort to aggregate information as it takes to understand it.

- Information should not be too easy to get because demand is geometric...people begin to request data they do not need.

- Information requests are generated based upon priorities, memory, and experience.

- Managers use contacts, inside and outside, to scan the environment and customers for problems.

- The perception is that most information is not useful.

- BPA uses subject experts... if they leave the expertise leaves with them.

- Decisions in BPA are not well documented for future reference.

- Committees are information tools, not decision bodies.

- Most managers want the ability to track activity, which implies standardized definitions over time.

- "What-if" analysis is needed for decisions and comparative purposes.

\section{Posttest Interviews}

- Read the news, clips, and Clearing up regularly.

- All levels of management need information pertaining to events and results. 
- Semi-annual reviews in the Area Offices are not often enough....we need the ability to change direction quickly.

- Information needed is by program.

- Most information still verbal or hard copy reports.

- BPA needs tracking by key issues and performance indicators.

- We need fewer sources of information, but of high quality and well focused.

- We still get too much paper.

- Until the new Administrator sets his priorities, information will remain unsettled.....once he selects his main focus, all assistant administrators will want that information.

- There is too much numerical data, there is a preference for graphic representations.....all we need is enough to see trends.

- An executive support system (ESS) is good but there is only one right now....it is too labor intensive but would not be bad if more used it.

- Personnel computer compatibility is still an issue for some parts of the organization.

- We need BPA wide performance indicators.

- We need real-time financial and budget information even if it is not $100 \%$ accurate.

- IRM is better since the reorganization....acquisition of hardware and software has improved. 
- IRM has moved away from its gatekeeper role, not as confrontational.

- Software standards for personal computers are set too high....we need to set minimum standards and allow people to order additional software as needed.

- The networking effort is good.

- One page summaries of programs (content) and their status would be excellent for us and our customers.

- Most information is still too detailed.... needs to be no more than two or three pages.

- We need customer profiles.

- Information requirements vary depending on what is hot and what is not.

- If issues are hot in the community, in the media, or politically, information must come immediately from the program Office.... this information needs to be on-line all the time for us and our customers.

- Installation of local area networks (LANs) in the Area Offices have improved communications.

- There has been no progress in reducing data requirements since IRM.

- If new systems are going to be added, that's good, but, old systems need to be dropped.

-Areas do not care about information by Office.... summaries and other reports need to be by programs.... that is what the customer sees. 
- Most manage by exception, that is they devote most of their time to events or situations which are out of the ordinary (the $80 / 20$ rule, $80 \%$ of the business gets $20 \%$ of the attention, and $20 \%$ of the business gets $80 \%$ of the attention).

- Most of management's time is spent acquiring information.

- Information reduces uncertainty.

- Politically sensitive issues raise uncertainty levels.

- Most managers trust information more after their staff has examined, verified and generally massaged it.

- Managers have staff massage information because there may be hidden agendas or they simply distrust data acquired where there is no accountability for the condition of the data.

- Improve the legibility of PACS (personnel, accounting and costs system).

- Information analysis is more important than more information, we have enough information.

- Managers use contacts, inside and outside, to scan the environment and customers for problems.

\section{Interview Findings}

Findings from the interviews are summarized in the following discussion. Both pretest and posttest interview findings are combined to create a composite of the opinions of BPA executives and their information. Some of the analysis compares pretest and posttest results 
and some of the findings are general observations about the data from the interviews. Each of the pertinent findings from the interviews is examined for relevance to the direction of IRM.

First, an idea of how BPA executives manage and use information can be drawn from the interviews. Executives manage by exception; that is they give much of their attention to parts of the organization that are not functioning well. Less of their time is spent dealing with parts of the organization that are doing fine.

BPA executives are constantly looking for information. They gather information from every available source, inside the organization and outside the organization. Inside of BPA they get information from staff, personal contacts, each other, and occasionally from corporate databases.

Executives prefer personal contacts for information because individuals can be queried in-depth for information on the spot. This provides the necessary depth to understand information without going to several sources.

\section{Internal Information}

Executives prefer personal contacts for information. Internal business environment scanning is provided through financial, budget, staffing, program and project information. This information is provided in the form of staff reports, briefings, and personal contacts within BPA. 
Managers also use subject experts to help them make decisions. Subject experts and those with lengthy experience in BPA provide expertise which constitutes corporate memory. No automated record system is used to recall information on previous decisions. As experienced personnel retire and experts leave the organization, corporate memory goes with them.

Most of the management's time is spent acquiring information. They acquire information to reduce uncertainty. Politically sensitive issues define most of the urgent information needs. Politically sensitive issues are most often mentioned as part of the twenty percent of business that receives eighty percent of management's attention, ${ }^{156}$ Therefore, by its own report, management spends eighty percent of its time acquiring information to reduce uncertainty, most often on politically sensitive issues.

Issues of trust arise again and again in the interviews. All executives mentioned that they had their staff "massage" the information before they looked at it. "Massaging the information" means that staff members take information from various sources around the organization and assemble, re-compute, and reformat it from the perspective of the Office or sub-organization they work for. More than one manager said specifically that he had his staff handle the information and it was due to a degree of trust. Executives are simply more comfortable with 
information which has been examined by their staff. This could be true for two reasons. First, executives have a long standing relationship with staff based upon daily interaction. Second, staff are accountable for what they provide. Information obtained directly from a computer system without staff changes is not considered trustworthy or accountable. Further, it is difficult to find one individual who is accountable for the information. In the eyes of executive management at BPA, without accountability, the value of information is decreased. With accountability, the value of information is increased.

In situations where uncertainty is high, additional information is needed. This fact is brought out by comments like, "distrust increases reporting requirements." Where this statement seems to apply most is in the Area Offices of BPA. The Area Office's comments indicate that much of their administrative staff spends too much time with "constant and duplicate data requirements" (requests for information).

Field office executives identified another problem in interviews. Area Office executives deal in programs rather than Office or project issues. The problem arises because little information is available by program. This puts Area Office personnel in the position of developing information about programs from several sources. Area Offices want information by program, about programs, and summarized by program because programs are what the customers see and how the Area Office does business. 
Generally, BPA executives want to look at a single page summary which conveys information using graphs as much as possible. Executives state that there is too much numerical data, reports are too long, and there are no standards for data. Consequently, executives are never quite sure of what they are looking at.

An off shoot is the impression that there are no data priorities. Therefore, executives are not sure of what is important and what is not. Comments like, "there is too much data", "BPA has enough data but we need focused data/information", and we are, "waiting for the new Administrator to set priorities" indicates a lack of focus for information. These comments all point to un-prioritized information.

Prioritization was mentioned with more emphasis in the posttest interviews than in pretest. Executives want the Administrator to set business priorities and to list several topics of constant interest. In this way, they felt, that it would be easier for them to keep constant tabs on information they truly need.

\section{External Information}

Information outside of BPA was not often mentioned. However, sources outside BPA were mentioned. Without exception, all interviewees reported using newspaper clippings, the news in some form, and Clearing Up, an industry publication. These sources, combined with other professional publications, customer contacts, and contacts within the industry, provide much of the scanning of the external environment. External scanning is useful but has not changed from pretest to posttest. 


\section{Information Successes and Shortcomings}

Interviews indicated that there are two areas of positive change since the establishment of IRM, acquisition and connectivity. Both areas are considered important. Acquisition of personal computers and software have improved. When the IRM was established, acquisition of computer equipment could take as long as a year and a half. When the posttest interviews were done, acquisition was down to about 30 days. Interviews pointed out the success of acquisition and the fact that the IRM no longer "acts as a gatekeeper", controlling the acquisition of computers and software.

The second area of improvement is connectivity. Connectivity, the ability to connect one computer or device to another, is improving according to interviews. IRM is presently installing LANs (Local Area Networks), throughout BPA. Posttest interviews all mentioned the positive contribution of LANs to the work environment.

Interviews also showed three areas which need improvement: major systems, database consolidation and prioritization (previously discussed). Major systems, large mainframe operated computer programs, are viewed by interviewees as having not changed since the establishment of IRM. Major systems, particularly financial and budget systems, are seen as illegible and untimely. Some of the executives 
stated that no computer system matters if the financial and budget systems are not right.

Databases are another topic which was raised in interviews. Many of the managers felt that database standards and consolidation is of importance. "There is too much data", "What we need is focused data of high quality not more data" and "We need standards and qualifications for data, if the data already exists or does not qualify then don't put it in the database", were comments indicating the need for database consolidation. Without database consolidation many databases contain the same data. The question then becomes which data is official, most trustworthy, and why are we spending so much time keeping up all these databases?

\section{Combined Analysis}

Frequency analysis points out a couple of significant differences in the ways that information is received. First, middle managers reported in pretest that they received $65 \%$ of their information in hard copy reports. Posttest reports showed that $53 \%$ of the information was received in hard copy reports, a difference of $12 \%$. There was a slight decline in the way middle managers preferred to get information in hard copy reports, $43 \%$ in pretest and $40 \%$ in posttest. So, there was a difference of $22 \%(65 \%-43 \%)$ in pretest and $13 \%(53 \%-40 \%)$ in posttest between what managers wanted in hard copy reports and what they received. 
Middle managers reported that they receive information about three percent of the time in some electronic form (electronic data or floppy diskette) in the pretest. In the posttest they reported getting electronic information about five percent of the time. The respondents prefer to get electronic data $18.1 \%$ of the time in pretest and $30.9 \%$ in posttest, an increase of about 13\%. Clearly, respondents of the posttest prefer to get information increasingly in the form of electronic information.

A surprising change was that about $13.5 \%$ of the respondents got their information from staff work in both pretest and posttest. However, they preferred to get their information from staff work only about eight percent of the time in pretest and only about two percent of the time in posttest. So it appears that middle managers would like to shift the sources of information that they get in hard copy form to electronic data and they really prefer to get the information directly, not from staff.

Even so, respondents reported that about half of the time they had staff check the information they received to make decisions. About a third of the time staff checked information provided to others for decision making. This was unchanged in both pretest and posttest. So, there appears to have been a lot of duplicate information checking, if one manager's staff checked the information provided and the receiving manager has his/her staff also check the information. There was a subtle distinction between where information comes from, where managers preferred information to come from (see above), and checking 
the information to "massage" it. Considerable staff time was spent checking and rechecking information. So, staff "massage" the information received to make decisions about half the time, they "massage" information sent to others for decision making about a third of the time, and they spend about $13 \%$ of their time just checking information for all purposes.

Interviews indicated that staff were adding valuable "trust" to the information when checking or "massaging" it. Executives reported that they used the information to make decisions for problematic parts of BPA. They spent most of their time doing so. Executives also reported that this was especially true of information used for making politically sensitive decisions.

Middle managers whose responses were recorded in questionnaires reported directly to executives whose responses were recorded in interviews. Middle managers were closest to the origin of corporate information input into data systems for reporting to executives. Executives got their information from their middle managers. 


\section{CHAPTER VI}

\section{CONCLUSIONS}

This study used questionnaires and interviews to evaluate the link between changes in a bureaucratic organization, the Bonneville Power Administration (BPA), and the installation of an information resources management (IRM) organization. The purpose of the evaluation is to determine if the installation of the IRM organization successfully made a difference in information supplied to decision makers, thereby, changing the quality of organizational decision making and the organization. The nature and extent of change in information was determined through statistical and content analysis of the data. Conclusions are based upon the findings and analyses from the study, along with ideas contained in literature.

Evaluations of information resource management organizations are difficult. First, it is hard to define the term "information". Everyone defines the term differently, according to his or her needs. As the literature on information management states, corporate attempts to define information in an operational way do not often meet their goal, i.e., to supply information for decision making. ${ }^{157}$ In this case, every opportunity has been given to those who use information to define it for themselves.

157 Kelleher, J., Tackling Information Management, Business Computer Systems, pg. 65, October 1985. 
Regardless of where the information is used in private industry or a public bureaucracy, information organizations do not exist in a vacuum. Organizations that are responsible for information do not exist merely to create self-serving products. Information is used to make decisions which alter organizations. This study has examined information in a bureaucratic environment. Now conclusions can be drawn related to the three questions; is the information better; and, if so, why is the information better; and, finally, what are the effects of the IRM organization?

\section{Is the Information Better?}

Statistical analyses of the questionnaire data shows that a portion of the information has improved for middle managers. Here is where the information middle managers use has improved.

Question "A": Is information received from others to support decision making better? The answer is yes for the following categories. ${ }^{158}$

\begin{tabular}{|l|l|}
\hline Categories & $(+/-) \%$ change \\
\hline Useful & $+5 \%$ \\
\hline Complete & $+6 \%$ \\
\hline Timely & $+4.9 \%$ \\
\hline Relevant & $+6.9 \%$ \\
\hline Format & $+8.7 \%$ \\
\hline Frequent & $+5.1 \%$ \\
\hline
\end{tabular}


Question "B": Is information supplied to others to support decision making better? ${ }^{159}$ The answer is yes to the following categories.

\begin{tabular}{|l|l|}
\hline Categories & $(+/-) \%$ change \\
\hline Useful & $+6.8 \%$ \\
\hline Timely & $+5.8 \%$ \\
\hline $\begin{array}{l}\text { Outside } \\
\text { Requirement }\end{array}$ & $+11.9 \%$ \\
\hline Frequent & $+1.6 \%$ \\
\hline
\end{tabular}

Question "C": Is information the respondent would like to support decision making better? ${ }^{160}$ The answer is yes to the following categories.

\begin{tabular}{|l|l|}
\hline Categories & $(+/-) \%$ change \\
\hline Complete & $+23.8 \%$ \\
\hline Timely & $+32 \%$ \\
\hline
\end{tabular}

Question " $\mathrm{D}$ ": Is information the respondent does not need to support decision making better? ${ }^{161}$ The answer is yes for the following categories.

\begin{tabular}{|l|l|}
\hline Categories & $(+/-) \%$ change \\
\hline Complete & $+23.1 \%$ \\
\hline Accurate & $+23.6 \%$ \\
\hline
\end{tabular}

159 Based on information contained in Table 4.9, pg 105.

160 Based on information contained in Table 4.10. pg. 105.

161 Based on information contained in Table 4.11, pg. 106. 
So, it can be said that categories displayed in these tables are improved information according to respondents surveyed in the questionnaire (middle managers). Further, we can tell where the information improved by examining budget classification results:

\begin{tabular}{|l|l|}
\hline Overhead Management & $37.5 \%$, \\
\hline Overhead information & $12.5 \%$, \\
\hline Personnel information & $18.8 \%$, \\
\hline Budget information & $9.4 \%$, \\
\hline System maintenance & $3.1 \%$, \\
\hline Transmission system design & $9.4 \%$, \\
\hline Power scheduling information & $6.3 \%$. \\
\hline
\end{tabular}

No changes were identified in budget classifications of accounting, system operations, information resources, planning council, power marketing, energy resources, or support services.

By examining the findings we know what changed, how much it changed, and when the change occurred (during the test period). Exactly who changed as a result of the improved information cannot be surmised from the questionnaire data analysis. We can surmise that the quality of middle manager's decisions changed because they report that information has improved, but this hypothesis will require further study. Why the information changed is the focus in this study. There are 
several possible reasons for improved information. Interviews and literature give some clues as to why.

Why is the Information Better?

First, time alone could account for the changes. As BPA managers grow accustomed to information in a particular way or format, or develop alternative sources of information, the quality of information would seem to improve. Interviews indicate some change in information from staff, but not from corporate systems. So, the fact that information desired for decision making changed during the test period might indicate either increased comfort levels or new systems for information. Thus, one might be conclude that some alternative sources of information are being used or that managers are using the same information with more comfort.

The data collected through the interviews, however, did not indicate that management developed alternative sources or grew accustomed to the sources they found elsewhere. On the contrary, executives reported using the same sources of information in posttest that they used in pretest. They also complained of the same problems with information. Executives did note that acquisition improved and connectivity is changing. Large database applications have not changed.

Another possible explanation for the changes that occurred is that the organizational change itself, from the old organization to IRM, is responsible for improvement in information. The only major 
organizational change during the test period was the move of the Division of Information Services (DIS) to IRM. The change moved computing from the second layer of the organization, the Office of Management Services, to the top layer, the Office of the Administrator. The Administrator's Office carries more political clout than the Office of Management Services. Additionally, organizations in the Office of the Administrator are less likely to become involved in turf battles because the Office of the Administrator has to compete less for resources. Thus, the organizational change has prompted a perceived improvement in importance in information resources activities.

Comparison of decisions made by the IRM organization management and the theoretical concept of IRM are difficult. In theory, IRM is an all encompassing organization which manages computing, telecommunications, printing, library, records management, and in some cases graphic arts; all the functions necessary to manage information. However, in BPA the IRM organization manages only computing and recently telecommunications. Therefore, the theoretical IRM and BPA's IRM are different. BPA's IRM does not contain all the functions considered necessary for information management. It is, therefore, difficult to credit information improvement to the IRM organization. Only the mission of IRM and decisions made by IRM's management can distinguish it from previous or other ADP organizations.

It is important to note that the other sub-organizational parts of BPA did not stand still during the test period. Their initiatives may have 
had an effect on the improvement of information in BPA. However, the interviews did not indicate such an effect. The primary improvements by IRM are reported and supported in follow-up interviews.

A likely conclusion then is that improvement in information at BPA is primarily due to decisions made by IRM management and IRM's organizational location in the Office of the Administrator. Those IRM management decisions which have had an impact are a relaxed computer acquisition policy, not being the gatekeeper for ADP funds, and the adoption of policies to move toward a LAN environment.

Interviews point out that IRM set policies which maintain standards for acquisition by defining standards of compatibility and software design. This allows Offices to acquire their needed ADP equipment in any configuration needed, ordering the appropriate hardware and software for their work. The result has been a significant increase in the number of personal computers in BPA and a significant decrease in the time required to acquire a personal computer.

The second policy which had impact was the move toward LAN's. Several interviewees mentioned their satisfaction with the decision. LAN's give each Office the ability to share information within and between Offices without accessing the mainframe computer. LAN's provide an information network controlled by each Office or Area. 
Information networks are essential to any large organization. Information networks existed before computerization. As Downs points out, formal information networks are not efficient for daily business. Subformal information networks are where most communication occurs in a bureaucracy. While mainframe computing provides one method to communicate, it requires the information to pass from one computer user to the computer and back to the information receiver in an inflexible channel. As for the information network models (Tables 2.1, 2.2, 2.3, and 2.4), the LAN's most closely resemble a subformal information network. Therefore, the decision to move to a LAN environment has created a technological symbiosis. The way communication and information move in a bureaucracy is being supported through automation. The automation network resembles the normal subformal communication network. Since the automation network resembles the subformal communication network, communication is supported as it is found, without adding complexity.

\section{Effects}

Much of what Anthony Downs writes applies to this situation. His work helps to understand the environment in which management and decision making exist. He writes that decision making has limits because: time is limited, only a limited number of factors can be weighed, priorities compete, information is limited, information costs, and some information is not attainable. ${ }^{162}$ All of these factors affect the decision process. In short, information must flow to a decision maker 
whose priorities change depending upon motivation to change or alter the environment. In addition, sometimes the information flow is distorted because individuals tend to: maximize themselves, be biased toward some policies, serve their own interests, and seek their own goals. The result is that timely, accurate, high quality information is at a premium.

Downs states that information in a bureau is communicated through formal and subformal communication networks which arise from formal and informal authority structures. Formal authority and communication networks are official channels for information based upon organizational charts, directives, and other official rules. ${ }^{163}$

Mintzberg writes that formal information is too limited and general for decision making because it is often too aggregated, too late, and too negotiated to be reliable. ${ }^{164}$ Thus, organizational "by-passes" occur. The "by-pass" is an informal authority structure which flattens the organizational structure and reduces the number of communication steps. ${ }^{165}$

Informal authority and subformal communication, and therefore subformal information, are based upon need. Some subformal communication and information exists on informal and formal lines of

\begin{tabular}{ll}
\hline 163 & Downs, pgs. 113-115. \\
164 & Mintzberg, pgs 73-74. \\
165 & Downs, pgs. 123-126.
\end{tabular}


authority and communication networks to fill gaps. Most subformal communication networks fill information needs.

Downs points to five characteristics of subformal communication channels; "1. A high degree of correlation exists between subformal communication and interdependent activities, 2. High degrees of uncertainty proliferate subformal channels, 3. In times of crisis subformal channels are more often used because they are faster. Top managers search for information during a crisis tends to rely on subformal channels, 4. Organizational conflict curtails subformal communication, 5. New or changing organizations have fewer subformal channels than old organizations."166

Consequently, formal communication structures provide very limited information for decision making. Formal communication structures are based upon lines of authority and are almost identical to lines of authority in formal organizational charts. Informal or subformal communications provide most of the avenues for communication. Subformal communication cuts across organizational lines and provide information most often used in a bureaucracy.

Based on Down's hypotheses, an organization whose managers and executives spend most of their time dealing with problem parts of the organization depend on subformal communication most often. BPA managers and executives clearly manage by exception, that is they spend

166 Downs, pgs 114-115. 
much of their time looking for information to deal with problem parts of the organization. Further, if subformal communication is used regularly, then information from these subformal communications and informal authority structures is used to make decisions most of the time. The only problem is that subformal communication is uncertain. Yet, executives constantly gather information to reduce uncertainty, particularly in politically sensitive situations. So, there appears to be a paradox. Information in BPA is gathered to reduce uncertainty in the decision process, but the information is uncertain and tentative because its source is informal.

How did this paradox happen and what are its implications? Interviews tell us that large mainframe computer systems in use at BPA (accounting system, financial systems, budget systems) are not used often or trusted by executives. Executives state that the reports from these systems are untimely and often not useful. In short, mainframe systems are too slow to be useful. If mainframe systems attempt to mirror or represent a formal channel of communication, then, according to Mintzberg, the communication is too aggregated, too late, and, too negotiated for decision making.

Instead, executives depend on staff and personal contacts for information. In The Organization Man, William $\mathrm{H}$. Whyte contends that bureaucratic organizations serve as substitutes for community. Whyte's observations imply allegiance to bureaucracy, a bond. Within the bond are the threads which create social networks coming from those who 
believe in belonging. Though bureaucracies are created to perform functions in society they also serve as community. And, within the community of bureaucracy are the social networks which do not follow the corporate structure. ${ }^{167}$

Consequently, the primary way timely and useful information can be otherwise acquired is to keep duplicate systems in each executive's organization. There is no other way to acquire the information. Data requirements (data needed to compile information) are needed both by the official mainframe systems and by executives' staffs for unofficial systems. Therefore, a lot of time is spent filling duplicate data requirements as reported in the interviews. Additional data requirements also mean additional reporting requirements. Interviewees state that Area Offices see this as distrust. But, it appears to be distrust of information, not distrust of the Area Office organizations by Headquarters organizations.

Since formal communication cannot provide the information needed for decision making, then executives and managers must rely on informal channels of communication, even if they are unreliable. As Downs points out, informal channels of communication are networks established over long periods of time. These networks form the structure of informal of authority and are used to get information.

167 Whyte W., The Organization Man, Simon and Schuster, New York, N.Y., 1956. 
Interviews indicate that personal computers (PC's), local area networks (LAN's), and connectivity were most often mentioned as improvements since pretest. PC's, LAN's, and connectivity make sense as a specific answer to the question, why is the information better?

Mainframe computer systems provide information that is just like information otherwise communicated formally. On the other hand, PC's and LAN's allow communication to anyone who is connected to the LAN without going through a central system. PC's and LAN's automate existing informal channels of communication. These automated informal connections are supported by electronic mail, shared files, and multiple data entry points or whatever tools the work group decides to make. These informal channels exist with formal approval because they provide useful information. However, the systems they support are not approved. In short, the addition of PC's and LAN's allow the existence of unblessed information systems which supply information to decision makers in a way that mirrors the pre-existing informal structures.

This leads to the research question, does the information research management (IRM) organization make a difference in BPA? In this case, I believe, based upon this research the answer is no. Here's why.

First, if our conclusion is correct, any organization in charge of computer equipment with the authority to purchase, distribute, and install PC's, as well as implement LAN's could have made the same difference. While, in this case, IRM did purchase, distribute, and 
implement PC's and the LAN's, the activity is not exclusive to the IRM organizational form. The organization IRM replaced could have done the same thing.

Second, information necessary to manage BPA (budget, finance, and accounting) has not changed. IRM has not managed the information needed to make corporate management decisions. Instead, IRM has supported the informal information network. If any conclusion can be drawn from the support of the informal network, one could as easily conclude that information management at BPA is worse than before IRM because IRM gave license to the proliferation of informal systems without changing the primary corporate information business systems which are operated on the mainframe computer. Thus, IRM is indirectly supporting duplicate data and reporting requirements.

Third, as staff continue to use informal networks to acquire information, it will become routine. The informal automated network of communication will become the accepted norm. Therefore, while some reliability will be gained through computerization of informal communications, uncertain and tentative informal channels of communication will become ingrained and more difficult to replace with corporate wide systems.

Duplicate data reporting and systems will continue to be the norm unless action is taken to improve mainframe computer systems or to take advantage of the informal network to develop corporate data. 
Meanwhile, staff will continue to gather data, check and recheck data, and "massage" data to the satisfaction of executive management.

If automated informal networks become routine, then middle management may be rendered helpless. As Downs points out, informal channels of communication create organizational "by-passes". These "by-passes" tend to flatten the organization structure. Therefore, if information requirements can be filled in lower parts of the organization, then middle management will not be needed as information conduits, a functional part of the organization.

Finally, as information used to make official decisions mingles with informal information it becomes impossible to distinguish between official informal information and unoffical informal information. A request for information to satisfy unofficial curiosity carries the same weight as a request for official information required by policy and decision makers. The result may be curtailed informal information traffic, or the development of ways to distinguish between official and unofficial requests.

\section{Research}

This research is a little different than traditional information studies. The difference is in the approach. Usually, information organizations are researched using approaches which focus on hardware, software, or systems design. This study used traditional social research methods to evaluate BPA's information organization. 
Social research and evaluation is often used in social settings where it is difficult to define precisely and clearly what is being measured. Evaluation research tries to bring objectivity into situations where products or services are very personal and often emotionally charged. As demonstrated in this study, information is personal. Indeed, information does not exist except in the mind of the one who interprets data, thereby creating information.

This raises the question of whether this kind of research and evaluation is an appropriate tool for measuring change in information resource management? Clearly, IRM serves clients. Clients receiving services from IRM are just like clients of other services. Some are served well and some are not. Research evaluation's purpose is to help decision makers come to grips with what parts of a program or organization work and which parts do not. I believe that this approach has worked well.

Social research methods could also be used to examine other topics. For example, the organizational "by-passes" discussed by Anthony Downs have many implications in light of the electronic information community. Understanding electronic social networks and the roles they play, and will play, is important. Additionally, the future of large mainframe computers is questionable. How the computing environment supports information needs and how the responding social network adapts needs further study.

And, finally, this study assumes that improved information equals improved decision making. But, far too little is known about information 
and decision makers interpretation of it. The quality of information, the quantity of information, and the potential for increased speed of information are all important factors. What are the limits of information that a decision maker's mind can handle, given the state of information? How can the limits be avoided? Are there better ways to present information that can be better incorporated into the decision process? These topics call for future study. 


\section{BIBLIOGRAPHIC REFERENCES}

Argyris, C. Overcoming Organizational Defenses: Facilitating Organizational Learning, Allyn and Bacon, Needham Heights, MA., 1990.

Arthur Young Information Technology Group, The Arthur Young Practical Guide to Information Engineering, Wiley, New York, N.Y., 1987.

Atre, S., Information Center: Strategies and Case Studies, Atre International Consultants, 1986.

Babbie, E., The Practice of Social Research, 2nd ed., Wadsworth Publishing, Belmont CA., 1979.

Bedell, E., The Computer Solution: Strategies for Success in the Information Age, Dow Jones-Irwin, 1985.

Beer, M., Eisenstat, R., Spector, B., The Critical Path to Corporate Renewal, Harvard Business School Press, Boston MA., 1990.

Beyer, D., "Information Management", Inform, December, Pg. 16-18, 1987.

Bogan, R. and Taylor, S., Introduction to Qualitative Research Methods: A Phenomenological Approach to the Social Sciences, Wiley and Sons, New York, N.Y., 1975.

Bradford, L., Design for Decision:Guidelines for the non - Data Processing Manager, Consulting Course Material by Bradford, L., 1985.

BPA internal study to determine the extent of ADP and its location in the agency. Termed the Pre-A-76 Review, 1989. All BPA executive were interviewed by S. Kallio and R. Perrin.

Bryce,M. and Bryce, T., The IRM Revolution: Blueprint for the 21st Century, MBA Publications, Palm Harbor Florida, 1988. 
Burk, C. and Horton, F., InfoMap:A Complete Guide to Discovering Corporate Information Resources, Prentice-Hall, Englewood Cliffs N.J., 1988.

Campbell, D., and Stanley, J., Experimental and Quasi-Experimental Designs for Research, Rand $\mathrm{M}^{\mathrm{C}}$ Nally College Publishing Company, Chicago IL., 1963.

Chen, Ye-Sho, "Analysis of Lotka's Law: The Simon-Yule Approach", Information Processing \& Management, Vol. 25, No. 5, 1989.

Connor, D., Computer Systems Development:Strategic Resource Information Planning and Execution, Prentice-Hall, Englewood Cliffs N.J., 1988.

Denvir, K., "Winning at the Information Game", Enterprise, winter, 1991.

Devaux, S. and Milgram, S., "Pushing Down Decision-making: Organizational flattening calls for upgrading the skills of IS specialists", Computer World, vol 23, Dec. 1989

Downs, A., Inside Bureaucracy, Little, Brown and Company, Boston MA., 1967.

Earl, M., Management Strategies for Information Technology, PrenticeHall, Englewood Cliffs N.J., 1989.

Emberton, J. and Mann, R., "Methodology for Effective Information System Planning", Information and Technology, Vol 30, No. 4, 1988.

Endicott, J., "Getting Data with Integrity", Enterprise, winter, 1991.

Ermann, D., and Lundman, R., Corporate and Governmental Deviance: Problems of Organizational Behavior in Contemporary Society, Oxford University Press, New York, N.Y., 1978.

Federal Evaluations: A Directory issued by the Comptroller General, 1984 Congressional Sourcebook Series, U.S. General Accounting Office, Information Handling and Support Facility, Gaithersburg MD, 1984.

Federal IRM Planning Support Center, The IRM Organization:Concepts and Considerations, Government Printing Office (GPO), 1989.

Festinger, L., A Theory of Cognitive Dissonance, Stanford University Press, Irvine CA., 1957. 
Fitz-Gibbon, C. and Morris, L., How to Design a Program Evaluation, Sage Publications, Newbury Park CA., 1987.

Friedman, M. and R., Free to Choose, Avon, New York, N.Y., 1980.

French, W., Bell, C., Zawacki, R., Organization Development: theory, practice, and research, Business Publications, Inc., Dallas TX., 1978.

Gallo, T., Strategic Information Management Planning, Prentice-Hall, Englewood Cliffs N.J., 1988.

Garvin, A. and Bermont, H., How to Win with Information or Lose without it, Bermont Books, Washington D.C., 1980.

Glaser, B. and Strauss, A., The Discovery of Grounded Theory: Strategies for Qualitative Research, Adline Publishing, Chicago Ill., 1965.

Golden, P., The Research Experience, F.E. Peacock Publishers, Inc., Itasca IL., 1976.

Gray, P., ed., The Management of Information, Dryden Press, 1989.

Head, R., Planning and Implementing Information Resources Centers for End-User Computing, Information Sciences, Vol. 3, pg. 186, 1985.

Hoaglin, D., Light, R., McPeek, B., Mosteller, F., Stoto, M, Data for Decisions, Abt Books, Cambridge MA., 1982.

Horton, F., Information Resource Management:Concept and Cases, Association for Systems Management, 1979.

Humphrey, W., Managing for Innovation: Leading Technical People, Prentice-Hall, Englewood Cliffs NJ., 1987.

Hussain, D., Information Resource Management, Donna Hussain and K.M. Hussain, 1988.

IE/IMPACT, Information Engineering Management Guide, Pacific Information Management, Inc., Santa Monica CA., 1989.

Information Resource Management Course book by Manus Professional Services, Olympia Washington, W. Smith Instructor, 1986. 
Jackson, T., Measuring Management Performance: A Developmental Approach for Trainers and Consultants, Nichols/GP Publishing, New York, 1991.

Jones, J. and McLeod, R., "The Structure of Executive Information Systems: An Analysis", Decision Science, Vol 17, Pgs. 220-249, 1986.

Kanter, R., The Change Masters, Simon and Schuster, New York N.Y., 1983.

Kim, J., and Meuller, C., Factor Analysis: Statistical Methods and Practical Issues, A Sage University Paper, Beverly Hills CA., 1982.

Kim, J., and Meuller, C., Introduction to Factor Analysis: What is it and How to do it, A Sage University Paper, Beverly Hills CA., 1982.

Law, M.H., Guide to Information Resource Dictionary System Applications: General Concepts and Strategic Systems Planning, GPO/Institute for Computer Science and Technology, 1988.

Levitt, T., Thinking About Management, The Free Press, New York N.Y., 1991.

Loomis, C. (translator), Community and Society by Ferdinand Tonnies, Michigan State University Press, 1957.

Lytle, R., "Information Resource Management: A Five Year Plan", Information Management Review, Vol 3, No. 3, 1988.

Madnick, S., The Strategic Use of Information Technology, Oxford University Press, New York, N.Y., 1987.

Marchand, D., Infotrends:Profiting from Your Information Resources, Wiley, New York, N.Y., 1986.

Martin, J and Leben, J., Strategic Information Planning Methodologies, 2nd ed., Prentice-Hall, Englewood Cliffs N.J., 1989.

Martindale, D., The Nature and Types of Sociological Theory, Houghton Mifflin, Boston MA., 1960.

McCall, R., Fundamental Statistics for Psychology, 2nd ed., Harcourt Brace Jovanovich, New York, N.Y., 1975. 
Mintzberg, H., Mintzberg On Management: Inside Our Strange World of Organizations, The Free Press, New York N.Y., 1989.

Murphy, J., Getting the Facts: A Fieldwork Guide for Evaluators and Policy Analysts, Goodyear Publishing Inc., Santa Monica CA., 1980.

Ostaszewski, S. , Long-Range Strategic Planning for Information

Systems, American Management Association, New York, N.Y., 1989.

Palmer, R. and Varnet, H., How to Manage Information: A Systems Approach, ORYX Press, Phoenix Ar., 1990.

Parker, M. and Benson, R., Information Economics: Linking Business Performance to Information Technology, Prentice-Hall, Englewood Cliffs N.J., 1988.

Punset, E. and Sweeney, G. ed, Information Resources and Corporate Growth, Pinter Publishers/Consult Library, 1989.

Ricks, B., Information Resource Management, South-Western , Cincinnati OH, 1984.

Rosak, T., The Cult of Information, Pantheon, New York N.Y., 1986.

SAS User's Guide: Basics, version 5 Ed., SAS Institute, Cary, N.C., 1985.

Schlaifer, R., Analysis of Decisions Under Uncertainty, Robert E. Krieger Publishing Company, Malabar FL., 1978.

Stephenson, B., "Management by Information", Information Strategy: The Executive Journal, summer 1985.

Selig, G., Strategic Planning for Information Resources Management: A Multinational Perspective, Research Press, 1983.

Synnott, W. , Information Resource Management:Opportunities and Strategies for the 1980's, Wiley, New York, N.Y., 1981.

Synnott, W. The Information Weapon: Winning Customers and Markets with Technology, Wiley, New York, N.Y., 1987.

The Senior IRM Manager: Major Roles and Responsibilities as We move into the 1990's, GSA, 1989. 
U.S. Army Materials Command, Information Resource Management: Information Strategy for the 90's, DCS Command for Information Management, 1987.

Vickers, P., "Information Management in the United Kingdom:Barriers and Breakthroughs", IRM, Vol. 1, No. 4, Pg. 69-74, 1986.

Welcome to Information Resource Management in the Federal Government IRM, GSA, 1989.

Wiess, C., Evaluation Research: Methods of Assessing Program Effectiveness, Prentice-Hall, Englewood Cliffs NJ., 1972.

Wilson, J., Bureaucracy: What Government Agencies do and Why They do it, Basic Books Inc. 1989.

Wholey,J., Zero-Base Budgeting and Program Evaluation, Lexington Books, D. C. Heath and Company, Lexington MA., 1978.

Whyte W., The Organization Man, Simon and Schuster, New York, N.Y., 1956. 


\section{LIST OF ATTACHMENTS}

\section{ATTACHMENT ONE}

Interview Questions

ATTACHMENT TWO

Questionnaire

ATTACHMENT THREE

Bonneville Power Administration Organization Chart

ATTACHMENT FOUR

Information Resource Management organization chart and decision information.

ATTACHMENT FIVE

Raw Data Set

ATTACHMENT SIX

Frequency graphs of Pretest/Posttest by rating variables

ATTACHMENT SEVEN

Frequency graphs of Pretest/Posttest by rating variable and question

ATTACHMENT EIGHT

Frequencies of Pretest/Posttest by buget classification and rating variable

ATTACHMENT NINE

Statistical analysis of "NPAR1WAY" 
Attachment One

Interview Questions 


\section{Attachment One}

\section{Interview Questions}

We want to understand how information is managed (i.e., needs assessed and implemented). We want to learn how you get your information needs met.

- What information do you use?

- Is the information you use hard (a report, written copy) or soft (verbal report, personal contact)?

- Are you comfortable with the information you get (summarized appropriately, timely, too much or little)? 
- Where does the information come from?

How does the information get to you (delivery system)?

- Is the format you receive information in suitable?

- Is there a particular information source you find most useful? 
Attachment Two

Questionnaire 


\section{Management Information Assessment Questionnaire}

\section{Instructoons}

On the right side of this questlonnaire there are betters (A-D). numbers. and blank lines. The letters correspond to the
questions below and the numbers identify each blanik line.

Each of the following questions inquire as to the kinds of information you use to manage your organization (stafing budget inventory control. etc). Please list information and specilac report names when posstble.

Next check the box noxt to your enty if the report is different than originally supplied by an information systern falered or summarized by stafi). Once you have answered the questions please open this booklet and rate the information sources you have isted. Please do so carefully using the two scales provided inside $\alpha$ and $Y$ ).

When you have enished. please fold the questonnalre in half so that the address label on the back is vistble. then staple the questionnatre closed and place it in the intermal mall. The information you provide will help establish management information roquirements and help BPA leam to use information in a more constructive way. Thank you for your cooperation.

Please answer the foDoung questions stretly from a management perspective.

Please list information/data you need from others to make dectsions.

b. Nexi Lsi the information you enerate b support others docisions.

c. Niou Lsi the information that would be helpful in makung declsions Uat you cannol pe:

D Rrally. List the information you get but do not neod in decision makung

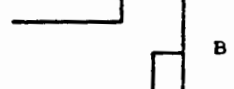




\section{Definitions and Explanations of Rating Factors}

Plesse use scale $X$ (shown below) to rate factors $1-8$.

1. Useful - The extent to which the information is approprtate and its with other information to support your work and decision making.

2. Complete - The extent to which the information satisfles all needs for dectsion-making from a single source rather than multiple sources.

3. Timely - The extent to which the information is supplied when needed.

4. Accurate - The extent to which the information is corroct and reliable.

5. Relevant - The extent to whuch the information can contribute to meeting the organization's goals and objoctives.

6. Ontside Requiremeots - The extent to which the information is used to satisfy requirement outside BPA.

7. Format - The extent to which the information is presented in a usable configuration.

8. Frequency - The extent to which you elther receive or provide Information with appropriate constance.

Please use scale $Y$ (shown below) to rate factors $\theta-10$.

9. Present Origin - What is the present source of origin of information you provide or recelve?

10. Preferred Oripin - Is there another origin for the information that is better than the way you provide or recelve $t$ now?

\begin{tabular}{|c|c|c|c|c|}
\hline \multicolumn{5}{|c|}{ Scales } \\
\hline $\mathbf{X}$ & & & $\bar{Y}$ & \\
\hline 0 & $\cdots \cdots$ & Don't know & & Source Origin \\
\hline 1 & - & $0 \%$ & & 1. Hardcopy Report \\
\hline $\begin{array}{l}2 \\
3\end{array}$ & & $25 \%$ & & 2. Electronic data/Information \\
\hline 4 & & & & 3. Floppy Diskette (5.25 or 3.5$)$ \\
\hline 5 & & $50 \%$ & & $\begin{array}{l}\text { 4. Periodical/library information } \\
\text { 5. Personal contact (verbal) }\end{array}$ \\
\hline 6 & & & & 6. Observatton \\
\hline 7 & & $75 \%$ & & 7. Hislorical/performance records \\
\hline $\begin{array}{l}8 \\
9\end{array}$ & & $100 \%$ & & 8. Staff work \\
\hline & & & & 9. Experience \\
\hline
\end{tabular}




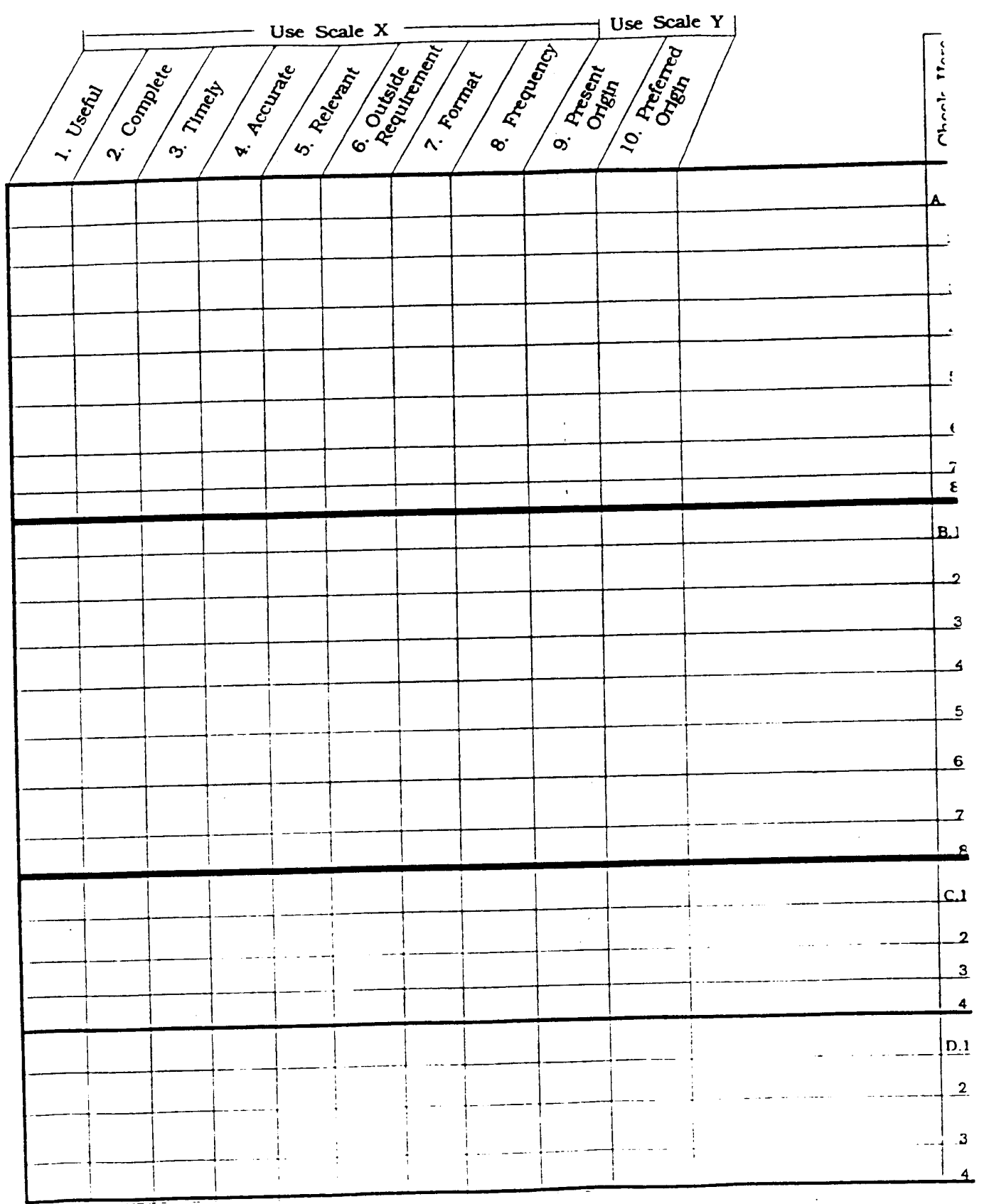


To: Marsha Ard Routing: AIA ISP Team No.

Comments: 


\section{Attachment Three}

Bonneville Power Administration Organization Chart 


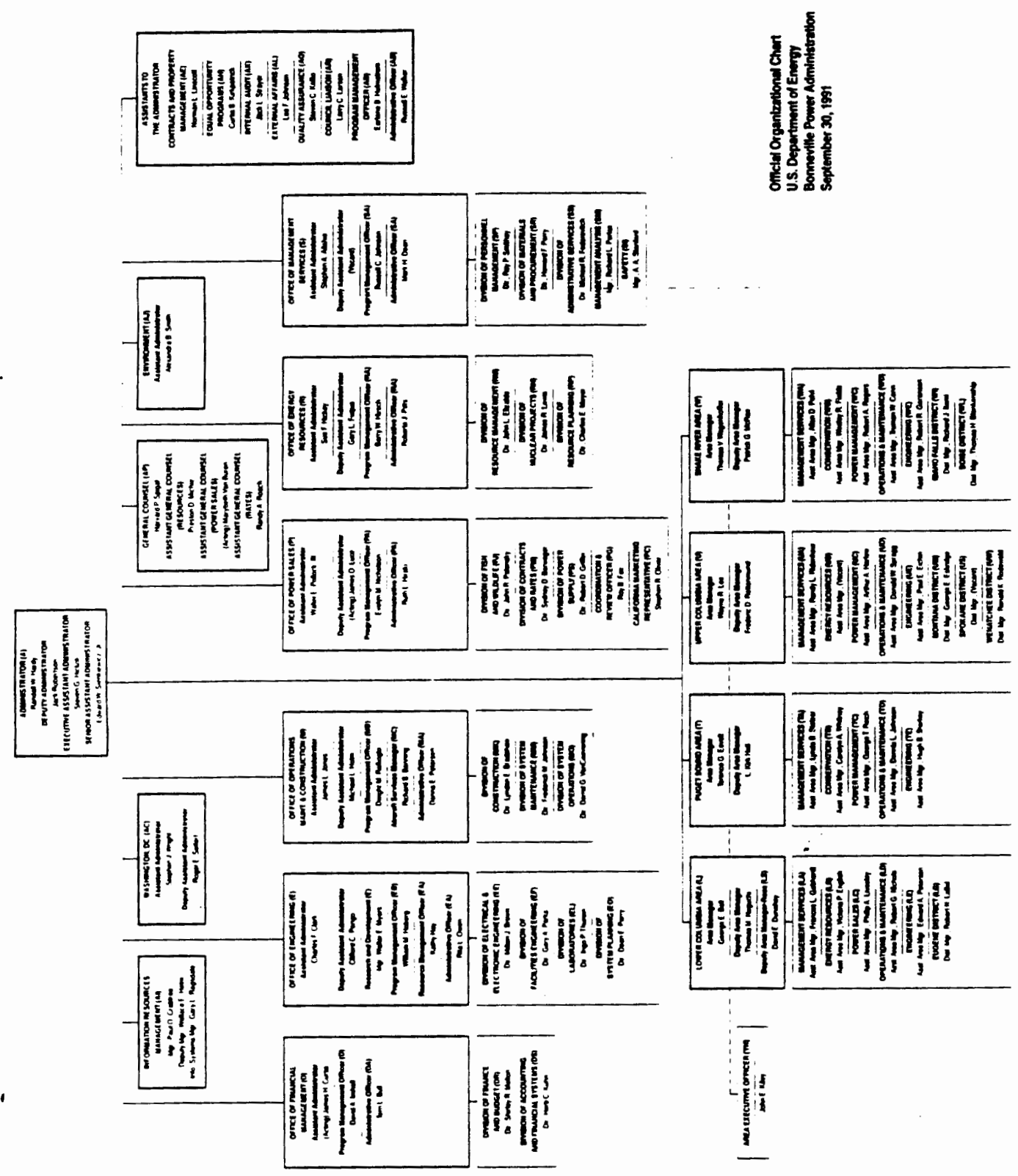


Attachment Four

Information Resource Management organization chart 


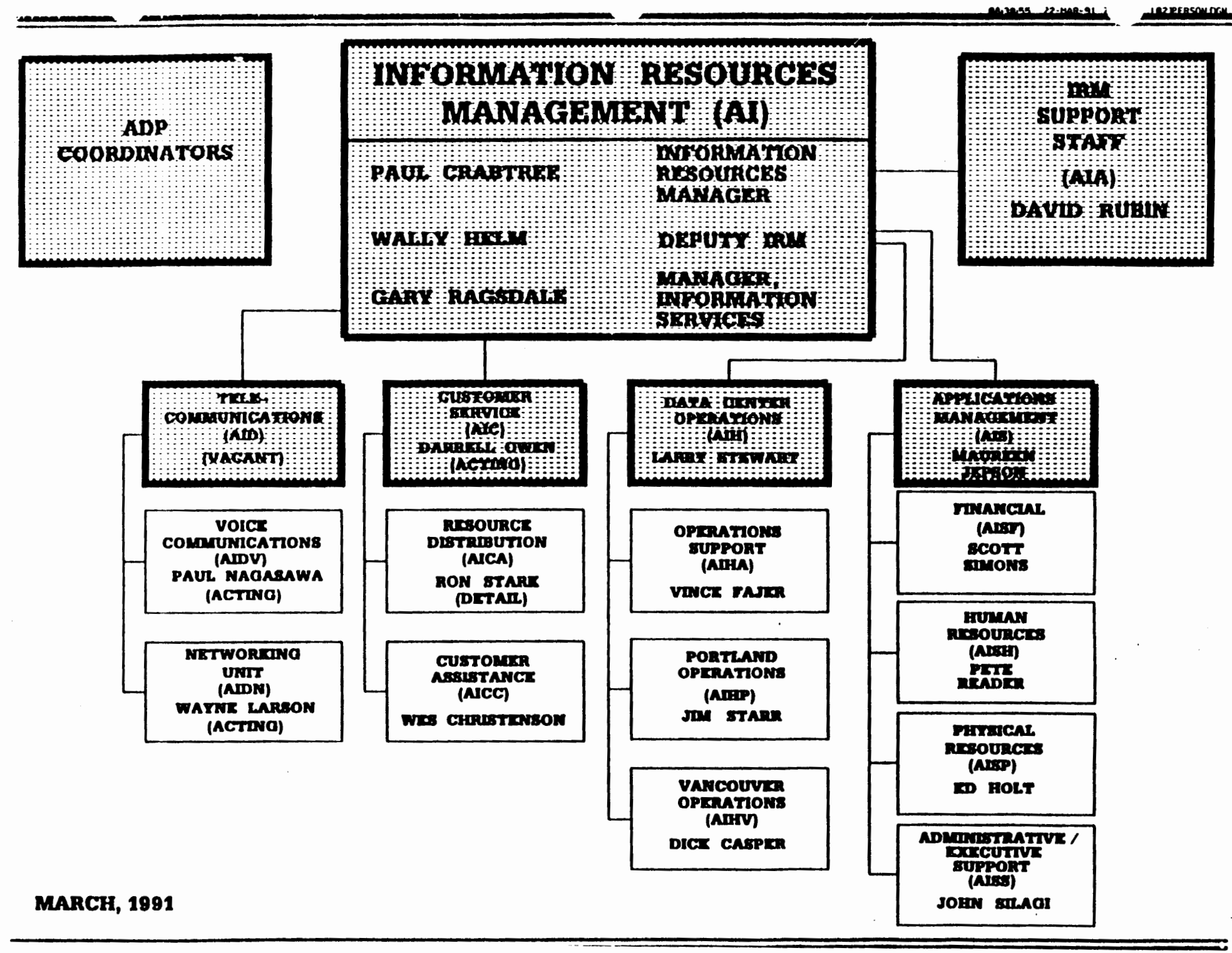




$$
22789
$$

CUSTOMERS

1. Top Management

\section{Expectations}

(1) Decision information

- Believable

- Understandable

- Accountable

- Verifiable

- Consistent

- Timely

(2) Cost reduction/containment

(3) No IG probiems

(4) Better communications (interface) (integrate)

(5) No customer complaints

(6) Reduction of duplication/redundant burden

\section{Agency Operations}

A. $O F M$

(1) Auditable

- Accurate

- Verifiable (traceable)

- Security

- Controlled (monitored)

(2) Agreement with financial regulations

(3) Under positive control (authorized/in the loop for everything): timely

(4) Procurement information 
B. ENGINEERING wants information on:

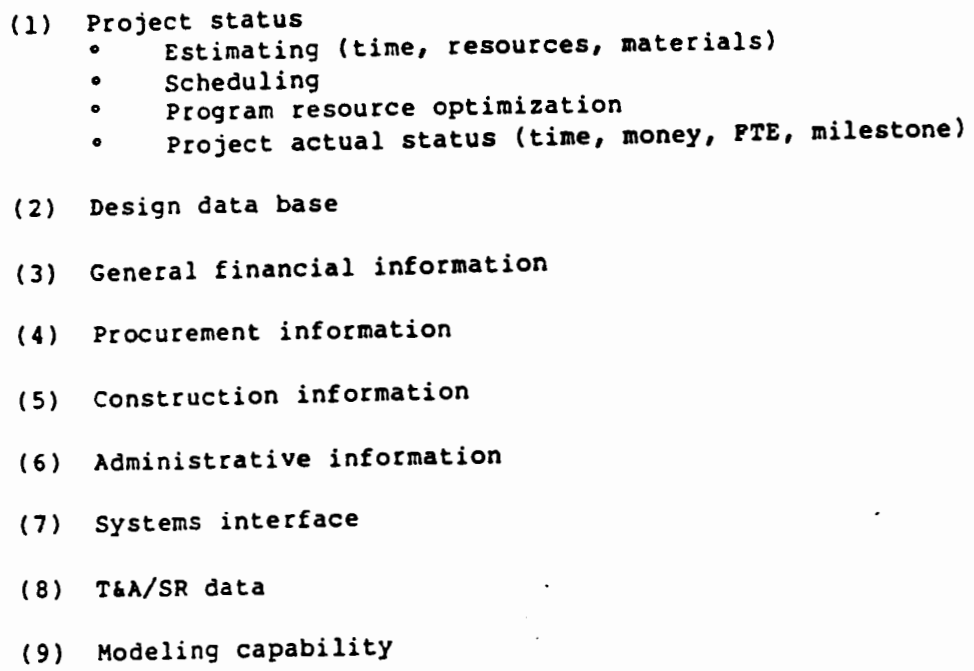

(2) Design data base

(3) General financial information

(4) Procurement information

(5) Construction information

(6) Administrative information

(7) Systems interface

(8) T\&A/SR data

(9) Modeling capability

c. OM\&C

(2) Independent development and operation... including minimal interface

(2) Actual financial data

(3) Detailed maintenance data

(4) TaA/SR data

(5) Procurement

(6) Inventory control

(7) Power system operational reports

\section{MANAGEMENT SERVICES}

(1) Administrative/personnel

(2) Procurement

(3) MEP

- Procurement tracking information

- Inventory control

- System equipment records 
E. ADMINISTRATOR'S OFFICE

(1) Legal data base

(2) Linscott - procurement information

(3) Environmental (3)

(4) External Affairs - summary Agency data

F. POWER SALES
(1) Modeling capability
(2) Resource information
(3) Economic data base/demographic, etc.
(4) WPB information
(5) Scheduling/operations
(6) Contracts
(7) Financial data
(8) Projects management
- Rates
- $F$ \&
(9) Procurement
(10) External customer information

G. ENERGY RESOURCES
(1) Conservation accounting
(2) Modeling
(3) Forecasting data
(4) Pinancial data
(5) Procurement data
(6) Power council 
H. AREAS
(1) All of the above
(2) Variability
(3) Independent development/technological solutions
(4) Less burdensome information and usable output
(5) Less duplication of $\mathrm{B} / \mathrm{W}$ (Power System Control and gen. purchase)

3. Regulators
(1) Long range plans on upside
(2) Lack of interfaces
(3) Lack of effective policies/accountability

4. DOE (administrative)
(1) Personnel
(2) Financial
(3) Procurement

5. Regional interests

(1) Summary agency data

6. Producers
(1) Scheduling information
(2) Planning (resource) information 
7. Federal agencies

COngress/DOE OMB/DOE

BERC

GSA

(1) Financial

(2) Procurement

(3) Timeliness

(4) Plant accounting

LB-VS16-1238C 


\section{CUSTOMER NEEDS/WANTS}

A. 10 Most Important Items

(1) Financial information

(2) Workload information

(3) Top managenent decision information

(4) Procurement/inventory information

(5) Administrative/personnel information

(6) Project status/design information

(7) Physical plant information

(8) Modeling and forecasting

(9) Summary agency data

(10) Audit trail

(Most effort? Which most affect company business?)

(11) Power systero operational reports

(12) Operations and maintenance information

Characteristics

- Consistent

- Accurate

- Timely

Verifyath

- Available

- Accessible

- Useable

seicese platien

Also: Delivery Systems

B. STRATEGIC ITEMS
(1) Workable systems
(2) Cost effective
(3) Interface of systems 
C. OTHER CONCERNS
(1) Independence
(2) Less burden
(3) Less duplication
(4) No interference with getting job done

VS16-LB-1238C 
BACKGROUND ON FORMATION OF THE IRM

Chronology:

1982-1987 Development of major systems (FMIS, MMS, PMIS, SMIS) generally characterized by cost overnuns, delayed schedules, and role/responsibility disputes between offices. Peter Johnson concerns about ADP management, DOE and Congressional oversight criticism, and heavy time commitment by Jura, Hickok, and other AAs on ADP steering committee. Doug Hansen directed to 'get a handle' on ADP cost and performance issues.

1987 Reorgenization of ADP function docided not to be a part of BPA-wide MEO because upcoming A-76 study of ADP fuaction would be a charce to 'do it right'.

1988 Major DOE audit criticism-concludes BPA financial system (meaning PACS, procurement, revenue systems, and obligations tracking parts of PMIS and other program systems) not in conformance with the intent or specifics of federal requirements, i.e. Core requirements. Jura veryconcerned; pledges fix. Kallio study starts work in earnest.

Kallio reports conclude exiting BPA approach to ADP duplicative, lacking in strategic planning, uncoordinated, behind in tochnology, and too narrow in scope-need an information function, not an ADP outlook. Proposes a 200-person organization inclusive of records, printing, library, management analysis, etc., plus all ADP.

Advertisement and selection of Information Resources manager. Jura overriding concern the control of costs. Hickock concerned to ensure professional management, smooth service delivery of service, addressing of nonconformance issues, and current technology (i.e. Kallio issues).

Formation of IRM organization and promulgation of IRM 'Constitution'- Key Points on the IRM Function and Organization. 
Attachment Five

Raw Data Set 
Conbined Date Set

\begin{tabular}{|c|c|c|c|c|c|c|c|c|c|c|c|c|c|}
\hline Times & Info & Clas: & Useful & $\operatorname{cosp}$ & $V i=1 y$ & $\begin{array}{c}\text { Accur- } \\
\text { ete }\end{array}$ & $\begin{array}{l}\text { Role- } \\
\text { vent }\end{array}$ & $\begin{array}{l}\text { Outside } \\
\text { Req. }\end{array}$ & Forment & $\begin{array}{l}\text { Erequ- } \\
\text { ency }\end{array}$ & $\begin{array}{l}\text { Present } \\
\text { Origin }\end{array}$ & $\begin{array}{l}\text { Prefer } \\
\text { Oriain }\end{array}$ & Chack \\
\hline$\hat{~} 14$ & $\begin{array}{l}\text { NOMLI RECULATIOWS } \\
\text { AIRTFS }\end{array}$ & GM & $\begin{array}{l}7.00 \\
3.00\end{array}$ & $\begin{array}{l}4.00 \\
5.00\end{array}$ & $\begin{array}{l}7.00 \\
7.00\end{array}$ & $\begin{array}{l}7.00 \\
5.00\end{array}$ & $\begin{array}{l}7.00 \\
2.00\end{array}$ & $\begin{array}{l}7.00 \\
0.00\end{array}$ & $\begin{array}{l}7.00 \\
3.00\end{array}$ & $\begin{array}{l}6.00 \\
7.00\end{array}$ & $\begin{array}{l}1.00 \\
1.00\end{array}$ & $\begin{array}{l}1.00 \\
1.00\end{array}$ & 0.00 \\
\hline in & AVERAGE. GRNOE & GP & 2.00 & 6.00 & 6.00 & 5.00 & 3.00 & 0.00 & 7.00 & 5.00 & 1.00 & 1.00 & \\
\hline in & AVERAGE. GRNOE. SAS. 35 & $G P$ & 8.00 & 8.00 & 9.00 & 8.00 & 9.00 & 0.00 & 9.00 & 9.00 & 1.00 & 1.00 & 0.00 \\
\hline in & AMARDS. JUSTIFICATIOWS & $G P$ & 7.00 & 5.00 & 3.00 & 5.00 & 5.00 & 2.00 & 5.00 & 7.00 & 1.00 & 0.00 & \\
\hline iA & $\begin{array}{l}\text { AHAROS. TRACKI HG } \\
\text { COYPUTER UTHLIZATIOH }\end{array}$ & SP & 7.00 & 7.00 & 5.00 & 8.00 & 7.00 & 1.00 & 7.00 & 7.00 & 1.00 & 1.00 & 0.00 \\
\hline in & $\begin{array}{l}\text { COAPUIER.UTILILATIOW } \\
\text { COWTRACT.ACTIVITY }\end{array}$ & s & $\begin{array}{l}8.00 \\
7.00\end{array}$ & $\begin{array}{l}8.00 \\
5.00\end{array}$ & $\begin{array}{l}9.00 \\
5.00\end{array}$ & $\begin{array}{l}8.00 \\
6.00\end{array}$ & $\begin{array}{l}9.00 \\
8.00\end{array}$ & $\begin{array}{l}6.00 \\
0.00\end{array}$ & $\begin{array}{l}8.00 \\
6.00\end{array}$ & $\begin{array}{l}9.00 \\
4.00\end{array}$ & $\begin{array}{l}1.00 \\
1.00\end{array}$ & $\begin{array}{l}1.00 \\
1.00\end{array}$ & $\begin{array}{l}0.00 \\
1.00\end{array}$ \\
\hline in & CONTRACT.status & s & 9.00 & 5.00 & 3.00 & 5.00 & 8.00 & 6.00 & 5.00 & 4.00 & 5.00 & 7.00 & 0.00 \\
\hline 1A & courracts & s & 6.00 & 0.00 & 2.00 & 8.00 & 8.00 & 9.00 & 9.00 & 2.00 & 1.00 & 2.00 & 0.00 \\
\hline iA & COST.DATA/TRA & & 9.00 & 6.00 & 6.00 & 6.00 & 8.00 & 0.00 & 7.00 & 6.00 & 1.00 & 1.00 & 1.00 \\
\hline $1 \mathrm{n}$ & DRAFT. FEEDBACK & cy & 5.00 & 5. & 3.0 & & 5.00 & 3.00 & & & 1.00 & 0 & \\
\hline 14 & ORAFT.STLOY.OOCUMENTS & GM & 7.00 & 5.00 & 3.00 & 5.00 & 5.00 & 2.00 & 5.00 & 7.00 & 8.00 & & 0.00 \\
\hline 19 & EEO(419-625) & GP & 9.00 & 9.00 & 9.00 & 8.00 & 9.00 & 7.00 & 8.00 & 9.00 & 1.00 & 1.00 & 0.00 \\
\hline $1 \wedge$ & EEO.MEPORTS.L.STATS & $\infty$ & 7.00 & 8.00 & 8.00 & 7.00 & 8.00 & 4.00 & 5.00 & 0.00 & 1.00 & 2.00 & 1.00 \\
\hline 1 & EWV..COWTRACTS.EFFORTS & s & 6.00 & 2.00 & 3.00 & 4.00 & 7.00 & 9.00 & 1.00 & 5.00 & 1.00 & 1.00 & 0.00 \\
\hline$\hat{u}$ & EWV. .PROGRRAS & G & 6.00 & 2.00 & 3.00 & 4.00 & 7.00 & 9.00 & 1.00 & 5.00 & 1.00 & 1.00 & 0.00 \\
\hline$\hat{x}$ & EUV.. STAFFIMG & $G P$ & 8.00 & 2.00 & 3.00 & 4.00 & 7.00 & 9.00 & 1.00 & 5.00 & 1.00 & 1.00 & 0.00 \\
\hline ia & & $G P$ & 7.00 & 5.00 & 6.00 & 7.00 & 8.00 & 1.00 & 5.00 & 8.00 & 1.00 & 2.00 & 1.00 \\
\hline I & FTE & $G P$ & 9.00 & 8.00 & 0.00 & 7.00 & 7.00 & 0.00 & 9.00 & 9.00 & 1.00 & & 0.00 \\
\hline & FTE & GP & 6.0 & a. & 7.0 & & e. & 0. & & 6.00 & 1.00 & 1.00 & \\
\hline in & FTE. (PACS) & $G P$ & 7.00 & 5.00 & 8.00 & 4.00 & 3.00 & 0.00 & & & 1.00 & 1.00 & \\
\hline in & FTE.ALLOCATIOW & GP & 0.00 & 8.00 & 5.00 & 5.00 & 7.00 & 0.00 & 8.00 & 8.00 & 5.00 & 5.00 & 0.00 \\
\hline in & FTE.ALLOCS. STATUS, REPORTS & GP & 6. & 3.00 & 3.00 & 8.00 & 6.00 & 1.00 & 8.00 & 7.00 & 1.00 & 1.00 & 1.00 \\
\hline iA & FTE.AMALYSIS & GP & 8. & 8.00 & 9.00 & 8.00 & 0. & 8.00 & 9.00 & 1.00 & 1.00 & 0.00 & \\
\hline in & FTE. MANAGEMEAT & GP & 9.0 & 9.00 & 9.00 & 9.0 & 9. & 5.00 & 9.00 & 9.0 & 8.00 & 0.00 & 0.00 \\
\hline ia & FTE.PROJECTIOWS & $G P$ & 6.0 & 5.00 & 4.00 & 6. & 7. & 4.00 & 6.0 & & 1.00 & & 1.00 \\
\hline in & FTE.REPORI & $G P$ & 5.00 & B. 00 & 9.00 & 0.0 & 5.00 & 1.00 & 0.00 & & 1.00 & 1.00 & 0.00 \\
\hline 1 & FTE. REPORT . (SH) & $\rightarrow \infty$ & 30 & 3.0 & 0 & 9. & 5.00 & 7.00 & & & 1.00 & 1.00 & 0.00 \\
\hline iA & FIE.REPORTS & GP & 6. & 7. & 8. & 7. & 7. & & & & & 1.00 & 1.00 \\
\hline in & FTE.TRACKING & GP & 7. & 8.00 & 7.00 & 8.00 & 7. & 1.00 & 7. & 6.00 & 1.00 & 2.00 & 1.00 \\
\hline in & ITE. USE. AND .PROJECTED.EOY & $G P$ & 8. & 0.00 & 8.00 & a. & 8. & 1.00 & 6. & & 1.00 & 1.00 & 1.00 \\
\hline in & FTE. USEAGE & GP & 9. & 9.00 & 9.00 & 7. & & 0.00 & & & 1.00 & 2.00 & 1.00 \\
\hline ik & HICKOK. GRAMS & an & 9. & 0.00 & 8.00 & & . & 3.00 & & & 3.00 & & 0.00 \\
\hline$\hat{\mu}$ & IMTERHAL POLICIES \&.PROCEO. & Gim & 7.00 & 6.00 & 7.00 & 7.00 & 6.00 & 1.00 & 7.0 & 7.00 & 1.00 & 1.00 & 0.00 \\
\hline$\hat{x}$ & KEY.IMDICATOR. MUMBERS & on & 5.00 & 4.00 & 8.00 & 8.00 & 8.00 & 0.00 & 7.00 & 9.00 & 1.00 & 1.00 & 0.00 \\
\hline in & IMCENTIVE. AMARDS. BRANCH & $G P$ & 70 & 7.0 & 5.00 & 8.00 & 8.00 & 1.00 & 6.00 & 5.00 & 1.00 & 1.00 & 1.00 \\
\hline in & IMVENTORIES & c & 5. & 6. & 7.0 & 7. & 7. & 3.0 & & & 8.00 & 2.00 & 1.00 \\
\hline IA & IWVEWTORY.LEVELS & c & 7.00 & 6.00 & 7.00 & 6.C & 6.0 & 0.00 & 6.0 & 7. & 1.00 & 1.00 & 0.00 \\
\hline $1 \mathrm{~A}$ & MEMOS & GH & 5.0 & 3.00 & 4.00 & 5.0 & s. & 5.00 & 5. & 5.00 & 1,00 & & 0.00 \\
\hline in & RISC.PAYPERS.REP & GP & 9.0 & 9.0 & 9.00 & 9.00 & 9.00 & 5.00 & 9.00 & 9.00 & 1.00 & 1.00 & 0.00 \\
\hline in & MHS. INVEHTORY.CO & & 6.00 & 4.00 & 2.00 & 3.00 & 3.00 & & & & & & 0.00 \\
\hline
\end{tabular}




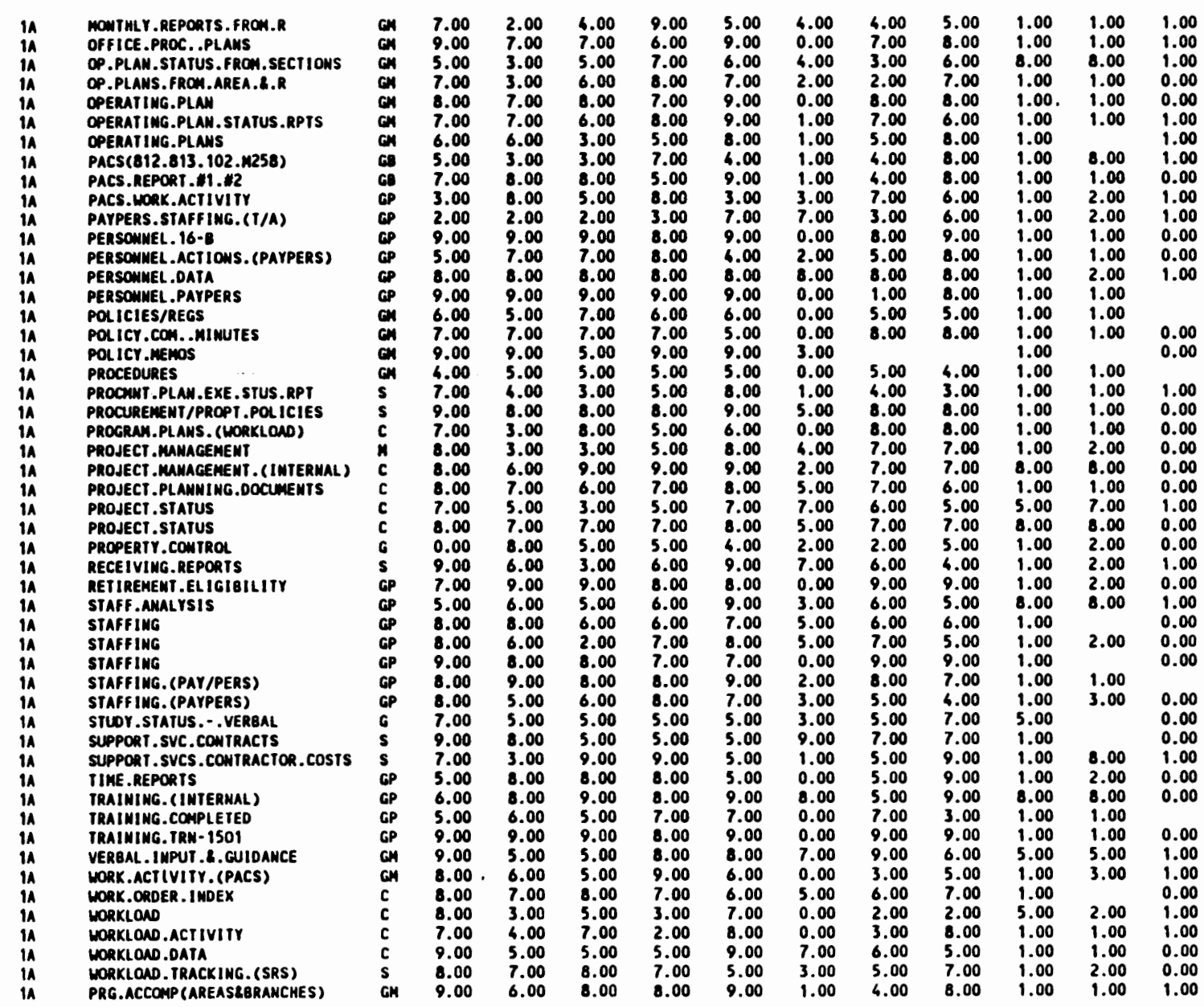




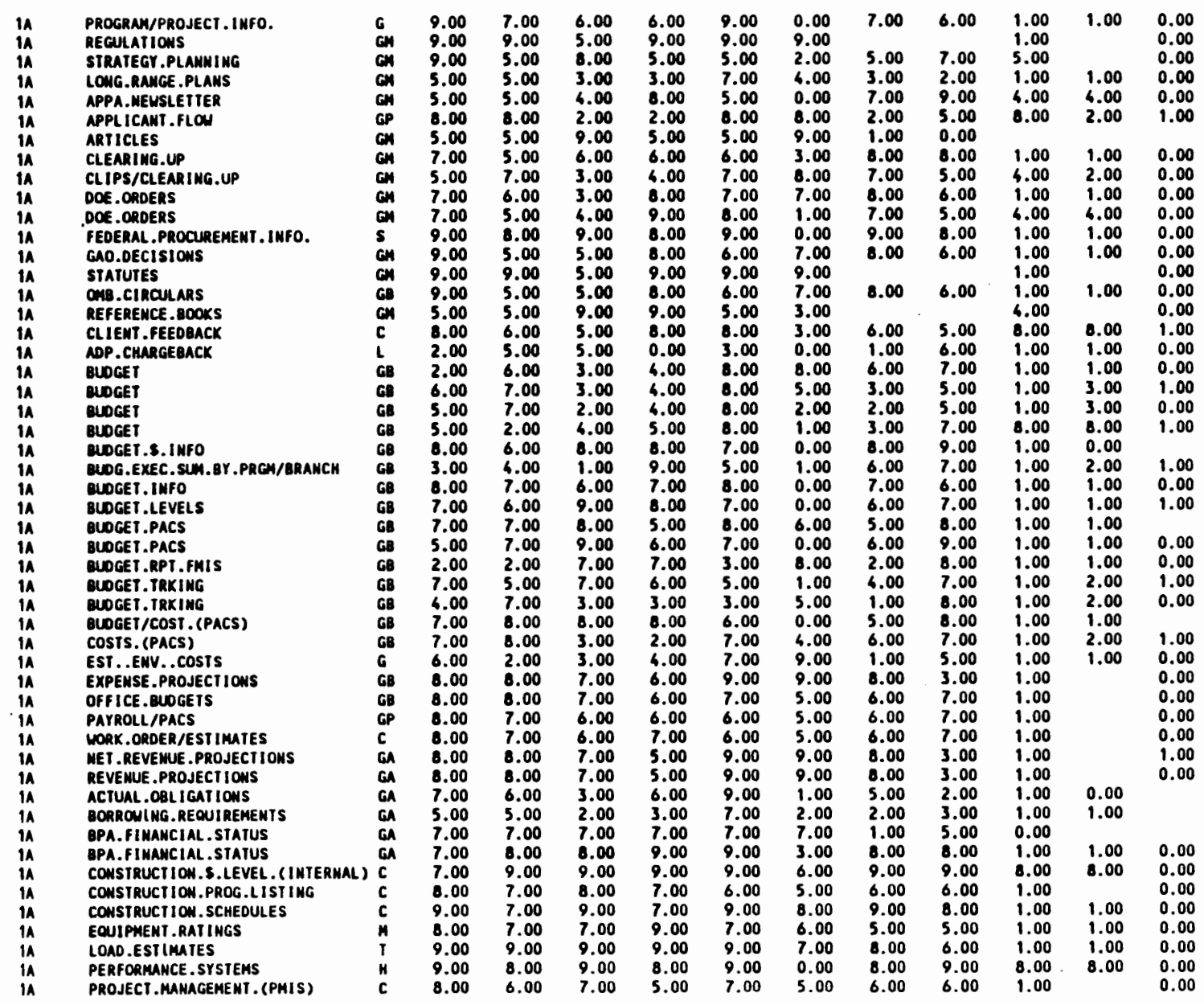




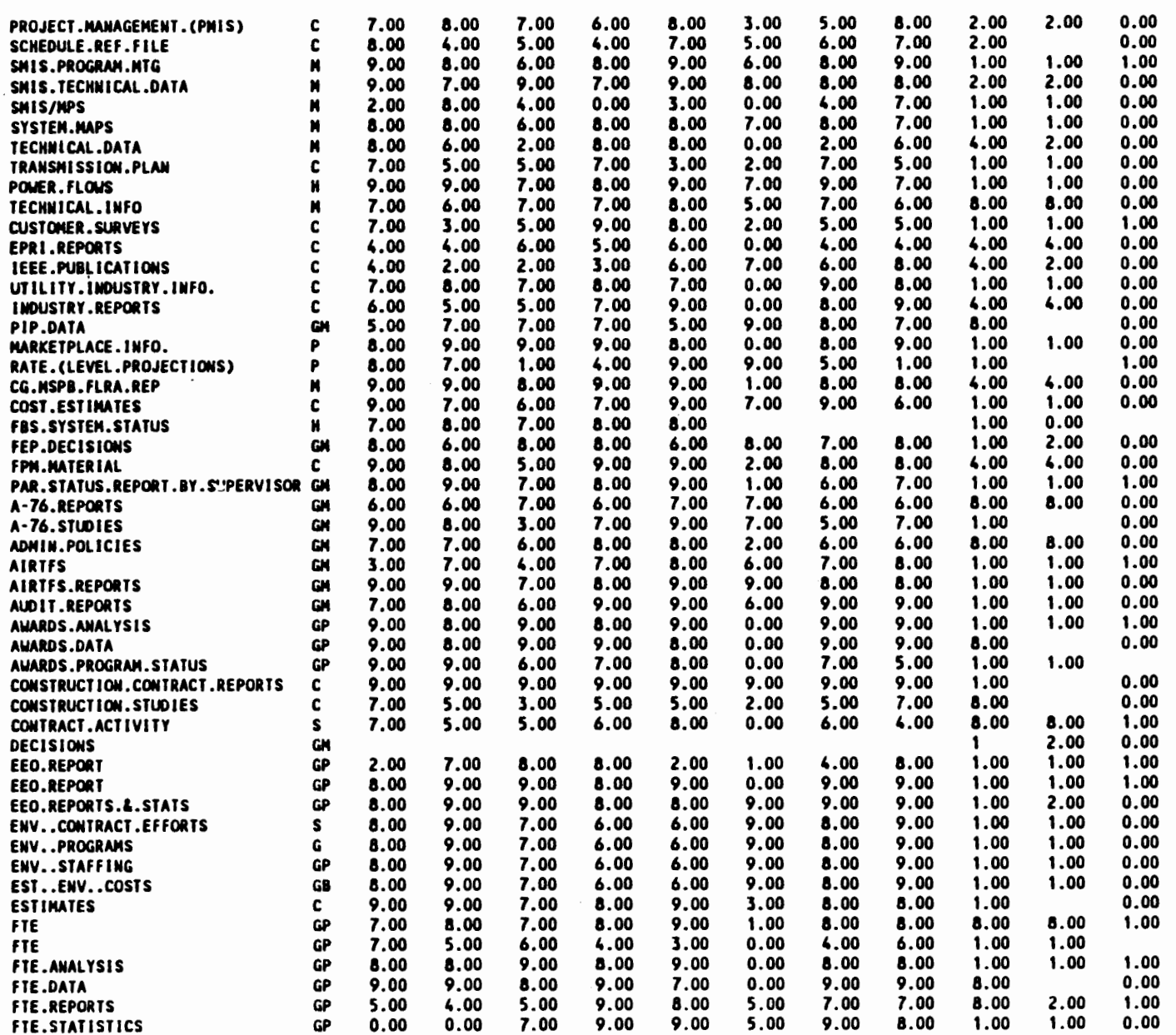




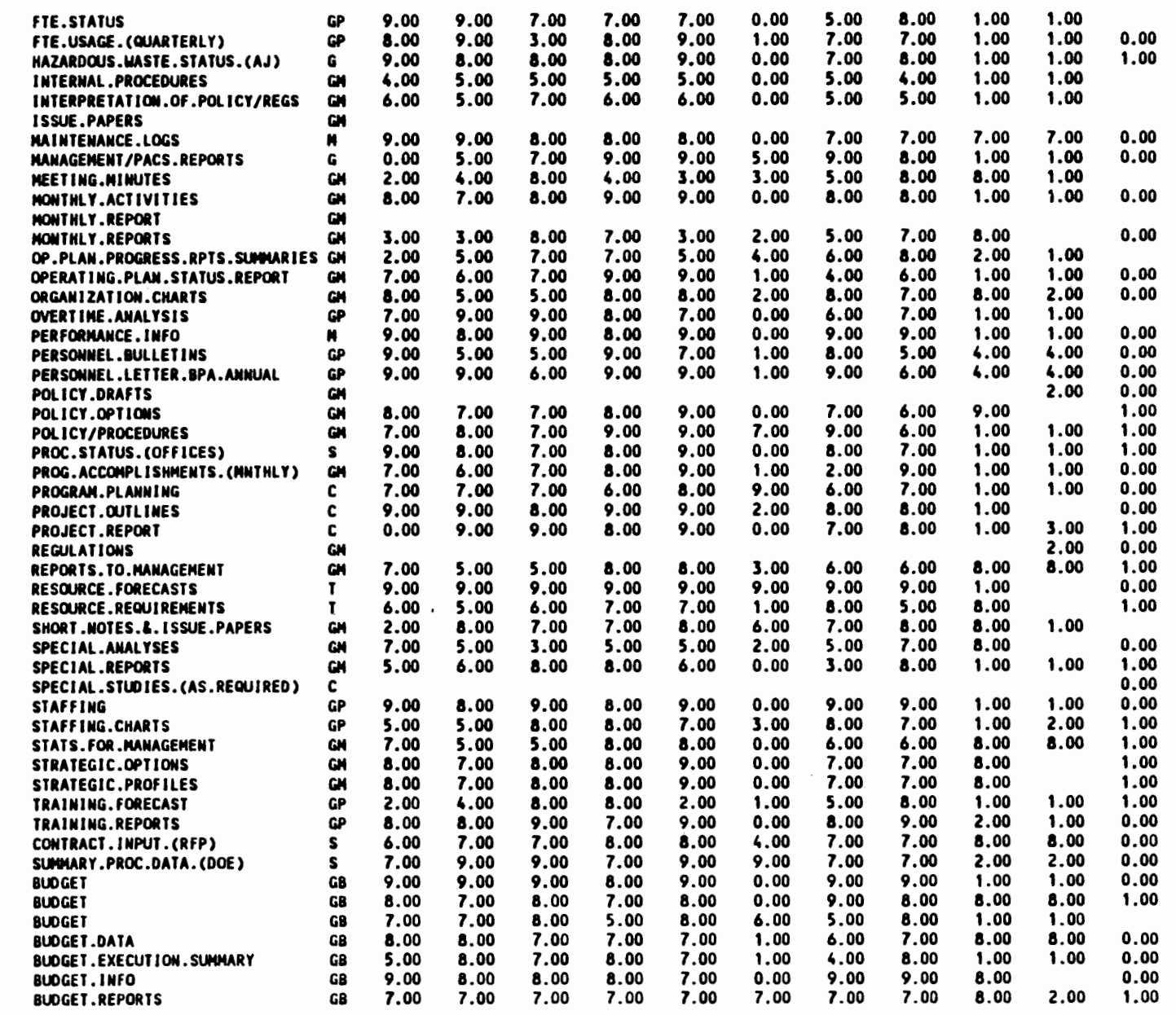




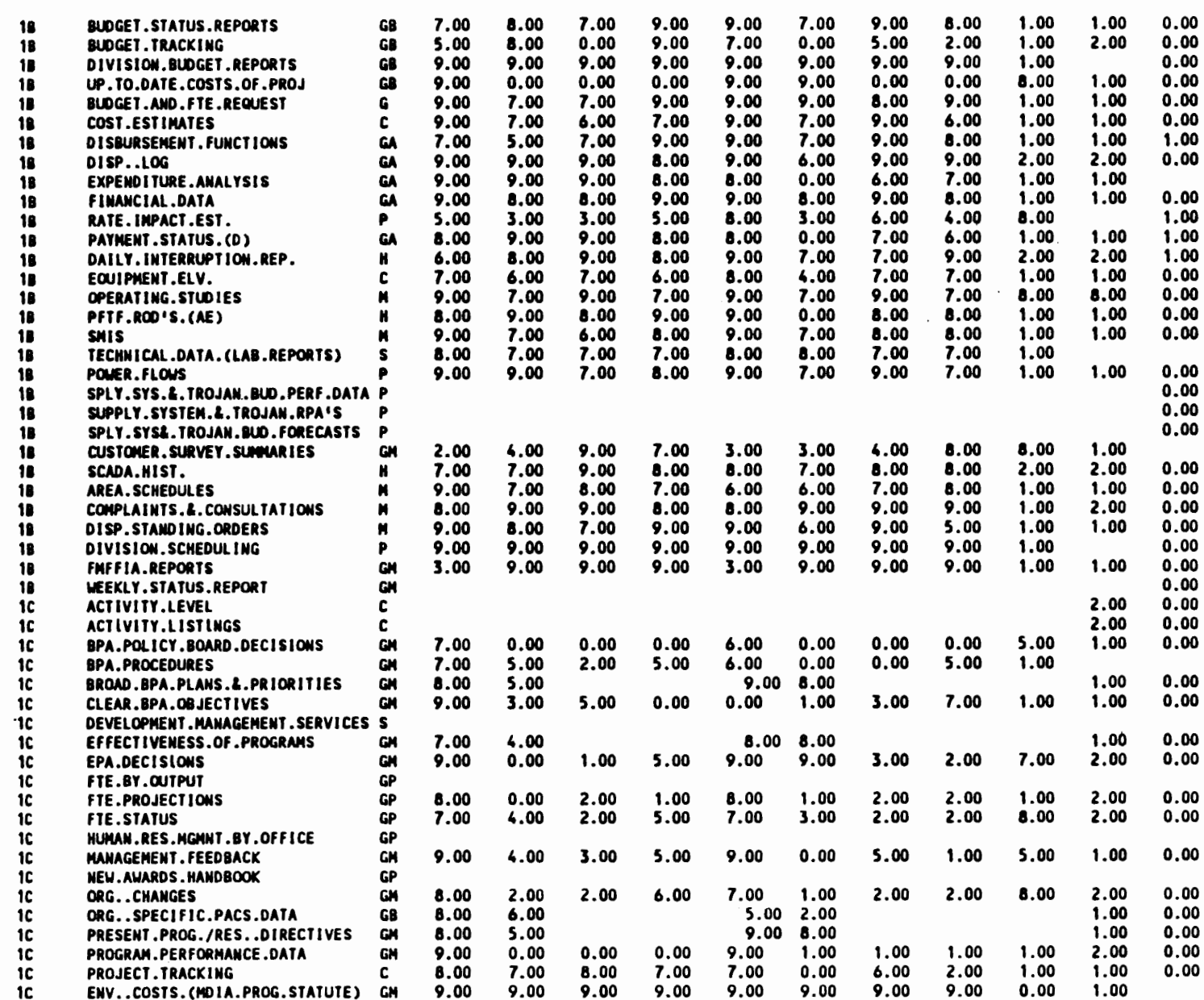


COUTRACT.S.EXPEMDED. (PACS) OCOGET/FIMAMCIAL.KISTORIES CURRENT. OBL IGATIONS TECHMOLOCICAL. CHAMGES MATERIAL.SCHEDULES

auolits

GPA.THIS. WEEX

QPA.THIS. MEEK

FTE. IMFO. SOWE.PACS. REPLATS

MeMosooks

MHAGEMENT AHAL YSIS

MAMAGEMENT. REVIEU

OTHER PACS. REPOETS

PACS

PACS. (ACTIVITY)

PACS. DETAL

PAYPERS

PROCEOURES

SAFETY L. HEALTH. PROG. HLHOBOO

SIGWATURE. FORHS

SOME.PACS.RUNS

WORK. ACIIVITY. (PACS)

Donkentions

PACS BUDGET.DATA

SNIS

NDVERTISEMENTS

JUMK.MAIL

muiry

POSITION MGMT PLAN

PROJECT STATUS (CRIT)

EMPLOYEE FEEDBACX

LEAVE/OT RPT

RETIRENENT ELIGB. RPT

AVG MEGAUATTS OTRLY

OBLIGATED S BY PLC

EXPENOITURES BY PLO

PRE PROJ.

WORKLONO FORECAST

RESOURCE ALLOCATION

ras

CURRENT PROJECT DATA
PACS RPTS

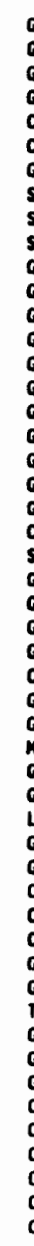

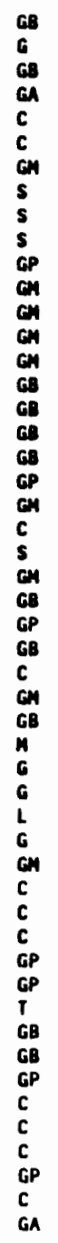

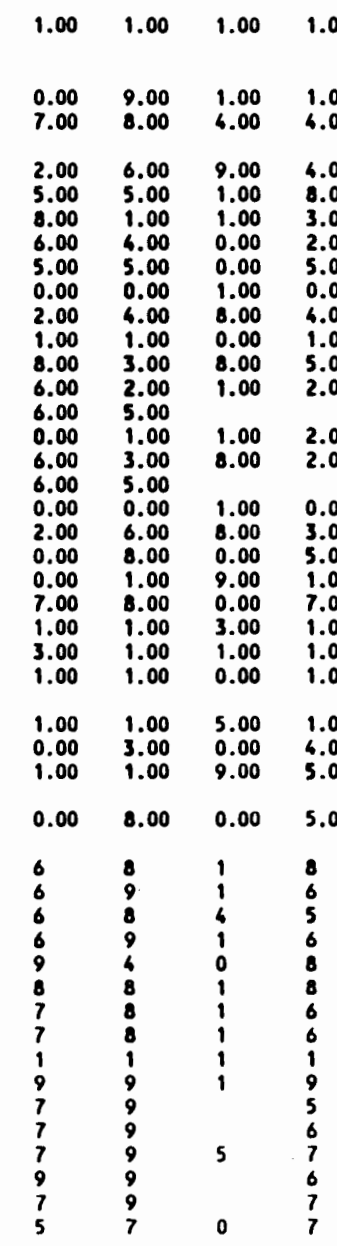

1.00

$1.00 \quad 0.00$

$0.00 \quad 0.00$

$\begin{array}{llllllllllll}9.00 & 0.00 & 1.00 & 0.00 & 9.00 & 1.00 & 1.00 & 1.00 & 1.00 & 2.00 & 0.00\end{array}$

\begin{tabular}{lllllllllll}
7.00 & 4.00 & 4.00 & 7.00 & 8.00 & 6.00 & 4.00 & 6.00 & 6.00 & 8.00 & 0.00 \\
\hline
\end{tabular}

$\begin{array}{lllll}4.00 & 3.00 & 4.00 & 5.00 & 0.00\end{array}$

$3.00 \quad 4.00$

7.00

3.002 .00

$3.00 \quad 0.00$

3.00
1.00

$5.00 \quad 4.00$

$9.00 \quad 9.00$

5.00

$0.00 \quad 0.00$

$3.00 \quad 4.00$

9.00
7.00

$3.00 \quad 3.00$

5.00
3.00 $\quad \mathbf{0 . 0 0}$

$1.00 \quad 1.00$

$\begin{array}{llll}8.00 & 4.00 & 0.00 \\ 1.00 & 1.00 & 1.00\end{array}$

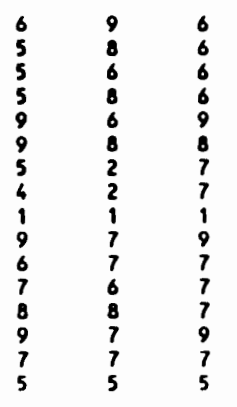

$9.00 \quad 4.00$

$\begin{array}{llll}4.00 & 1.00 & 4.00 & 0.00 \\ 3.00 & 4.00 & 2.00 & 0.00\end{array}$

$\begin{array}{llll}7.00 & 1.00 & 1.00 & 0.00\end{array}$

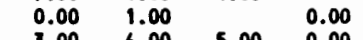

$\begin{array}{llll}3.00 & 4.00 & 5.00 & 0.00\end{array}$

$\begin{array}{llll}1.00 & 5.00 & 1.00 & 0.00 \\ 2.00 & 4.00 & 1.00 & 0.00\end{array}$

$\begin{array}{lllll}2.00 & 9.00 & 1.00 & 1.00 & 0.00\end{array}$

$\begin{array}{lllll}0.00 & 0.00 & 1.00 & 0.00 \\ 3 & & 0.00\end{array}$

$\begin{array}{lllll}3.00 & 3.00 & 4.00 & 4.00 & 0.00\end{array}$

$\begin{array}{lllll}\$ .00 & 8.00 & 1.00 & 1.00 & 0.00 \\ 1.00 & & & & \end{array}$

$\begin{array}{llll}8.00 & 1.00 & 1.00 & 0.00\end{array}$

$\begin{array}{lllll}1.00 & 1.00 & 1.00 & 2.00 & 0.00\end{array}$

$\begin{array}{llll} & & 4.00 & 0.00 \\ 4 & & 2 & 0.00\end{array}$

$\begin{array}{lllll}.00 & 7.00 & 1.00 & & 0.00 \\ & 1.00 & 1.00 & 0.00\end{array}$

$\begin{array}{llll}.00 & 7.00 & 1.00 & 0.00\end{array}$

$\begin{array}{ll}1.00 & 0.00 \\ 1.00 & 0.00\end{array}$

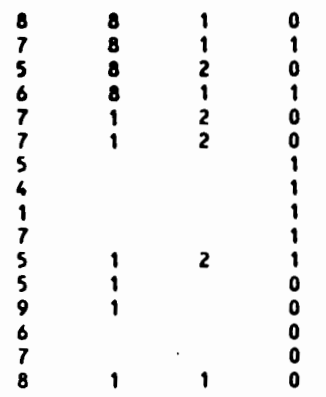



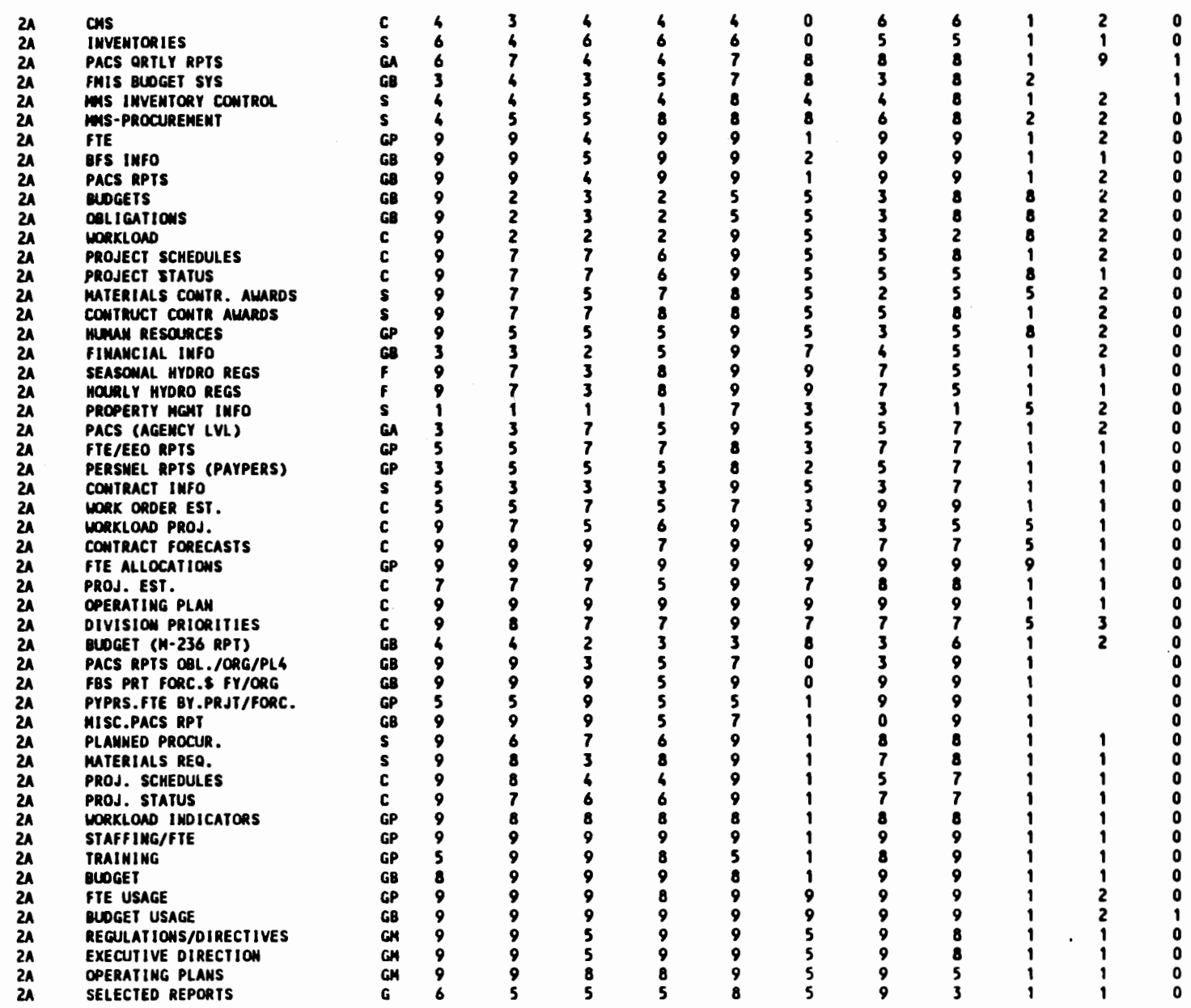


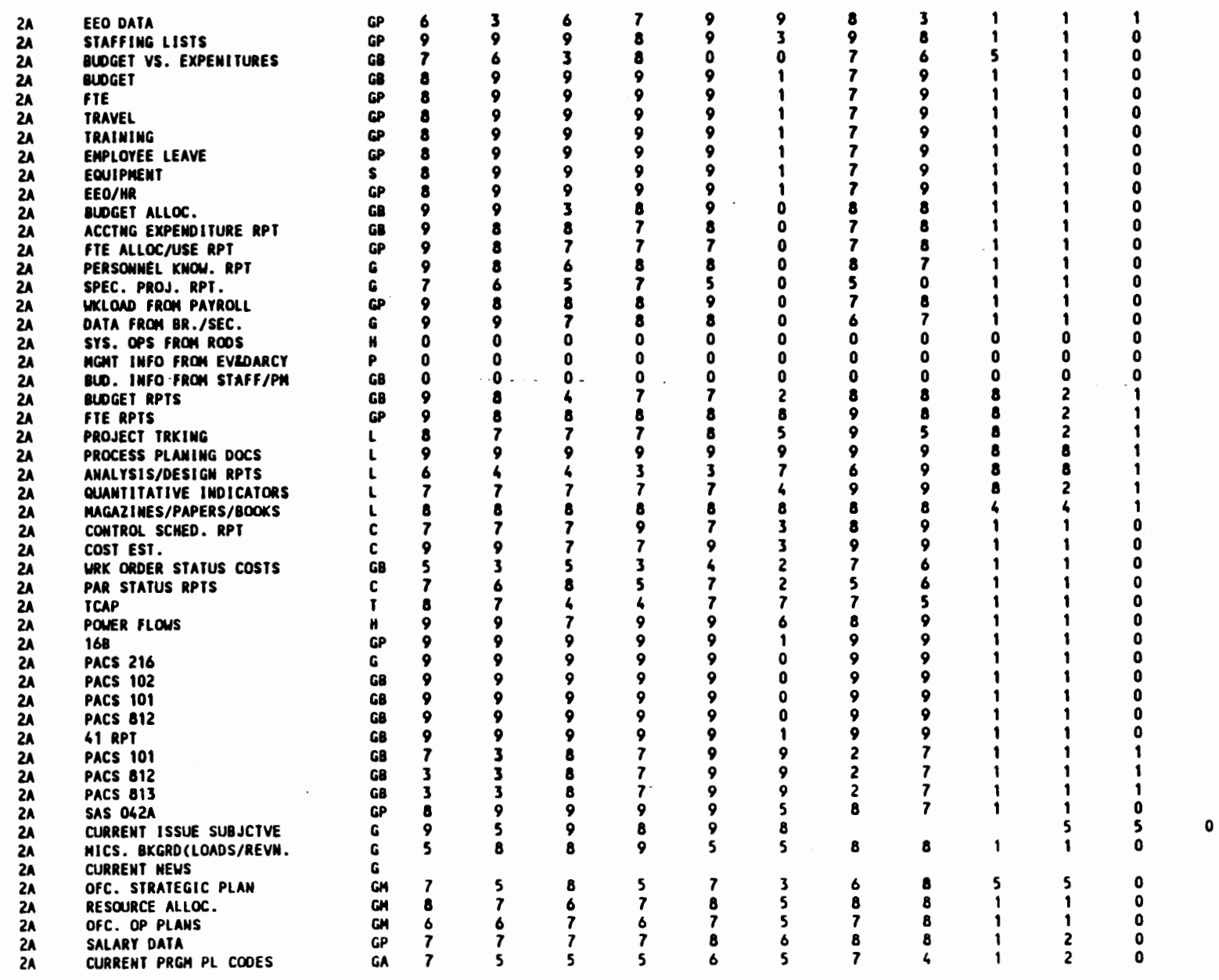




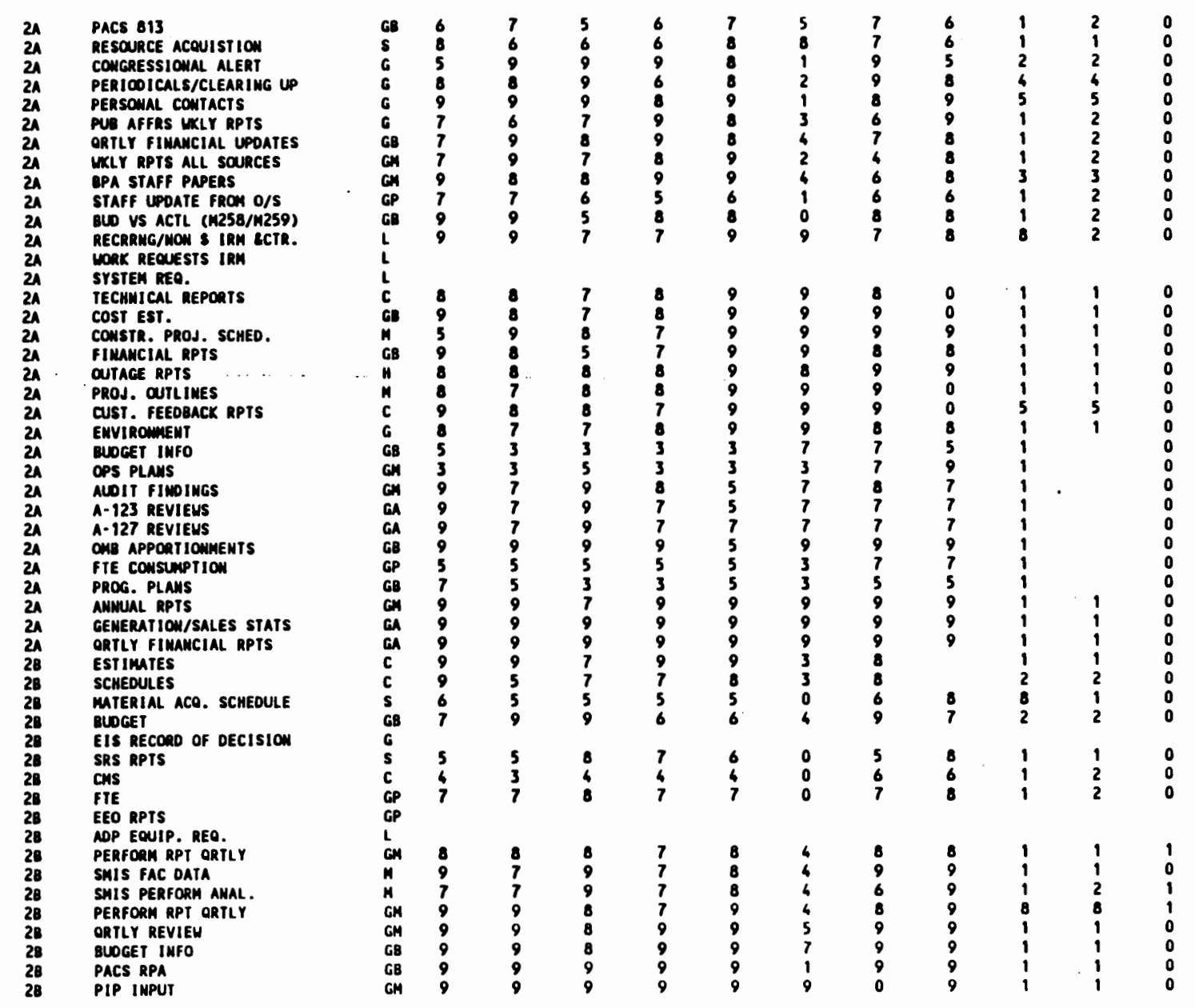




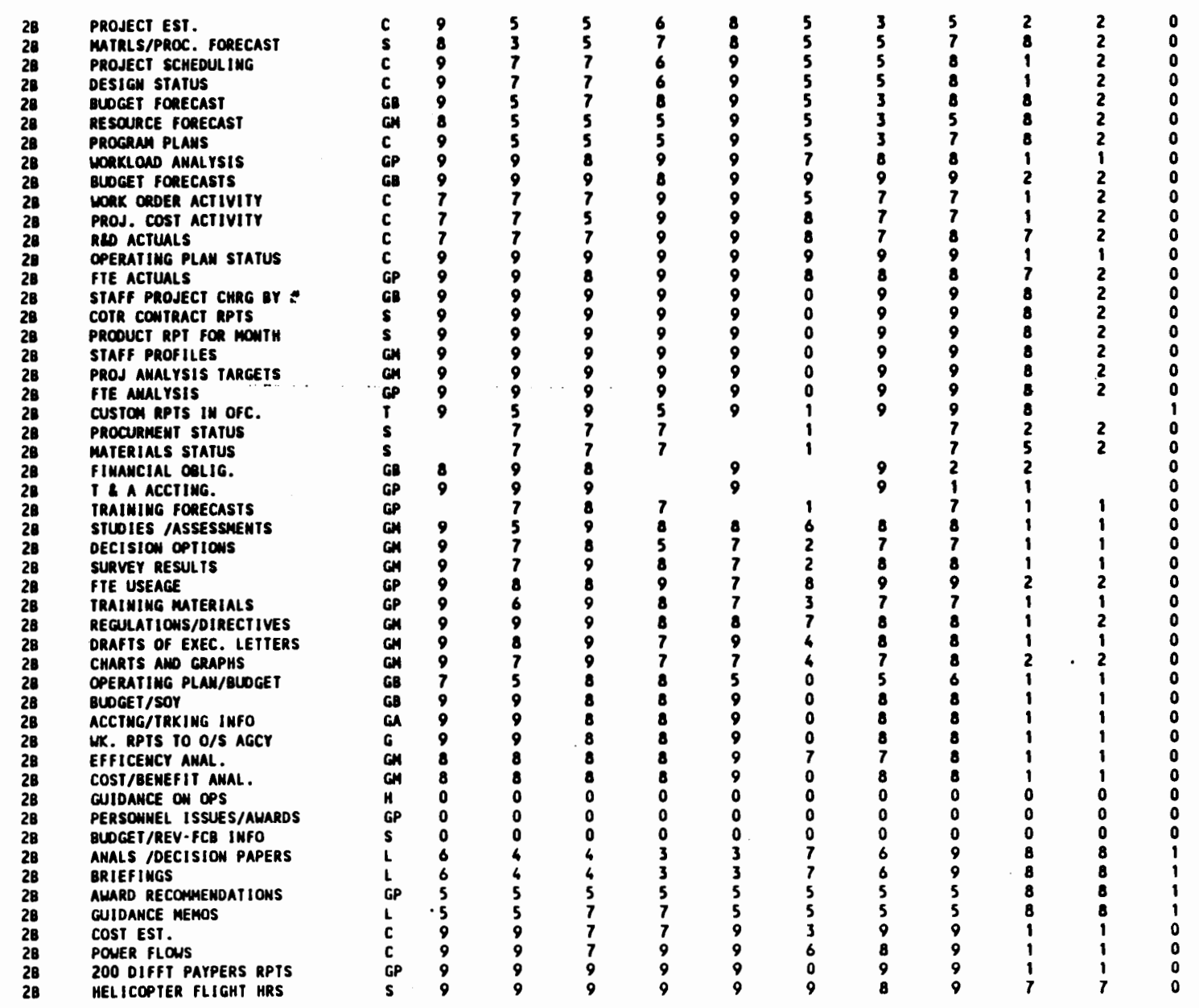



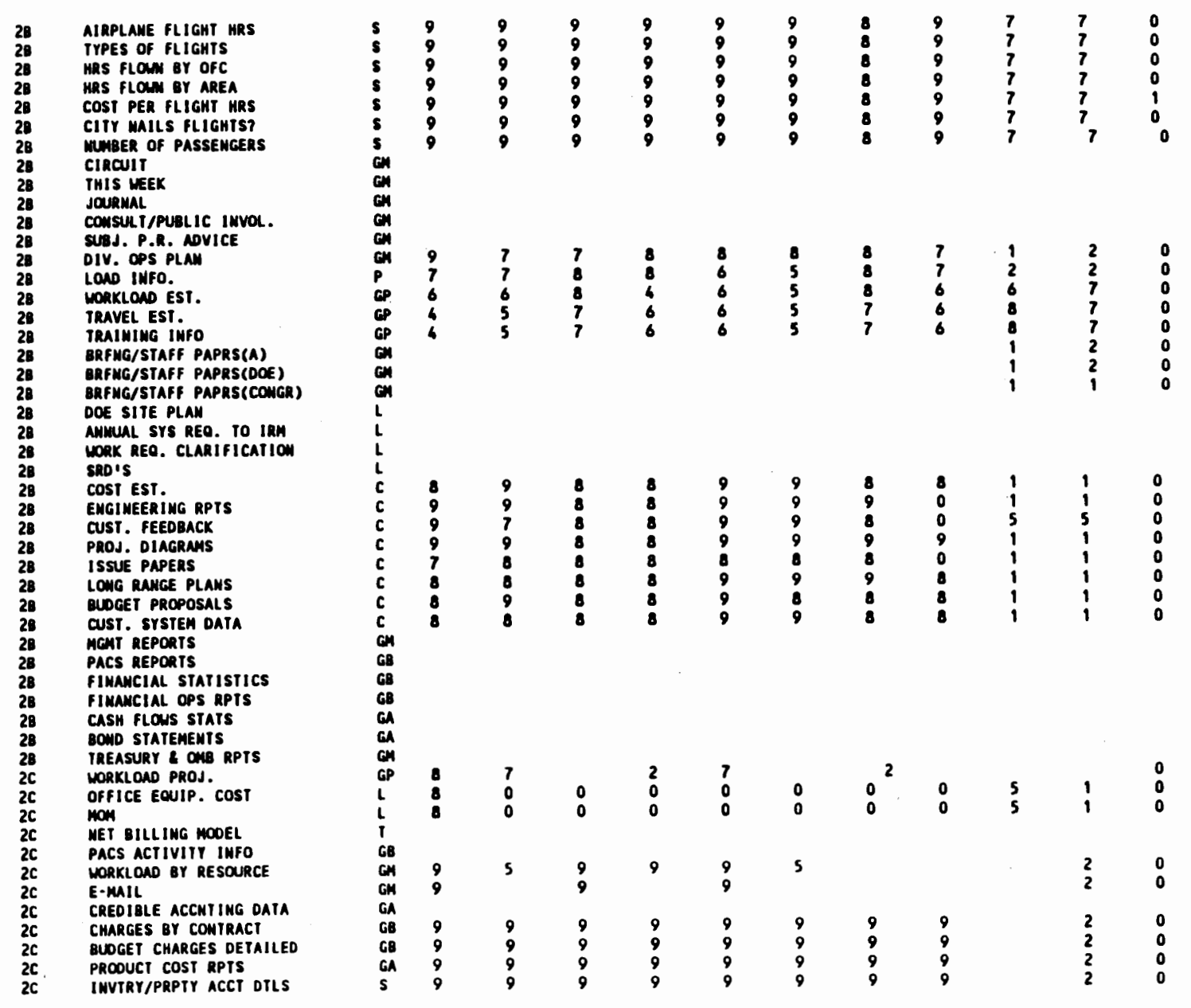

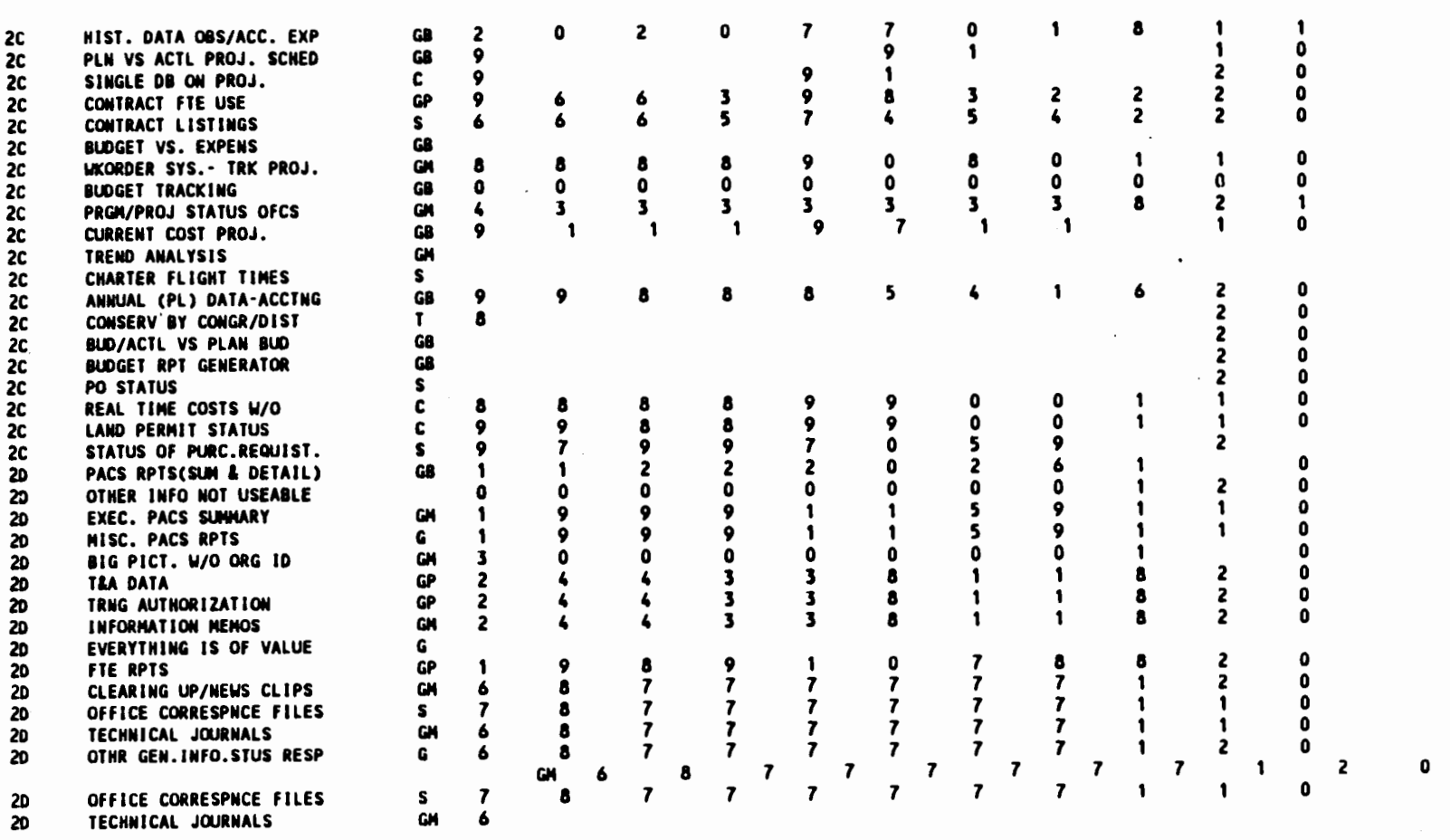


\section{Attachment Six}

Frequency graphs of Pretest/Posttest by rating vartables 
FRQSIMP.XLS Chart 2

USBFUL

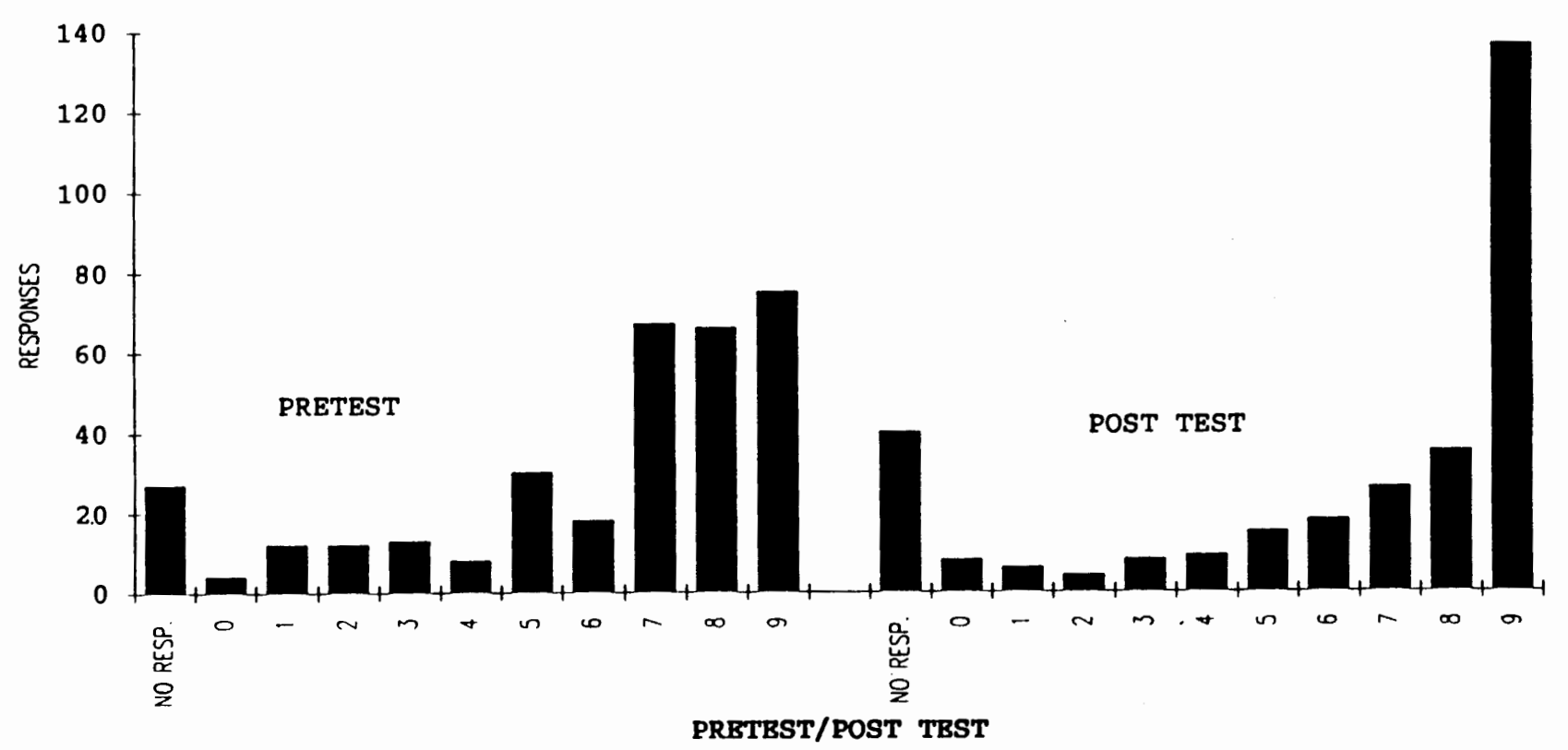




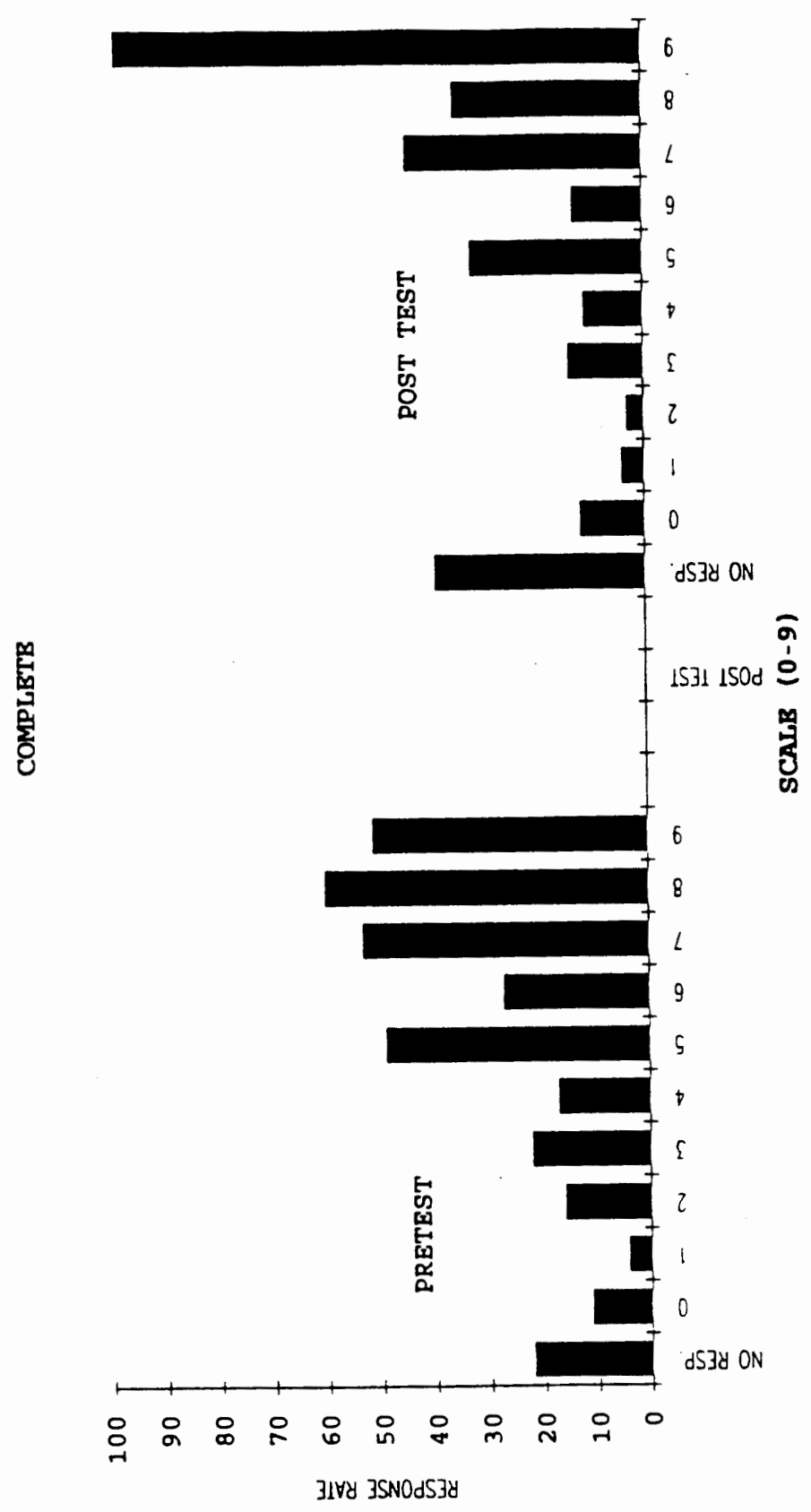


年

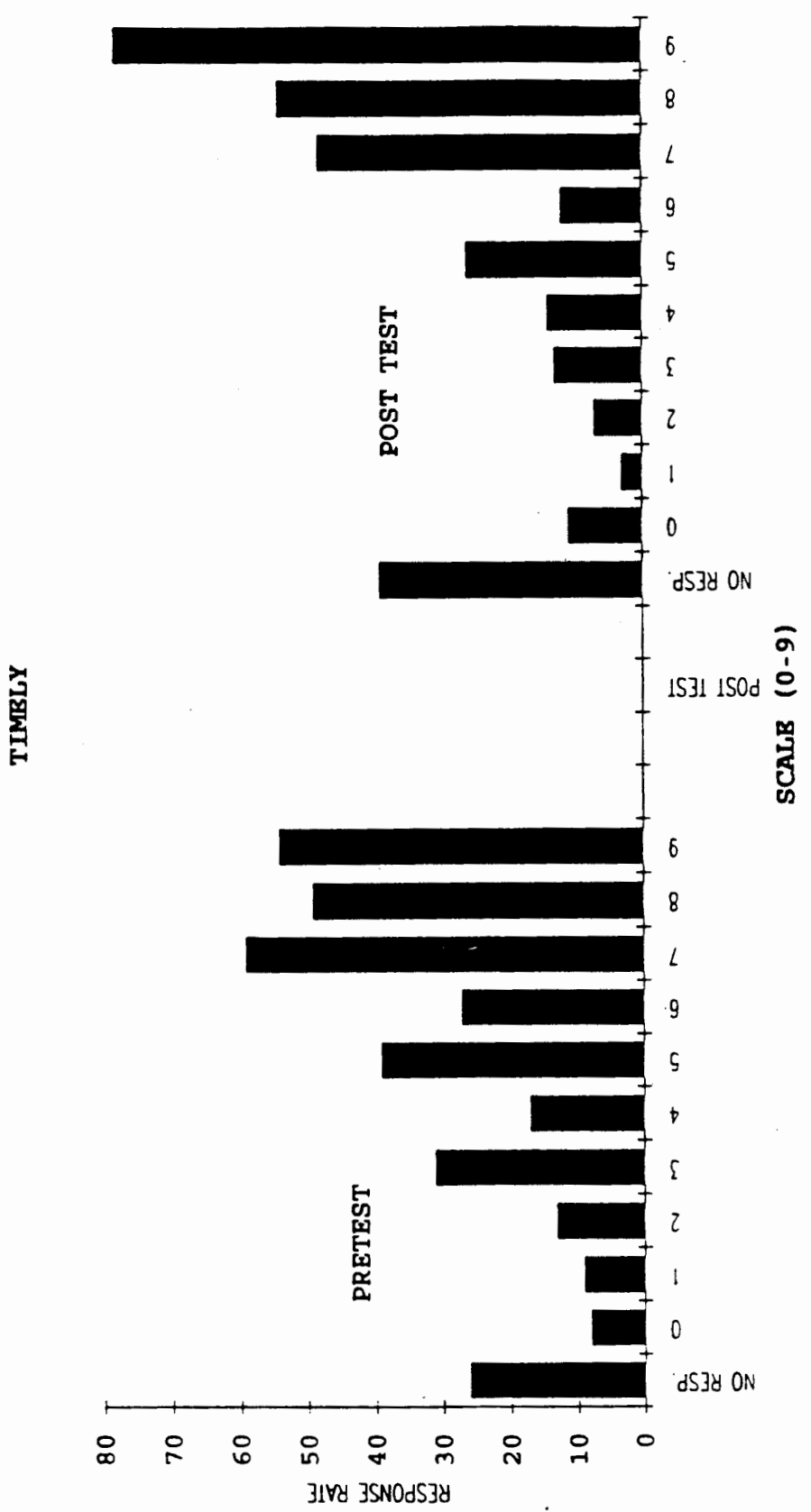


FRQSIMP.XLS Chart 9

OUTSIDB RBQUIREMBNT

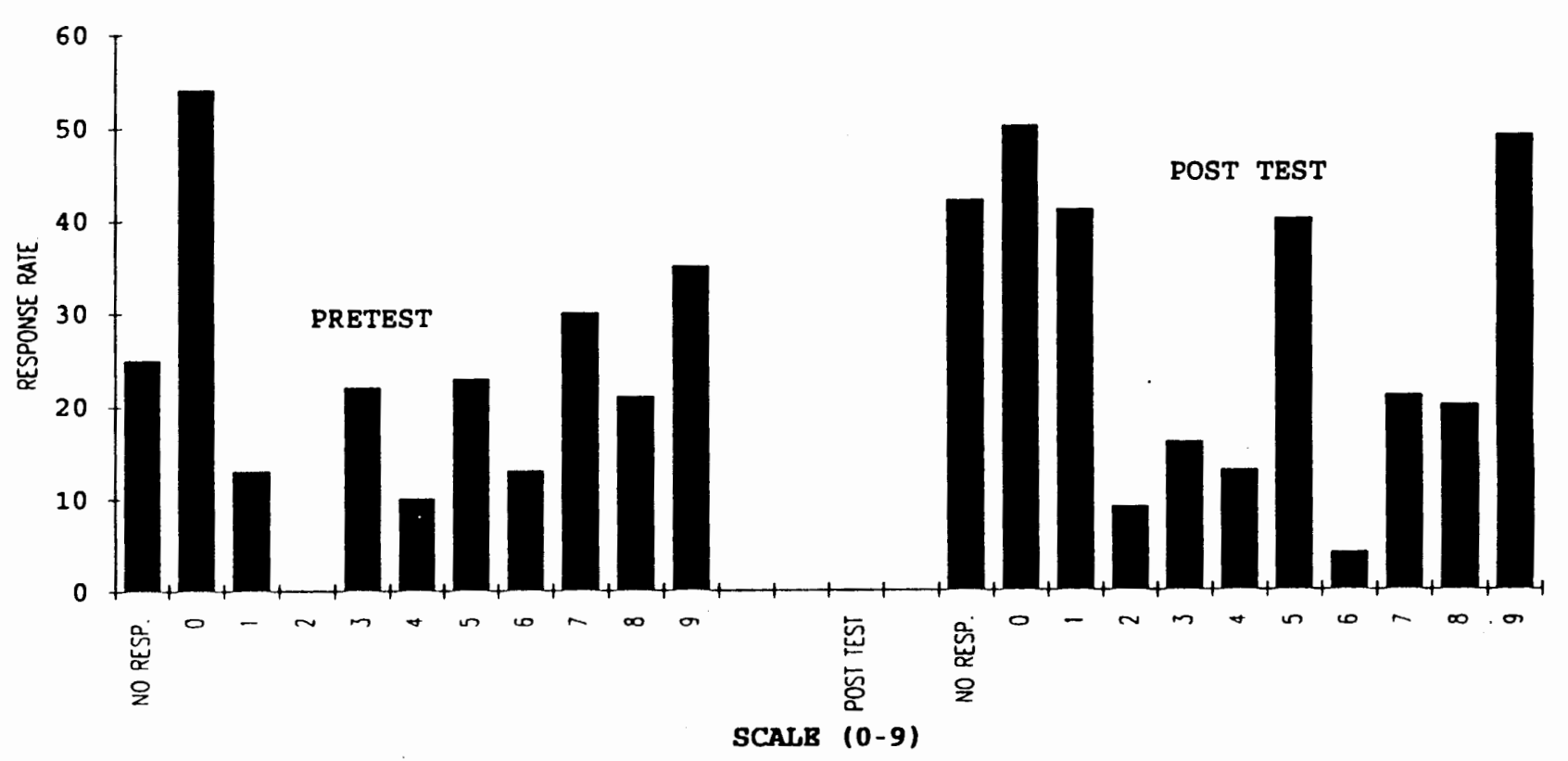




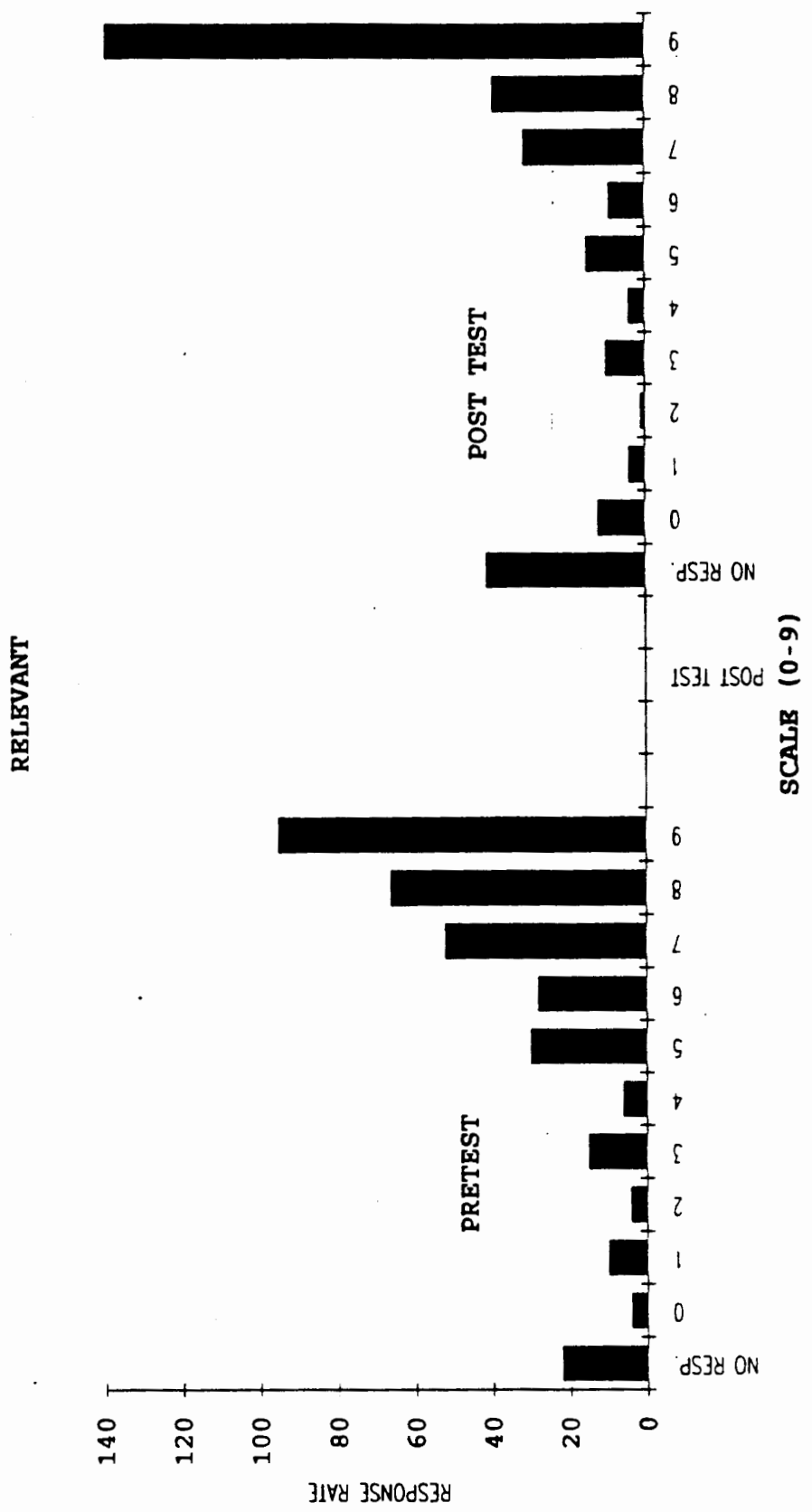



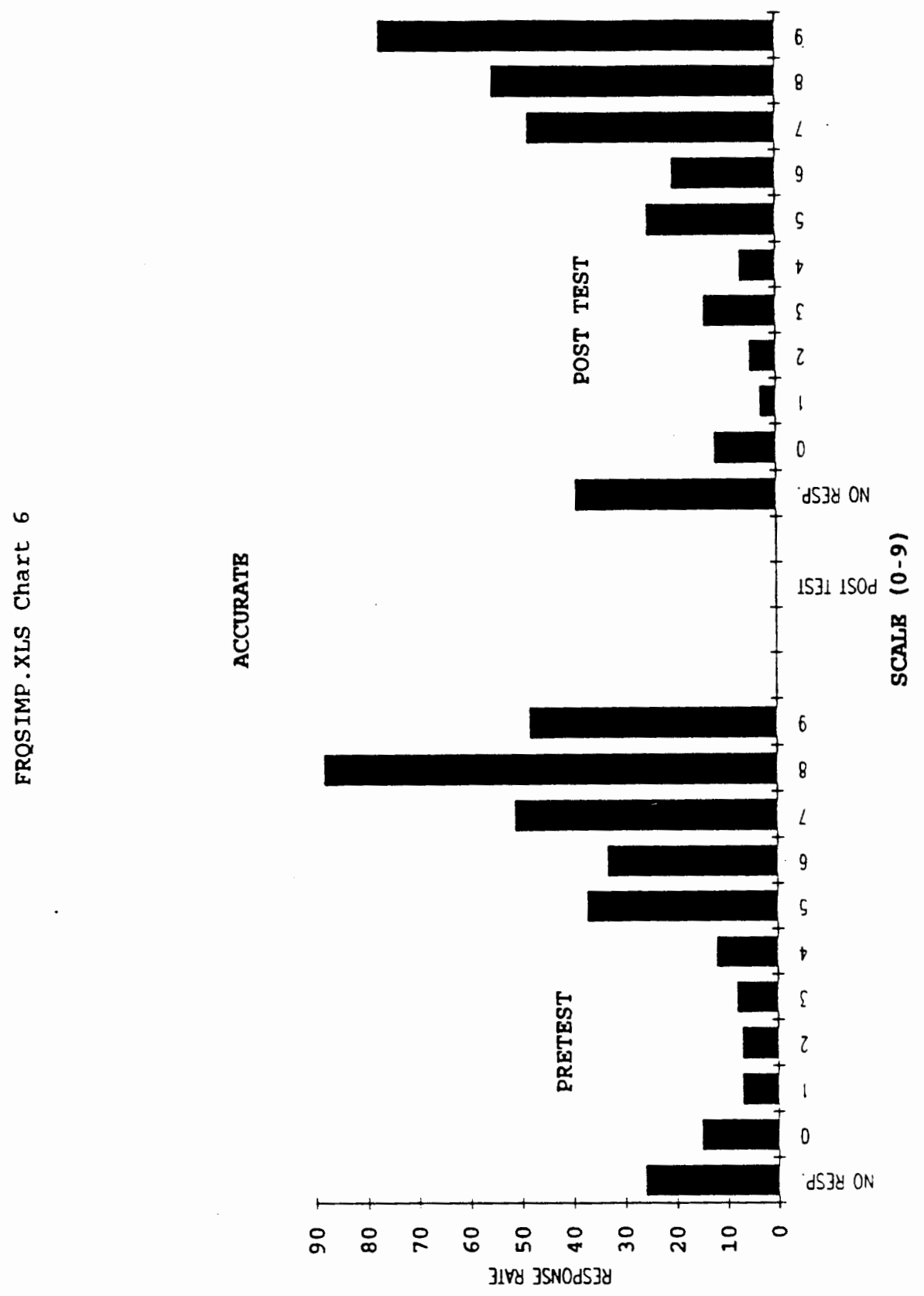
号

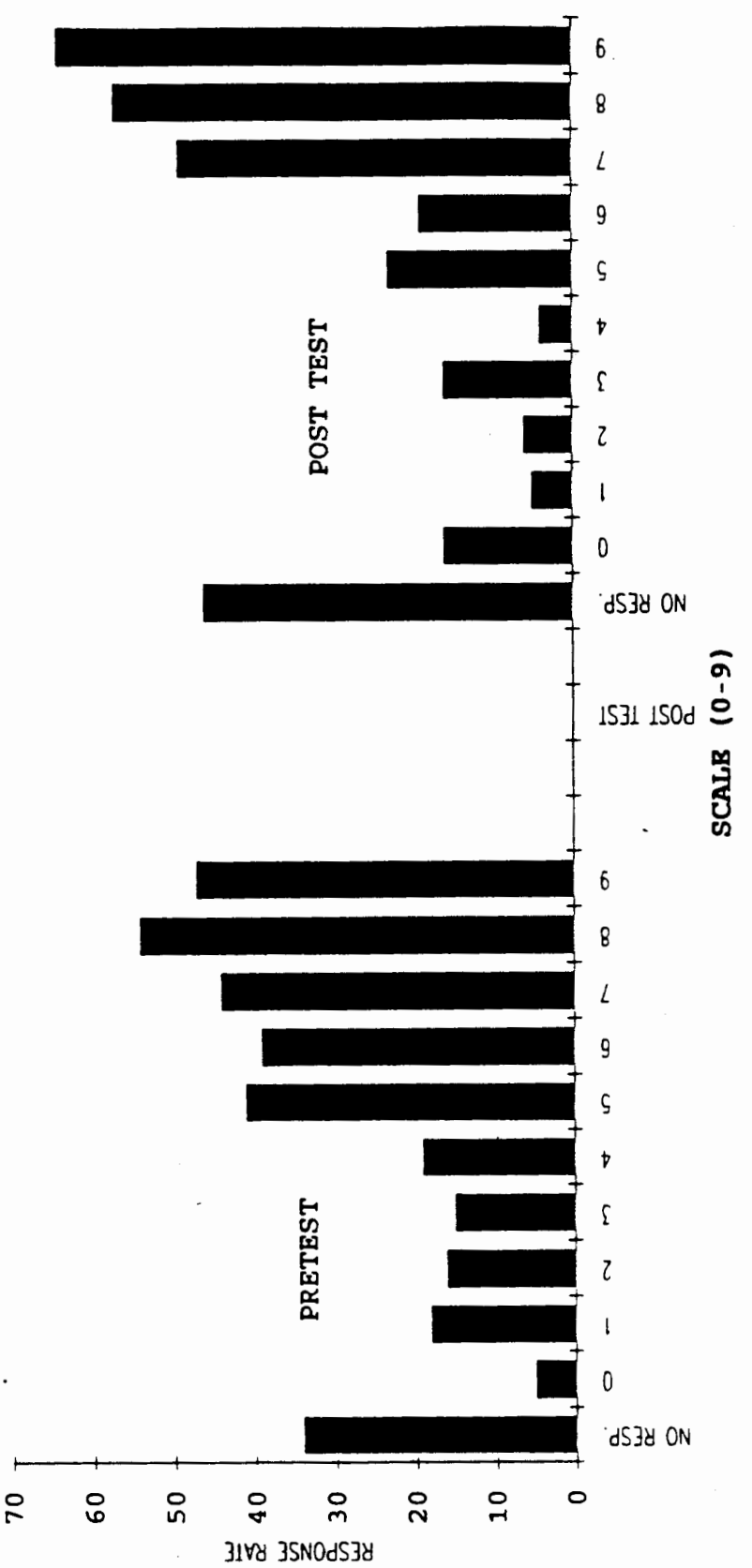


FRQSIMP.XLS Chart 11

PRBQUBNCY

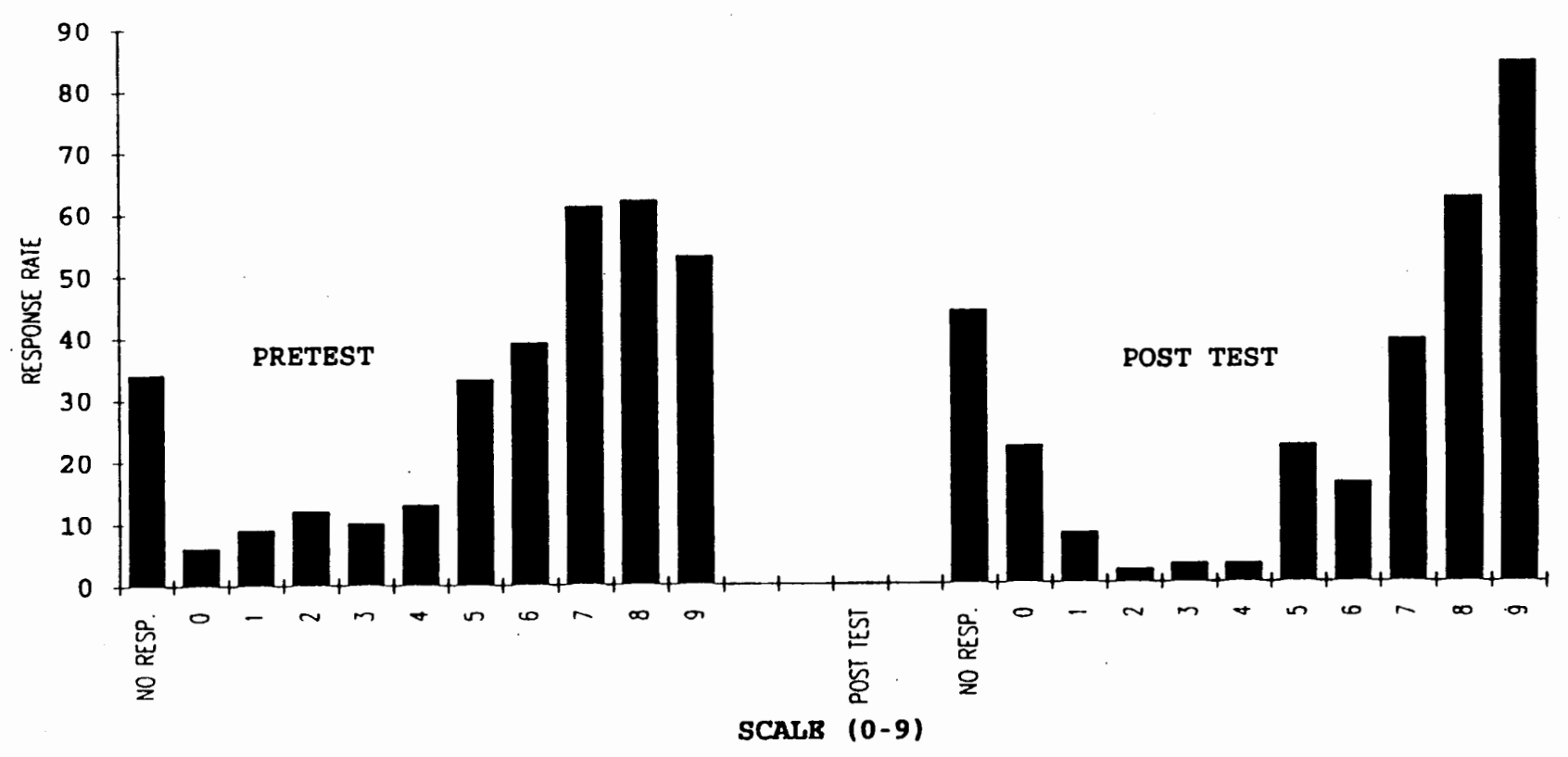


FROSIMP.XLS Chart 12

PRBSRNT AND PRBPBRRBD

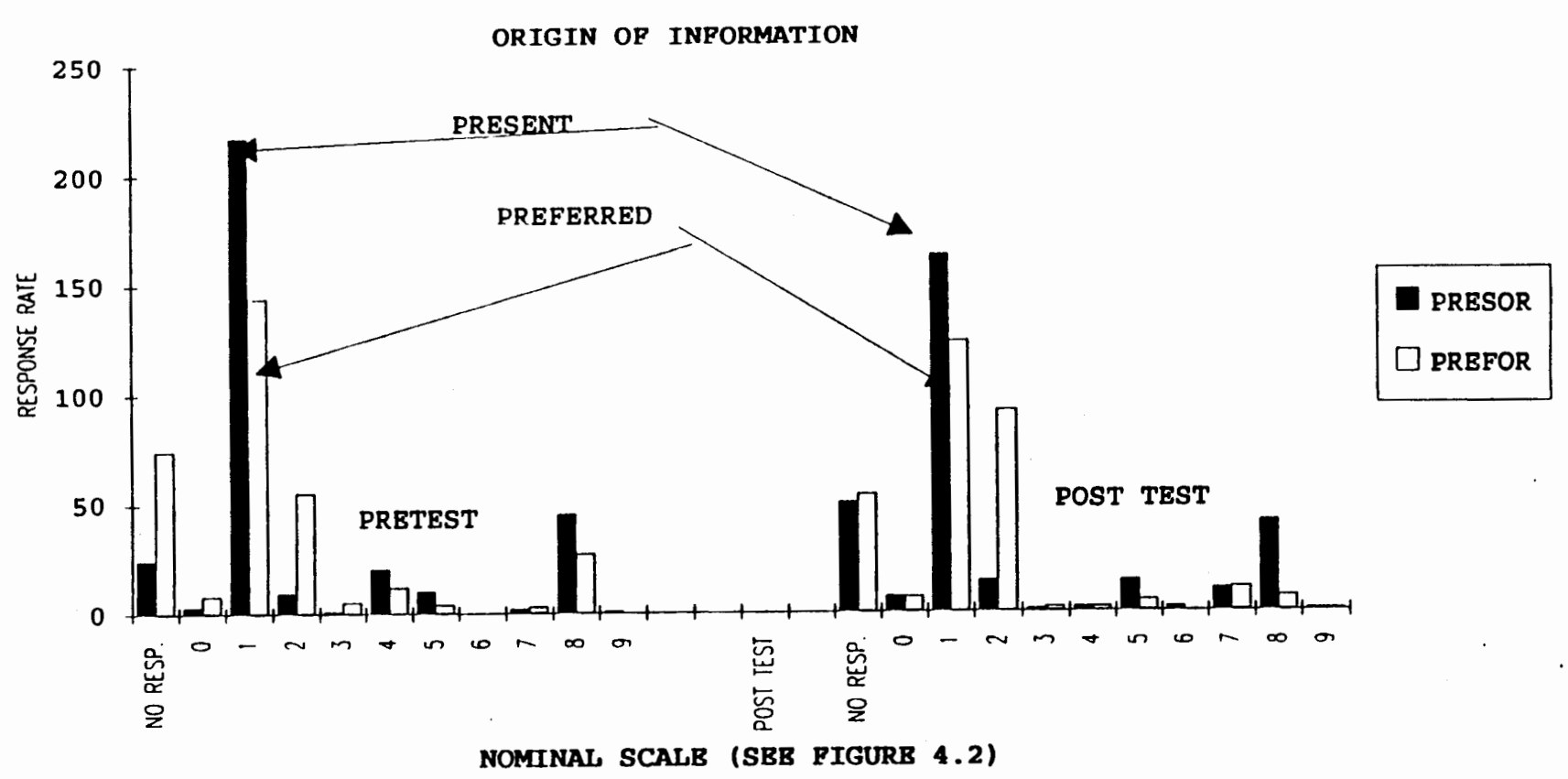




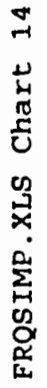

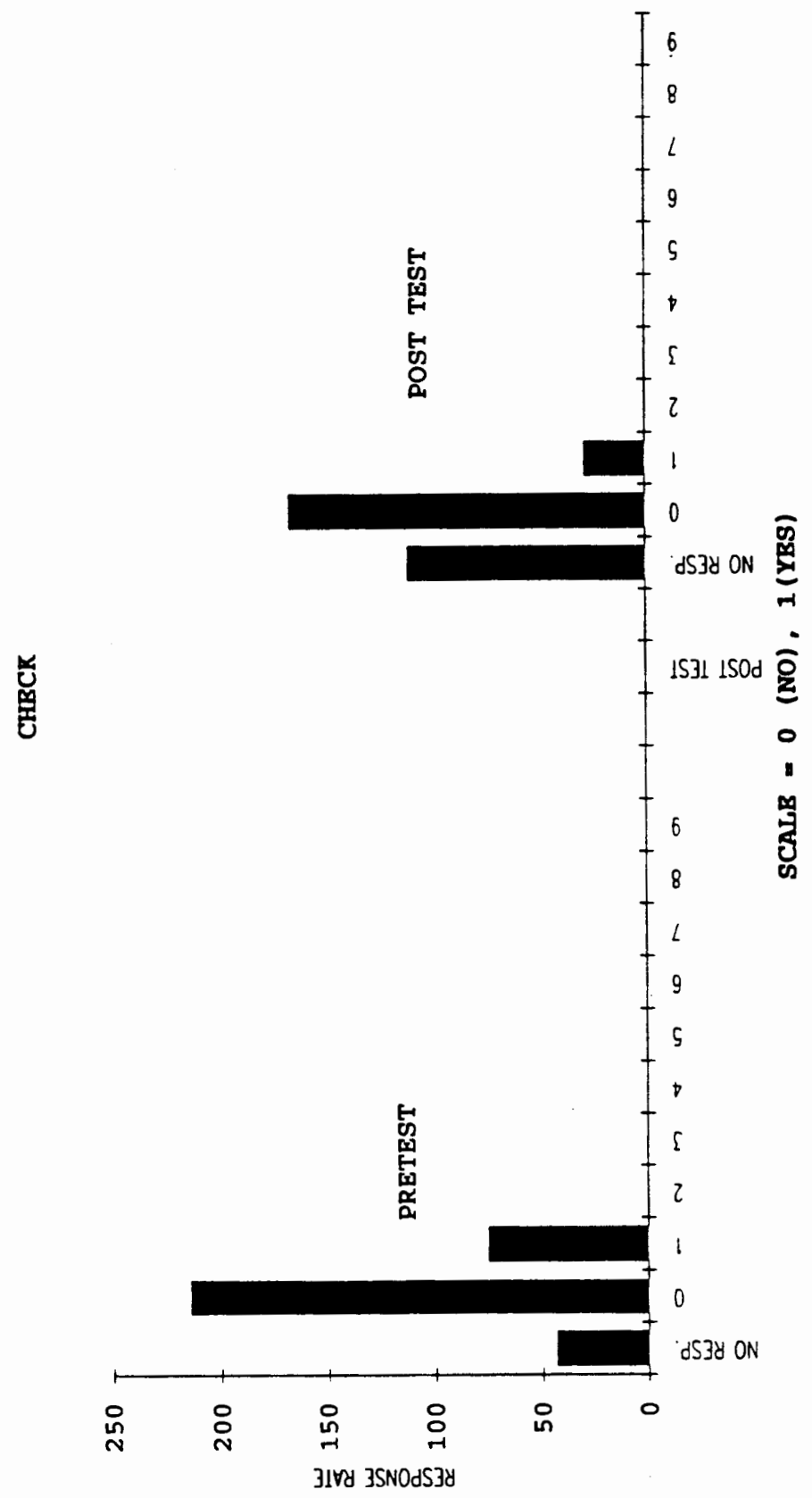


Attachment Seven

Frequency graphs of Pretest/Posttest by rating variable and question 


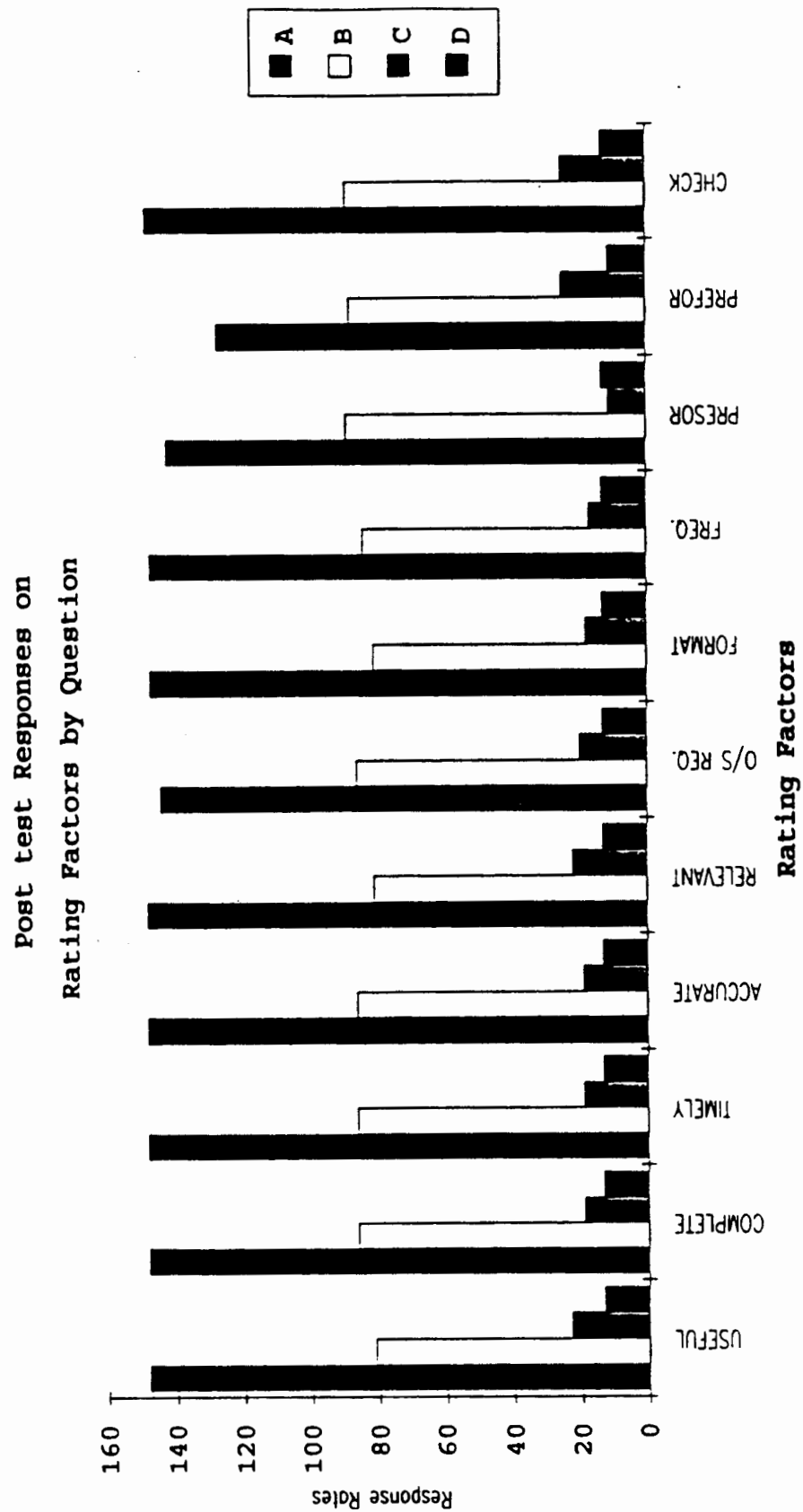




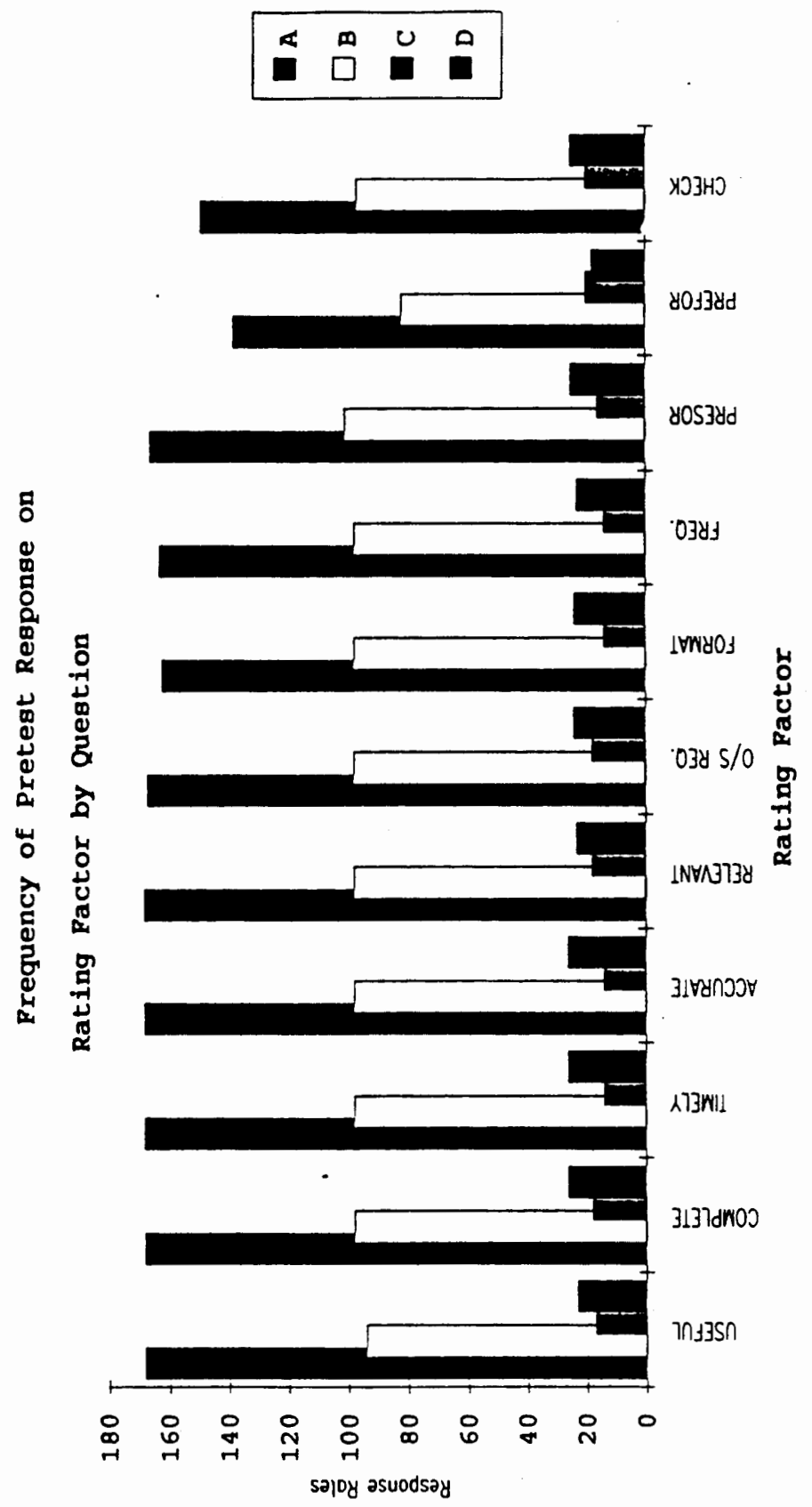




\section{Attachment Eight}

Frequencies of Pretest/Posttest by

buget classification and rating vartable 


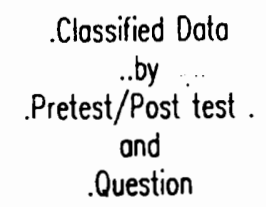

CLASS SORT

CLASS $=C$

CUMULATIVE CUMULATNE

TIMES FREQUENCY PERCENT FREQUENCY PERCENT

$\begin{array}{rrrrr}\text { IA } & 27 & 29.7 & 27 & 29.7 \\ 1 B & 9 & 9.9 & 36 & 39.6 \\ 1 C & 5 & 5.5 & 41 & 45.1 \\ 10 & 2 & 2.2 & 43 & 47.3 \\ 2 A & 24 & 26.4 & 67 & 73.6 \\ 2 B & 21 & 23.1 & 88 & 96.7 \\ 2 C & 3 & 3.3 & 91 & 100.0\end{array}$


CLASS SORT

CLASS $=F$;

CUMULATNE CUMULATME

TIMES FREQUENCY PERCENT FREQUENCY PERCENT

$\begin{array}{lllll}2 A & 2 & 100.0 & 2 & 100.0\end{array}$ 


\section{CLASS SORT}

CLASS $=C$

\section{CUMULATINE CUMULATIVE}

TIMES FREQUENCY PERCENT FREQUENCY PERCENT

$\begin{array}{lllll}1 \mathrm{~A} & 6 & 18.8 & 6 & 18.8 \\ 1 B & 4 & 12.5 & 10 & 31.3 \\ 1 \mathrm{C} & 1 & 3.1 & 11 & 34.4 \\ 10 & 3 & 9.4 & 14 & 43.8 \\ 2 \mathrm{~A} & 13 & 40.6 & 27 & 84.4 \\ 2 B & 2 & 6.3 & 29 & 90.6 \\ 20 & 3 & 9.4 & 32 & 100.0\end{array}$


CLASS SORT

CLASS $=C A$

\section{CUMULATIVE CUMULATNE}

TIMES FREOUENCY PERCENT FREOUENCY PERCENT

$\begin{array}{ccccc}\text { IA } & 7 & 26.9 & 7 & 26.9 \\ 1 B & 5 & 19.2 & 12 & 46.2 \\ 1 C & 1 & 3.8 & 13 & 50.0 \\ 2 A & 8 & 30.8 & 21 & 80.8 \\ 2 B & 3 & 11.5 & 24 & 92.3 \\ 2 C & 2 & 7.7 & 26 & 100.0\end{array}$


CLASS SORT

$C L A S S=C B$

CUMULATINE CUMULATIVE

TIMES FREOUENCY PERCENT FREOUENCY PERCENT

$\begin{array}{lllll}1 A & 20 & 19.6 & 20 & 19.6 \\ 1 B & 12 & 11.8 & 32 & 31.4 \\ 1 C & 3 & 2.9 & 35 & 34.3 \\ 10 & 7 & 6.9 & 42 & 41.2 \\ 2 A & 36 & 35.3 & 78 & 76.5 \\ 2 B & 12 & 11.8 & 90 & 88.2 \\ 2 C & 11 & 10.8 & 101 & 99.0 \\ 20 & 1 & 1.0 & 102 & 100.0\end{array}$


CLASS SORT

CLASS $=$ GM

CUMULATIVE CUMULATIVE

TIMES FREOUENCY PERCENT FREOUENCY PERCENT

$\begin{array}{lllll}1 A & 36 & 26.9 & 36 & 26.9 \\ 1 B & 32 & 23.9 & 68 & 50.7 \\ 1 C & 11 & 8.2 & 79 & 59.0 \\ 10 & 8 & 6.0 & 87 & 64.9 \\ 2 A & 12 & 9.0 & 99 & 73.9 \\ 2 B & 25 & 18.7 & 124 & 92.5 \\ 2 C & 5 & 3.7 & 129 & 96.3 \\ 20 & 5 & 3.7 & 134 & 100.0\end{array}$


CLASS SORT

CLASS $=G P$

CUMULATIVE CUMULATIVE

TIMES FREOUENCY PERCENT FREOUENCY PERCENT

$\begin{array}{ccccc}1 A & 43 & 35.2 & 43 & 35.2 \\ 1 B & 22 & 18.0 & 65 & 53.3 \\ 1 C & 5 & 4.1 & 70 & 57.4 \\ 10 & 3 & 2.5 & 73 & 59.8 \\ 2 A & 29 & 23.8 & 102 & 83.6 \\ 2 B & 15 & 12.3 & 117 & 95.9 \\ 2 C & 2 & 1.6 & 119 & 97.5 \\ 20 & 3 & 2.5 & 122 & 100.0\end{array}$


CLASS SORT

CLASS $=H$

CUMULATNE CUMULATNE

TIMES FREQUENCY PERCENT FREQUENCY PERCENT

$\begin{array}{lllll}1 A & 3 & 30.0 & 3 & 30.0 \\ 1 B & 3 & 30.0 & 6 & 60.0 \\ 2 A & 3 & 30.0 & 9 & 90.0 \\ 2 B & 1 & 10.0 & 10 & 100.0\end{array}$


CLASS SORT

CLASS $=\mathrm{L}$

$$
\text { CUMULATNE CUMULATIVE }
$$

TIMES FREQUENCY PERCENT FREQUENCY PERCENT

$\begin{array}{rrrrr}1 A & 2 & 9.5 & 2 & 9.5 \\ 10 & 1 & 4.8 & 3 & 14.3 \\ 2 A & 8 & 38.1 & 11 & 52.4 \\ 2 B & 8 & 38.1 & 19 & 90.5 \\ 2 C & 2 & 9.5 & 21 & 100.0\end{array}$




\section{CLASS SORT}

CLASS $=M$

$$
\text { CUMULATINE CUMULATME }
$$

TIMES FREQUENCY PERCENT FREQUENCY PERCENT

$\begin{array}{ccccc}1 A & 9 & 42.9 & 9 & 42.9 \\ 1 B & 7 & 33.3 & 16 & 76.2 \\ 10 & 1 & 4.8 & 17 & 81.0 \\ 2 A & 2 & 9.5 & 19 & 90.5 \\ 2 B & 2 & 9.5 & 21 & 100.0\end{array}$


CLASS SORT

CLASS $=P$

CUMULATINE CUMULATIVE

TIMES FREOUENCY PERCENT FREQUENCY PERCENT

$\begin{array}{lllll}1 A & 2 & 20.0 & 2 & 20.0 \\ 1 B & 6 & 60.0 & 8 & 80.0 \\ 2 A & 1 & 10.0 & 9 & 90.0 \\ 2 B & 1 & 10.0 & 10 & 100.0\end{array}$




\section{CLASS SORT}

CLASS $=S$

CUMULATIVE CUMULATIVE

TIMES FREQUENCY PERCENT FREOUENCY PERCENT

$\begin{array}{lllll}1 A & 12 & 21.4 & 12 & 21.4 \\ 1 B & 6 & 10.7 & 18 & 32.1 \\ 1 C & 1 & 1.8 & 19 & 33.9 \\ 10 & 4 & 7.1 & 23 & 41.1 \\ 2 A & 11 & 19.6 & 34 & 60.7 \\ 28 & 16 & 28.6 & 50 & 89.3 \\ 2 C & 5 & 8.9 & 55 & 98.2 \\ 20 & 1 & 1.8 & 56 & 100.0\end{array}$


CLASS SORT

CLASS $=T$

CUMULATINE CUMULATIVE

TIMES FREOUENCY PERCENT FREOUENCY PERCENT

$\begin{array}{ccccc}\text { IA } & 1 & 12.5 & 1 & 12.5 \\ \text { IB } & 2 & 25.0 & 3 & 37.5 . \\ \text { IC } & 1 & 1.8 & 19 & 33.9 \\ \text { ID } & 4 & 7.1 & 23 & 41.1 \\ 2 A & 2 & 25.0 & 5 & 62.5 \\ 2 B & 1 & 12.5 & 6 & 75.0 \\ 2 C & 2 & 25.0 & 8 & 100.0\end{array}$




\section{Attachment Nine}

Statistical analysis of "NPARIWAY" 
ALLMEAN.XLS

\begin{tabular}{|c|c|c|c|c|c|c|c|}
\hline & A & $\mathrm{B}$ & C & DI & $E$ & $F$ & G \\
\hline 1 & Venouger & aneses & lovert & m & mear & stavenos oev. & Dor.mimans \\
\hline 2 & vesere & c & in & 27 & 7.393239393 & 1.35012434 & \\
\hline 3 & comp & c & 1 Ia & 27 & 8.00000007 & 1.00073242 & \\
\hline 4 & rmar & c & in & 27 & 0.26026028 & 1.72220020 & \\
\hline 5 & Accumate & c & In & 27 & - 200352329 & iseor41640 & \\
\hline 6 & nagnr & c & IA & 27 & 7.200303939 & 1.M11Eose & \\
\hline 7 & oseno & c & In & 27 & 3.40140148 & 2.07 rencos & \\
\hline 8 & Fomenat & c & in & 27 & 0.40740741 & 1.737 mox & \\
\hline 9 & mea & c & in & 27 & 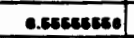 & 1.02512327 & \\
\hline 10 & mercon & c & in & 27 & $3.11111,1$ & 2.73027100 & \\
\hline 11 & moron & c & In & 22 & 3.1300000 & 2.7025212 & \\
\hline 12 & crencx & e & in & 27 & 0.22222222 & 0.42000027 & \\
\hline 13 & weoner & c & 10 & +1 & 7.126 & s.onvieses & \\
\hline 14 & come & c & Iis &. & 7.025 & 1.60 romess & \\
\hline 15 & rmar & c & in & - & 7 & 102724022 & \\
\hline 16 & Accumate & c & 12 & 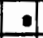 & 7.28 & 1.40000702 & \\
\hline 17 & and & ic & is &. & 0.28 & 1.30075018 & \\
\hline 18 & oseneo & c. & 18 & 1 & 4.5 & 0,42201307 & \\
\hline 19 & romenat & c & 18 & - & 7370 & $1.40 \pi$ eneses & \\
\hline 20 & Fon & c & 12 & -1 & 7.8 & 0.0200201 & \\
\hline 21 & meson & $c$ & 10 & 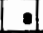 & 1.878 & 2.47407373 & \\
\hline 22 & meron & c & 18 & 4 & 1.5 & 1 & \\
\hline 23 & CHECX & $c$ & 18 & .1 & וויוויו1ו.1ו & 0.323320320 & \\
\hline 24 & useror & $c$ & Ic & 2 & 7.6 & 0,70710070 & \\
\hline 25 & comp & tc & ic & 2 & 8.5 & 2.121320034 & \\
\hline 26 & trman & $c$ & ic & 2 & 1 & 2.02042712 & \\
\hline 27 & Accumate & c & he & 2 & 7 & of & \\
\hline 28 & monv & E & Ie & 2 & 7.5 & 0.70710010 & \\
\hline 29 & OSAE:O & te & ic & 2 & 2 & 2.02042712 & \\
\hline 30 & romanat & te & ic & 2 & 5 & 1.41421356 & \\
\hline 31 & FAeO & c & IC & 2 & 4 & 2.02042712 & \\
\hline 32 & meseon & c & ic & 3 & 2 & 1.73206001 & \\
\hline 33 & meron & c & Tic & 4 & 3.26 & 3.20166212 & \\
\hline 34 & CMECR & ic & ic & 5 & 0 & 0 & \\
\hline 35 & 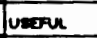 & ic & 10 & 2 & 3 & 2.02042712 & \\
\hline 36 & coin & c & 10 & 2 & ] & 0 & 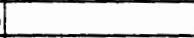 \\
\hline 37 & numeir & $c$ & 10 & 2 & 2 & 2.02842712 & \\
\hline 38 & Accumate & ke & 10 & 2 & 1.6 & 0.70710070 & \\
\hline 39 & nainm & Tc & 10 & 2 & 3.6 & 3.65600301 & \\
\hline 40 & osereo & c & 10 & 2 & 4 & 5.06cencess & \\
\hline 41 & Fomarat & c & 10 & 2 & 2 & 1.41421350 & \\
\hline 42 & FnEO & $c$ & 10 & 2 & 2.5 & 0.70310878 & \\
\hline 43 & reseson & ic & 10 & 2 & 4 & 01 & \\
\hline 44 & PAEFOA & c & 10 & 2 & 4 & of & \\
\hline 45 & aneax & ic & 10 & 2 & 0 & 0 & \\
\hline 46 & userur & $c$ & $2 A$ & 24 & Q.30333303 & 1.37200001 & \\
\hline 47 & comp & c & $2 A$ & 24 & 0.000000007 & 1.20501070 & \\
\hline 48 & Trmely & Ic & $2 A$ & 24 & 6.70833303 & 1.62799334 & 0.44007407 \\
\hline
\end{tabular}


ALLMEAN.XLS

\begin{tabular}{|c|c|c|c|c|c|c|c|}
\hline & $A$ & $B$ & C & D & $E$ & $F$ & $\mathbf{G}$ \\
\hline 49 & Accumate & $c$ & $2 A$ & 24 & 0.200339303 & 1.c6aneses: & 0.120 \\
\hline 50 & nenvir & c & $2 A$ & 24 & 0.8 & 1.1 rosiseses & 8.10menes? \\
\hline 51 & Oanes & c & $2 A$ & 21 & 4.47618040 & 207 conesis & osenges \\
\hline 52 & Fomenat & c & $2 A$ & 24 & 0.45033323 & 9.70070145 & 0.00002502 \\
\hline 53 & $m=0$ & c & $2 a$ & 24 & A.14erecent & 2.6000045 & 0 \\
\hline 54 & rexen & c & 24 & 20 & 3.2179013 & 200ararea & 0.10002010 \\
\hline 55 & maron & $c$ & $2 A$ & 21 & 1.02300005 & 0.00070744 & -1.01200012 \\
\hline 56 & CHeax & $c$ & $2 A$ & 10 & 0.1 ecenect & 0.00040240 & - \\
\hline 57 & vaserus & $\varepsilon$ & 28 & 21 & 0.10047010 & 12407010 & 1. \\
\hline 58 & comp & c & 28 & 23 & 7.42087140 & 1.71 (190006s & 0.tmanzans \\
\hline 59 & mingr & c & 20 & 21 & 7.04701008 & 1.20060014 & $0.0 n 7 e r v e n$ \\
\hline 60 & accumare & c & 20 & 21 & 7.67942057 & 1.4342740 & exsrasers \\
\hline 61 & mant & c & 20 & 21 & c.010047ea & 1.1100000 & axposies \\
\hline 62 & onso & e & 28 & 21 & 0.4200714a & 2.0782097 & 100007140 \\
\hline 63 & romuat & c & 28 & 21 & 7.230000024 & 1,04132457 & 0.19000070 \\
\hline 64 & meo & c & 29 & 19 & 0.6200167 & 3.0700949 & sorscenzi \\
\hline 65 & meson & c & 20 & 21 & 1.0047010 & 2.07134007 & 0.0221010 \\
\hline 66 & moron & c & 28 & 21 & 1.01004742 & 0.22000220 & o.116antea \\
\hline 67 & checx & $e$ & 28 & 10 & 0 & 0 & 0.11111119 \\
\hline 68 & userpus & $c$ & $2 c$ & 3 & s.eceecest & 0.67735027 & 1.90000607 \\
\hline 69 & conem & c & $2 c$ & 2 &. .6 & 0.70710070 & 긔 \\
\hline 70 & rewerer & c & $2 c$ & 2 & 1 & 의 & 2 \\
\hline 71 & Accumure & c & $2 c$ & 2 & 1 & 0 & 1 \\
\hline 72 & Reivart & c & $2 c$ & 3 & 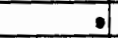 & 0 & 1.6 \\
\hline 73 & osmea & c & $2 c$ & 3 & 0.323333230 & 4.01000216 & 4.9000000 \\
\hline 74 & FOMUAT & c & $2 c$ & 2 & 0 & 0 & - \\
\hline 75 & FAEO & $c$ & $2 c$ & 2 & 0 & 0 & 4 \\
\hline 76 & posson & Tc & $2 x$ & 2 & 1 & 0 & -1 \\
\hline 77 & meson & c & $2 c$ & 3 & 1.3202030233 & 0.67735027 & . 1.016ecenes? \\
\hline 78 & EMECx & c & $2 c$ & 3 & of & 0 & 0 \\
\hline 79 & userur & c & 20 & & & & 3 \\
\hline 80 & COMP & c & 20 & & & & 3 \\
\hline 81 & Truesr & c & 20 & & & & .2 \\
\hline 82 & ACcurate & c & 20 & & & & -1.5 \\
\hline 83 & aeing & $c$ & 20 & & & & 3.5 \\
\hline 84 & osin $\leq 0$ & ic & 20 & & & & 4 \\
\hline 85 & Fomanat & c & 20 & & & & -2 \\
\hline 86 & Faso & c & 20 & & & & -2.0 \\
\hline 87 & preson & c & 20 & & & & 4 \\
\hline 88 & PAREOA & c & 20 & & & & 4 \\
\hline 89 & cmeox & c & 20 & & & & 0 \\
\hline 90 & USEFUL & if & in & & & & \\
\hline 97 & comp & E & in & & & & \\
\hline 92 & TIMEEYY & F & In & & & & \\
\hline 93 & ACCURATE & F & IIA & & & & \\
\hline 94 & PeELVNT & F & in & & & & \\
\hline 95 & ospeo & IF & in & & & & \\
\hline 96 & Forasat & $f_{E}$ & In & & & & \\
\hline
\end{tabular}


ALLMEAN.XLS

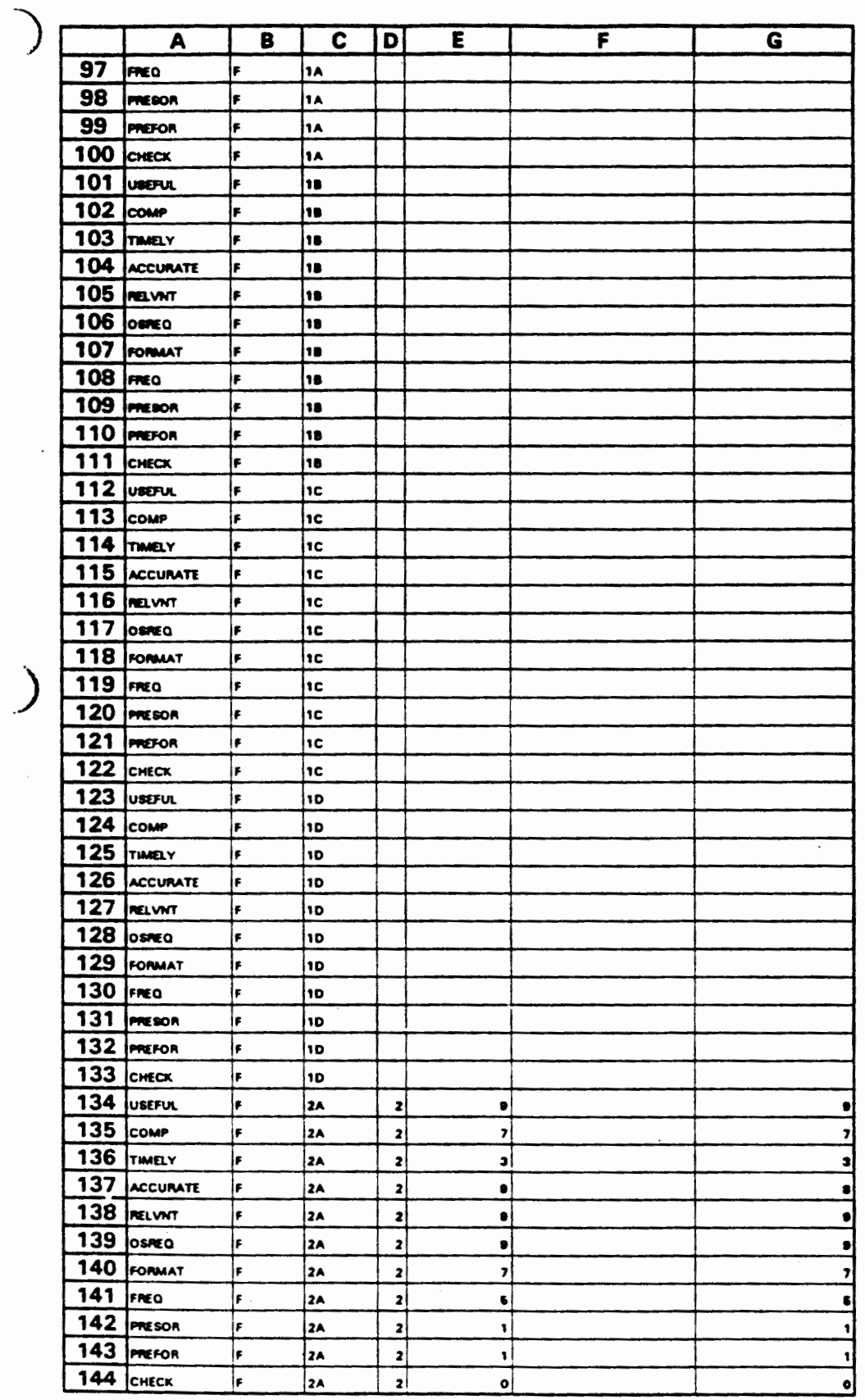


ALLMEAN.XLS

\begin{tabular}{|c|c|c|c|c|c|c|c|}
\hline & A & B & C & D & $E$ & $F$ & G \\
\hline 145 & weserer & $T_{F}$ & 28 & & & & ? \\
\hline 146 & counp & $F$ & 20 & & & & $\circ$ \\
\hline 147 & Trear & If & 28 & & & & . \\
\hline 148 & accumure & E & 28 & & & & . \\
\hline 149 & newws & $F$ & 20 & & & & . \\
\hline 150 & Tonse & F & 20 & & & & 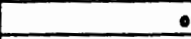 \\
\hline 151 & rosmut & $F$ & 28 & & & & $\therefore$ \\
\hline 152 & meo & F & 25 & & & &. \\
\hline 153 & miseon & IF & 29 & & & & $\therefore$ \\
\hline 154 & moron & $E$ & 20 & & & & 은 \\
\hline 155 & checx & E & 20 & & & & 0 \\
\hline 156 & Juserer & E & $x$ & & & & $\circ$ \\
\hline 157 & comp & IF & $2 c$ & & & & 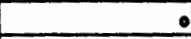 \\
\hline 158 & Tremar & E & $x$ & & & & $\therefore$ \\
\hline 159 & accumuTE & $F$ & $x$ & & & &. \\
\hline 160 & raw & $F$ & $2 c$ & & & &. \\
\hline 161 & Jomese & $F$ & $2 c$ & & & & 0 \\
\hline 162 & roment & IF & $2 c$ & & & & $\circ$ \\
\hline 163 & Fino & If & $2 c$ & & & & 0 \\
\hline 164 & meson & If & $2 c$ & & & & 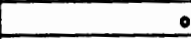 \\
\hline 165 & meron & IF & $x$ & & & & 0 \\
\hline 166 & $\operatorname{cosec}$ & If & $2 c$ & & & & 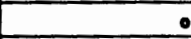 \\
\hline 167 & USEFur & IF & 20 & & & & $\circ$ \\
\hline 168 & comp & IE & 20 & & & & 의 \\
\hline 169 & Trmer & IF & 20 & & & & 0 \\
\hline 170 & Accumute & IF & 20 & & & & 0 \\
\hline 171 & neLLw & If & 20 & & & & 0 \\
\hline 172 & ospeo & $F$ & 20 & & & & 0 \\
\hline 173 & romanat & $E$ & 20 & & & & . \\
\hline 174 & enco & I & 20 & & & & 0 \\
\hline 175 & presen & IE & 20 & & & & 0 \\
\hline 176 & meron & $F$ & 20 & & & & 0 \\
\hline 177 & CMECX & if & 20 & & & & 0 \\
\hline 178 & Jusear & io & in &. & - I reaceaner & 3.3115067 & \\
\hline 179 & comp & 10 & in & of & .1 & 2.62002213 & \\
\hline 180 & TimelY & a & in & -1 & 4.eresens? & 1.3002001 & \\
\hline 181 & AccumitE & 10 & in & . & 5 & 0.00442719 & \\
\hline 182 & nenver & to & in &. & e.escecener & 1.00100007 & \\
\hline 183 & osase & 6 & Tin & 4 & 5.169060s? & 3.07072021 & \\
\hline 184 & romamat & 10 & in & - & 2.03335023 & 2.06773003 & \\
\hline 185 & FPEO & 10 & in & 4 & 5.0606000? & o.moneese & \\
\hline 186 & meson & $G$ & in & -1 & 1.eresenes & 1.00200310 & \\
\hline 187 & preston & to & In & 6 & 1.2 & 0.472130 & \\
\hline 188 & CMEEX & to & In & .1 & $0.100 c 0 e s ?$ & 0.40024020 & \\
\hline 189 & USERUL & 6 & 18 & 4 & 0.0 & 4. J50000094 & \\
\hline 190 & comp & ic & 10 & 4 & 7.26 & 1.70702613 & \\
\hline 191 & TrMELY & 10 & 18 & 4 & 7.25 & 0.6 & \\
\hline 192 & Accurure & is & in & 4 & .1 & 1.41621368 & \\
\hline
\end{tabular}


ALLMEAN.XLS

\begin{tabular}{|c|c|c|c|c|c|c|c|}
\hline & A & B & C & D & $E$ & $F$ & $\mathbf{G}$ \\
\hline 193 & mant & To & 18 & 4 & .28 & 1.8 & \\
\hline 194 & Denso & 10 & 18 & 4 & .78 & 4.27200197 & \\
\hline 195 & romemat & b & 10 & 4 & .1 & o.evenoeses & \\
\hline 196 & teneo & 10 & 10 & 4 & .0 & 0.57135027 & \\
\hline 197 & minseon & a & 18 & 4 & 1 & of & \\
\hline 198 & meron & to & 130 & 4 & 1 & 0 & \\
\hline 199 & crece & 0 & 18 & 4 & 0.25 & 0.5 & \\
\hline 200 & verern. & 10 & Ic & 0 & 0 & & \\
\hline 201 & coner & 0 & ic & 0 & of & & \\
\hline 202 & Trmear & T6 & ic & 0 & 0 & & \\
\hline 203 & AccumutE & lo & IC & of & 01 & & \\
\hline 204 & nans & to & Ix & 0 & of & & \\
\hline 205 & omea & 0 & ic & 0 & of & & \\
\hline 206 & FomaAt & 0 & ic & of & 0 & & \\
\hline 207 & Treo & To & ic & 0 & 0 & & \\
\hline 208 & premon & ic & is & .1 & 1 & & \\
\hline 209 & preson & 10 & ic & 0 & 0 & & \\
\hline 210 & CHECK & 0 & ic & 1 & 0 & & \\
\hline 211 & vererr & 10 & 10 & 1 & 3 & & \\
\hline 212 & comp & 16 & 10 &. &. & & \\
\hline 213 & rmar & to & 10 & , & 1 & & \\
\hline 214 & accumate & to & 10 & 3 & 1 & & \\
\hline 215 & nanvin & to & 10 & 3 & 1 & & \\
\hline 216 & ospeo & a & 10 & 1 & 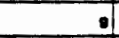 & & \\
\hline 217 & romar & 10 & 10 & 1 & t) & & \\
\hline 218 & Fato & 16 & 10 & 1) & 7 & & \\
\hline 219 & meson & 10 & 10 & 2 & 3 & & \\
\hline 220 & Deneron & o & 10 &. & 0 & & \\
\hline 221 & CMECx & Ta & 10 & 1 & of & & \\
\hline 222 & userur & o & 24 & 12 & 7.602030330 & 1.senzrezes & 1,4100000 \\
\hline 223 & comp & 10 & 24 & 12 & 7.41000007 & 1.60427020 & 2.4100000 \\
\hline 224 & remely & 0 & $2 A$ & 12 & 7.0 & 1.6000000 & $2 . \operatorname{mos} 00$ \\
\hline 225 & accumure & 6 & $2 A$ & 12 & 7.03239203 & $1.26730 \mathrm{men}$ & 2.0000000 \\
\hline 226 & neing & 6 & $2 a$ & 12 & 7.033232330 & 1.40346053 & 1.10000000 \\
\hline 227 & osnea & $G$ & $2 A$ & 12 & 2.00203023 & 2.21456028 & .2 .30000 \\
\hline 228 & fonmat & 6 & $2 A$ & 11 & 0.72727270 & 1.42002720 & 3.0000000 \\
\hline 229 & ineo & G & $2 A$ & in & C.ecoseven & 2.07307240 & 0.0000000 \\
\hline 230 & meson & to & $2 a$ & 12 & 2 & 1.06144606 & 0.00000 \\
\hline 231 & meron & 6 & $2 A$ & 12 & 2.009333033 & 1.02136372 & 0.00 \\
\hline 232 & TEMECK & to & $2 A$ & 11 & 0 & 0 & 0.80000000 \\
\hline 233 & USEFuz & to & 28 & .1 & .1 & & 20 \\
\hline 234 & comp & $a$ & 20 & it & 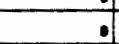 & & $3 . \pi$ \\
\hline 235 & TIMEELr & a & 28 & 1 & 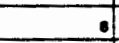 & & 0.70 \\
\hline 236 & Accumite & to & 28 & 1 & . & & 0 \\
\hline 237 & NESUNT & to & 28 & 1 &. & & 0.70 \\
\hline 238 & osese & 6 & 20 & 1 & o) & & 5.70 \\
\hline 239 & romenat & to & 20 & 1 & 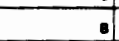 & & . \\
\hline 240 & FREO & ta & 28 & 1 & 0 & & 0.0 \\
\hline
\end{tabular}


ALLMEAN.XLS

\begin{tabular}{|c|c|c|c|c|c|c|c|}
\hline & $\bar{A}$ & $\mathrm{~B}$ & C & D & $E$ & $F$ & $G$ \\
\hline 241 & ercson & o & 28 & 1 & 3 & & 0 \\
\hline 242 & Protor & a & 280 & , & 1 & & -0 \\
\hline 243 & CHECK & to & 20 & 1 & 0 & & -20 \\
\hline 244 & Juekrer & to & $x$ & & & & 0 \\
\hline 245 & cones & To & $x$ & & & & 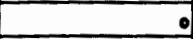 \\
\hline 246 & Fumar & 0 & $2 x$ & & & & 0 \\
\hline 247 & Accumare & a & $2 x$ & & & & 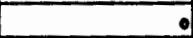 \\
\hline 248 & new & 10 & $x$ & & & & 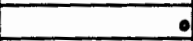 \\
\hline 249 & oenco & 10 & $2 c$ & & & & $\bullet$ \\
\hline 250 & Fonmat & a & $2 c$ & & & & 0 \\
\hline 251 & $m \in 0$ & o & $2 x$ & & of & & 0 \\
\hline 252 & mexion & to & $x$ & & -1 & &. \\
\hline 253 & meron & to & $x$ & & of & & 0 \\
\hline 254 & CMECX & o & $x$ & & 1 & & 0 \\
\hline 255 & veerur & a & 20 & 2 & 3.6 & J.6068000 & 28 \\
\hline 256 & comp & e & 20 & 2 & .0 & 0.70710080 & 7.8 \\
\hline 257 & numer & 0 & 20 & 2 & 0 & 1.41421350 & 3 \\
\hline 258 & ACCUMATE & to & 20 & 3 & 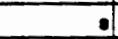 & 1.4142136 & $?$ \\
\hline 259 & nawr & e & 20 & 2 & 4 & 4.24204000 & 3 \\
\hline 260 & Toseneo & io & 20 & 2 & 4 & 4.24264000 & 3 \\
\hline 261 & Fomeat & Ta & 20 & 2 & .1 & 1.4142195 & 1 \\
\hline 262 & anso & 10 & 20 & 2 & 0 & 1.41621960 & 3 \\
\hline 263 & $m=s o n$ & 6 & 20 & 2 & 1 & 0 & 0 \\
\hline 264 & meston & 0 & 20 & 2 & 1.5 & 0.70710078 & 1.5 \\
\hline 265 & CHEOX & 10 & 20 & 0 & 0 & & 0 \\
\hline 266 & USEFUL & tan & in & 7 & 0.71420671 & $1.265 \cos 34$ & \\
\hline 267 & comp & tan & in & 7 & 0.67142067 & 1.01034718 & \\
\hline 268 & trmar & toA & in & 7 & 0 & 2.490000074 & \\
\hline 269 & accumare & an & in & 7 & 0.14206714 & 2.02600000 & \\
\hline 270 & $\log n$ & toa & ia & 7 & 0.2067 mez) & 0.06110073 & \\
\hline 271 & Joseno & TaA & In & 7 & 0.42067140 & 3.023400032 & \\
\hline 272 & Tromeat & GA & In & 7 & .607142067 & 2.00206207 & \\
\hline 273 & $t=0$ & GA & in &, & $4.7142 a 61$ & 2.7610220 & \\
\hline 274 & menson & os & in & 7 & 0.06714200 & $0.3770 \mathrm{ens}$ & \\
\hline 275 & meron & OA & in & 4 & 0.76 & 0.6 & \\
\hline 276 & EmEex & TaA & In &. & 0.26 & 0.6 & \\
\hline 277 & USEFUL & toA & 10 & . &. .4 & 0.00012710 & \\
\hline 278 & comp & JaA & 10 & . & .1 & 1.73206001 & \\
\hline 279 & TiMeLr & TA & 18 & . & 0.4 & $0.000 \times 27110$ & \\
\hline 280 & AccumTE & ToA & 18 & . & 0.4 & 0.54772260 & \\
\hline 281 & netunt & Ta & 18 & . &.. & 0.64773250 & \\
\hline 282 & tosece & GA & 10 & 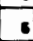 & 4.2 & 3.00071774 & \\
\hline 283 & FonMAT & ga & 10 & . &. & 1.41421366 & \\
\hline 284 & FreO & lon & tio & . & 7.6 & 1.14017600 & \\
\hline 285 & Deson & GA & 10 & 5 & 1.2 & 0.4772138 & \\
\hline 286 & DPeron & ga & 10 & 6 & 9.2 & 0.472130 & \\
\hline 287 & CGECK & on & 18 & 4 & 0.6 & 0.67736027 & \\
\hline 288 & USEFUL & $T_{a A}$ & ic & , & . & & \\
\hline
\end{tabular}


ALLMEAN.XLS

\begin{tabular}{|c|c|c|c|c|c|c|c|}
\hline & A & B & $\mathbf{C}$ & D] & $E$ & $F$ & G \\
\hline 289 & cone & an & ic & 3. & 0 & & \\
\hline 290 & traner & an & ic & 7 & 1 & & \\
\hline 291 & ACcumite & an & Ic & 1 & 0 & & \\
\hline 292 & navir & tan & Ic & 3 & -1 & & \\
\hline 293 & $0=0$ & an & ic & 1 & 1 & & . \\
\hline 294 & Foment & on & ic & 1 & 1 & & \\
\hline 295 & men & an & IC & 1 & 1 & &. \\
\hline 296 & meson & an & ic & 1 & 1 & & . \\
\hline 297 & maron & an & IC & 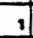 & 2 & & . \\
\hline 298 & CHECX & eA & Ic & 1 & of & & \\
\hline 299 & veear & an & 10 & & & & \\
\hline 300 & comp & en & 10 & & & & \\
\hline 301 & rumer & en & 10 & & & & \\
\hline 302 & Accuruts & an & 10 & & & & \\
\hline 303 & mant & an & 10 & & & & \\
\hline 304 & 0 oenco & on & 10 & & & & \\
\hline 305 & Fomat & GA & 10 & & & & \\
\hline 306 & Fineo & las & 10 & & & & \\
\hline 307 & $m \in 80 n$ & lon & 10 & & & & \\
\hline 308 & meron & tan & 10 & & & & \\
\hline 309 & CMECX & lan & 10 & & & & \\
\hline 310 & Uxarl & lon & 24 &. & 7.28 & $2.187 e 2 \pi 5$ & 0.0007109 \\
\hline 311 & romp & GA & 24 &. & .6 & 2.07010000 & 0.0714207 \\
\hline 312 & trimelr & ToA & $2 A$ & 0 & 7.126 & 2.1612440 & 1.120 \\
\hline 313 & Accumate & Ga & $2 A$ &. & .376 & 1.02200000 & 0.20214200 \\
\hline 314 & nesinvt & an & 24 & 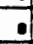 & 7376 & 1.50600000 & 0.01071420 \\
\hline 315 & 0000 & loA & $2 A$ & 7 & 0.28 & 2.04607050 & 1.02142000 \\
\hline 316 & ronomat & tan & $2 A$ & 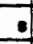 & 1.376 & 1.50247010 & 1.000007149 \\
\hline 317 & ENeO & lon & $2 A$ & 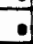 & 7.276 & 1.67 mow & 2.00071420 \\
\hline 318 & ereson & Tan & $2 a$ & . & 1 & 0 & 0.14206714 \\
\hline 319 & meron & loA & $2 A$ & $\bullet$ & 2.060000067 & 3.14112600 & i.01000007 \\
\hline 320 & CMECX & GA & 21 & 7 & 0.14205114 & 0.37 reens & 0.1071420 \\
\hline 321 & userur & 6A & 28 & 3 & of & & 0.0 \\
\hline 322 & comp & ToA & 20 & 1 & -1 & & , \\
\hline 323 & remer & an & 20 & 1 & .1 & & - \\
\hline 324 & Accumate & ian & 20 & 1 &. & & 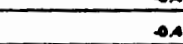 \\
\hline 325 & $\operatorname{man} x$ & Tan & 28 & 7 & . & & 04 \\
\hline 326 & osseo & oA & 20 & 1 & 0 & & 4.2 \\
\hline 327 & FonMAT & GA & 28 & 1. & - & & $\circ$ \\
\hline 328 & aneO & loA & 20 & 1 & -1 & & 0.4 \\
\hline 329 & preson & Ga & 28 & 1 & 1 & & 0.2 \\
\hline 330 & meron & Tan & 28 & 1 & 8 & & 0.2 \\
\hline 331 & CWECK & Ga & 28 & , & 0 & & 0.0 \\
\hline 332 & Juserul & toa & $2 c$ & 7 & . & & 。 \\
\hline 333 & COMP & GA & $x$ & 1 & .1 & & 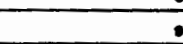 \\
\hline 334 & TIMELIY & GA & $2 c$ & 1 & 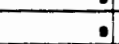 & & 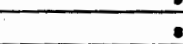 \\
\hline 335 & accunate & Ga & $2 c$ & 1 & 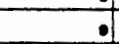 & & $\bullet$ \\
\hline 336 & ReLUWr & Ga & $2 c$ & 1 & 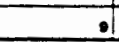 & &. \\
\hline
\end{tabular}


ALIMEAN.XLS

\begin{tabular}{|c|c|c|c|c|c|c|c|}
\hline & $A$ & $B$ & C & DI & $E$ & $F$ & $\mathbf{G}$ \\
\hline 337 & oereo & an & $2 c$ & 1 & -1 & & 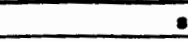 \\
\hline 338 & Foman & an & $2 x$ & 1 & . & & 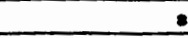 \\
\hline 339 & faEO & an & $2 c$ & 1 & 1 & & 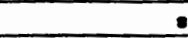 \\
\hline 340 & micon & ian & 26 & 0 & 0 & & -1 \\
\hline 341 & maron & tan & $x$ & 1 & 2 & & 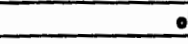 \\
\hline 342 & creca & $\tan$ & $2 c$ & 1 & 0 & & . \\
\hline 343 & vasern & $\tan$ & 20 & & & & 0 \\
\hline 344 & cons & tan & 20 & & & & 0 \\
\hline 345 & Trwar & tan & 20 & & & & 0 \\
\hline 346 & Accumure & ian & 20 & & & & 0 \\
\hline 347 & nowr & as & 20 & & & & $\therefore$ \\
\hline 348 & oenco & en & 20 & & & & 2 \\
\hline 349 & romenat & $\tan$ & 120 & & & & 0 \\
\hline 350 & FAsO & Tan & 20 & & & & 0 \\
\hline 351 & meson & an & 20 & & & & . \\
\hline 352 & moron & as & 20 & & & &. \\
\hline 353 & canecx & an & 20 & & & & 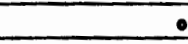 \\
\hline 354 & userer & se & in & 20 & 0 & 2.0610667 & \\
\hline 355 & cone & as & 14 & 20 & 0.00 & $1 . \operatorname{sen} \theta x$ & \\
\hline 356 & trmary & as & in & 20 & .6.6s & $2.6 \mathrm{censi20}$ & \\
\hline 357 & Accumure & es & in & 20 & .0 & 1.0002000 & \\
\hline 358 & Renw & 10 & IA & 20 &. .0 & 1.eventsoo & \\
\hline 359 & ospeo & 60 & in & 20 & 3.2 & 3.15601321 & \\
\hline 360 & romais & as & in & 20 & 5 & 2.0774070 & \\
\hline 361 & knEO & 68 & in & 20 & , & 1.4500626 & \\
\hline 362 & exeson & Tos & in & 20 & 1.36 & $1.6 \mathrm{es} 2475$ & \\
\hline 363 & prefon & $\infty$ & 19 & 10 & 2.1 acanecer & 22667117 & \\
\hline 364 & CAHECX & $a$ & $1 \mathrm{a}$ & 17 & 0.41170471 & 0.0072000 & \\
\hline 365 & yerper & 10 & 10 & 12 & 7.560200203 & 1.00237607 & \\
\hline 366 & cone & es & 18 & 12 & 7.23332330 & 2.42402110 & \\
\hline 367 & Truatir & $\infty$ & 18 & 12 & c.41eneces? & 3.00034604 & \\
\hline 368 & accunare & as & 18 & 12 & - cor aseces? & 2.00302847 & \\
\hline 369 & rerunr & as & 18 & 32 & ,.78 & 1.005220071 & \\
\hline 370 & oseo & 60 & 10 & 12 & 4.003333323 & 4.02300776 & \\
\hline 371 & romarar & 60 & In & 12 & c.ecosecen? & 2.00001700 & \\
\hline 372 & kneo & 68 & 10 & 12 & 7 & 2.023200004 & \\
\hline 373 & meson & ias & 10 & 12 & J.8160eene? & J.10046006s & \\
\hline 374 & preson & 60 & 10 & 10 & 2.0 & 2.07618116 & \\
\hline 375 & CMECK & $\infty$ & 10 & 11 & 0.18181010 & 0.40461002 & \\
\hline 376 & usefur & as & IC & 2 & 4.6 & 0.04074747 & \\
\hline 377 & comp & $\infty$ & ic & 2 & 3.8 & 3.83663391 & \\
\hline 378 & TPMEIr & 6 & ic & 1 & 1 & & \\
\hline 379 & Accumare & 60 & Ic & , & 1 & & \\
\hline 380 & ranur & 68 & Ic & 2 & 3 & 2.02042712 & \\
\hline 381 & osneo & as & ic & 2 & 1.5 & 0.70710078 & \\
\hline 382 & Fonmat & 108 & ic & 1 & 1 & & \\
\hline 383 & EASO & Tos & ic & 1 & 1 & & \\
\hline 384 & PPASSOR & co & Ic & 1 & of & & \\
\hline
\end{tabular}


ALLMEAN.XLS

\begin{tabular}{|c|c|c|c|c|c|c|c|}
\hline & A & 8 & C & DI & $E$ & $F$ & $\mathbf{G}$ \\
\hline 385 & moron & $\infty$ & ic & 2 & 0.6 & 0.7031067 & \\
\hline 386 & EMECX & es & ic & 2 & 0 & 0 & \\
\hline 387 & useren & os & 10 & 7 & 1.57142053 & 0.7007067 & \\
\hline 388 & comp & es & 10 & 7 & 4.20671420 & 3.00377266 & \\
\hline 389 & rimer & $\infty$ & 10 & 7 & 4.87142013 & 0.2071300 & \\
\hline 390 & ACcumaTE & as & 10 & 7 & 4.14208719 & 2.70046256 & \\
\hline 391 & naverr & $\infty$ & 10 & 7 & 3 & 2.04070131 & \\
\hline 392 & oseneo & $\infty$ & 10 & 4 & 2.200609077 & 3.14112600 & \\
\hline 393 & romant & as & 10 & 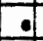 & 2.6 & 2.26091700 & \\
\hline 394 & Ex:o & as & 10 & of & 8.20302000 & 3.00050106 & \\
\hline 395 & meson & es & 10 & 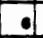 & 1 & 0 & \\
\hline 396 & moron & es & 30 & 4 & 3.25 & 0.5 & \\
\hline 397 & CMmex & $\infty$ & 10 & ) & of & 0 & \\
\hline 398 & usefur & $a$ & 24 & se. & 7 & 2.00300047 & 1 \\
\hline 399 & comp & 60 & $2 A$ & 20 & -sor11111 & 3.0002100 & 0.81111319 \\
\hline 400 & nemear & $\infty$ & $2 \mathrm{~A}$ & 30 & 0.000232300 & 2021 comens & 0.00 \\
\hline 401 & accumare & 6 & $2 A$ & 30 & 0.323232023 & 2.00020157 & 0.900 \\
\hline 402 & mant & as & $2 a$ & 30 & asensusen & 2.72406013 & 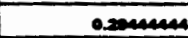 \\
\hline 403 & oenco & cos & $2 A$ & 20 & 3.66erstese & 3.01302767 & 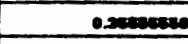 \\
\hline 404 & ronoun & CB & $2 n$ & 20 & $0.02 \mathrm{~mm} 7$ & 2.000370 & $1.02 \mathrm{~mm}$ \\
\hline 405 & freO & Ge & $2 A$ & 30 & 7.05056660 & $2.600 \mathrm{nopen}$ & $0.0600 \mathrm{cos}$ \\
\hline 406 & $m \in s o n$ & 60 & $2 A$ & 34 & 1.79650412 & 2.1070327 & $0>0$ acen12 \\
\hline 407 & maron & ios & $2 A$ & 27 & 1252020323 & 0.6547002 & $0 . \operatorname{sen}$ \\
\hline 408 & CHECX & 60 & $2 A$ & 20 & 0.20023077 & 0.46234432 & 0.9426000 \\
\hline 409 & USEFur & $G$ & 28 & 1 & 0.6 & 0.0260201 & 0.01 eneses) \\
\hline 410 & comp & las & 28 &. & 0 & 1.33200001 & 0.0000000 \\
\hline 411 & Trmar & Go & 28 & 0 & o.sucuenes & 0.72 ecesye & 2.0273777 \\
\hline 472 & accuratr & $\omega$ & 28 & .1 & 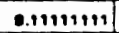 & 0.02700073 & 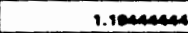 \\
\hline 413 & man w & 160 & 20 & et & 0.126 & 1.06200050 & 0.97 \\
\hline 414 & toseco & Gs & 20 & 1 & 3.10000000 & 3.02240001 & 0.1 cumanan \\
\hline 475 & romenar & 100 & 28 & -1 & 7.028 & 232000421 & 0.0600000 \\
\hline 416 & Tene & 100 & T28 & 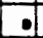 & .222222222 & 1.00200402 & 1.220202020 \\
\hline 417 & eneson & 00 & 128 & 1 & 2.0000000 & 203040040 & -1.0277777 \\
\hline 418 & meron & lo & 20 & $\cdot 1$ & 1.65660660 & 0.62704020 & $-1.0 \mathrm{manmen}$ \\
\hline 419 & EMEex & 60 & 28 & 4 & 0 & 0 & 0.18101010 \\
\hline 420 & USEFur & 100 & $2 c$ & 3 & 0.11420671 & J.201000nos & 2.21020571 \\
\hline 421 & Comp & se & $2 c$ & - & 4.00000007 & 4.70005220 & 1.10000007 \\
\hline 422 & Truenr & $\omega$ & $2 c$ & .1 & 4.03333033 & 4.20223720 & 3.00000000 \\
\hline 423 & necurate & 10 & $2 c$ & 0 & 4.6 & C.60347300 & 2.8 \\
\hline 424 & neivers & eo & $2 x$ & , & 7.20671420 & 3.20223500 & 0.20071420 \\
\hline 425 & OSFEO & Gs & $2 c$ & 7 & 0.4206710 & $3.020857 \pi 0$ & 3.02067140 \\
\hline 426 & rommat & 150 & $2 c$ &. & 3.03030350 & 0.20223720 & 2.000000 \\
\hline 427 & kneo & es: & $x$ & .1 & 3.6 & 4.27704003 & 2.0 \\
\hline 428 & freson & 68 & $2 c$ & 3 & 4.e0000006? & 4.100332 & 4.000000007 \\
\hline 429 & preston & 60 & $2 c$ &. & $1.0 \mathrm{mensm}$ & 0.72 eccesia & o.menaras \\
\hline 430 & EHECK & 68 & $2 c$ &. & 0.126 & 0.36366330 & 0.128 \\
\hline 431 & USEFUL & 60 & 20 & 1 & , & & 0.67102087 \\
\hline 432 & coMp & leg & 120 & 1 & 7 & & 3.20571420 \\
\hline
\end{tabular}




\section{ALLMEAN.XLS}

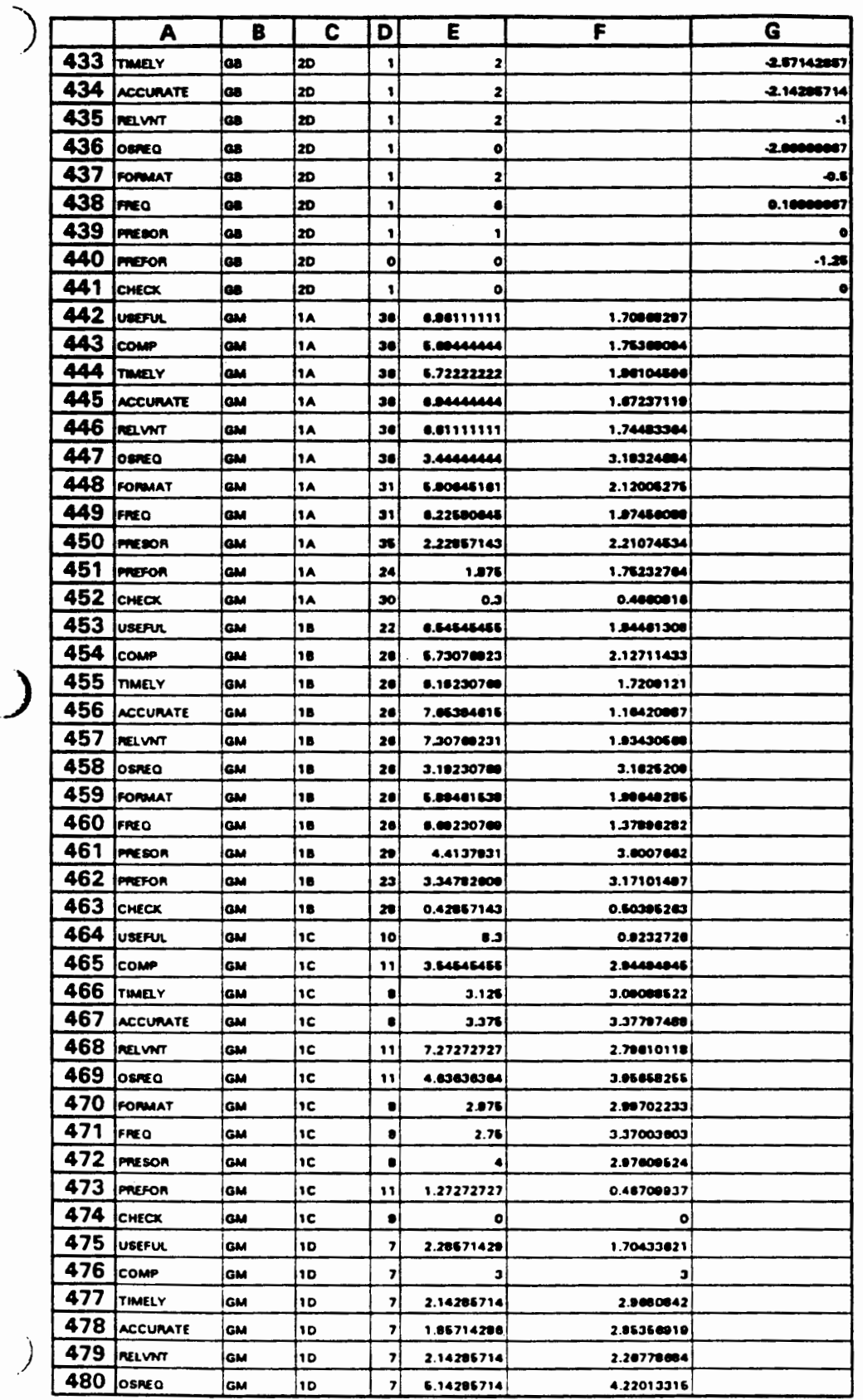

$$
925^{c}
$$$$
5
$$ 
ALLMEAN.XLS

\begin{tabular}{|c|c|c|c|c|c|c|c|}
\hline & A & B & C & D & $E$ & $F$ & G \\
\hline 481 & Fomat & an & 10 & 7 & 2.14208714 & 2.11670004 & \\
\hline 482 & FneO & am & 110 & 4 & 2.16000009 & 120070022 & \\
\hline 483 & meson & $\mathrm{cm}$ & 10 & 7 & 2.42067140 & 1.61106700 & \\
\hline 484 & meron & an & 10 & 4 & 3.5 & 2.30047014 & \\
\hline 485 & CHECX & an & 10 & 7 & 0 & 0 & \\
\hline 486 & veoren & an & $2 a$ & 12 & $7 . \pi$ & 101803000 & שחمستص: \\
\hline 487 & comp & an & $2 x$ & 12 & 7.25 & 1 206023044 & 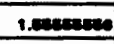 \\
\hline 488 & rumenr & $\mathrm{em}$ & $2 n$ & 12 & 7 & $1 A 7700700$ & $12 \mathrm{rmm}$ \\
\hline 489 & accumure & $\operatorname{en}$ & 24 & 12 & 7.26 & 1.01207004 & oswacesen \\
\hline 490 & raver & an & $2 A$ & 12 & $7.060 \times 40007$ & 1.02276060 & 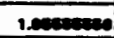 \\
\hline 491 & oeneo & an & $2 n$ & 12 & 4.6 & 2.16322100 & 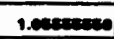 \\
\hline 492 & romar & an & $2 n$ & 12 & 7.0 & 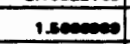 & 1 . \\
\hline 493 & $p \in O$ & $a m$ & $2 n$ & 12 & 102000000 & 1.0900575 & 1.007esen \\
\hline 494 & ensson & am & $2 a$ & 12 & 2.009333090 & 223037324 & 0.1402001 \\
\hline 495 & pmeron & $\cos$ & 24 & 10 & 1.7 & 1.23740381 & a.1\% \\
\hline 496 & check & an & $2 a$ & 0 & 0 & of & 0 \\
\hline 497 & userut & an & 28 & 10 & 0.78 & 0.4472130 & 2 sonenense \\
\hline 498 & comp & an & 28 & 10 & $1 . \pi$ & 1.24162070 & 2.0102000 \\
\hline 499 & rmary & om & 20 & 10 & 0.28 & 1.00460120 & 2007 mear \\
\hline 500 & ACCUMATE & an & 23 & 10 & 7.026 & 1.25000574 & 0.00000015 \\
\hline 501 & mant & GM & 20 & 10 & .376 & 0.00022677 & 1.0075070 \\
\hline 502 & osineo & om & 26 & 10 & 0.1078 & 2.02357012 & - .0061902 \\
\hline 503 & Fonmat & om & 20 & 10 & 7.1006 & 2.37350040 & 130020000 \\
\hline 504 & FA:O & $\mathrm{Gm}$ & 20 & 10 & 0 & 1.03270660 & 1.207001 \\
\hline 505 & PRESOR & Tam & 28 & 10 & 2.62001670 & 2.01200768 & $.1,10747721$ \\
\hline 506 & PEEFOR & $G M$ & 28 & 10 & 1.70004790 & 1.60301003 & . 1.5eseses41 \\
\hline 507 & CMECX & jam & 20 & 23 & 0.160504016 & 0.37563231 & 0.27472020 \\
\hline 508 & usetur & an & $x$ & 4 & 3.5 & 2.20047014 & 0.0 \\
\hline 509 & cone & $\mathrm{cm}$ & Te & 3 & 6.323330330 & 2.51001140 & 1.78707070 \\
\hline 510 & nmar & am & $2 c$ & 4 & 3.26 & 2.07220132 & 4.128 \\
\hline 511 & accumate & lam & $2 c$ & 3 & 0.00000007 & 3.21066026 & 3.20100007 \\
\hline 512 & nervint & Tom & $2 c$ & 4 & 7.6 & 3 & 0.22727273 \\
\hline 513 & oeneo & $\operatorname{tam}$ & $x$ & 3 & 2.00000007 & 2.61001100 & .1 .0000007 \\
\hline 514 & FonNaT & GM & $2 c$ & 2 & 6.5 & 3.63653301 & 2.028 \\
\hline 515 & FnEO & $\mathrm{Gm}$ & $2 c$ & 2 & 1.6 & 2.12132034 & .1 .25 \\
\hline 516 & preson & om & $x c$ & 21 & 4.5 & 4.04674747 & 0.0 \\
\hline 517 & PAEFOR & $\mathrm{Gm}$ & $2 c$ & 4 & 1.76 & 0.6 & 0.41727273 \\
\hline 518 & CHECX & om & $2 c$ & 3 & 0.203330235 & 0.67736027 & 0.2000 \\
\hline 519 & USEFU & iom & 20 &. & 3.0 & $2.30217 \mathrm{ze0}$ & 1.3142007 \\
\hline 520 & comp & $\mathrm{cm}$ & 20 &. & 6.0 & 3.70028074 & 2.8 \\
\hline 521 & TMAELYY & $G M$ & 120 & .1 & 6.4 & 3.60713658 & 3.26714200 \\
\hline 522 & ACcumute & GM & $T_{20}$ & . & 6.2 & 3.00310042 & 3.24206714 \\
\hline 523 & nawn & aM & 20 &. & 3.1 & 3.20003636 & 1.467 14200 \\
\hline 524 & osn:0 & $\mathrm{Gm}$ & 20 & 5 & 4.0 & 3.78163400 & 0.01205714 \\
\hline 525 & FonMAT & om & 20 & 6 & 4 & 3.31002470 & 1.06714200 \\
\hline 526 & freso & $G M$ & 20 & 5 & 4.0 & 4.02402230 & 2.00000000 \\
\hline 527 & mesor & $\mathrm{Gm}$ & 20 & 6 & 2.4 & 3.13060617 & 0.02001740 \\
\hline 528 & PAREFOR & $\operatorname{Tam}$ & 20 & . & .6 & 0.57736027 & \\
\hline
\end{tabular}


ALLMEAN.XLS

\begin{tabular}{|c|c|c|c|c|c|c|c|}
\hline & A & B & C & D) & $\mathbf{E}$ & $F$ & G \\
\hline 529 & CHECX & am & 20 & . & of & o] & ? \\
\hline 530 & Uoveral & or & in & $\infty$ & .0302326 & 109070074 & \\
\hline 531 & COMP & op & in & $\infty$ & 7.04061100 & 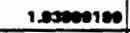 & \\
\hline 532 & Trumar & as & 11 & $\infty$ & c.0741100 & 2.2763400 & \\
\hline 533 & Accumurte & $\infty$ & in & $\omega$ & 1960372003 & 1.04213009 & \\
\hline 534 & nentr & or & in & $\infty$ & essuseas? & 2.00008600 & \\
\hline 535 & ons:0 & lor & $1 a$ & $\infty$ & 2.72000020 & 2. Parecen 17 & \\
\hline 536 & commat & 60 & in & 4 & 0.61102701 & 2.16003162 & \\
\hline 537 & $F=0$ & or & in & $\infty$ & 7.00302320 & 1.0240004 & \\
\hline 538 & meson & $\infty$ & 11 & $\infty$ & 1,74010000 & $2.11674 \pi \mathrm{na}$ & \\
\hline 539 & meron & ar & in & 30 & $1047300 \times 2$ & 1.0057240 & \\
\hline 540 & checex & $\infty$ & in & 30 & 0.4 & 0.40705012 & \\
\hline 541 & verens & es & 10 & 22 & 7.04 censess & $2.03727 \times 47$ & \\
\hline 542 & comp & GP & 18 & 22 & 7.22727273 & 2.20000002 & \\
\hline 543 & Inmar & op & 10 & 22 & 7.40000001 & 1.00007704 & \\
\hline 544 & Accumare & or & 18 & 22 & 7.00000090 & 1.10002120 & \\
\hline 545 & NeINT & $\infty$ & 10 & 22 & 7.210181e2 & 2.2300400 & \\
\hline 546 & oenco & GP & 10 & 22 & 1.0mentene & 200112001 & \\
\hline 547 & Fomanat & ar & 18 & 22 & 7.5 & 1.0020002 & \\
\hline 548 & FNOO & ap & 10 & 22 & 7.72727273 & 131600000 & \\
\hline 549 & PnEson & a) & 18 & 22 & 2.510000000 & $2 . \pi \times 37472$ & \\
\hline 550 & meron & ap & 10 & 20 & $1+1$ & 1. rososens & \\
\hline 551 & CMECX & op & ie & 10 & 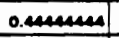 & 0.11130000 & \\
\hline 552 & USEPUL & GP & $1 c$ & 2 & 7.8 & 0.70710070 & \\
\hline 553 & comp & Gop & I. & 2. & 2 & 2.02002712 & \\
\hline 554 & rmar & 100 & ic & 2) & 2 & 0. & \\
\hline 555 & Accurate & GP & II & 2 & 3 & 2.022012712 & \\
\hline 556 & KEIVNT & Gr & Ic & 2 & 7.5 & 0.70710070 & \\
\hline 557 & oeneo & GP & $1 \mathrm{ic}$ & 2 & 2 & 1.41421300 & \\
\hline 558 & Fonmat & $\omega$ & ic & 2 & 2 & 0 & \\
\hline 559 & Eneo & top & ic & 2 & 21 & 의 & \\
\hline 560 & peson & ap & ic & 2 & 4.6 & 4.00074747 & \\
\hline 561 & meron & Gep & ic & 2. & 2 & 0 & \\
\hline 562 & CHECX & op & ic & 2. & - & 0 & \\
\hline 563 & USEFuL & lop & 10 & 3 & 2.033233333 & 182162623 & \\
\hline 564 & comp & JGP & 10 & 3 & 8 & 2 & \\
\hline 565 & TrMEELY & 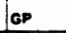 & 10 & 3 & 4.6800000? & 2.001000 & \\
\hline 566 & Accumate & top & 10 & I) & 4 & 2.04676131 & \\
\hline 567 & Retury & or & 10 & J & J.060eceses: & 2.30000100 & \\
\hline 568 & OSNEO & ap & 10 & 2 & 1.6 & 2.12132030 & \\
\hline 569 & FoROAAT & GP & 10 & 2 & 3. & 2.82042712 & \\
\hline 570 & EAEQ & Gep & 110 & 2 & 4 & 4.24241000 & \\
\hline 571 & meson & GP & 10 & 2 & 1 & 0 & \\
\hline 572 & mefon & GP & 10 & 2 & 1.6 & 0.70710070 & \\
\hline 573 & EMECX & $G P$ & 10 & 2 & 0 & 0 & \\
\hline 574 & USEFUL & $G$ & $2 A$ & 20 & 0.61724130 & 1.70337240 & 0.60700002 \\
\hline 575 & comp & TP & $2 A$ & 20 & 7.02760021 & 8.77410033 & $0.70107 a 59$ \\
\hline 576 & TTMELY & igP & $2 A$ & 20 & 7.02000000 & 1.60784186 & 0.04027100 \\
\hline
\end{tabular}




\begin{tabular}{|c|c|c|c|c|c|c|c|}
\hline & $\bar{A}$ & B & C & D & $E$ & $F$ & G \\
\hline 577 & AccumarE & $\infty$ & $2 n$ & 20 & 7.70310006 & 1.47907627 & 0.00000 \\
\hline 578 & pant & $e p$ & $2 n$ & 20 & 0.003494270 & 1.5232103 & 9.000000000 \\
\hline 579 & oseno & lop & $2 n$ & 20 & 2.71420671 & 2.02060000 & - o.comenase \\
\hline 580 & Fomat & ap & $2 A$ & 20 & 7.5002000 & 1.00180000 & $2.02 \times 0780$ \\
\hline 581 & meO & ap & $2 n$ & 20 & $7 . r 002000$ & 1.46441200 & - excestas \\
\hline 582 & $m=\infty$ & or & 20 & 27 & istaerael & 2.3000000 & Q.orenaze \\
\hline 583 & meron & GP & $2 A$ & 26 & 1.32 & 0.470000523 & $0.02 \pi$ menas \\
\hline 584 & CHECX & ap & 24 & 10 & 0.11111111 & 0.02500000 & 0.200 \\
\hline 585 & veseru & $\infty$ & 28 & 12 & e.ececesen? & 2020000 & osmerare \\
\hline 586 & com & as & 28 & 14 & 0.79420671 & 2.6240042 & 0.01201102 \\
\hline 587 & Trungry & 6 & 20 & 14 & 7.36714200 & 2.37516670 & s.esieneses \\
\hline 588 & Aceumure & $\infty$ & 20 & 14 & 0.02057143 & 2.01640002 & areveren \\
\hline 589 & hans & $\infty$ & 28 & 12 & a.cecenceer & 2.00400000 & e.envesers \\
\hline 590 & OSESO & ap & 28 & 14 & 4 & 3.32020110 & 2averate? \\
\hline 591 & romart & $\infty$ & 28 & 12 & 7 & 2.40002024 & 0.8 \\
\hline 592 & Kx:O & GP & 28 & 14 & 0.02057140 & 2.40077920 & 0.7007019 \\
\hline 593 & preseon & GP & 28 & 94 & 3.70571420 & 3.40007264 & 1.1000002 \\
\hline 594 & meron & ap & 28 & 14 & 3 & 2.006000000 & 1.2 \\
\hline 595 & CHECX & $G$ & 28 & . & 0.100 cenent & 0.00024020 & $0.2 \mathrm{~mm}$ \\
\hline 596 & unerer & $\theta$ & 20 & 2 & 0.6 & 0.70710070 & 7 \\
\hline 597 & comp & ap & $2 c$ & 2 & 0.5 & 0.70710078 & 4.8 \\
\hline 598 & numar & $G$ & $2 c$ & 1 & $\cdot$ & & 4 \\
\hline 599 & ACcumite & GP & $2 c$ & 2 & 2.6 & 0.70710070 & 0.0 \\
\hline 600 & RavinT & $G P$ & $x$ & 2 & 0 & 1.41421360 & 0.0 \\
\hline 601 & ospeo & GP & $2 c$ & 1 & - & & 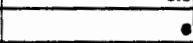 \\
\hline 602 & romemat & $G P$ & $2 c$ & 2 & 2.5 & 0.70710070 & 0.8 \\
\hline 603 & feneO & GP & $x$ & 1 & 2 & & 0 \\
\hline 604 & meson & $G$ & $2 x$ & 1 & 2 & & 2.8 \\
\hline 605 & mexoon & lap & $2 c$ & 1 & 2 & & $\because$ \\
\hline 606 & CMECK & $G$ & $2 c$ & 2 & of & of & 0 \\
\hline 607 & USEFUI & lop & 20 & 3 & 1.06000007 & 0.67736027 & 0.060 esense \\
\hline 608 & Comp & top & 20 & 3 & s.ecesecese & 2.80076196 & 0.cenisens \\
\hline 609 & Trmaktr & ap & 20 & 3 & .320330230 & 2.50000100 & o.ceneneren \\
\hline 610 & accumare & GP & 20 & 3 & 5 & 3.4910102 & \\
\hline 611 & neuver & GP & 20 & 3 & 2.2033322303 & 1.16470060 & 1. \\
\hline 612 & osare & ICP & 20 & 3 & 0.220332030 & 0.01800216 & 3.000000 \\
\hline 613 & Fonmat & igr & $\sqrt{20}$ & 3 & 3 & J.4entores & 0 \\
\hline 614 & Freo & Ge & 20 & 3 & 3.220332303 & 0.041461000 & 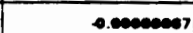 \\
\hline 615 & ensson & OP & 20 & 3 & . & 0 & , \\
\hline 616 & mexion & $G$ & 20 & 3 & 2 & 0 & 0.5 \\
\hline 617 & CHECK & $G$ & 20 & 1 & 0 & & 0 \\
\hline 618 & USEFUL & $H$ & in & 3 & 0.23333230 & 1.1470004 & \\
\hline 619 & COMP & $\mu$ & In & 3 & 0.03330323 & 0.67736027 & \\
\hline 620 & TIMEER & H & in & 3 & 7.00000007 & 1.16470064 & \\
\hline 621 & ACCuMATE & $H$ & in & 3 & - & of & \\
\hline 622 & RELWNT & in & in & 3 & -.000000007 & 0.67736027 & \\
\hline 623 & osneo & In & in & 2 & 3.6 & 0.04974747 & \\
\hline 624 & ForaMAT & Im & in & 2 & 0.5 & 0.70710078 & \\
\hline
\end{tabular}




\section{ALIMEAN.XLS}

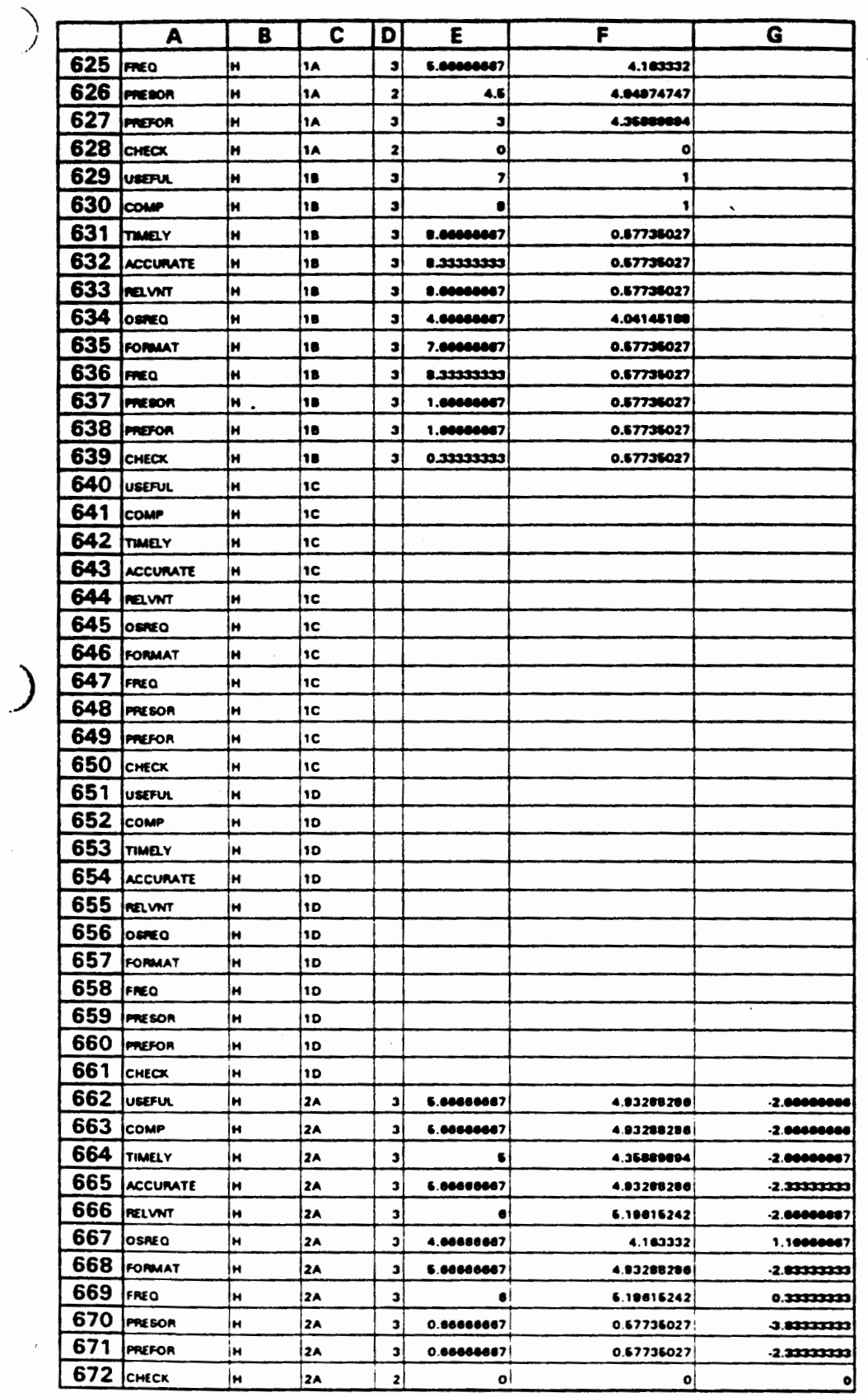


ALLMEAN.XLS

\begin{tabular}{|c|c|c|c|c|c|c|c|}
\hline & A & $\mathbf{B}$ & $\bar{c}$ & D & $E$ & $F$ & $G$ \\
\hline 673 & uasefrr & $H$ & 28 &. & 0 & .) & .7 \\
\hline 674 & comp & H & 26 & 1 & 0 & 0 & 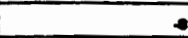 \\
\hline 675 & Trmar & $H$ & 28 & . & 0 & 0 & s.cencouns? \\
\hline 676 & necumuTE & $\omega$ & 20 & 1 & 0 & 0 & $=0$ \\
\hline 677 & now $m$ & $\mathrm{H}$ & 28 & 1 & 0 & 0 & 0.6000007 \\
\hline 678 & osene & H & 28 & 1 & 0 & of & 4.0000007 \\
\hline 679 & Fомиат & $H$ & 28 & 1 & 0 & 0 & 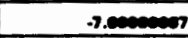 \\
\hline 680 & $\Rightarrow \in 0$ & $\mathrm{H}$ & 20 & .1 & of & o] & 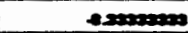 \\
\hline 681 & preseon & jH & 20 & 1 & 0 & 0 & -1.6000007 \\
\hline 682 & meron & H & 20 & 1 & 0 & of & .1 .000000 \\
\hline 683 & chex & H & 20 & 0 & 0 & 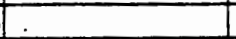 & 0.2000000 \\
\hline 684 & veser & $\omega$ & $x$ & & & & $\bullet$ \\
\hline 685 & conm & IM & $2 x$ & & & & . \\
\hline 686 & Trmear & $T_{H}$ & $2 c$ & & & & 0 \\
\hline 687 & ACCUMATE & H & $x$ & & & & $\bullet$ \\
\hline 688 & $\operatorname{man} n$ & $H$ & $2 c$ & & & & 0 \\
\hline 689 & osene 0 & $H$ & $2 x$ & & & & . \\
\hline 690 & romar & $H$ & $2 x$ & & & & 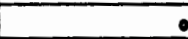 \\
\hline 691 & mano & $\omega$ & $2 c$ & & & &. \\
\hline 692 & incson & $H$ & $z$ & & & & 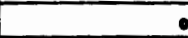 \\
\hline 693 & moron & $H$ & $2 c$ & & & & 0 \\
\hline 694 & CHECX & in & $x$ & & & & 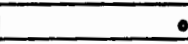 \\
\hline 695 & USEFUL & $\mathrm{H}$ & 20 & & & & 0 \\
\hline 696 & comp & In & 20 & & & & 0 \\
\hline 697 & rumerr & IH & 20 & & & & . \\
\hline 698 & Accurute & in & 20 & & & & . \\
\hline 699 & Reiver & in & 20 & & & & . \\
\hline 700 & osseo & H & 20 & & & & 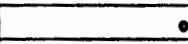 \\
\hline 701 & Fonmat & TH & 20 & & & & . \\
\hline 702 & Frea & $T_{H}$ & 20 & & & & . \\
\hline 703 & messon & $\mathrm{H}$ & 20 & & & & . \\
\hline 704 & Preron & In & 20 & & & & $\circ$ \\
\hline 705 & CMECX & I & 20 & & & & . \\
\hline 706 & USEFU & $i$ & in & 2 & . & $0.2420 \mathrm{mon}$ & \\
\hline 707 & comp & I & in & 2 &. .5 & 2.12132003 & \\
\hline 708 & Trmear & $T_{2}$ & in & 2 & , & 2.02042712 & \\
\hline 709 & Accumute & it & IA & 2 & 4 & s.escescuse & \\
\hline 710 & neine & it & In & 2 &. & 0.24200000 & \\
\hline 711 & Tosneo & te & in & 2 & 3 & 4.24204000 & \\
\hline 712 & roremat & K & in & 2 & 4.5 & 4.06074097 & \\
\hline 713 & FNEO & is & in & 2 & 7.5 & 2.12132003 & \\
\hline 714 & meson & $t_{t}$ & in & 2 & 1 & 0 & \\
\hline 715 & PREFOA & t & in & 2 &. & 0 & \\
\hline 716 & CMECK & L & in & 2 & 0 & 0 & \\
\hline 717 & userier & it & 18 & & & & \\
\hline 718 & Comp & I & 10 & & & & \\
\hline 719 & TIMAELY & is & 1,8 & & & & \\
\hline 720 & Accumare & it & 110 & & & + & \\
\hline
\end{tabular}


ALLMEAN.XLS

\begin{tabular}{|c|c|c|c|c|c|c|c|}
\hline & A & $B$ & C & D] & $E$ & $F$ & 6 \\
\hline 721 & nanver & $k$ & 10 & & & & \\
\hline 722 & osenso & $i$ & 28 & & & & \\
\hline 723 & romeat & $L$ & 10 & & & & \\
\hline 724 & FNESO & $k$ & 30 & & & & \\
\hline 725 & mecon & L & 18 & & & & \\
\hline 726 & moson & t & 18 & & & & \\
\hline 727 & conea & 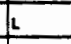 & 18 & & & & \\
\hline 728 & Uevark & $t_{2}$ & Ic & & & & \\
\hline 729 & conp & I & Is & & & & \\
\hline 730 & nnmar & 1 & ic & & & & \\
\hline 731 & Aceunute & L & Isc & & & & \\
\hline 732 & newn & $L$ & Is & & & & \\
\hline 733 & oense & 1 & Ic & & & & \\
\hline 734 & rommit & t & ic & & & & \\
\hline 735 & Fiseo & $L$ & ic & & & & \\
\hline 736 & maseon & $L$ & ic & & & & \\
\hline 737 & meron & th & IIC & & & & \\
\hline 738 & EMECX & $L$ & ic & & & & \\
\hline 739 & ueserer & $t_{2}$ & 10 & 1 & 3 & & \\
\hline 740 & comp & $k$ & 10 & 1 & 0 & & \\
\hline 741 & trmar & L & 10 & 1 & 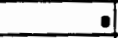 & & \\
\hline 742 & ACcuRTE & I & 110 & 1 & 0 & & \\
\hline 743 & Raw & 2 & 10 & i) &. & & \\
\hline 744 & osenco & L & 10 & 1 & 0 & & \\
\hline 745 & Jomat & k & 10 & 1 & 5 & & \\
\hline 746 & PNEO & $L$ & 10 & 3 & 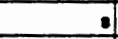 & & \\
\hline 747 & meson & L & 10 & 1 & 1 & & \\
\hline 748 & meron & $i$ & 10 & 1 & 1 & & \\
\hline 749 & CHECX & L & 10 & 1 & 0 & & \\
\hline 750 & Uuseful & te & $2 n$ & 0 & 1.03333000 & 1.10004110 & 2000000 \\
\hline 751 & comp & L & $2 A$ & - & 7.32303333 & 1.001000e? & 0.00000 \\
\hline 752 & Tmanr & t & $2 A$ &. & 7 & 1.67232006 & 0 \\
\hline 753 & Accumare & $L$ & $2 A$ & If & 0.093323330 & 2.04124145 & 2000000 \\
\hline 754 & neıvm & t & $2 n$ & of & 7222332230 & 2.25002674 & 1.20000000 \\
\hline 755 & ospea & $k$ & 24 & -1 & 7 & 2.0078177 & 4 \\
\hline 756 & Fonmar & to & $2 A$ & 3 & 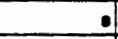 & 1.20401100 & 3.0 \\
\hline 757 & FAEO & tit & $2 n$ & . & 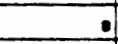 & 1.64918534 & 0.5 \\
\hline 758 & merean & is & $2 A$ & 1 & 7.230303303 & 1.00200310 & 0.20000000 \\
\hline 759 & pereron & is & $2 A$ &. & 4.23303033 & 2.04322020 & 9.2000000 \\
\hline 760 & CMECK & L & $2 A$ & 5 & 0.8 & 0.4472136 & 0.0 \\
\hline 761 & USEFUL & $i$ & 20 & 3 & 6.60000007 & 0.67736027 & s.enesenes? \\
\hline 762 & comp & IL & 20 & 3 & 4.23323339 & 0.67756027 & 4.20000000 \\
\hline 763 & timery & t & 20 & 3 & 5 & 1.73206001 & 5 \\
\hline 764 & Accurate & I & 28 & 3 & 4.033230330 & 2.30040100 & 4.500000 \\
\hline 765 & aELLWT & $L$ & 20 & 3 & 3.60006067 & 1.16470064 & 2.060 aneser \\
\hline 766 & osneo & is & 28 & 3. & 6.333233333 & 1.16470064 & 0.200000 \\
\hline 767 & Fomamat & $L_{L}$ & 20 & 3] & 0.00000087 & 0.67735027 & s.cesecenes \\
\hline 768 & I Fase & it & $T_{28}$ & 3 & 7.00000007 & 2.30040100 & 7.00000007 \\
\hline
\end{tabular}




\section{ALLMEAN.XLS}

\begin{tabular}{|c|c|c|c|c|c|c|c|}
\hline & A & $B$ & $C$ & D) & $E$ & $F$ & $\mathbf{G}$ \\
\hline 769 & meson & k & 28 & ] &. & o] & $\bullet$ \\
\hline 770 & meron & $L$ & 28 & ] & -1 & 0 & - \\
\hline 771 & checox & L & 28 & $1]$ & 1 & & 1 \\
\hline 772 & userer & L & $2 c$ & 2 & 1 & & . \\
\hline 773 & com & L & $2 c$ & 2 & . & & • \\
\hline 774 & mear & L & ac & 2 & 0 & & 0 \\
\hline 775 & accurate & $L$ & $2 c$ & 2 & 0 & & ? \\
\hline 776 & rant & 1 & $2 c$ & 2 & 0 & & 9 \\
\hline 777 & onseco & $L_{L}$ & $2 c$ & 2 & of & & - \\
\hline 778 & coment & $T_{L}$ & $2 c$ & 2 & 0 & & - \\
\hline 779 & $m=0$ & $\sqrt{2}$ & $2 c$ & 2 & of & & $\bullet$ \\
\hline 780 & meseon & IL & $2 x$ & 2 & 5 & & 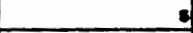 \\
\hline 781 & meron & te & $2 x$ & 2 & 1 & & 1 \\
\hline 782 & checx & $L$ & $2 x$ & 1 & of & & 0 \\
\hline 783 & ueger & $L$ & 20 & & & & \pm \\
\hline 784 & comp & L & 20 & & & & 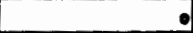 \\
\hline 785 & Trmar & $t$ & 20 & & & & - \\
\hline 786 & accumate & $L$ & 20 & & & & $\therefore$ \\
\hline 787 & NeInT & L & 20 & & & & . \\
\hline 788 & 0 osne & L & 20 & & & & - \\
\hline 789 & Fonmat & is & 20 & & & & $\$$ \\
\hline 790 & FREO & $L$ & 20 & & & & \pm \\
\hline 791 & pacson & $L$ & 20 & & & & .1 \\
\hline 792 & porton & 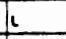 & 20 & & & & -1 \\
\hline 793 & CHEOX & L & 20 & & & & - \\
\hline 794 & USEFUL & im & in & -1 & 7.06560560 & 2.10601284 & \\
\hline 795 & come & $m$ & in & - & 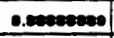 & 1.70303421 & \\
\hline 796 & nmar & $m$ & in & -1 & S. & 2.203212903 & \\
\hline 797 & LCEUMUTE & Im & in & - & $0.7 \mathrm{~mm} 7 \mathrm{~T}$ & 201050000 & \\
\hline 798 & Kantr & im & In & - & 7.00000000 & 1.070030en & \\
\hline 799 & DEREO & $m$ & In &. & 4.11311111 & 3.06050320 & \\
\hline 800 & Foremat & I & Iin &. & - 202323230 & 2.1 reneas? & \\
\hline 801 & $F \in 0$ & Im & in & . & 7 & $1.2247 \mathrm{man}$ & \\
\hline 802 & meson & m & in &. & 2.60565650 & 2.400370000 & \\
\hline 803 & prefor & $m$ & In & $\bullet$ & $2.0 \mathrm{senem}$ & 2.20730140 & \\
\hline 804 & CMECX & In & lin & - & $0.11 \cdots \cdots$ & 0.320232320 & \\
\hline 805 & USEFUL & Im & 18 & 3 & e.esmazes & 0.3 moen? & \\
\hline 806 & Comp & $\ln$ & 10 & 7 & 7.06314200 & 0 0007כטו & \\
\hline 807 & rmar & $j$ & 10 & 7 &. & 1.16470064 & \\
\hline 808 & accumate & In & 10 & 3 & 7.06714200 & $0.00006 s$ & \\
\hline 809 & RELinT & M & 10 & 3 & 0.26571420 & 1,11200720 & \\
\hline 810 & ogene & Im & 18 & 7 & 4 & 3.00002000 & \\
\hline 811 & Konamat & Im & 18 & 7 & .20571420 & 0.06110073 & \\
\hline 812 & FREO & Es & 10 & 3 & 3.67142057 & 1.30727820 & \\
\hline 813 & preson & Im & 18 & 3 & 2.06714200 & 0.10470620 & \\
\hline 814 & prefor & in & 18 & 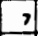 & 3 & 3.10012006 & \\
\hline 815 & CMECX & m & 18 & 7 & 0 & 의 & \\
\hline 816 & USERUL & $\operatorname{lm}$ & Ix & & & & \\
\hline
\end{tabular}


ALLMEAN.XLS

\begin{tabular}{|c|c|c|c|c|c|c|c|}
\hline & A & $\bar{B}$ & C & D & $E$ & $\bar{F}$ & $\bar{G}$ \\
\hline 817 & comp & $m$ & ic & & & & \\
\hline 818 & remer & $M$ & Ic & & & & \\
\hline 819 & accumate & $m$ & Iic & & & & \\
\hline 820 & rewt & $I_{M}$ & ic & & & & \\
\hline 821 & oenso & $\omega$ & ic & & & & \\
\hline 822 & romeat & $M$ & ic & & & & \\
\hline 823 & $F=0$ & $T_{m}$ & Tic & & & & \\
\hline 824 & mineon & $m$ & Ie & & & & \\
\hline 825 & meron & Im & ic & & & & \\
\hline 826 & creax & $T_{m}$ & Tic & & & & \\
\hline 827 & verear & $m$ & 10 & 1 & 2 & & . \\
\hline 828 & $\cos n$ & in & 10 & 1 & 7 & & . \\
\hline 829 & Trmar & in & 10 & 1 & 4 & & \\
\hline 830 & accumute & $m$ & 10 & i. & 0 & & \\
\hline 831 & nawr & $m$ & 10 & 1 & 3 & & \\
\hline 832 & oensec & $m$ & 110 & 1 & 0 & & \\
\hline 833 & romanat & $m$ & 10 & 1 & 4 & & . \\
\hline 834 & EREO & $m$ & 100 & 1 & 7 & & \\
\hline 835 & neson & Im & 10 & 1 & 1 & & \\
\hline 836 & merson & $\omega$ & 10 & 1 & 1 & & \\
\hline 837 & CMECX & $M$ & 10 & 1 & 0 & & \\
\hline 838 & usear. & $\omega$ & $2 a$ & 2 & 0.6 & 2.12132034 & 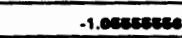 \\
\hline 839 & comp & $T_{m}$ & $2 A$ & 2 & 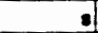 & 1.01421360 & 1.1111111 \\
\hline 840 & trmar & $M$ & $2 A$ & 2 & - & 0 & 220002002 \\
\hline 841 & accurate & $m$ & $2 \mathrm{~A}$ & 2 & 7.8 & 0.70710070 & 0.72020022 \\
\hline 842 & NannT & Im & $2 a$ & 2 & 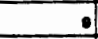 & 0 & 1.200000000 \\
\hline 843 & oseseco & $m$ & 24 & 2 & 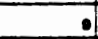 & 0 & 4.00 \\
\hline 844 & romar & Im & $2 A$ & 2 &. & 0 & 2.0000007 \\
\hline 845 & ineo & Im & $2 A$ & 2 & 4.6 & 0.3050100 & 2.8 \\
\hline 846 & meson & $m$ & $2 A$ & 2 & 1 & 0 & 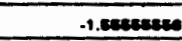 \\
\hline 847 & meron & Im & $2 A$ & 2 & 1 & 0 & - \\
\hline 848 & EMEOX & $M$ & $2 A$ &. & 0 & & 0.11111111 \\
\hline 849 & usterut & Im & 28 & 2 & 0 & .41421300 & 0.0671420 \\
\hline 850 & comp & $m$ & 28 & 2 & 7 & 0 & 0.0671420 \\
\hline 851 & Trumelr & M & 20 & 2 & 0 & 01 & \\
\hline 852 & Accumate & $M$ & 28 & 2 & 7 & 0 & 0.20314200 \\
\hline 853 & RRVWT & $\mathrm{m}$ & 28 & 2 &  & 0. & 0.220871420 \\
\hline 854 & osene & Im & 28 & 2 & 4 & of & .1 \\
\hline 855 & Fomeat & in & 28 & 2. & 7.6 & 2.12132000 & 0.70071420 \\
\hline 856 & ENESO & Tim & 28 & 2 & 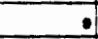 & 0 & 1.42001140 \\
\hline 857 & preson & m & 20 & 2 & 1. & 0 & 9.45714200 \\
\hline 858 & meron & $m$ & 28 & 2 & 1.5 & 0.70710070 & .9 .0 \\
\hline 859 & CMECK & $m$ & 28 & 1 & , & & , \\
\hline 860 & USEFU: & m & $2 c$ & & & & . \\
\hline 861 & comp & $M$ & $2 c$ & & & & $\circ$ \\
\hline 862 & rimelr & $m$ & $2 c$ & & & & 0 \\
\hline 863 & ACCURATE & $m$ & $2 c$ & & & & $\therefore$ \\
\hline 864 & Retiver & $T_{M}$ & Tc & & & & 0 \\
\hline
\end{tabular}


ALLMEAN.XLS

\begin{tabular}{|c|c|c|c|c|c|c|c|}
\hline & A & $B$ & C & D & $E$ & $F$ & $\mathbf{G}$ \\
\hline 865 & oenco & $m$ & $2 c$ & & & & 0 \\
\hline 866 & Fomuat & im & $2 c$ & & & & 0 \\
\hline 867 & $F \in=0$ & 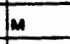 & $x$ & & & & 0 \\
\hline 868 & preson & m & $x$ & & & & 0 \\
\hline 869 & mevon & $m$ & $x$ & & & & 0 \\
\hline 870 & chece & $m$ & $x$ & & & & 0 \\
\hline 871 & usagex & $\omega$ & 20 & & & & $\Rightarrow$ \\
\hline 872 & comp & $m$ & 20 & & & & -1 \\
\hline 873 & rmaar & $m$ & 20 & & & & 4 \\
\hline 874 & accumute & in & 20 & & & & 0 \\
\hline 875 & nean & $m$ & 20 & & & & 3 \\
\hline 876 & osenco & $m$ & 20 & & & & 음 \\
\hline 877 & roment & $m$ & 20 & & & & 4 \\
\hline 878 & FN=0 & im & 20 & & & & $\rightarrow$ \\
\hline 879 & meson & m & 20 & & & & .1 \\
\hline 880 & meron & $\mu$ & 20 & & & & .1 \\
\hline 881 & CHECX & $m$ & 20 & & & & 0 \\
\hline 882 & ues?ut & 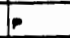 & In & 2 &. & 0 & \\
\hline 883 & comp & $p$ & in & 2 & 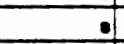 & 1.A1421360 & \\
\hline 884 & rmar & $P$ & in & 2 & 5 & 6.000 & \\
\hline 885 & AccuruTE & I & in & 2 & 0.5 & o.4STE3001 & \\
\hline 886 & nant & tp & in & 2 &. .5 & 0.70710070 & \\
\hline 887 & Osaro & $p$ & In & 2 & 4.5 & .30300103 & \\
\hline 888 & romamar & $p$ & in & 2 & .0 .5 & 2.12132000 & \\
\hline 889 & exeO & $p$ & in & 2 & 5 & s.060use & \\
\hline 890 & Pneson & $p$ & in & 2 & 1 & 0 & \\
\hline 891 & meron & In & in & 1 & I & & \\
\hline 892 & сMECX & t. & in & 2 & 0.8 & 0.70110070 & \\
\hline 893 & ustrur & To & 18 & 3 & 7. eececeen & 230000100 & \\
\hline 894 & comp & T & 10 & 3) & , & 2.49410102 & \\
\hline 895 & rimar & $p$ & 18 & 9 & 0.232323323 & 3.06506040 & \\
\hline 896 & accumars & I & 18 & 3 & 7.232303203 & 2.001000 & \\
\hline 897 & nEIVWT & Is & 10 & 9 & -.00ec00007 & 0.67736027 & \\
\hline 898 & osen:o & T & 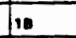 & 3 & 0.22303333 & 0.06605040 & \\
\hline 899 & Fomenat & T. & 18 & 3 & .1 & 1.79206001 & \\
\hline 900 & ENEO & ip & 18 & 3 & c.enecesens & 2.61001190 & \\
\hline 901 & pacson & 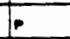 & 18 & 3 & 3.233233333 & 4.04146100 & \\
\hline 902 & puston & $p$ & 10 & 1 & 1 & & \\
\hline 903 & Check & te & 10 &. & 0.10000609 & 0.40024020 & \\
\hline 904 & USEFUL & p & IC & & & & \\
\hline 905 & comp & $p$ & ic & & & & \\
\hline 906 & TrMELY & $p$ & ic & & & & \\
\hline 907 & Accumute & ip & ic & & & & \\
\hline 908 & nELUNT & p & ic & & & & \\
\hline 909 & ospeo & $f_{p}$ & ic & & & & \\
\hline 910 & ropmat & $f_{p}$ & ic & & & & \\
\hline 911 & FREO & $f_{p}$ & ic & & & & \\
\hline 912 & Peneson & $T_{p}$ & Tie & & & & \\
\hline
\end{tabular}


ALLMEAN.XLS

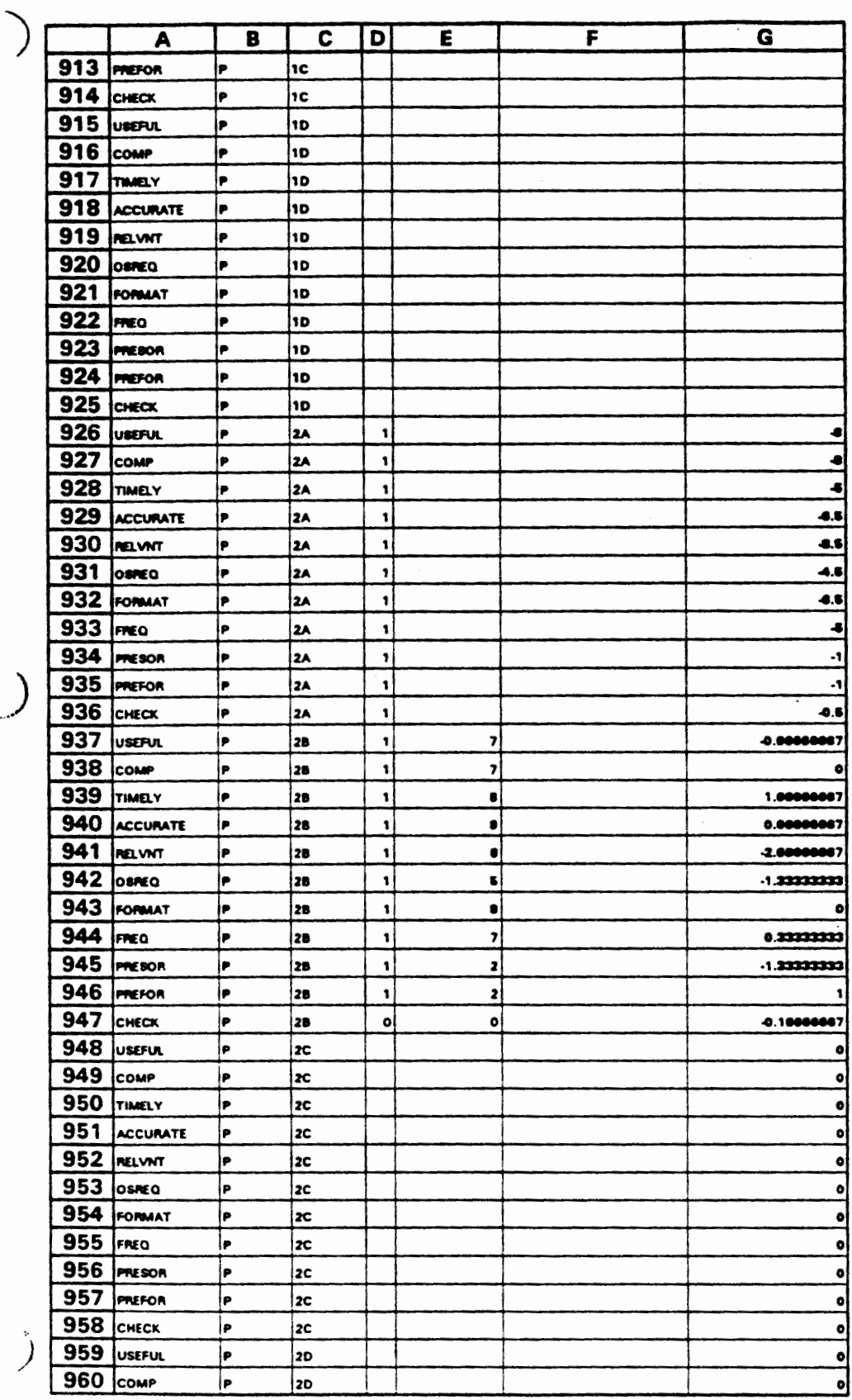




\begin{tabular}{|c|c|c|c|c|c|c|c|c|}
\hline & & & & & & ALLMEAN.XLS & & \\
\hline & A & $\mathbf{B}$ & C & D & $E$ & $F$ & $\mathbf{G}$ & G \\
\hline 961 & monar & $p$ & 20 & & & & & 0 \\
\hline 962 & Accumate & $p$ & 20 & & & & & 0 \\
\hline 963 & naw & p & 20 & & & & & 0 \\
\hline 964 & oen:o & $p$ & 20 & & & & & of \\
\hline 965 & roment & t & 20 & & & & & 0 \\
\hline 966 & Fus & E & 20 & & & & & 0 \\
\hline 967 & meson & $p$ & 20 & & & & & . \\
\hline 968 & mesoon & F & 20 & & & & & 0 \\
\hline 969 & CMECX & F & 20 & & & & & 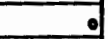 \\
\hline 970 & vecrer. & 6 & in & 12 & 7.5 & 1.e2anouge & & \\
\hline 971 & com & 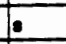 & in & 12 & s.eceneon? & 2.14017390 & & \\
\hline 972 & rumer & 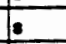 & in & 12 & 5 & 2.70000112 & & \\
\hline 973 & accumare & 10 & in & 12 & 0.100000007 & 1,00009007 & & \\
\hline 974 & reant & 1 & 13 & 12 & 7 & 2 & & \\
\hline 975 & oseo & 8 & in & 12 & 4.78 & 3.60000373 & & \\
\hline 976 & Fomuat & 8 & in & 12 & .78 & 2,30110547 & & \\
\hline 977 & Faso & 8 & in & 12 & S.4teapen & 22740012 & & \\
\hline 978 & meson & 8 & in & 12 & 1.220230230 & 1.16470004 & & \\
\hline 979 & prexon & 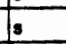 & in & 11 & 2.04000005 & 2.50404120 & & \\
\hline 980 & crtex & 3 & In & 12 & 0.200032030 & 0.0023050 & & \\
\hline 981 & Juserul & $s$ & 18 & . & 7.5 & 1.04000005 & & \\
\hline 982 & comp & 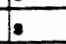 & 10 & -1 & 7.0 & 1.51067600 & & \\
\hline 983 & rimesr & 18 & 18 & of & $?$ & 120401100 & & \\
\hline 984 & Accunute & $T_{8}$ & 16 &. & , & 0.0042710 & & \\
\hline 985 & ReInT & is & 10 & -1 & . & 1.00644512 & & \\
\hline 986 & Tosesco & 18 & 180 & -1 & 5 & 420062212 & & \\
\hline 987 & roneme & is & 10 & -1 & 7.10000007 & $0.702772 \mathrm{ex}$ & & \\
\hline 988 & Fase & s & 18 & $\cdot 1$ & 0.023232330 & 1.00200180 & & \\
\hline 989 & messon & 15 & 10 &. & 3.6 & 3.6071356 & & \\
\hline 990 & meron & Is & 18 & 5 & 4 & J.074230es & & \\
\hline 991 & CMECX & 18 & 18 & 5 & 0.4 & 0.64772256 & & \\
\hline 992 & userus & is & ic & 0 & & & & \\
\hline 993 & comp & ts & Iic & o) & & & & \\
\hline 994 & rumetr & to & ic & 0 & & & & \\
\hline 995 & accumart & is & ic & 0 & & & & \\
\hline 996 & J REL Un & 3 & I. & 0 & & & & \\
\hline 997 & toseneo & $T_{s}$ & IC & 0 & & & & \\
\hline 998 & romenat & is & ic & 0 & & & & \\
\hline 999 & Eaxo & is & Tic & 0 & & & & \\
\hline 1000 & emeson & ts & Ic & 0 & & & & \\
\hline 1001 & meroron & is & ie & 0 & & & & \\
\hline 1002 & checx & s & is & 0 & & & & \\
\hline 1003 & USEFUL & 5 & 10 & 4 & 3.6 & 1 & & \\
\hline 1004 & COMP & is & 10 & 4 & 2.20 & 1.70702613 & & \\
\hline 1005 & TIMELLY & is & 10 & 4 & .8 & 2.58047614 & & \\
\hline 1006 & ACECURATE & is & 10 & 4 & 4.70 & 3.40042004 & & \\
\hline 1007 & AELLWT & 5 & 10 & 4 & 4.6 & 2.06075136 & & \\
\hline 1008 & OSAEO & is & 190 & 4 & 0.6 & 0.87736027 & & \\
\hline
\end{tabular}


ALLMEAN.XLS

\begin{tabular}{|c|c|c|c|c|c|c|c|}
\hline & $\mathbf{A}$ & B & $c$ & DI & $\mathbf{E}$ & $F$ & $\mathbf{G}$ \\
\hline 1009 & Fomuar & 5 & 10 & 4 & 4.8 & 2.04576131 & \\
\hline 1010 & $m \in=0$ & $\because$ & 10 & 4 & of & 284302020 & \\
\hline 1011 & eneson & 2 & 110 & 4 & 2.5 & 1.73204001 & \\
\hline 1012 & moron & 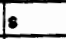 & 10 & J) & 2.230932303 & 1.62702623 & \\
\hline 1013 & emeax & 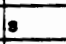 & 10 & 4 & 0 & of & \\
\hline 1014 & uegar & $E$ & 24 & 11 & c.045esasts & 2.79502000 & osmoness \\
\hline 1015 & cone & 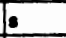 & $2 A$ & 11 & c.ABacasas & 2.230301000 & -0.21212122 \\
\hline 1016 & rmar & 1 & $2 n$ & 11 & c.101erese & 222702100 & 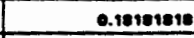 \\
\hline 1017 & Accumate & 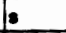 & $2 a$ & ii] & .1 & 2,40000074 & +0.1000000 \\
\hline 1018 & nawr & 2 & $2 n$ & 11 & .00000000 & o.saseresel & 1.000000000 \\
\hline 1019 & $0=0$ & 1 & $2 x$ & iI & 3.72727273 & 2.2 nevorila & -1.02272727 \\
\hline 1020 & romuit & I. & $2 n$ & 11 & S.reterove & iscomeses & accerseres \\
\hline 1021 & FnEO & 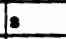 & 24 & i1 & s.coserosen & $22022 \mathrm{mes}$ & $121 \times 0007$ \\
\hline 1022 & meneon & is & $2 n$ & 11 & 1. evereise & 1. coi rasea & exaremen \\
\hline 1023 & meron & . & $2 A$ & w & 1.4 sesessess & 0.52220207 & -1.0000009 \\
\hline 1024 & creax & 6 & $2 n$ & 10 & 0.1 & $0.310227 m$ & $02 x+0$ \\
\hline 2025 & userin & $=$ & 28 & 14 & I.monese & 2.67737400 & 0.2007142 \\
\hline 1026 & Comp & 1 & 28 & 10) & 79120 & $2.7260 \mathrm{enp} 7$ & 0.1078 \\
\hline 1027 & remer & 18 & 28 & 10 & 3.028 & $2.47310 \mathrm{kes}$ & 0.025 \\
\hline 1028 & accurarte & s & 20 & 10 & $7.0 \mathrm{ng}$ & 2.200504sil & 0.0078 \\
\hline 1029 & Jent & 5 & 20 & is & 7.70071420 & $2.5 \mathrm{~m} 73700$ & 0.21420679 \\
\hline 1030 & osenco & 1 & 22 & in & 40378 & 430002003 & 0.0025 \\
\hline 1039 & Romenat & s & 28 & 14 & 7 & 2.20505670 & $0.1000 \times 1007$ \\
\hline 1032 & Fine & 8 & 28 & io & 2037 & 2.24070000 & 1.901100017 \\
\hline 1033 & eneson & 18 & 20 & 10 & .1 & 2.00700000 & 2.8 \\
\hline 1034 & preson & Is & 28 & 10 & 0.28 & 200005135 & 0.25 \\
\hline 1035 & Eneax & s & 120 & 10 & 0.0026 & 0.25 & 0.200 \\
\hline 1036 & usorver & 18 & $2 c$ & ग) & . & 1.73206001 & \\
\hline 1037 & comp & Is & $2 c$ & 3 & 1.203020003 & 1.62752623 & 1.0000 \\
\hline 1038 & nemer & is & $2 x$ & 3 &. & 1.73206001 & 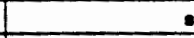 \\
\hline 1039 & Accumate & Is & $2 x$ & 3 & 7.everesens & 2.30040108 & 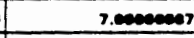 \\
\hline 1040 & Lanent & Is & $x$ & 3 & 7.enomeces & 3.16470064 & 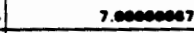 \\
\hline 1041 & oseno & 5 & $2 c$ & 3 & 4.23393303 & 4.00224076 & 4.2000000 \\
\hline 1042 & romat & 3 & $x$ & 3 & - .233953933 & 230040100 & $0.9 \times 000003$ \\
\hline 1043 & Fne & 8 & $2 c$ & 3 & 7.233233320 & 2.09076135 & 7.2000000 \\
\hline 1044 & meson & 18 & $2 c$ & 1 & 2 & & 2 \\
\hline 1045 & preson & s & $2 c$ & 4 & 2 & a) & 2 \\
\hline 1046 & enecx & Is & $2 c$ & 2 & - & 0 & 0 \\
\hline 1047 & usem & is & 20 & 1 & ]) & & 3.0 \\
\hline 1048 & comp & s & 20 & 1 & 1 & & 6.78 \\
\hline 1049 & trumer & 8 & 20 & 1 & ㄱ) & & 0.0 \\
\hline 1050 & AccumuTE & 5 & 20 & 1 & 7 & & 2.26 \\
\hline 9051 & $n \in \ln r$ & s & 20 & 1 & 7 & & 2. \\
\hline 1052 & Osneo & s & 20 & 1 & 7 & & 0.0 \\
\hline 1053 & Fomat & s & 20 & 1 & 7 & & 2.0 \\
\hline 1054 & Fase & is & 20 & 1 & 7 & & 1 \\
\hline 1055 & pensson & s & 20 & 1 & 1 & & .18 \\
\hline 1056 & Paneroa & is & 20 & 1 & 1 & & .1 .30000003 \\
\hline
\end{tabular}


ALIMEAN.XLS

\begin{tabular}{|c|c|c|c|c|c|c|c|}
\hline & A & $\mathbf{B}$ & C & D) & $E$ & $F$ & G \\
\hline 1057 & CHECX & 8 & 20 & 1 & 0 & & . \\
\hline 1058 & USEPR & $T$ & ix & 1 & -1 & & $\therefore$ \\
\hline 1059 & cons & Tr & lin & I) &. & & . \\
\hline 1060 & Trmar & $\pi$ & in & 1 &. & & $\therefore$ \\
\hline 1061 & Acemaner & I & in & 1 & -1 & & $\therefore$ \\
\hline 1062 & $\operatorname{lng}$ & $T$ & in & 1 & $\bullet$ & & \\
\hline 1063 & onme & $T$ & in & 1 & 7 & & \\
\hline 1064 & romat & $T$ & in & 1 & - & & \\
\hline 1065 & Fiso & $T$ & in & 1 & 1 & & \\
\hline 1066 & 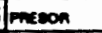 & 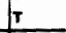 & lin & 1 & 1 & & \\
\hline 1067 & mogron & 7 & in & 1 & 1 & & \\
\hline 1068 & conecx & 5 & in & 1 & 0 & & \\
\hline 1069 & veserer & $\pi$ & in & 2 & 3.0 & $2.12132 \times 004$ & \\
\hline 1070 & come & 7 & 10 & 2 & 3 & 202042712 & \\
\hline 1079 & trmany & $\tau$ & 10 & 2 & 7.8. & 2.12132000 & \\
\hline 1072 & AccumuTE & $T$ & 18 & 2 & -1 & 1,41421360 & \\
\hline 1073 & NeInI & $T$ & 10 & 2 & - & 1.41421360 & \\
\hline 1074 & onseo & $T$ & 18 & 2 & 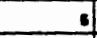 & s.encesest & \\
\hline 1075 & foomear & Tr & 18 & 2 & 0.5 & 0.70710070 & \\
\hline 1076 & FNEO & $T$ & 18 & 2 & 7 & 2.02042712 & \\
\hline 1077 & $m=80 n$ & I & 10 & 2 & 4.6 & 489074947 & \\
\hline 1078 & moron & IT & 10 & of & 0 & 의 & \\
\hline 1079 & CMECX & $i$ & 18 & 2 & 0.5 & 0.70710079 & \\
\hline 1080 & USEFR & $\pi$ & ic & of & 0 & of & \\
\hline 1081 & comp & $T$ & Ie & of & of & of & \\
\hline 1082 & Trimer & I & ic & of & 0 & of & \\
\hline 1083 & accumate & it & ic & of & of & of & \\
\hline 1084 & NELWN & $T$ & ic & o) & 0 & of & \\
\hline 1085 & Josese & Tr & ic & of & 으 & of & \\
\hline 1086 & romunt & ir & Ic & 0 & 0 & of & \\
\hline 1087 & freoc & Ir & IIC & 0 & 0 & 0 & \\
\hline 1088 & porson & $i$ & ic & o) & 0 & 0 & \\
\hline 1089 & eneron & $T$ & ic & 0 & 0 & of & \\
\hline 1090 & CAEEK & $T_{T}$ & ic & of & 0 & 0 & \\
\hline 1091 & USEFUL & $T$ & 10 & of & 0 & 0 & \\
\hline 1092 & cones & IT & 10 & o) & 0 & 0 & \\
\hline 1093 & TMMELY & I & 10 & of & 0 & 0 & \\
\hline 1094 & accumare & $T$ & 10 & 0 & 0 & 0 & \\
\hline 1095 & ilneivent & $i$ & 10 & of & 0 & of & \\
\hline 1096 & osmeo & IT & 10 & of & 0 & 0 & \\
\hline 1097 & romuat & $T$ & 10 & of & 0 & 의 & \\
\hline 1098 & Freo & I & 10 & of & 0 & 01 & \\
\hline 1099 & peneson & $T$ & 10 & of & 0 & 0 & \\
\hline 1100 & Prefor & I & 10 & 0 & 0 & o) & \\
\hline 1101 & checx & IT & 10 & 0 & 0 & 0 & \\
\hline 1102 & USEFut & it & $T_{2 A}$ & 2 & ...6 & 2.12132034 & .2 .0 \\
\hline 1103 & COMF & 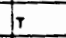 & $2 A$ & 2 & $\because$ & 1.41421360 & 5 \\
\hline 1104 & trumsar & is & 21 & 2 & 3 & 1.41421360 & 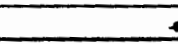 \\
\hline
\end{tabular}


ALLMEAN.XLS

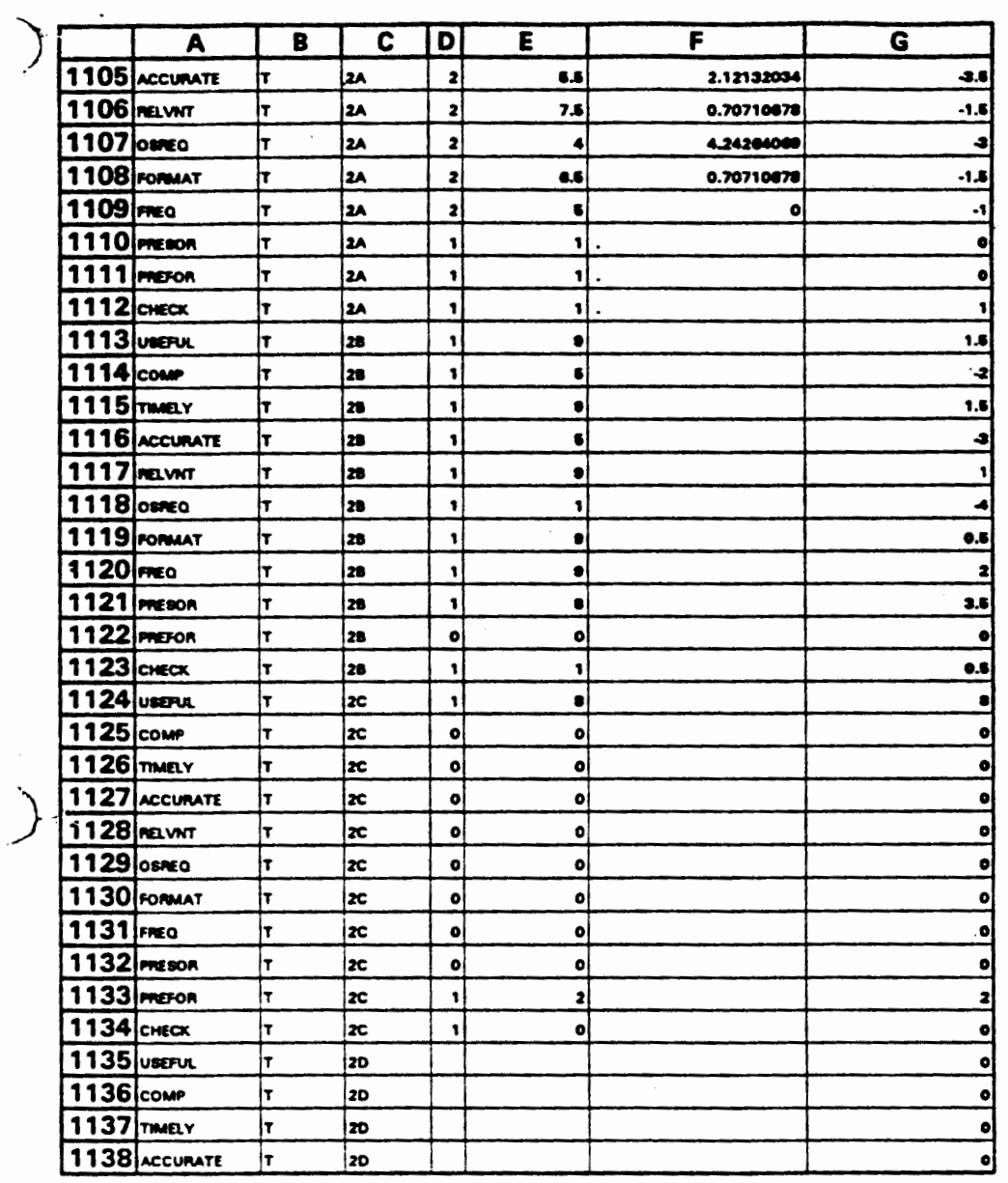

